\title{
Exploring Variations In The Relative Technical Efficiency In Providing School Education: A Case Study Of Sindh, Pakistan
}

\author{
Iqbal Hussain Durrani
}

A thesis submitted in partial fulfilment of the requirements of Nottingham Trent University for the degree of Doctor of Philosophy 


\section{DECLARATION}

I hereby declare that this thesis, neither as a whole nor as a part thereof, has been copied from any source. It is further declared that I have carried out this research by myself and completed this thesis on the basis of my personal efforts under the guidance and help of my supervisors. No portion of the work presented in this thesis has been submitted in support of any application for any other degree or qualification in Nottingham Trent University or any other university or institute of learning.

lqbal Hussain Durrani 
Dedicated to:

My parents (late) I saw them struggling throughout their lives

to provide adequate education to their children including myself 



\section{ABSTRACT}

The Constitution of Pakistan has placed the responsibility for basic education in the State. In the 65 years of Pakistan, around 23 policies and action plans have been introduced with commitments to attaining universal primary education and other allied indicators. This has been evidenced by a series of activities aimed at boosting school enrolment and learning through significant though not sufficient allocations at the federal and provincial levels to education, currently standing at approximately 2 percent of GDP (approximately in the range of 25 to 30 percent of provincial budgets). Success has been limited; with the current state of education in Pakistan being dismal, characterized by low literacy and enrolment, acute regional and gender inequalities and poor learning levels. There are few if any chances of the country achieving the EFA goals. This is undoubtedly highly undesirable for a country of 180 million people, which is struggling to attain political stabilization and sustained economic growth for last many years. It is engulfed in a highly complex set of external and internal security challenges and which are expected to intensify in the post 2014 scenario subsequent to the departure of NATO forces from Afghanistan. Hence, improving the overall status on education is more a 'security issue' for Pakistan for ensuring not only peace and prosperity of its citizens but also its integrity and cohesion.

This research paper encompasses various facets of education status in Pakistan, with emphasis on Sindh (the prime focus of this research), the second largest province in the country. The purpose of my research is to analyze the efficiency of the education resources and their impact on education. The aim of this study is to explore Variations in Relative 
Technical Efficiency in providing School Education in the province of Sindh, Pakistan. The methodology of this study has been determined with the aim of achieving the objectives defined in the research proposal. Econometric techniques have been used to build model for the analysis, which is based on panel data regressions for primary, middle and secondary education enrolment of 23 districts of Sindh in the period from 2005 to 2010. Estimations have been carried out using the fixed effect procedure as given in the STATA statistical package.

Evidence from this study questions the efficacy of educational expenditure and finds no compelling evidence for the impact of education expenditure in case of primary level enrolment. Though the coefficient on public expenditures is positive and statistically significant but indicates a small impact on enrolment at primary level. The impact of education expenditures on the middle level and the secondary level is more pronounced. The coefficients for both these levels are statistically highly significant as well. The study finds that on an average; the mean efficiency for primary, middle and the secondary level are 39 percent, 64 percent and 75 percent respectively. The regression results from the production function that accounts for efficiency differences indicate that it costs less per students for efficient districts to achieve a set of standards. The present analysis reveals that it is not only the total allocation or expenditure but its utilization and management which determines the outcome. 


\section{ACKNOWLEDGEMENTS}

Having worked as a public servant for about two decades and then going for a research degree is undoubtedly a highly demanding effort. This would have been almost impossible without the continuous and active support of many people. I stand extremely indebted to many people who guided me and provided assistance to me in varying ways and at different stages of this intricate assignment. I would like to thank Dr. Andrew Cooke for his support and guidance throughout my research, and in particular for his supervision of this dissertation, both as a supervisor at the beginning and then as director of studies. Secondly, I am grateful to all the supervisors (as three left during the process) for their valuable time and patience.

I would like to acknowledge the support of different officials of the provincial, and district governments. My special thanks are especially to Zamir Khan of RSU, without his support, help and enthusiasm at every stage of this assignment, this study would not have been possible. I am highly grateful to Masood Qazi for his professional and technical assistance. Finally, thank you as always to my wife for her unfailing, if sometimes bemused, support and encouragement throughout my study, and to my youngest daughter, Rahimeh for her patience for not disturbing me during my panic moments. Last but not least, thank you to my son, Sherebaz for buoying me up with Chelsea wins and finally to my eldest daughter Shazmeneh, who will now be very grateful the word "SPSS and "STATA" will no longer be a daily discussion topic.

lqbal Hussain Durrani 
Table of Content

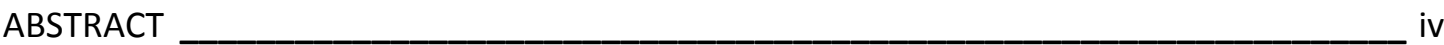

ACKNOWLEDGEMENTS _______ vi

GLOSSARY ___ Xvi

CHAPTER 1 : INTRODUCTION AND OVERVIEW OF THE STUDY ____ 1

1.1. INTRODUCTION

1.2. STATEMENT OF THE PROBLEM __ 6

1.3. OBJECTIVES OF THE STUDY __ 7

1.4. SIGNIFICANCE OF THE STUDY __ 7

1.5. MOTIVATION ___ 8

1.6. KEY THEMES AND THE ESTABLISHED LITERATURE __ 9

1.7. RESEARCH METHODOLOGY AND PHILOSOPHY__ 10

1.8. STRUCTURE OF THE THESIS ___ 12

CHAPTER 2 : PAKISTAN - INSTITUTIONAL FRAME WORK____ 14

2.1. BACKGROUND ___ 14

2.2. ADMINISTRATIVE STRUCTURE ___ 18

2.3. STATE OF ECONOMY ___ 19

2.3.1. Macro and micro indicators ___ 21

2.3.2. Demographic profile ___ 22

2.4. INCLUSIVE GROWTH ___ 24

2.5. EDUCATION POLICIES AND STRATEGIES ___ 26

2.6. INTERNATIONAL COMMITMENTS ___ 27

2.7. FORMAL EDUCATION SYSTEM IN PAKISTAN___ 28

2.8. CONCLUSION___ 29

CHAPTER 3 : SINDH - EDUCATION PROFILE AND CHALLENGES ___ 31

3.1. SINDH'S POLITICS \& ECONOMY _____________ 31

3.2. THE DEVOLUTION FRAMEWORK $2001 \_35$

3.3. PROVINCIAL EDUCATION MANAGEMENT STRUCTURE ___ 36

3.4. THE DISTRICT EDUCATION OFFICE ___ 37

3.5. SCHOOL EDUCATION IN SINDH ___ 39

3.5.1. School data and indicators ___ 41

3.5.2. School enrolments and retention __ 47 
3.5.3. School infrastructure ___ 51

3.5.4. Education financing and expenditure in Sindh ___ 54

3.6. EDUCATION INDICATORS - A COMPARISON BY DISTRICT____ 58

3.7. CONCLUSION___ 83

CHAPTER 4 : LITERATURE REVIEW ___ 84

4.1. SCHOOL EFFECTIVENESS RESEARCH AND PRODUCTION FUNCTION ___ 85

4.2. PRODUCTION AND COST FUNCTIONS FOR PUBLIC EDUCATION ___ 92

4.3. PREVIOUS WORK DONE IN AREA OF STUDY AND FINDINGS _ 96

4.3.1. Determinants of learning in developing countries ___ 105

4.4. METHODOLOGICAL ISSUES____ 109

4.5. EFFICIENCY MEASUREMENT___ 114

4.5.1. Parametric techniques ___ 117

4.5.2. Non-parametric techniques _______________ 118

4.6. PANEL DATA MODEL _ 119

4.6.1. Benefits and limitations of panel data __ 120

4.7. FIXED AND RANDOM EFFECTS MODEL___ 121

4.8. APPLICATION OF SFA AND DEA IN EDUCATION __ 123

4.8.1. Efficiency measurement using DEA _ 124

4.8.2. Efficiency analysis using DEA___ 127

4.8.3. Efficiency measurement using SFA 130

4.8.4. Efficiency measurement using SFA 132

4.9. LITERATURE REVIEW IN THE CONTEXT OF PAKISTAN 136

4.9.1. Education cost and production function studies in Pakistan

4.9.1.1. Gender differentials in the cost of primary education ___ 146

4.9.1.2. Educational production function for rural Pakistan

4.9.1.3. Cost function of school education in Punjab____ 151

4.10. CONCLUSION_ 153

CHAPTER 5 : METHODOLOGY ___ 155

5.1. ESTIMATION METHOD ___ 155

5.1.1. Log-linear regression model __ 157

5.2. THEORITICAL FRAME WORK___ 160

5.3. EDUCATION ENROLMENT EQUATION____ 162 
5.4. ESTIMATION OF THE MODEL ___ 165

5.5. THE SELECTED MODEL ___ 166

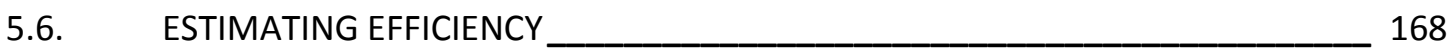

5.7. DATA COLLECTION AND CONSTRAINTS ___ 169

5.8. CONCLUSION____________ 172

CHAPTER 6 : PRELIMINARY ANALYSIS ___ 173

6.1. INTERNAL EFFICIENCY ___ 173

6.1.1. Dimension of unnecessary inputs __ 174

6.1.2. Allocative efficiency model __ 179

6.2. A MODEL OF ALLOCATIVE EFFICIENCY BASED ON THE SSR___ 181

6.2.1. Undesirable output dimension of wastage/internal efficiency___ 187

6.2.2. Monetary aspect of wastage ___ 187

6.3. ANALYSIS OF PUBLIC AND PRIVATE SCHOOLS MANAGEMENT__ 189

6.4. RESULTS__ 191

6.5. CONCLUSION __________ 194

CHAPTER 7 : ECONOMETRIC RESULTS ___ 196

7.1. DESCRIPTIVE ANALYSIS ___ 196

7.2. ESTIMATION RESULTS ____________ 201

7.3. EFFICIENCY FRONTIERS __ 211

7.4. RESULTS OF THE STOCHSATIC FRONTIER ANALYSIS ___ 213

7.5. CONCLUSION ___ 216

CHAPTER 8 : DISCUSSION, CONCLUSION AND RECOMMENDATIONS ___ 218

8.1. RECAPTURE OF THE PROBLEM AND CONTEXT___ 219

8.1.1. Provincial context _ 219

8.1.2. District context 220

8.1.3. Ambit of thesis__ 221

8.2. SUMMARY OF MAJOR EMPIRICAL FINDINGS __ 221

8.2.1. Technical efficiency: results from panel data __ 222

8.2.2. Productivity differences across public and private managers___ 225

8.2.3. Overarching structural issues _ 225

8.2.4. Relevant local evidence___ 227

8.2.5. Relevant global evidence___ 227 
8.3. POLICY IMPLICATIONS

8.4. CONTRIBUTIONS OF THE STUDY ___ 234

8.5. LIMITATIONS OF THE STUDY____ 234

8.6. CONCLUSION AND RECOMMENDATIONS___ 235

BIBLIOGRAPHY _ 239

APPENDICES ___ 252 


\section{List of Tables}

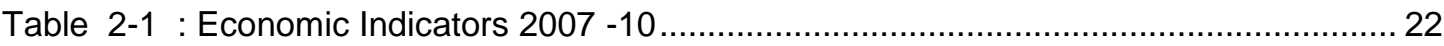

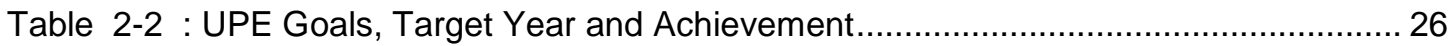

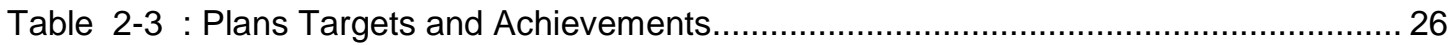

Table 3-1 : Grade-wise Total Management and Support Staff in Districts ........................... 38

Table 3-2 : Percentage of Population (10 Years and Older) Ever Attended School ............. 39

Table 3-3 : Schools, Enrolments \& Teachers; 4- Years Comparison.................................... 44

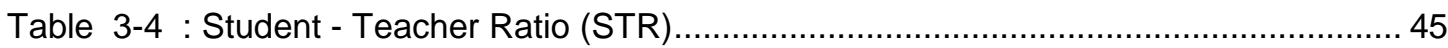

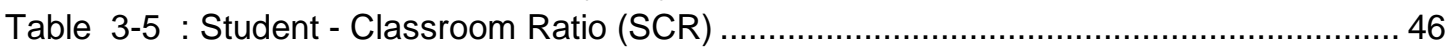

Table 3-6 : Gross Enrolment Rate Primary Level (5-9) Excluding Kachi Class ....................4 47

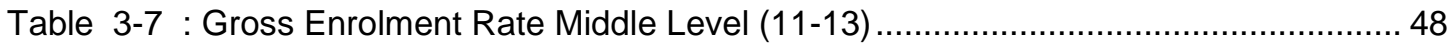

Table 3-8 : Gross Enrolment Rate Secondary Level (14-15) …….................................... 49

Table 3-9 : Gender Parity Index 2006-07 - 2009-10 ................................................ 50

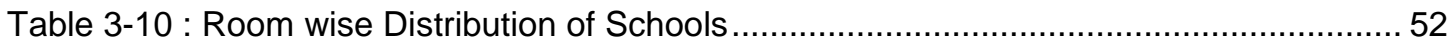

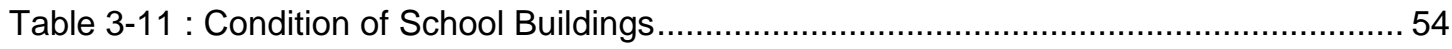

Table 3-12 : Education Expenditures ( FY 2009-10 to 2011-12) (Rs. in million).......... 55

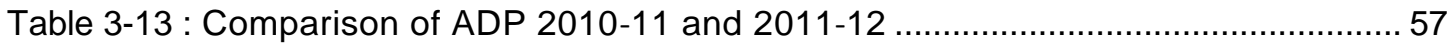

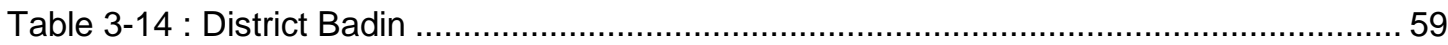

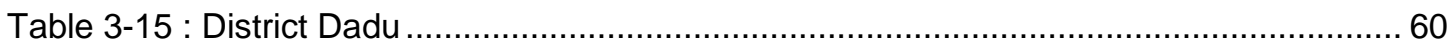

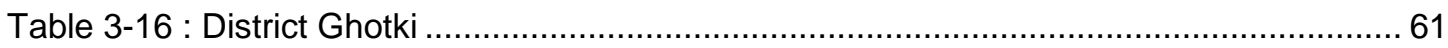

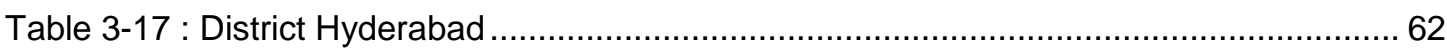

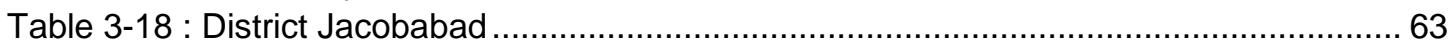

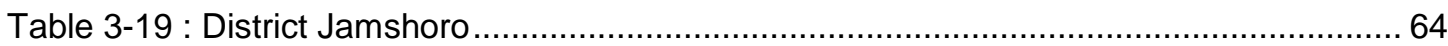

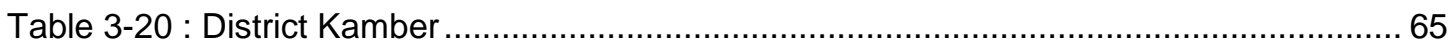

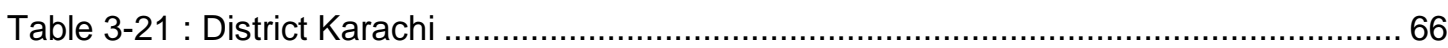

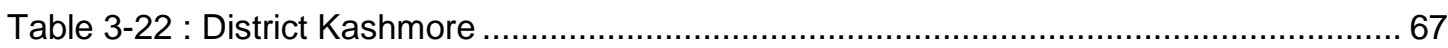

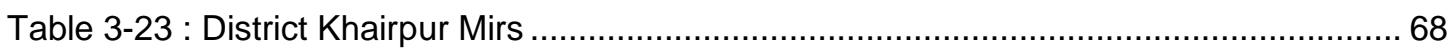

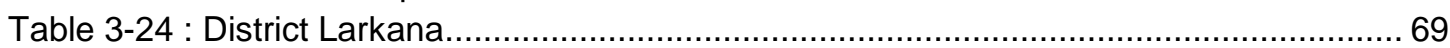

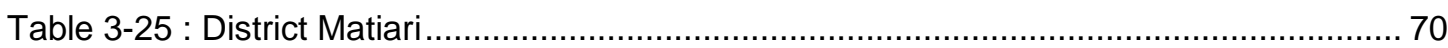

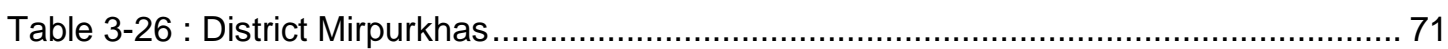

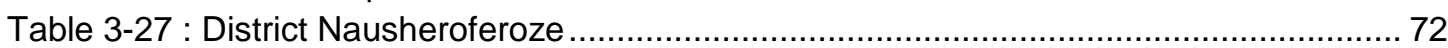

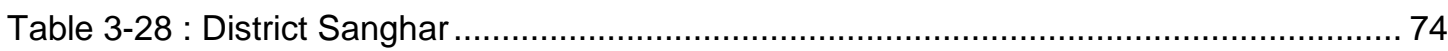

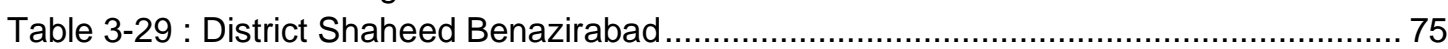

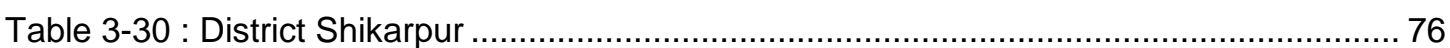

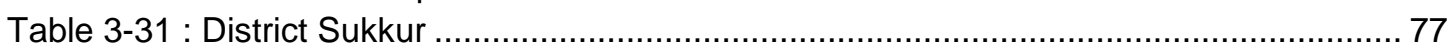

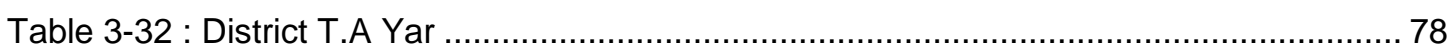

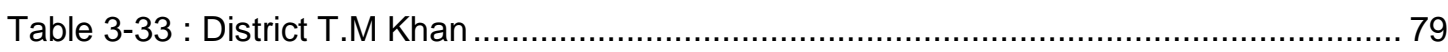

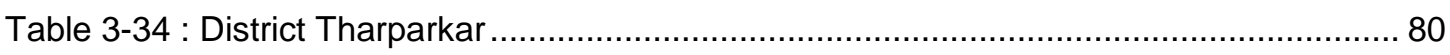

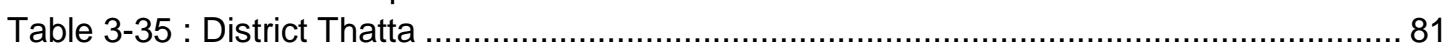

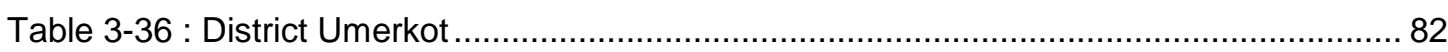

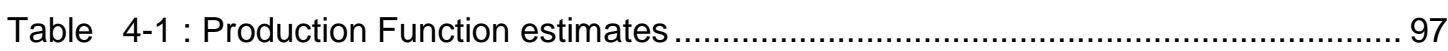

Table 4-2 : Comparison between Hanushek and DHK studies ........................................ 102

Table 4-3 : Comparison between Hanushek and DHK studies (Sig. +ve) ......................... 103

Table 4-4 : Krueger's Reanalysis of Hanushek's (1997) Class Size Studies......................... 105

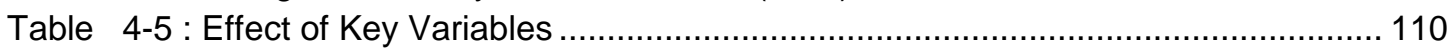

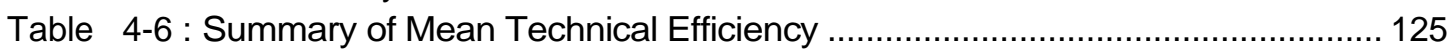

Table 4-7 : Educational Cost Function Estimates ....................................................... 126

Table 4-8 : Variable used in the DEA efficiency measurement ......................................... 128

Table 4-9: The average efficiency and the percentage share of efficient schools ............. 129 
Table 4-10: Elasticities of test scores.....

Table 4-11: Average inefficiency in panel data models....................................................134

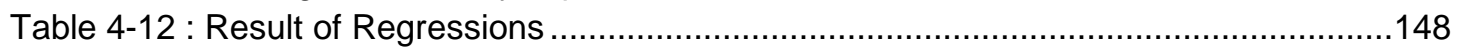

Table 4-13: Comparative tally of the field evaluations in 43 villages, $1998 \ldots \ldots \ldots \ldots \ldots \ldots \ldots \ldots . . .150$

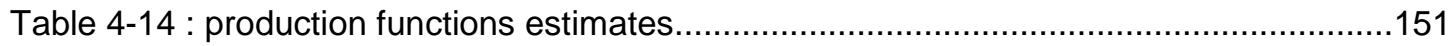

Table 4-15 : Level of Efficiency in Education Expenditure Punjab......................................153

Table 6-1: District wise Efficiency Premium Calculations (Rs. In million) …...........180

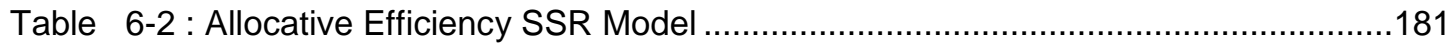

Table 6-3 : Allocative Efficiency CR Model ..............................................................188

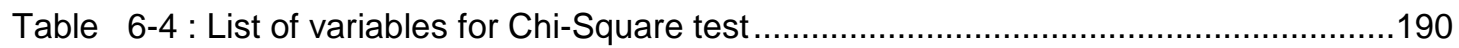

Table 7-1: Descriptive Statistics Primary Level Education ................................................199

Table 7-2 : Descriptive Statistics Middle Level Education.................................................200

Table 7-3 : Descriptive Statistics Secondary Level Education ............................................200

Table 7-4: Summary of significant findings using the fixed effects model .........................204

Table 7-5: Summary of significant findings using the fixed effects model ........................207

Table 7-6: Summary of significant findings using the fixed effects mode ..........................209

Table 7-7 : District Mean Efficiency (Primary Education) ……….....................................214

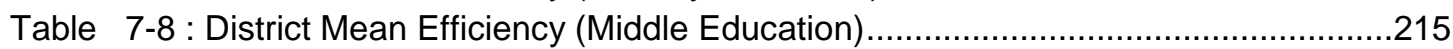

Table 7-9 : District Mean Efficiency (Secondary Education) …...........................................215 


\section{List of Figures}

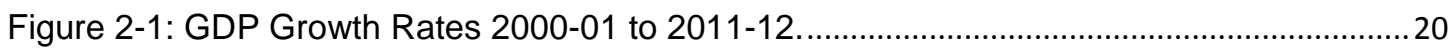

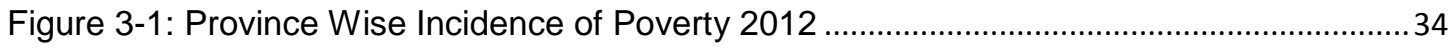

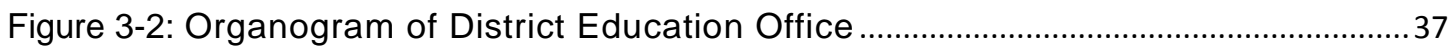

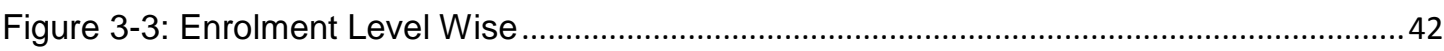

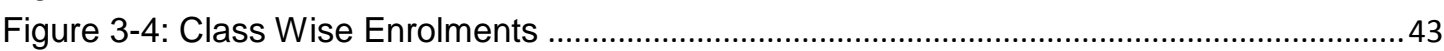

Figure 5-1: Histogram and Kernel density of primary enrolment distribution.............................158

Figure 5-2: Histogram and Kernel density of primary enrolment (log) distribution.....................159

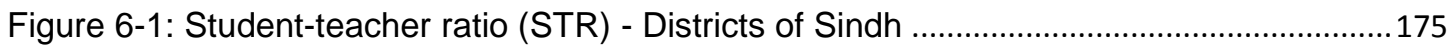

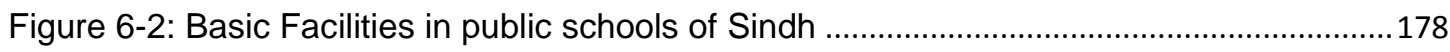

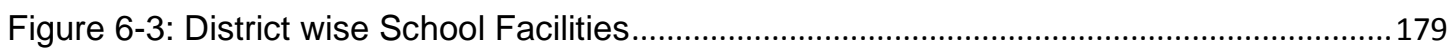

Figure 7-1: Mean Primary Enrolment (log) and Mean Expenditure (Log) in Sindh..................197

Figure 7-2: Mean Middle Enrolment (log) and Mean Expenditure (Log) in Sindh.....................197

Figure 7-3: Mean Secondary Enrolment (log) and Mean Expenditure (Log) in Sindh .............198 


\section{List of Abbreviations}

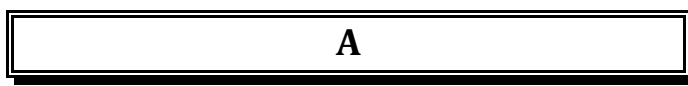

AEPAM

Academy of Education Planning \& Management, 27

AFDC

percent of student qualified for free and subsidized lunch, 125

AML

Average marks in Language, 128

AMM

Average marks in Mathematics, 128

B

BISE

Board of Intermediate and Secondary

Education, 28

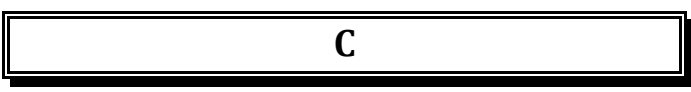

CRS

Constant returns to scale, 129

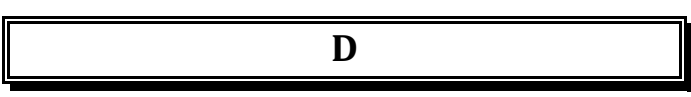

DEA

Data Envelopment analysis, 116

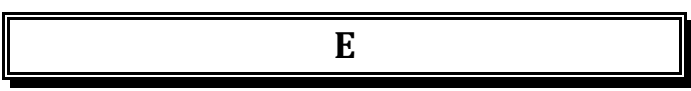

EPF

Education Production Function, 91

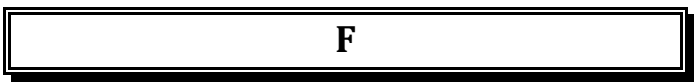

FANA

Federally Administered Northern Areas, 18 FATA

Federally Administered Tribal Ares, 18 FE

Fixed Effects, 133

FTE

full-time equivalent, 131

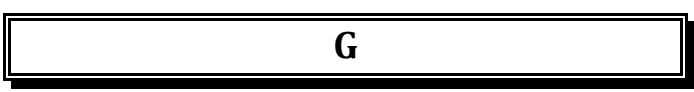

GPA

Grade Point Average, 134

GPI

Gender Parity Index, 51

\section{$\mathbf{H}$}

$\mathrm{HDI}$

Human Development Index, 21

HSSC

Higher Secondary School Certificate, 28

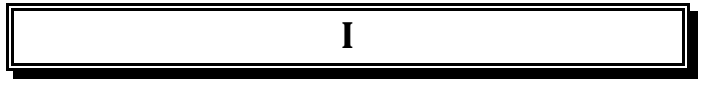

ICT

Islamabad Capital Territory, 18

ITBS

lowa Test of Basic Skills, 131

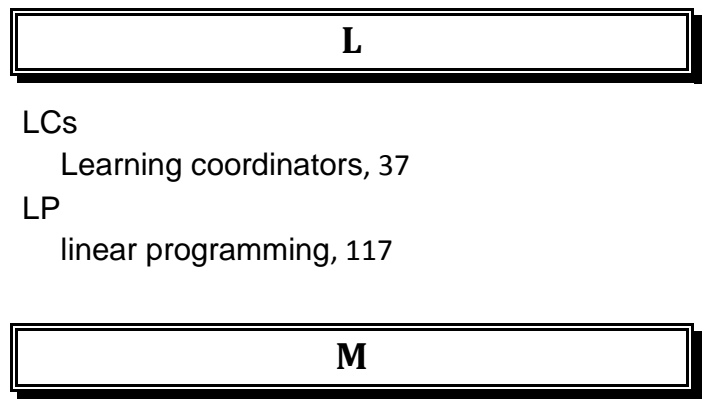

MLES

Maximum Likelihood estimates, 131 MTDF

Medium Term Development Framework, 51

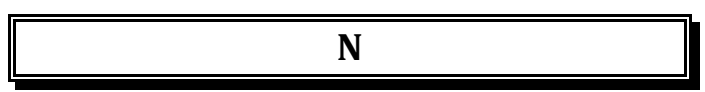

NCERT

National Council of Educational Research and Training, 127

NEP

National Education Policy, 26 NGO

None Government Organization, 149

NLES

National Educational Longitudinal Study, 112 NWFP

North Western Frontier Provience, 19

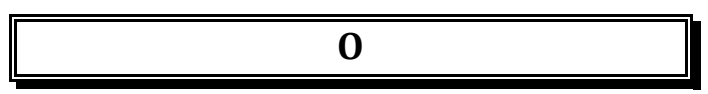

OLS

Ordinary least squares, 117

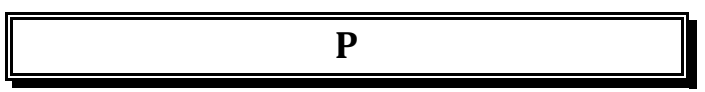

PPP 
Pakistan People's Party, 18

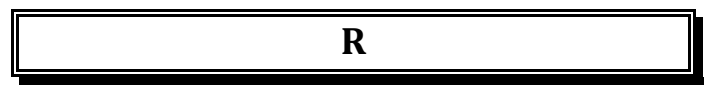

RE

Random Effects, 133

RPs

Resource Persons, 37

RSU

Reform Support Unit, 189

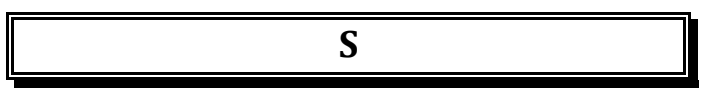

SEMIS

Sindh Education Management Information System, 41 SERP

Sindh Education Reform Programe, 57 SFA

Stochastic Frontier Analysis, 130

Stochastic Frontier Analysis, 84

STATA

statistical package, 166

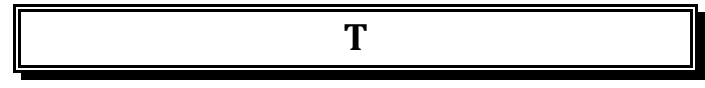

TAP

Test of Achievement and Proficiency, 131 TEI

Teacher experience index, 128

TFE

True Fixed Effects, 133

TFP

Total factor productivity, 126

TQI

Teacher experience index, 128

TRE

True Random Effects, 133

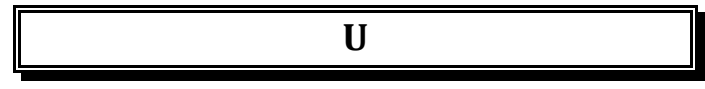

UNDP

United Nations Development Programme, 24 UPE

Universal Primary Education, 26

USAID

US Agency for International Development, 57 


\section{GLOSSARY}

Amendment XVIII (the Eighteenth Amendment) of the Constitution of Pakistan: was passed by the National Assembly of Pakistan on April 8, 2010, removing the power of the President of Pakistan to dissolve the Parliament unilaterally, turning Pakistan from a semi-presidential to a parliamentary republic, and renaming North-West Frontier Province to Khyber Pakhtunkhwa. This also abolished the 'concurrent list' in the constitution thereby transferring those functions to the provinces.

Annual Development Program (ADP): Provincial and district government development programs.

District Coordination Officer (DCO): The highest ranked civil servant in the district government. DCOs are usually federal or provincial government employees posted to the district governments.

District Officer (DO): An official in a district government department who reports to the Executive District Officer.

Education for All (EFA): An international education development initiative of UNESCO that promotes primary education, adult literacy, and early childhood education and targets.

Education Sector Reform Action Plan (ESRA) 2001-2004/5/6: A federal education plan for developing education at the federal, provincial, and district levels.

Executive District Officer (EDO): The head of a district government department. EDOs are provincial government employees posted to district governments.

Local Government Ordinance (LGO): The basic legislation that defines the existence, structure, operations, and responsibilities of local governments. For example, for the province of Sindh, the Sindh Local Government Ordinance, 2001 was promulgated. LGOs were developed by the NRB for each of the four provinces and were identical in structure and content.

Medium Term Development Framework (MTDF): A five-year centralized economic planning initiative of the federal government. Provincial governments were required to implement this in their jurisdictions.

National Economic Council (NEC): A federal institution under the Constitution of Pakistan, 1973 responsible for approving central economic plans and foreignfunded projects throughout the country.

National Finance Commission (NFC): A federal institution created under the Constitution of Pakistan, 1973 to share resources between the federal and provincial governments.

National Plan of Action on Education for All (NPA-EFA): A centralized education planning initiative conducted at the federal level under the auspices of UNESCO in compliance with the EFA initiative. 
National Reconstruction Bureau (NRB): An institution created by General Pervaiz Musharraf after the Pakistan Army coup on October 12, 1999 to design reforms for the country.

Nazim: Organizer or coordinator. The district government is led by a nazim (Mayor), an elected representative.

Poverty Reduction and Growth Facility (PRGF): A lending instrument of the International Monetary Fund.

Poverty Reduction Strategy Paper (PRSP): A document defining how the borrower of the poverty reduction and growth facility would comply with loan covenants including centralized expenditure planning.

Provincial Consolidated Fund (Article 118, Constitution of Pakistan): All revenues received by the Provincial Government, all loans raised by that Government, and all moneys received by it in repayment of any loan, shall form part of a consolidated fund, to be known as the provincial consolidated fund.

Provincial Finance Commission (PFC): A provincial government institution responsible for sharing resources between the provincial and district governments.

Public Sector Development Program (PSDP): The federal government's development expenditure program for the entire country.

Sindh Education Management Information System (SEMIS): The provincial government database of school enrolment in Sindh.

Sindh Public Service Commission (SPSC): The premier institution of the Government of Sindh responsible for human resource management.

Social Action Programme (SAP): A social development initiative promoted by the World Bank and implemented by the federal and provincial governments in Pakistan during the 1990s. SAP is the name given to Pakistan's overall effort to improve basic social services over the five year period 1993/94-1997/98.

Stand-by Arrangement (SBA): All member countries facing external financing needs are eligible for SBAs subject to IMF policies. However, SBAs are more often used by middle income (and, more recently, advanced) member countries, since low-income countries have a range of concessional instruments tailored to their needs.

Statement of New Expenditures (SNEs): A request for sanctioning / budgeting new recurrent expenditures issued by a department to the finance department for approval.

The Department for International Development (DFID) is a United Kingdom government department with the goals "to promote sustainable development and eliminate world poverty".

United States Agency for International Development (USAID): USAID is currently implementing a number of projects in Pakistan. 



\section{CHAPTER 1 : INTRODUCTION AND OVERVIEW OF THE STUDY}

\subsection{INTRODUCTION}

This thesis investigates the efficiency of the education system through impact of expenditures on education outcomes in the 23 districts of Sindh, Pakistan. Pakistan is today faced with a complex set of challenges both on internal and external security front; political stability including strengthening of the democratization process; a long term sustained and inclusive economic growth; on the development front both human and infrastructure development to provide the critical ingredients for the envisaged long term growth. This is definitely a tall order especially given the existing security environment both within and on the eastern and western borders which is likely to become more complex in the coming days. The aspirations for greater democratization including empowerment of people through greater participation are also pillared on a fragile political environment which has lately witnessed a peaceful transition from one political government to another, an unprecedented event in the political history of the country which has lived through four lengthy military regimes. Equally, if not more challenging is the desire to move towards better economic growth by way of overcoming some of the structural impediments which have held back the true potential of a resource rich country for long. There is however, a general recognition that all these big goals are likely to remain elusive unless the country resolves to put its house in order on some of the fundamental human development components; most critical being the education. In the recent past all the major political parties have assigned central attention to improving education in the country and a few leaders have gone to the extent of proposing 'imposition of an education emergency' 
symbolically ${ }^{1}$. This is a very positive development as without political ownership and resolve to improve upon the status of education in the country; this overarching objective is unlikely to be realized in the foreseeable future. In fact, lack of adequate political will backed by actions to undertake the difficult decisions on education has remained elusive all along the past several decades of efforts to improve the education outcomes. Although the education sector has remained under the attention of policy makers, implementers, donors and the analysts however, most of the interventions in the past have either been a routine administrative prescription or at best a part of the 'reform package' of authoritarian regimes which were inherently not backed by public accountability. There is little record to show whether any elected regime in the country took up the task of fighting illiteracy as a major political promise though on paper this goal together with improving education is part and parcel of the manifestos of almost all the political parties in the country. The coming in of the democratic regimes since 2008 does entail brighter prospects for service delivery components in Pakistan; given the intrinsic compulsions of democratically elected regimes in terms of their accountability to the masses. Pakistan is a federation of four provinces, a capital territory and federally administered tribal areas. The Constitution of Pakistan places the responsibility for education on the state and this has been lately reinforced under the $18^{\text {th }}$ Amendment to the Constitution. The newly inserted Article 25-A now makes it compulsory for the state to provide free education to all the eligible school age children. Under the Constitution the subject stands assigned to the provinces

\footnotetext{
${ }^{1}$ The Chairman Pakistan Tehrek-e-Insaaf called for an education emergency during his election campaign interviews prior to May 2013 elections in Pakistan. The new Governor Punjab, Chaudhry Mohammad Sarwar has also publically issued statements regarding declaring an education emergency in the Punjab, Pakistan
} 
however, in the past major policy framework was undertaken at the federal government level. Various governments have, in the past, formulated a range of policies and plans to fulfill the constitutional commitment, together with attempts to reduce inequities. Success has been limited; as such, the current state of education in Pakistan continues to be dismal, characterized by low levels of public spending, low levels of literacy and enrolment, high levels of dropout from the schooling system, acute regional and gender inequalities. Both demand and supply factors explain this state of affairs. On the demand side, poverty and illiteracy appear to be significant factors that adversely affect household decisions to send children to school, however education in Pakistan is not a demand issue as despite poverty and illiteracy a robust demand exists. One of the major weaknesses on the demand side is believed to be weak accountability of service providers by the parents and the community at large; which in turn has allowed the policy makers and the implementers to get away with extremely low levels of service delivery on education. Over the years, continued decline in the standards of public education system has led to a situation where the well to do segments of population now predominantly rely on private education institutions leaving the public education largely to the poor in the society. This situation has further weakened the parental accountability of the service providers, not allowing the peoples' voice to be registered in the democracy project in Pakistan.

Weak education outcomes are thus generally believed to be a supply issue in the case of Pakistan. Though high population growth rates, lack of sufficient financial resources are a few of the central and serious challenges towards the ultimate aim of providing universal education however, these are not the core 
causes of system weaknesses. The core supply issue is seemingly, the inability of the government to evolve a system that can deliver and which obviously involves politics. This has been witnessed in the recent past where additional resources, including donor funding, increased teacher resources, teacher training inputs, etc. has neither translated into improved enrolment nor have these inputs facilitated better standards of education.

Sindh is Pakistan's second most populated province having a projected population of 43 million $^{2}$ and it is the second largest economy in the country with provincial GDP of US $\$ 50$ billion. $^{3}$ The public education in Sindh is faced with challenges on various components of the delivery of education which are not much different from other parts of the country however, the indicators are slightly more pronounced. According to Sindh Education Management and Information System (SEMIS) 2011 report; of the 6.7 million children in the 4 to 9 age group approximately, 4.3 million were enrolled in schools (class 1-5), which included around a million children in private schools (mostly big urban centers especially Karachi). Similarly as against approximately 2.9 million eligible population for middle school (class 6-8), 0.85 million were in formal education leaving behind around 2 million out of school, only at the elementary level. The education system at this level is therefore by-passing over 4 million children with no or little education. The gender disparities and rural-urban gap are large and growing in Sindh. Whereas the primary net enrolment rate for Pakistan as a whole and for all rural females is 56 percent and 48 percent respectively, the primary level NER and rural female NER for Sindh is one of the lowest in Pakistan at 53 percent and 39 percent respectively (PSLM 2010-11).

\footnotetext{
${ }^{2}$ Projected on the basis of population growth rates of Population Census Organization

${ }^{3}$ Projected on the basis of Pakistan's GDP of US \$ 176 in 2010-11
} 
The gender disparity in Sindh is clearly and predominantly a rural phenomenon. The 2001 devolution process led to the transfer of a large number of functions (including health and education) from the provincial to local governments, precisely to district governments. This was also the time when there was a surge in the economic growth in Pakistan and the GDP grew from a low of 2 percent in 2000-01 to 5.6 percent in 2003-04 and jumped to a peak of 9 percent in 2004-05. There was thus a visible enhancement in the levels of public expenditure backed by a significant increase in the revenue generation at the federal level which led to much higher fiscal transfers to the provincial and the local governments. A significant change in education expenditure took place during 2003-04, when the overall outlay increased in real terms by as much as 31 percent. Public expenditure on education peaked at 2.2 percent of the GDP during 2003-04 (SPDC, 2006-07). The relatively rapid growth in expenditure by local governments in this period, in line with macroeconomic buoyancy raises the question whether the enhanced outlays for delivery of services were characterized by higher or lower levels of cost-efficiency. For instance, was the increased education expenditure accompanied by a corresponding growth in student enrolment, student retention and completion rates?

The federal and provincial governments' offices have by now numerous documents on the education sector including the policies, plans, projects and program reviews etc. containing information and analysis of various components and aspects of the sector. However, there has been little review or any research which examines the system efficiency at any unit level of operation such as the district level. Also there is little analysis available which examines why and how certain regions exhibit better outcomes within 
comparable fiscal and administrative domain. The relationship between expenditure and educational development is a complex one. The development of education depends on the composition, efficiency and accountability of the expenditure on education. This research thus basically aims to explore the system efficiency at district level. This is a distinctive theme as for the first time performance based work has been undertaken on a large scale covering all 23 districts of Sindh. This study attempts to explore the linkages between education expenditures and the education outcomes especially in the context of school enrolments by comparing the situation at district level across all the districts in Sindh. The research also examines the key aspect, to assess the technical efficiency and efficiency differences among the 23 districts in Sindh for the primary, middle and secondary education.

\subsection{STATEMENT OF THE PROBLEM}

There is an increased recognition that the development of education depends on the composition, efficiency and accountability of the expenditure on education. In Sindh, there are a growing number of children and youth, estimated at $40 \%$ of the eligible cohort, who are out of school. This segment of the population cannot or will not be served by the current dysfunctional education structure. The out of school children therefore characterize both a qualitative and quantitative inadequacy of the current functioning of the school system, in that not only is schooling not accessible, but that cannot retain the children in schools. The issue of school retention at different levels i.e primary; middle and secondary is equally a serious issue. This reflects upon functionality of the system, which is unable to retain the students who get enrolled in public schools. It is therefore imperative to look at the system efficiency by exploring 
variations in Relative Technical Efficiency in providing school education in Sindh, Pakistan.

\subsection{OBJECTIVES OF THE STUDY}

The specific objectives of the thesis are the following:

i. To estimate the technical efficiency of the districts in Sindh in providing primary, middle and secondary education especially in the context of enrolments at these levels.

ii. To analyze the factors which explain the variations in the relative technical efficiency or inefficiency in providing school education at the provincial level in Sindh.

iii. To examine the structural and institutional weaknesses which hamper improvements in education in Sindh.

\subsection{SIGNIFICANCE OF THE STUDY}

The study is significant from theoretical as well as empirical perspectives and contributes to the current knowledge. From the theoretical point of view, the study is important, because it is the first study in Pakistan, to the best of the researcher's knowledge, which investigates different aspects of technical efficiency in primary, middle and secondary school levels, across all the districts in Sindh. This study contributes to the body of empirical research on service delivery in education in the province of Sindh. From an empirical point of view the field work and the analysis for this dissertation have yielded insights about the public sector in Sindh representing the whole province and the structural, institutional and political contexts which affect its performance. I hope this dissertation succeeds in highlighting the opportunities for public sector reform through efficient utilization of resources. 


\subsection{MOTIVATION}

As a civil servant I have been involved in the service delivery at various levels for more than three decades. The career has been generally highly gratifying though many a times interplay of complex situations and socio political environment impedes conversion of policies and plans into any worthwhile or discernible outcomes. It is probably this quest for examination and understanding the interplay of factors which make service delivery challenging in developing countries which has motivated me to undertake this research.

I have spent over five years in the Education Department of Sindh where I have worked in positions of Project Director for Sindh's Technical Education Project assisted by the ADB and Program Manager of the Sindh Education Reform Program (SERP) assisted by the World Bank. These assignments have been highly rewarding for me as other than being involved in a reform effort; I have gained a deeper insight into different aspects of the education management. My involvement with a range of complex reform programs and close interaction with a range of stakeholders has provided me with a technical understanding of sector challenges which in turn has motivated me to undertake this research.

The completed $\mathrm{PhD}$ thesis will produce an original contribution to knowledge in understanding the technical efficiency of providing school education in Sindh; the work undertaken in this thesis will also provide a comprehensive district efficiency index. The index of technical efficiency will be based on the predicted values of cost and actual cost. The ratio of actual to predicted cost will rank each district according to its relative technical efficiency. Such efficiency index will help the policy makers in understanding the issues related to expenditure effectiveness at the operational level and the 
factors which impinge on making spending effective. This is likely to create greater awareness on expenditure effectiveness and facilitate corrective actions.

\subsection{KEY THEMES AND THE ESTABLISHED LITERATURE}

There are different perspectives to the concept of efficiency and effectiveness of education systems. In simple terms it evaluates the outcomes on the basis of supply of inputs (Mandl et al., 2008, p.2). The outcome is often linked to welfare or growth objectives and it is likely to be impacted by a host of factors other than the direct inputs. Effectiveness is considered to be a wider term reflecting interplay of host of exogenous and cross cutting factors and it may be difficult to measure. It basically reflects that the resources utilized for given objective were able to attain that particular objective. This implies that efficiency and effectiveness are not always easy to isolate. Thus an education system is said to be efficient if maximum output is obtained from a given input, or if a given output is obtained with minimum possible input. Production function has been used as an important tool for economic analysis in the neoclassical tradition. The discussion over the economics of education started between the late 1950's and early 1960's with the developing conversation on human capital. The human capital model was the foundation of linking education to the labor market. The contemporary economic approach to education started developing from the late 1950's onwards with Jacob Mincer's application of human capital theory to the measurement of the economic return to education as the impact that the number of years of schooling an individual received has on his / her earnings. The literature on the effectiveness of public expenditure on education shows that there is a variable impact across regions, as well as within countries 
at a similar stage of development. The efficiency literature points to institutional factors that affect the level and quality of public services.

There is inadequate work done in Pakistan on the efficiency and effectiveness of public expenditure in different provinces and in Pakistan as a whole. Year after year different programs have highlighted the issues of low enrolments and ever increasing number of out -of -school children. This together with high levels of dropouts at different stages of education is a big question on functionality of the school system in Sindh. The resources spent on dropouts are a serious wastage, because the limited literacy and numeracy skills acquired at less than primary level are lost by the dropouts. All these aspects intensify the challenges of growth and development in country; a country which is unfortunately faced with extremely serious and complex security environment.

\subsection{RESEARCH METHODOLOGY AND PHILOSOPHY}

The choice of estimation method has been an issue of debate, with some researchers preferring the parametric and others the non parametric approach. According to Zamorano (2004), no approach is strictly preferable to any other. Measurement of efficiency in education is definitely a complicated issue. Several methodological approaches have been used to overcome problems in educational efficiency measurement. They all have their advantages and shortcomings. This study has used parametric technique for the main research. However, for a small component of a survey analysis non-parametric approach has also been used. Parametric techniques use econometric methods to estimate the parameters of a specific functional form of cost or production function, while non-Parametric techniques place no conditions on the functional 
form and use observed data to infer the shape of the frontier. The approach here is based on panel data regressions for primary, middle and secondary education enrolments. Panel data which combines the time series data with cross sectional data allows the impact of a time dimension in the production and cost frontier model. Therefore, this model allows for the identification of the channels through which district-wise public expenditure on education affects enrolment over time in Sindh. Panel analysis techniques such as the fixed effects method or the random effects method can be used to determine the consistency estimates after addressing time-invariant heterogeneity. Timeinvariant district-specific conditions include unique cultural characteristics, attitude toward education, and basic geography and location. If such characteristics remain fixed over time, then the fixed effects estimator produces consistent estimates. Unlike fixed effects, the random effects model makes the strong assumption that the unobserved fixed effects are un-correlated with the regressors. If this assumption holds true, then random effects produce a consistent and more efficient estimate than the fixed effects model. A panel data set for 23 districts of Sindh from 2005 to 2010 was compiled for this research. All data series are annual data and it has been taken from the Sindh Bureau of Statistics and SEMIS, Education Department, Government of Sindh. In this research, education enrolments are taken separately for primary education, middle education and secondary education. Data is taken mainly in whole figures (original unit of measures) for each variable. However, for the estimation, all the variables have been transformed into their natural log transformations. Because of the natural log transformation, these variables are interpreted in proportional terms. In the context of technical efficiency, the 
quantitative data has been analyzed through SPSS and STATA. Sindh's education scenario is complex with an interplay among diverse forces where geographic, demographic and socio- cultural factors may have led to some inefficient allocation of resources especially teachers and schools, however, the analysis signals structural weaknesses in the educational edifice where despite allocation of over 30 percent of the provincial budget to the education sector; outcomes remain dismally low.

\subsection{STRUCTURE OF THE THESIS}

This thesis is divided into eight chapters. Each chapter consists of an introduction to chapter contents and a brief description to set the contents in the context and how it relates to other parts of the research study. First chapter serves as a background to the research study introducing the research problem and presenting research objectives, significance of the study, research methodology and the contribution of the research study. The second chapter discusses Pakistan's institutional framework and major issues and challenges in the context of education. The third chapter describes the education scenario in Sindh. Literature review relating to different aspects of efficiency and to the production function analysis and technical efficiency has been undertaken in chapter four. Chapter five discusses the methodology, and the model estimation. This chapter also contains the key theme, starting with the debate on model preparation / selection and econometric techniques which have been used for the analysis. Chapter six produces preliminary analysis based on internal efficiency calculations. The analysis uses data from 23 districts of Sindh province (over 47,000 schools (2005-06)) to develop and test models of efficiency, with an empirical analysis concluding some of the initial 
findings on internal efficiency. This chapter further produces the results of a survey of 237 schools in the 23 districts of Sindh, containing 14 questions on management practices in public and private schools. The quantitative data from the questionnaires has been analyzed using the standard non-parametric statistical methods (Chi Square). Chapter seven presents the econometric results. This chapter examines the efficiency of public education. Efficiency estimates have been obtained using stochastic frontier analysis applied to panel data from all the public schools in 23 districts of Sindh, Pakistan. I have used the panel data estimator, programmed in STATA 11 to estimate the stochastic frontier production function. The final chapter, i.e., Chapter eight provides discussion, conclusion and recommendations. 


\begin{abstract}
Islamic Republic of Pakistan is a democratic State and has a parliamentary system of government. Since its inception, the country has been predominantly ruled by military or quasi-military regimes, with only two exceptions of democratic governments which succeeded in completing their tenure; one from 1972 to1977 and second from 2008 to 2013. The last decade and a half has witnessed high levels of political instability on account of 'war on terror' related events and their fall out on the country's internal security. Additionally, international challenges such as sharp increase in international oil and food prices, energy shortages, continued fiscal deficits, drain of resources on unproductive sectors especially internal security resulted in the low productivity and low growth during this period. Currently, the socio-economic ramification of the internal security situation is the biggest challenge before the country and failure on account of human development especially education is one of the critical factors behind the prevailing situation. The Constitution places the responsibility for basic education on the State and after the $18^{\text {th }}$ Amendment; the Constitution explicitly specifies provision of compulsory and free education to all the children in the age bracket of 5-16 years by the State. The burgeoning human development deficit especially on account of massive gaps on education is believed to be singularly responsible for the catch 22 situation today. Many believe that unless there is a serious effort to improve the education attainments in the country, the widespread radicalism in the country may be difficult to contain.
\end{abstract}

\title{
2.1. BACKGROUND
}

Pakistan was created in 1947 after India's Independence from the British rule and its partition. In the last 65 years; the country has remained under military rule for approximately 33 years with intermittent periods of democracy. The checkered political dispensation first led to cessation of East Pakistan followed by a short interlude of parliamentary democracy. This however, was followed by a decade long military rule from 1977 to 1988 and then again from 1999 to 2007. Interestingly both these 10 years long authoritarian/ quasi-military rules had support of western powers especially USA initially in the background of the Soviet war in Afghanistan and second time in the context of 'war on terror'. This is a fact that Pakistan has had the military rules for over 35 years of its existence and these interventions always had tacit international support. 
General Zia UL Haq's ${ }^{4}$ repressive martial law and Pakistan's frontal role in the Afghan war through 'Jehadism' sow the seeds of extremism in the country and in fact this period has been a major turning point in changing the cultural ethos of the country.

Subsequent to the 1998 military take over followed by a quasi military government under General Pervaiz Musharraf; the country limped back to democracy in 2008. Since then there are signs of transformation of the state and its institutions through robust participation by multiple players including political, judicial, media and civil society. Pakistan has suffered greatly over the past decade and a half in the post 9/11 world. The "war on terror' has cost the country lives of more than 35,000 citizens, 3500 security personnel, destruction of infrastructure, internal migration of millions of people from parts of northwestern Pakistan, erosion of investment climate, nose diving of production and growing unemployment and above all it has brought economic activity to a virtual standstill in many parts of the country (Economic Survey of Pakistan 2010-11).

Having born out of highly contested partition of India, Pakistan faced a tremendous amount of political instability in the initial years especially on account of India's aggressive posture; fiscal and administrative challenges and most significantly on account of crisis of leadership. The father of the nation, Quaid-e-Azam Mohammad Ali Jinnah who had led the struggle for Pakistan, died within a year of Pakistan's creation, and this was followed by the assassination of the country's first Prime Minister, Liaquat Ali Khan. This political vacuum led to the first Martial Law in 1958 which was soon followed by

\footnotetext{
${ }^{4}$ General Zia-ul Haq imposed martial law and overthrew an elected government in 1977
} 
a military takeover by General Ayub Khan, which lasted for over 12 years. This dictatorship was weakened after the 1965 war with India leading to the breakup of East Pakistan, which was followed by a brief democratic period led by Zulfiqar Ali Bhutto's populist rule from 1972 to 1977 in the remaining Pakistan. Mr. Bhutto's populist policies transformed the political culture of Pakistan to a large extent. Political and social mobilization by his Pakistan Peoples' Party (PPP) and other political parties reached new heights. Nationalization of banks and key institutions is believed to have retarded the economic growth however, PPP's pro- people policies and creation of mega projects like the Pakistan Steel Mills; an international port at Karachi and many other economic assets created big employment opportunities leading to a marked decrease in unemployment and poverty. Mr. Bhutto was removed by General Zia-UI-Haq in a military coup and he was subsequently executed through a highly controversial court case.

The Zia-Ul-Haq's regime followed a liberal economic policy framework with active support of western powers, however on the political front this is considered to be the most vindictive and brutal martial law in Pakistan. The army took control of large parts of the state apparatus including public enterprises. Most significantly, this was the time when Pakistan formally got engaged as a frontline state in the armed conflict in Afghanistan against the USSR supported intervention. This frontline war was fought through state sponsored Islamic militancy and through an official declaration of "Jehad" against military aggression in Afghanistan. This particular era is considered to be economically a high growth period when the economy grew at an average annual growth rate of 6 percent. 
Many economists like Bengali ${ }^{5}$ and others have put across forceful arguments showing that much of the growth during the 1980s was an offshoot of the investments undertaken during the 1970s. The Pakistan Steel Mills came into operation in 1983 and the foreign remittances in this period were because of the liberal export of labor initiated during the 1970s.

Benazir Bhutto, the daughter of Zulfiqar Ali Bhutto returned from her exile abroad and led a popular political movement against General Zia UI Haq's regime which, came to an end after his death in an aircraft crash. She got elected as the Prime Minister of Pakistan in 1988 and was the first Muslim women prime minister of an Islamic State. It was a short rule of about 18 months; cut short once gain by a military coup. The 1990 elections returned Nawaz Sharif in power in Pakistan. These musical chairs of short political tenures between the two major political parties continued throughout the 1990s. This decade is often referred to as being a "failed decade" due to low economic growth and political instability which remained a hallmark of this period. Continuous power struggles between elected governments on the one hand and the presidents and the army chiefs on the other, as well as the spillover of the civil war in neighboring Afghanistan, made these governments inwardly focused and preoccupied with the law and order problems. This democratic transition was disrupted by General Musharraf's military takeover in 1998. General Musharraf got himself elected as the President of Pakistan and remained Chief of Army Staff from 2002 till 2008. General Musharraf, incidentally again found himself on the right side of western powers. The post 9/11 world made Pakistan once again a strategic requirement for the western

\footnotetext{
${ }^{5}$ Dr Kaiser Bengali, Dec 2007, lecture on Making Sense of Pakistan's Economy at Shirkat Gah Karachi
} 
allies especially USA in its hunt for 'war against terror'. General Musharraf's complete support of US and allied forces brought forward many economic dividends with debt write- offs, liberal lending programs. These together with a slightly more disciplined economic management took the country towards a third cycle of high growth; averaging $5.5 \%$ in this period.

General Musharraf's long 9- year rule was rocked by country wide protests by the lawyers, political parties, and the civil society at large in the background of his confrontation with the judiciary and imposition of 'Emergency' in the country. Benazir Bhutto returned from her second round of exile and once again her return met with an unprecedented public support in the political history of Pakistan. This time, the country faced yet another heavy political blow; when the leader of one of the biggest political party, Ms. Bhutto was assassinated in a targeted firing and a bomb blast incident in December 2007 in Rawalpindi, Pakistan. The earlier announced elections were postponed and were held in February 2008 and the PPP emerged as the majority party all over Pakistan. This PPP led coalition government completed its 5- year tenure on March 16, 2013.

\subsection{ADMINISTRATIVE STRUCTURE}

Pakistan comprises of eight administrative units i.e. provinces / regions: Punjab, North West Frontier Province (renamed Khyber Pakhtunkhwa), Balochistan and Sindh and some administrative units which include Islamabad Capital Territory (ICT), Federally Administered Tribal Areas (FATA) and Federally Administered Northern Areas (FANA). Pakistan has a federal form of government with the provinces as its federating units. It is governed by the 1973 Constitution having a parliament and a senate at the federal level and 
provincial assemblies in each province. The President of Pakistan is the head of the state and the Prime Minister is the executive head. Political and civil administration in the provinces is run by the Chief Minister of each province. Each province is divided into small manageable units called districts. In all, there are 111 districts (Punjab 34, Sindh 23, KPK 24, and Balochistan 30). Each district is further divided into Tehsil or Talukas (sub- districts), thus there are 402 Tehsils in Pakistan. The national language is Urdu and there are a number of regional languages spoken in different parts of the country. The medium of education is Urdu (Sindhi in many schools in Sindh) but English continues to be used in higher education and professional colleges, particularly in scientific and technical fields. English is widely used for commercial, legal and official business in the country. About 97 percent of the population in Pakistan is Muslim.

\subsection{STATE OF ECONOMY}

Many analysts believe Pakistan's growth experience over the past 65 years to be impressive as well as disappointing. Husain (2010) presents a comprehensive analysis of Pakistan's growth record and finds it impressive because of the rapid growth rate which resulted in the increase of per capita incomes by four times and helped in lowering poverty levels by one half despite fairly high population growth. In these over six decades a predominantly agrarian economy has gradually transformed into a more diversified economy where almost 80 percent of its exports are manufactured goods. The economy grew at an average annual rate of slightly over 5 percent during the last six decades which was highest in the region in the initial three decades and in per capita terms the growth rate was 2.5 percent annually. According to Husain 
(2010), it is basically post 1990s that the country's growth pattern fell below the regional average. He asserts that, in the first 20 years after independence in 1947, Pakistan had the highest growth rate in South Asia. According to the World Bank (2002), Pakistan exported more manufactured goods than Indonesia, Malaysia, Philippines, Thailand and Turkey combined in 1965 (cited in Hussain, 2010, p. 14). By the 1990s, Pakistan however, became the slowest growing country in South Asia, an exact reversal of its previous role. The incidence of poverty, which declined from 46 percent in the mid-1960s to 18 percent in the late 1980 s rose to 34 percent by the late 1990s. Other than political instability, frequent policy changes, low investment in social sectors, the overall governance too remained less than desirable, throughout the $1980 \mathrm{~s}$ as well as during the fragile democratic period during 1990s. The sharp fluctuations in the GDP growth over the past decade or so are depicted in figure 2-1.For the past few years, especially after the democratic dispensation in the country since 2008, the economic growth has dipped.

Figure 2-1: GDP Growth Rates 2000-01 to 2011-12.

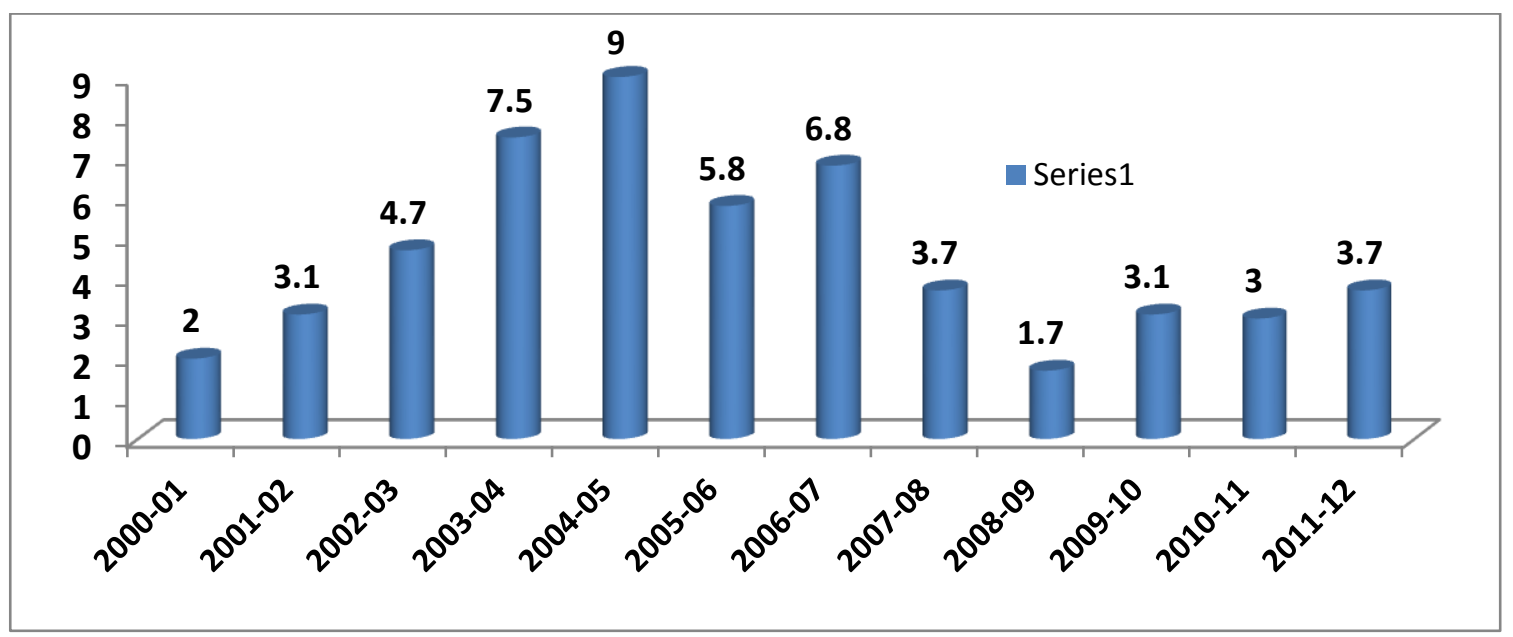

Source: Pakistan Economic Survey, 2012-13.

The international oil and food price hike in 2008; worsening of internal security as a fall out of the war on terror, and acute energy shortages; all 
accumulated into worsening macroeconomic situation resulting in the sharp decline of growth. The situation was exacerbated by repeated rounds of natural calamities; floods and torrential rains in 2010 and 2011 which also impacted growth. Memon (2012) gives an account of devastating floods in the summer of 2010 which, rendered 20 million people homeless and inflicted a massive damage of $\$ 10$ billion to public and private infrastructure as well as wiped out an estimated 2 percentage points from the growth rate. The most disappointing aspect of Pakistan's past six decades is its sheer failing on account of human development. As per BTI (2012) index of key indicators, with an HDI of 0.504, Pakistan ranks 145th amongst 187 countries with a dismal education index of 0.386 .

\subsubsection{Macro and micro indicators}

It can be seen from table 2-1, Pakistan's GDP was $\$ 143$ billion in the year 2007 which rose to $\$ 176$ billion by 2010 . It is quite interesting to note that while GDP growth declined to an average of 3 percent since 2007-08, in contrast the per capita incomes reflect an increase from US\$1015 in 2007-08 to US\$1254 in 2010-11; depicting an increase of 23 percent in the comparable period ${ }^{6}$. On the basis of this per capita income, Pakistan enjoys the status of a middle income country. However, the critical issue before the country has been as to how much the people gained from the increase in the per capita income? As per capita income is the average income per person it does not provide any information about various income categories. An increase in the per capita income during the last few years might have raised the income of some people substantially, while many people may not have seen any increase in their

\footnotetext{
${ }^{6}$ Pakistan Economic Survey 2010-11
} 
income at all. Given the double digit inflation rates (increase in inflation rate from 7.6 percent in 2007 to 13.9 percent in 2012), it is highly likely that many people's incomes would have been eroded rather than increased and as such, this higher per capita income is primarily reflective of a severely inequitable growth pattern which, has been historically the hallmark of growth in Pakistan.

Table 2-1: Economic Indicators $2007-10$

\begin{tabular}{|c|c|c|c|c|c|}
\hline Eco Indicators & & 2007 & 2008 & 2009 & 2010 \\
\hline GDP & \$ million & 143171.2 & 163891.7 & 161819 & 176869.6 \\
\hline GDP Growth & $\%$ & 5.7 & 1.6 & 3.6 & 4.1 \\
\hline Inflation (CPI) & $\%$ & 7,6 & 20.3 & 13.6 & 13.9 \\
\hline Unemployment & & 5.1 & 5 & & \\
\hline $\begin{array}{l}\text { Foreign Direct } \\
\text { Investment }\end{array}$ & $\%$ of GDP & 3.9 & 3.3 & 1.4 & 1.1 \\
\hline Export Growth & $\%$ & 2.3 & -5.3 & -3.3 & 15.8 \\
\hline Import Growth & $\%$ & -3.5 & 3.5 & -15.2 & 4.4 \\
\hline $\begin{array}{l}\text { Current Account } \\
\text { Balance }\end{array}$ & $\$ m n$ & -8286 & -15654.5 & -3993 & -1490 \\
\hline Public Debt & $\%$ of GDP & 54.6 & 58.7 & 57.3 & 56.8 \\
\hline External debt & $\$ m n$ & 41531.1 & 49057.4 & 54587.9 & 56772.9 \\
\hline Total Debt Service & $\$ m n$ & 2644.6 & 3017.6 & 3494.9 & 4338.4 \\
\hline Cash Surplus or Deficit & $\%$ of GDP & -4.2 & -7.4 & -4.8 & \\
\hline Tax Revenue & $\%$ of GDP & 9.8 & 9.9 & 9.3 & 10 \\
\hline Govt Consumption & $\%$ of GDP & 9.2 & 12.5 & 8.1 & 7.9 \\
\hline Public Exp on Edu & $\%$ of GDP & 2.8 & 2.9 & 2.7 & \\
\hline Public Exp on Health & $\%$ of GDP & 2.6 & 2.6 & 2.6 & \\
\hline Military Exp & $\%$ of GDP & 3 & 2.8 & 2.8 & \\
\hline
\end{tabular}

Source: BTI 2012, Pakistan Country Report, p.12.

Resultantly, a small number of beneficiaries would have gained from higher prices, such as industrialists, traders, importers, exporters and certain categories of self-employed persons. Over the last few years, a large number of families reportedly gained from the surge in income from home remittances, which have helped in raising living standards of many families.

\subsubsection{Demographic profile}

2013 elections, has publicly announced that resolving the issue of the energy 
crisis and improving the economic performance will remain its core priority. Earlier, in 2011, the federal Planning Division evolved a growth strategy believed to be a major departure from the earlier growth frameworks. The strategy was titled, 'New Growth Framework' (NGF) 2011. This sought to accelerate growth and attain sustained growth of 7 percent or more per annum and development based on economic reform and productivity. It stated that a lower growth than this would not be able to provide the levels of productivity and employment for the increasing number of young labor in the country. Pakistan, with projected 180 million people, is the sixth most populous country in the world. Pakistan's median age of 21.2 years-with a global range of 48.9 in Monaco and 15 in Uganda-makes Pakistan one of the world's youngest of countries. By 2050, with an annual growth rate estimated at 2.07 percent, Pakistan is expected to become the fourth most populous state. Many analysts believe Pakistan's population growth rate, its age structure, income distribution and the development of its human capital could be the principal determinants of the economy's productive capacity. According to Kugelman and Hathaway (2011), Pakistan's population promises to remain youthful over the next few decades and by the 2020s, the 15-24 age brackets are expected to swell by 20 percent. Pakistan's under- 24 population will still be in the majority come 2030 . And as late as 2050 , the median age is expected to be only 33 years.. However, the government of Pakistan's framework for economic growth (2011) states that with almost two - thirds of the population (68.4 percent) below the age of 30 , Pakistan is going to experience a youth bulge in coming years, which is likely to change the age structure of the labor force over the next couple of decades. A study by Population Action International (2003) suggests 
a strong correlation between countries prone to civil conflicts and those with burgeoning youth populations. Social scientists label this demographic profile 'youth bulge' and the theory contends that societies with rapidly growing young populations often end up with rampant unemployment.

\subsection{INCLUSIVE GROWTH}

Although Pakistan has seen sustained periods of economic growth, these have not always translated into a proportionate poverty reduction. ${ }^{7}$ Growth lowers poverty, but a visible and sincere pro-poor and inclusive growth requires an improvement in the distribution of income which, in Pakistan's case has not occurred. A UNDP (2009) report suggests that the second significant period when high growth rates did not translate into poverty reduction gains was the most recent period from 2002 till 2007.

Easterly (2001) argued a decade ago, that countries at the same level of growth and per-capita income compared to Pakistan, have achieved more in terms of education and health indicators. Pakistan's performance on almost all human development indices remains much below desirable levels. Its health, educational outcomes are poor. According to Easterly (2001), Pakistan has had a high per capita income over 1950-99 period and it received one of the highest level of international assistance ( $\$ 58$ billion) in this period; yet the country

\footnotetext{
${ }^{7}$ Over the past six decades, Pakistan's average economic growth rate was higher than the average growth rate of the world economy. The overall economic performance, according to the Asian Development Bank (ADB), "for the period 1961-1990 was respectable ... the average growth rate during the 1960s was 6.8 percent per annum, dropping lower than 5 percent in the 1970 s and then climbing to 6.5 percent in the 1980s."

Sustained periods of economic growth, however, have not always translated into poverty reduction. According to ADB, "Periods of slow growth (the 1970s and 1990s) have alternated with periods of high growth (the 1960s and 1980s). Although the incidence of poverty has tended to decline most when the economic growth rate was high and increased when the growth rate was low, it has also declined during period of slow growth (e.g., in the 1970s) and increased during periods of high growth (the 1960s)."
} 
underperforms on most of the social as well as political indicators including health, education, political stability and democracy etc.

Acemoglu et al. (2005) handles the issue of inequitable growth through a strong theoretical basis regarding the role of institutions in determining long-term growth. They argue that political and economic institutions need to be differentiated. The latter is mainly related to property rights and contract enforcement, which are associated with the rule of law. Political institutions, however pertain to both formal rules (the constitution or long established conventions), as well as the informal exercise of power. In many ways, this corresponds to North's (1990) distinction between formal and informal institutions. Formal political institutions are slow to change, as evidenced by the infrequency with which constitutions are altered. Informal political institutions refer to the power of the influential, and are very much related to the distribution of income or wealth. Political institutions and the distribution of wealth are the two state variables that jointly determine economic institutions, which in turn determine economic performance or growth, and the future distribution of resources and political institutions.

In Pakistan, historical and geographical patterns have long been behind the economic, social and political exclusion of large segments of the population. Inequality of economic opportunity is of two types: distributional and structural. Distributional inequalities persist primarily because of three factors: the government's fiscal policy, the government's commodity operations and monopolized markets. Structural inequality has four dimensions: gender, regional, economic class and social identity, regional, economic class and social identity. 


\subsection{EDUCATION POLICIES AND STRATEGIES}

In the last over 6 decades of Pakistan, around 23 policies and action plans have been introduced with explicit commitments to attain universal primary education. The founding fathers of Pakistan acknowledged the importance of education and Universal Primary Education (UPE) was set as a goal in the very first National Education Conference held in 1947. Subsequently, the Commission on National Education (1959); and the series of National Education Policies (NEP); 1970, 1972, 1979, 1992 all set ambitious targets for

Table 2-2: UPE Goals, Target Year and Achievement

\begin{tabular}{|c|c|c|c|}
\hline No & Policies/commissions/conferences & Target years & Total Period \\
\hline 1 & All Pak Education Conference (1947) & 1967 & $20 y$ \\
\hline 2 & National Education Commission (1959) & 1969 & $10 y$ \\
\hline 3 & Education Policy (1972) & 1979 & $7 y$ \\
\hline 4 & Education Policy (1979) & 1986 & $7 y$ \\
\hline 5 & Education Policy (1992) & 2002 & $10 y$ \\
\hline 6 & Education Policy (1998-20 10) & 2010 & $12 y$ \\
\hline 7 & Education Sector Reforms (2001-06) & $100 \%$ by 2004 & $5 y$ \\
\hline
\end{tabular}

Source: AEPAM, Research Study 2010, 237:6,p. 247.

various components of education including ( see table 2-2); UPE; need to reduce regional and gender disparities; promotion of adult education as well as technical education along with other aspects of education. Most of these targets have remained difficult to attain, but what is unfortunate is that the policy that

Table 2-3: Plans Targets and Achievements

\begin{tabular}{c|l|c|c}
\hline S \# & \multicolumn{1}{|c|}{ 5 Years Plans } & $\begin{array}{c}\text { Target } \\
\text { P/Rate }\end{array}$ & $\begin{array}{c}\text { ACH P/Rate } \\
\text { nercent }\end{array}$ \\
\hline 1 & First Five Year Plan (1955-60) & 58 & 30 \\
\hline 2 & Second Five Year Plan (1960-65) & 56 & 45 \\
\hline 3 & Third Five Year Plan (1965-70) & 70 & 46 \\
\hline 4 & 4th Five Year Plan (N.I)* (Non Plan Period/8y 1970-78) & 65 & 54 \\
\hline 5 & Fifth Five Year Plan (1978-83) & 68 & 48 \\
\hline 6 & Sixth Five Year Plan (1983-88) & 75 & 63 \\
\hline 7 & Seventh Five Year Plan (1988-93) & 80 & 69 \\
\hline 8 & Eighth Five Year Plan (1993-98) & 88 & 75 \\
\hline \multicolumn{2}{l}{ Source: AEPAM, Research study 2010,237:6, p.248. }
\end{tabular}

followed regretted non-attainment and set-out equally ambitious targets 
without addressing the challenges which had hitherto impeded visible progress on attaining the earlier targets. Moreover during last over six decades no efforts were made to have rationale thinking on it.

AEPAM (2010) report provides following summary account of different education policies and plans. The Education Conference (1947) set the target of 100 percent UPE in 20 years time. The Education Policies 1959, 1972, 1979, 1992, 1998 and ESR (2001- 06) set the target of 100 percent UPE in 10 years, 7 years, 7 years, 10 years, 12 years and 5 years respectively. However, there was marginal progress on any of these targets.

The report also examined the target participation rate under different Five year plans and found that the targets set in each Plan were overly ambitious and resultantly the results were considerably less than what was envisaged. Table 2-3 reflects the targets set-out under different five-year Plans and the achievements against these.

\subsection{INTERNATIONAL COMMITMENTS}

In April 2000, the world education forum, adopted the 'Dakar Framework for Action' where all the stakeholders including Pakistan committed themselves to achieve EFA goals and targets by the year 2015. These are; 1) Expanding and improving early childhood education and care (ECCE) especially for the most vulnerable and disadvantaged children; 2) Ensuring that by 2015 all children (especially girls and children in special circumstances) have access to and complete free and compulsory quality primary education; 3) Ensuring that the learning needs of all young people and adults are met through equitable access to appropriate learning and life skills; 4) Achieving a 50 percent improvement in adult literacy by 2015; 5) Eliminating gender disparity 
in primary education and secondary education by 2005 and achieving gender equality in education by 2015 ; 6 ) Improving the quality of education to ensure measurable learning outcomes are achieved by all, especially in literacy, numeracy, and essential life skills. Despite reform frameworks; the government was unable to translate these plans especially those relating to human development into any major breakthroughs on the ground.

\subsection{FORMAL EDUCATION SYSTEM IN PAKISTAN}

The country's formal education system comprises of pre-primary to tertiary, professional, technical and madressa education. The public schools provide pre-primary education (kachi class) for age groups of 3 to 4 years as part of the socialization process. Education for All (EFA), 1998-2010 provided recognition to kachi class as proxy for early childhood education whereas the NEP 2009 envisages a formal introduction of the kachi class in the primary schools but unfortunately this has not been introduced as yet. The next stage is primary schooling which has remained under focus since the inception of the country. It comprises of classes' 1 to 5 and enrolls children of age 5-9 years. The middle schooling for age-group 10-12 is of three years duration and comprises of class 6, 7 and 8 . The high school comprises of class 9 and 10 and thereafter the children appear for Secondary School Certificate (SSC) examination conducted by the Boards of Secondary Education. The higher secondary stage is also called the "intermediate stage" and is considered to be a part of college education. Higher secondary education consists of classes 11 to 12 . The Boards of Intermediate and Secondary Education (BISE) conduct the higher secondary level examination and award a certificate of higher secondary school education (HSSC). 


\subsection{CONCLUSION}

The overall economic scenario in Pakistan continues to be faced with inherent structural challenges such as large fiscal deficits, low expenditure on education and health, chronic energy shortages, lack of focus on the productive sectors resulting in high inflation, high unemployment and low economic growth. There is consensus that the country will have to accelerate the economic growth towards the 7 percent target on a sustainable basis for next many years; and for sustained economic growth, it will be critical to achieve macro-economic stability through fiscal prudence and improved governance. The current elected government has set about the task of addressing the energy shortages and gearing the economic framework towards a steady growth path; however, the government would need to undertake serious structural reforms to be able to evolve inclusive and pro-people growth strategy as the 'growth without development' types of growths may become too dangerous for a country fighting extremism and increasing divisiveness in the society.

In Pakistan, most of the educational reforms, action programs or initiatives have faltered due to complex issues largely related to governance. Many believe that it's generally the governance deficit, which is primarily responsible for non-conversion of a robust growth into better human development indices in different high growth periods of the country. The post $18^{\text {th }}$ Amendment coupled with the greater fiscal resources provided to the provinces under the $7^{\text {th }} \mathrm{NFC}$ Award has thrown up considerable opportunities for the country to produce better results on human development especially health and education. It is thus believed to be an opportune time for the federation and the provinces to make use of the devolved framework for attaining better outcomes under education 
especially. Availability of adequate financing will be a central issue however; utilizing existing resources more effectively can create space for expanding the opportunities of education for larger numbers of students. The 'political will', which will go after the education goals, may probably remain elusive until there are political incentives or disincentives for non performance. This will eventually link up with the larger issue of greater democratization and accountability in the country. 


\begin{abstract}
Sindh, the second largest province of the country is faced with tremendous amount of challenges on the development front including low economic growth with persistent inequities; low levels of human development; high levels of poverty and malnourishment. The education sector in Sindh is characterized by very low enrolments; high levels of rural and gender disparity and poor quality of education. The failure to exhibit better outcomes on education is increasingly becoming compelling as without visible improvements, the overarching challenges on the development paradigm are likely to intensify. More significantly the inability to perform on the education front is creating increasing space for innumerable disruptive forces especially the extremists who find easy following from amongst those who are hungry and illiterate. Financing is an important factor for meeting the big challenges of bringing millions of out of school children into school and for improving the learning attainments. The provincial governments in Pakistan are now mainly responsible for providing free and compulsory education to all the eligible children. Accordingly, the responsibility for enlarging the allocations for the sector in accordance with envisaged framework primarily falls on them. For Sindh, it is critically important to make the existing spending more effective, as apparently the entire sector is riddled with numerous inefficiencies leading to poor outcomes.
\end{abstract}

\title{
3.1. SINDH'S POLITICS \& ECONOMY
}

According to the Sindh Economic Report (2006), Sindh had left its problems untreated for decades and it faced formidable and complex development challenges. The description in the report relating to Sindh's chronic under performance throughout last many decades was true in 2006 and it's unfortunately true today in 2013. As per the report Sindh's per capita income at the time of Independence was nearly 55 percent higher than the rest of the country; by the early 1990s it was 36 percent higher; and by 2004-05 the difference was further reduced to 16 percent. One of the peculiar feature of Sindh is that it is one of the most unequal and diverse provinces in Pakistan. On one hand is Karachi, its capital city, which has the highest per capita income in the country; on the other are rural hinterlands where poverty levels are amongst the highest in the country. Sindh's overall human development 
status is poor; again having sharp contrast amongst the urban indicators compared to the rural. The overall health and education indicators of rural females in Sindh are one of the worst in the country and have remained so for long. Not only is there visible regional disparity in terms of economic and social development; but the province is also divided politically on ethnic lines. The native Sindhis (who are largely in Sindh's small towns and villages) and the Mohajirs (who mainly inhabit the bigger urban centers especially Karachi) have remained at logger heads for long. The two major ethnic groups' uneasy relationship has undermined Sindh's overall development for last many decades. The provincial capital, Karachi; the largest city in the country and the financial and trade hub of the country; has remained a battleground amongst a range of ethnic, sectarian and terrorist outfits which have continued to disrupt peace for last many decades. These conflicts coupled with land, drug and extortion mafias have been operating in the city which has witnessed unending incidents of rioting, bomb blasts, suicide attacks, street fights and target killings systematically and unabatedly throughout last over two and a half decades with the scale and dimension intensifying in last five to six years.

Sindh's projected population in 2011 is 43 million and being the most urbanized province in the country, almost half of its population is urban. Sindh houses a huge economic infrastructure; which contributes a significant share into the national GDP; estimated to be in the range of 29 to 31 percent (Bengali; 2001). Sindh produces over 71 percent and 61 percent of the country's total production of natural gas and oil respectively. The untapped Thar coal reserves are estimated to have 180 billion tons of coal; the fifth largest coal reserves of the world, which if exploited can provide massive indigenous fuel resource to 
the country for next many decades. Sindh generates and collects over $60 \%$ of the total national revenue in the form of federal taxes, customs duty and surcharges and indirect tax contributions. According to Pakistan Economic Survey 2010-11, Sindh accounts for 40 percent of large scale manufacturing production of the country and significant contribution to overall agricultural output of the country (32\% in rice, $24 \%$ in sugar cane, and $21 \%$ in wheat). The provincial economy is highly diversified. Heavy industry, information technology and finance are centered in and around Karachi. There is a substantial agricultural base along the Indus river which itself is at the tail-end of the Indus river irrigation system. The coastal fisheries are of considerable importance and the Karachi fish harbor is the main export outlet for seafood products. Manufacturing includes textiles, apparel, chemicals, metal, cement, plastics and many other goods. Sindh has a large variety of natural resources which, if developed wisely, can directly and immediately contribute to high, consistent and sustainable economic growth in the province.

As stated, Sindh can be said, to have a dual economy: (i) an industry and service-dominated economy in southern Sindh cities like Karachi, Hyderabad and (ii) an agrarian economy, generally referred to as rural Sindh. Economic policies which favor urban industrial development contribute to marked rural urban disparities. The development and revival of the rural economy is critical for long - term growth and competitiveness and in particular for rural areas. Sindh has extremely high levels of poverty especially in rural Sindh. There has not been any national level poverty headcount in last decade or so however, many reports earlier as well as recent highlight the situation based on various related surveys. Lately SDPI (2012) has published a research on multi- 
dimensional poverty in Pakistan. It has been argued in this research that poverty in Pakistan needs to be seen in the context of multiple deprivations of human capabilities as the poor face multiple deprivations and as such one of these deprivations alone cannot reflect the state of poverty. According to this; poverty levels in Sindh are extremely high where overall 33 percent of the households are under poverty with an extremely high proportion of 42 percent being in rural areas (figure 3-1).

Figure 3-1 : Province Wise Incidence of Poverty 2012

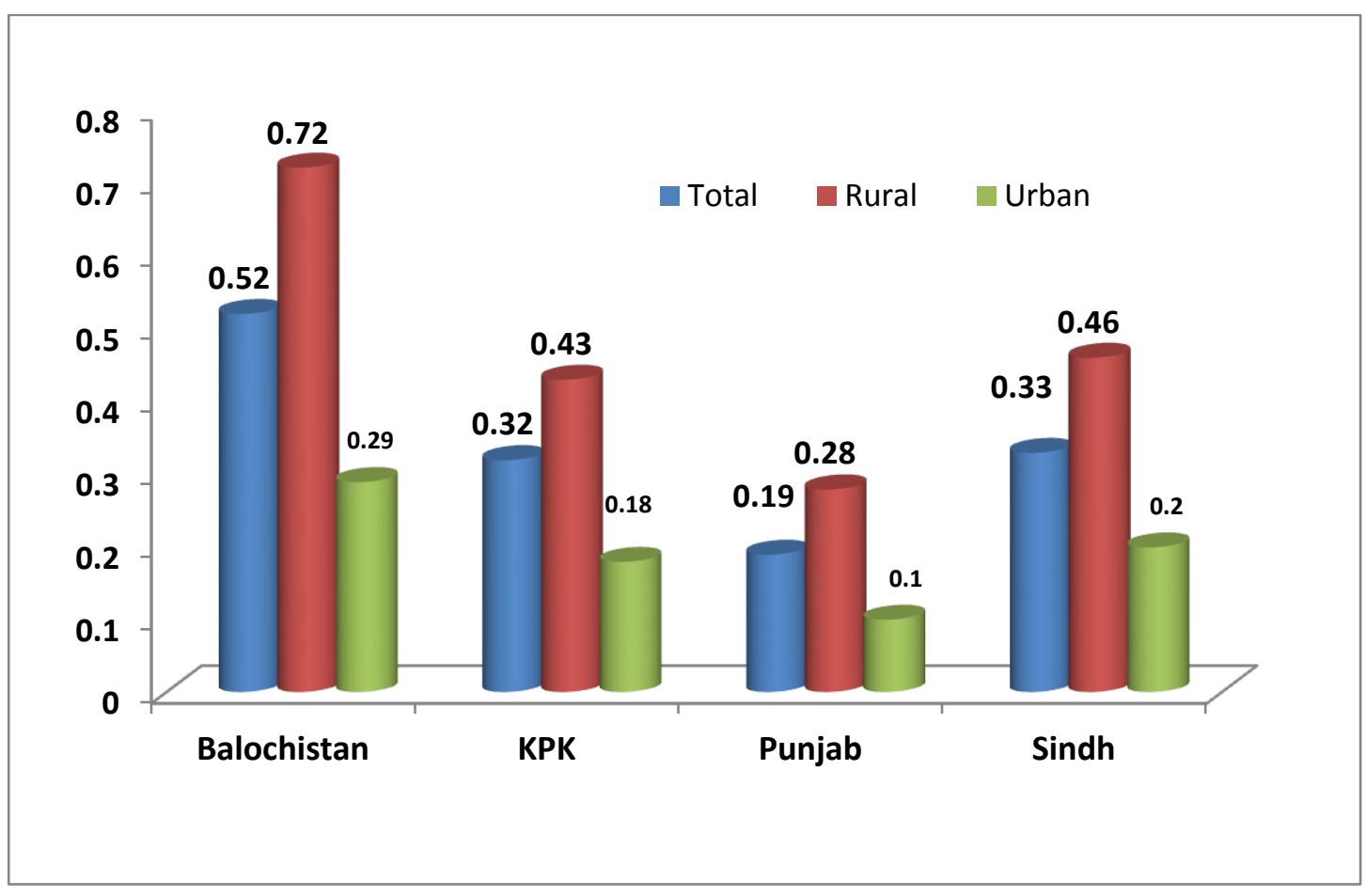

Source: SDPI 2012, p.19.

This assessment is in conformity with other similar reports in respect of poverty and deprivation. For instance, the National Nutrition Survey of Pakistan 2011 assessed Sindh to be the most food deprived province. Under this, only 28 percent households were found to be food secure and the rest 72 percent households assessed to be food insecure; of these 72 percent, 21.1 percent are food insecure without hunger, 33.8 percent are food insecure with moderate hunger and 16.8 percent are food insecure with severe hunger. 


\subsection{THE DEVOLUTION FRAMEWORK 2001}

The local government framework implemented in Pakistan in the period 2001 to $2010^{8}$ is considered to be a very extensive exercise relating to devolution of power and authority to lower tiers of government. It undoubtedly ushered one of the most significant structural changes in the overall governance structure of the country. Undertaken by General Pervaiz Musharraf as part of his reform agenda, it resulted in transfer of large segment of powers and jurisdiction from the provinces to the district level. The local government levels were made responsible for public service delivery for about 12 functions. These included the major social services like primary and secondary education, preventive and curative health, water supply, drainage and sewerage, and economic services like fisheries; livestock; urban transport and farm-to-market roads. Consequently, provincial governments were left with law and order, justice, higher education, agricultural development, irrigation, land reclamation, and highways. A major criticism against the devolution framework of 2001 was that it was primarily federal government's initiative and the entire exercise including the law, its rules, manuals, capacity development, reporting, etc was handled through the central National Reconstruction Bureau (NRB). ). Most significant aspect was that these developments took place when the provincial and National assembly's were in abeyance. The issues of ownership at the provincial level became evident after the coming in of elected governments in 2008 as none of four provincial governments showed any inclination to re enact the local government law and for reestablishing local government system.

\footnotetext{
${ }^{8}$ The Local Government Framework 2001 was protected under the $17^{\text {th }}$ Amendment to Constitution of Pakistan, which lapsed on December $31^{\text {st }} 2009$.
} 


\subsection{PROVINCIAL EDUCATION MANAGEMENT STRUCTURE}

The overall roles and responsibilities of the provincial Education Department have undergone considerable change in the last decade and a half. The experience of devolution of education management at the district level has remained mixed with the proponents of devolution arguing in favor of the local government system benefits and the detractors claiming that there were little gains if any. After the lapse of the constitutional protection to the local government framework in 2009, none of the four provinces re -enacted the law and in fact the system was almost reversed to a large extent with varying degrees in the four provinces.

At the provincial level, the Education department is responsible for the overall policy, and management of the education (except during devolution when management functions came under the domain of district governments). The department is headed by a provincial minister, assisted by the provincial secretary from the civil services, who manages numerous administrative wings, units and attached offices. The major offices under the department are the; provincial secretariat; the Bureau of Curriculum; Provincial Institute for Teacher Education (PITE); Sindh Teacher Education Development Authority (STEDA). All three incidentally relate to teacher development portfolio reflecting the presence of institutional maze. In addition there is the Reform Support Unit (RSU); the Sindh Textbook Board (STBB); and many Implementation units involved in the implementation of different donor assisted projects.

The Education department is the biggest department of the government of Sindh both in terms of the strength of its manpower and the size of its budget. Of the total 560,000 employees of the government of Sindh, around 250,000 
are in the Education Department. A bulk of these employees, were placed under the administrative control of the district governments. The Education department administers education through its divisional offices located in the five divisional headquarters and 23 district offices located in each of the 23 districts and subdivisions. All the five divisions (Karachi, Hyderabad, Sukkur, Larkana, and Mirpurkhas) are further divided into districts. The edifice of education management prior to devolution was based on a top - down and an overly centralized management system. Past studies conducted on the education management in Sindh indicate that despite a big hierarchical structure, all major decisions were made at the provincial level with the lower tier officers acting as receivers of information and implementers. The situation in Sindh in post devolution period was not much different.

\subsection{THE DISTRICT EDUCATION OFFICE}

As part of the Sindh Local Government Ordinance 2001 the district became the

Figure 3-2 Organogram of District Education Office

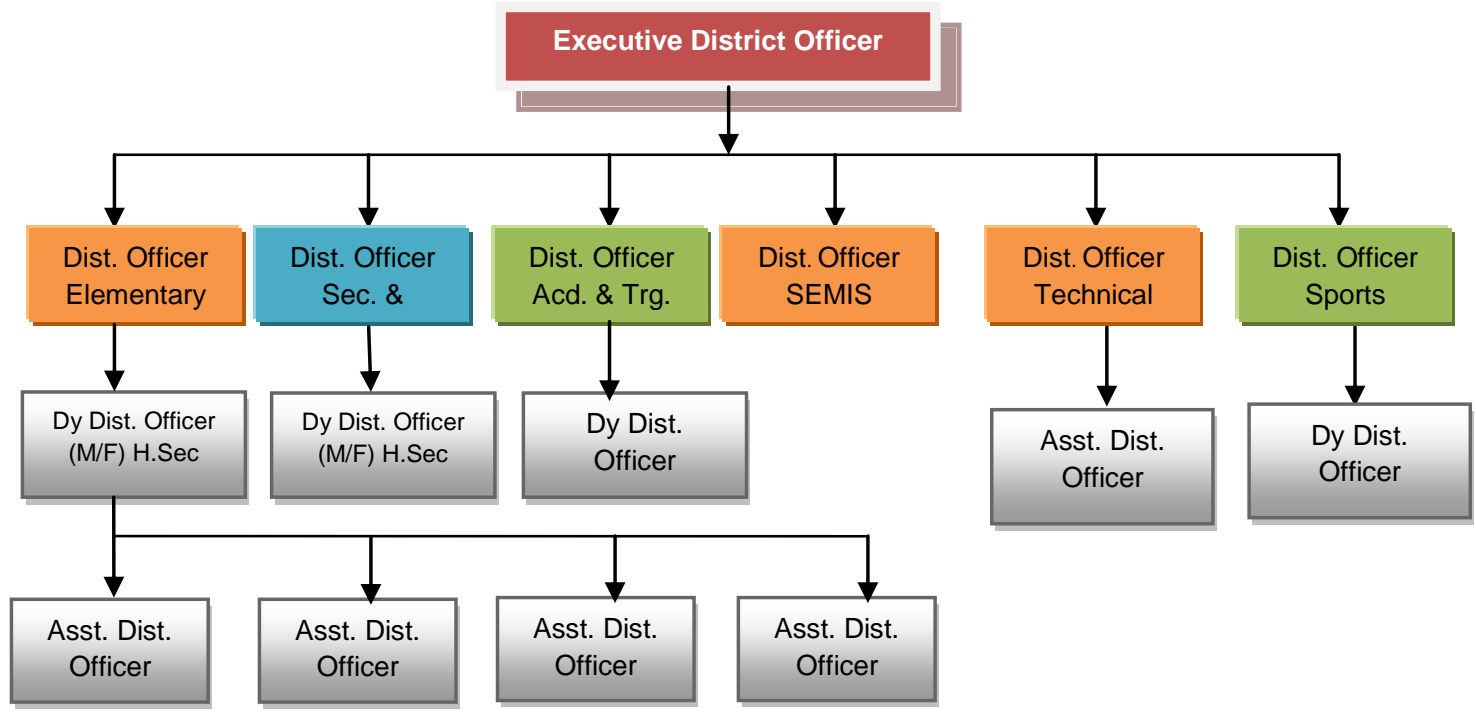

operational tier of governance. The senior education officers were posted as Executive District Officer (EDO) - Education and made responsible for 
managing the education portfolio at the district level. The teachers and the lower level education staff were placed under the overall control of the district governments (see figure 3-2).

Table 3-1 : Grade-wise Total Management and Support Staff in Districts

\begin{tabular}{|c|c|c|c|c|c|c|c|c|c|c|}
\hline Districts & $\begin{array}{l}\text { Grade } \\
\text { BS-20 }\end{array}$ & $\begin{array}{l}\text { Grade } \\
\text { BS-19 }\end{array}$ & $\begin{array}{l}\text { Grade } \\
\text { BS-18 }\end{array}$ & $\begin{array}{l}\text { Grade } \\
\text { BS-17 }\end{array}$ & $\begin{array}{l}\text { Grade } \\
\text { BS-16 }\end{array}$ & $\begin{array}{l}\text { Grade } \\
\text { BS-12 }\end{array}$ & $\begin{array}{l}\text { Grade } \\
\text { BS-11 }\end{array}$ & $\begin{array}{l}\text { Grade } \\
\text { BS-07 }\end{array}$ & $\begin{array}{c}\text { Grade } \\
\text { BS-1-5 }\end{array}$ & Total \\
\hline Karachi & 1 & 13 & 22 & 46 & 214 & 21 & 122 & 150 & 442 & 1031 \\
\hline Hyderabad & 1 & 6 & 9 & 19 & 97 & 9 & 67 & 47 & 216 & 471 \\
\hline Dadu & 1 & 6 & 9 & 14 & 62 & 2 & 20 & 33 & 71 & 218 \\
\hline Badin & 1 & 6 & 8 & 11 & 46 & 2 & 53 & 17 & 62 & 206 \\
\hline Thatta & 1 & 6 & 9 & 18 & 58 & 1 & 20 & 21 & 80 & 214 \\
\hline Mirpurkhas & 1 & 7 & 8 & 17 & 11 & 7 & 32 & 29 & 108 & 220 \\
\hline Sanghar & 1 & 6 & 9 & 13 & 57 & 2 & 19 & 20 & 69 & 196 \\
\hline Tharparkar & 1 & 6 & 9 & 8 & 42 & 2 & 40 & 13 & 48 & 169 \\
\hline Sukkur & 1 & 6 & 7 & 12 & 35 & 6 & 58 & 32 & 111 & 268 \\
\hline Khairpur & 1 & 6 & 11 & 20 & 61 & 2 & 13 & 32 & 94 & 240 \\
\hline Nausheroferoze & 1 & 6 & 8 & 8 & 39 & 2 & 46 & 22 & 67 & 199 \\
\hline Nawabshah & 1 & 6 & 8 & 6 & 31 & 2 & 42 & 19 & 64 & 179 \\
\hline Ghotki & 1 & 6 & 8 & 10 & 28 & 4 & 25 & 5 & 33 & 120 \\
\hline Larkana & 1 & 8 & 9 & 15 & 72 & 3 & 42 & 44 & 140 & 334 \\
\hline Shikarpur & 1 & 6 & 9 & 9 & 31 & 1 & 40 & 19 & 44 & 160 \\
\hline Jacobabad & 1 & 6 & 9 & 10 & 49 & 1 & 54 & 19 & 66 & 215 \\
\hline Matiari & 1 & 6 & 8 & 9 & 28 & 2 & 23 & 12 & 20 & 109 \\
\hline Tando A. Yar & 1 & 6 & 8 & 8 & 27 & 3 & 21 & 11 & 19 & 104 \\
\hline Tando M. Khan & 1 & 6 & 8 & 8 & 26 & 2 & 19 & 12 & 18 & 100 \\
\hline Jamshoro & 1 & 6 & 8 & 9 & 28 & 3 & 26 & 14 & 22 & 117 \\
\hline Kashmore & 1 & 6 & 8 & 8 & 22 & 2 & 23 & 11 & 19 & 100 \\
\hline Kambar @Sh.K & 1 & 6 & 8 & 7 & 19 & 2 & 21 & 10 & 18 & 92 \\
\hline Umarkot & 1 & 6 & 8 & 6 & 18 & 2 & 24 & 13 & 22 & 100 \\
\hline Total & 23 & 148 & 208 & 291 & 1101 & 83 & 850 & 605 & 1853 & 5162 \\
\hline
\end{tabular}

Source : Compiled from SEMIS 2008-09 and Finance Department Budget Book 2008-09.

The EDOs (Education) on an average supervised over 40 officers comprising district officers (DOs), deputy district officers (DDOs), assistant district officers (ADOs), and learning coordinators. It can be seen from table 3-1 that there were only 5162 management staff in 23 districts and of this approximately $66 \%$ were BS-11 or below. There were only 1510 (34\%) employees above BS-11 for management of the entire education portfolio at district level. The numbers have risen significantly in last 5 years. This staff managed around 48,000 schools and 144,610 teachers at this time. Earlier the primary school teacher, at the bottom of the hierarchy was in grade 9 with a nominal salary.

But the salaries have significantly increased and given the unemployment levels in the province this position continues to be highly coveted. However, 
given its low status these positions generally do not attract candidates with a relatively higher degree of competence.

\subsection{SCHOOL EDUCATION IN SINDH}

Education in Sindh has suffered from innumerable issues, as reflected by various educational indicators including, low literacy and enrolments, high levels of dropout from the schooling system particularly at primary level, low completion rates, acute regional and gender inequalities, teachers' absenteeism all leading to unsatisfactory school performances.

Table 3-2 below reflects the state of education in terms of school attendances

Table 3-2 : Percentage of Population (10 Years and Older) Ever Attended School

\begin{tabular}{|c|c|c|c|c|c|c|c|c|c|c|c|c|}
\hline \multirow[t]{2}{*}{ Province } & \multicolumn{3}{|c|}{ 2004-05 PSLM } & \multicolumn{3}{|c|}{ 2006-07 PSLM } & \multicolumn{3}{|c|}{ 2008-09 PSLM } & \multicolumn{3}{|c|}{ 2010-11 PSLM } \\
\hline & Male & Female & Both & Male & Female & Both & Male & Female & Both & Male & Female & Total \\
\hline URBAN AREAS: & 80 & 63 & 72 & 80 & 66 & 73 & 82 & 68 & 75 & 82 & 68 & 75 \\
\hline Punjab & 81 & 67 & 74 & 81 & 69 & 75 & 83 & 72 & 78 & 82 & 72 & 77 \\
\hline Sindh & 80 & 62 & 72 & 81 & 65 & 74 & 82 & 66 & 74 & 82 & 69 & 76 \\
\hline Khyber Pakhtunkhwa & 80 & 49 & 65 & 78 & 49 & 64 & 78 & 49 & 64 & 79 & 52 & 66 \\
\hline Balochistan & 74 & 41 & 59 & 75 & 41 & 60 & 77 & 47 & 63 & 80 & 39 & 61 \\
\hline RURAL AREAS: & 62 & 31 & 47 & 63 & 32 & 48 & 65 & 35 & 50 & 66 & 36 & 51 \\
\hline Punjab & 64 & 38 & 51 & 66 & 40 & 53 & 66 & 41 & 53 & 67 & 44 & 55 \\
\hline Sindh & 57 & 18 & 39 & 54 & 17 & 37 & 63 & 23 & 45 & 61 & 22 & 43 \\
\hline Khyber Pakhtunkhwa & 66 & 25 & 45 & 68 & 26 & 47 & 70 & 29 & 50 & 69 & 31 & 50 \\
\hline Balochistan & 47 & 13 & 32 & 49 & 13 & 33 & 56 & 14 & 37 & 55 & 13 & 36 \\
\hline OVERALL: & 68 & 42 & 55 & 69 & 44 & 57 & 71 & 46 & 59 & 71 & 47 & 60 \\
\hline Punjab & 69 & 47 & 58 & 71 & 50 & 60 & 72 & 51 & 62 & 72 & 53 & 63 \\
\hline Sindh & 69 & 41 & 56 & 68 & 43 & 56 & 73 & 45 & 60 & 72 & 47 & 60 \\
\hline Khyber Pakhtunkhwa & 69 & 29 & 48 & 70 & 30 & 50 & 71 & 32 & 52 & 71 & 35 & 53 \\
\hline Balochistan & 52 & 18 & 37 & 55 & 20 & 39 & 61 & 22 & 44 & 61 & 20 & 42 \\
\hline
\end{tabular}

Source: Author's Construction from PSLM 2004-05; 2006-07 and 2010-11.

over last 5 years. Sindh's indicators remain below the national averages and this is basically on account of poor indicators of the rural areas. In $2010-11$, the percentage of 10 year and above who had ever attended school in the rural Sindh was 43 as against national figure of 51 percent. There were only 22 percent 10 year and above rural women in Sindh who had ever attended school as against 36 percent across Pakistan and 44 percent in Punjab. There are many factors affecting schooling, both demand and supply factors explain this 
state of affairs. On the demand side, poverty and illiteracy adversely affect household decisions to send children to school and to undertake school performance accountability.

On the supply side, high population growth rates and lack of adequate political will coupled with a financial commitment and ability to deliver has caused illiteracy to rise. There have been noteworthy efforts in the private and nongovernment sectors, but the scale of these efforts is not sufficient to make a difference to the aggregate situation. Clearly, there is little alternative to public education, in a country of the size of Pakistan having 60 percent of the population living on less than 2 dollars a day. The supply side is related to infrastructure including school buildings and classrooms, school equipment and pedagogic materials, teachers and school management and overall school governance. While on the demand side, it includes household characteristics, the level of income of population and demographic characteristics, especially the ability of the population to demand an acceptable level of service delivery. The demand side over the years has become skewed. With rising levels of inequitable growth and income distribution, the well-off sections especially in urban and semi urban enclaves have gradually shifted to private sector education leaving only the poor and marginalized population in the public education system. The supply side of public education system in Sindh which still caters to more than $65 \%$ percent of school going children has gradually declined in performance both in providing access and quality of education due to complex set of reasons. This subject of falling standard of public education requires a very intensive research to understand the dynamics and pinpoint the critical aspects which eventually produce a very dismal set of out comes in this 
critical component of education in Sindh. The National Education Assessment Report $2005^{9}$ had placed Sindh at $7^{\text {th }}$ position, above AJK, in mathematics in comparison to eight (8) administrative units of Pakistan.

\subsubsection{School data and indicators}

Before examining the school data and analyzing the school indicators it is important to state the issues relating to data in Pakistan and in Sindh particularly. The Sindh education management information system (SEMIS) is now a well organized institutional set up in the Sindh education department and it undertakes an annual school census (ASC) to collect the school data, however, the school data issues and challenges continue to persist. Lately SEMIS has been considerably strengthened and it has remained under the review of international donors like the World Bank, however, despite investments and efforts, the data still suffers from inconsistency on account of many factors. Firstly, the children enrolled in kachi (pre primary) are a significant proportion of primary enrolment. But unfortunately this is not recognized officially whereas this data is an integral part of primary level enrolment data and is considered in all reform inputs like textbooks, etc. As it is not officially recognized, the number of children enrolled at this level remains highly fluid with wide fluctuations from one year to the other and within a year. Secondly presence of a large number of shelter less and one / two room schools (over $85 \%$ of total schools in Sindh) in remote and having difficult approaches(desert region, river bed, coastal belt)makes the data collection and verification process highly challenging. Thirdly, the survey forms are filled- in by the school head teachers and are collected at a given central point for

\footnotetext{
${ }^{9}$ The National Education Assessment (NEAS) is an yearly assessment done by federal government for proficiency in Science and English subjects
} 
facilitating the exercise. These forms are then entered into the system and are cleaned-up and verified. There are however, chances of misreporting and more importantly the data of enrolments may be true only in the context of children

Figure 3-3 : Enrolment Level Wise

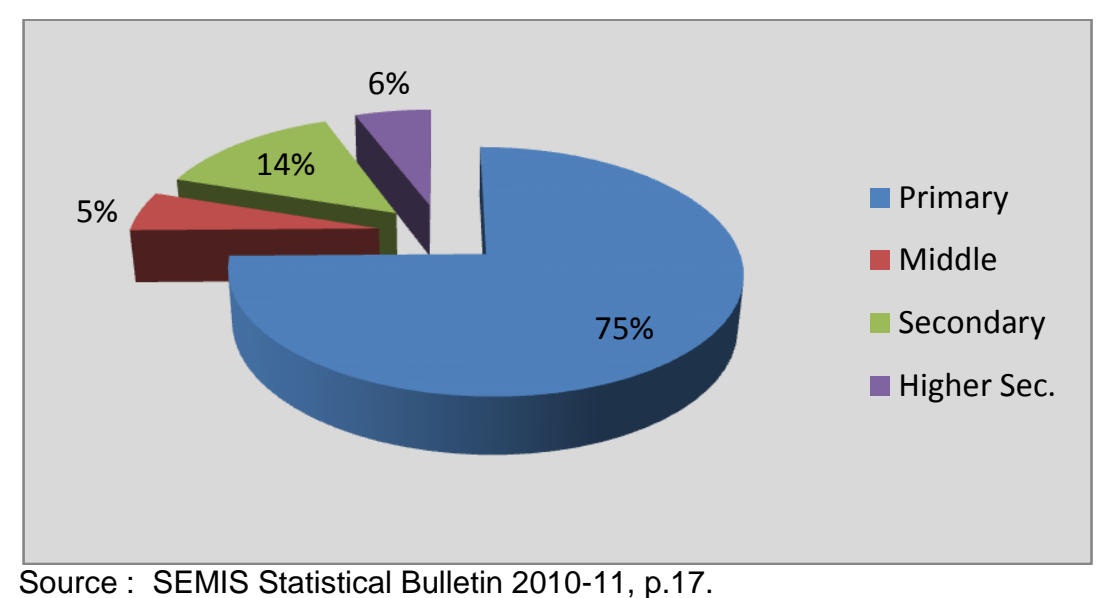

registered, it does not capture the children who may have registered but dropped out at any point in the year. Hence there is a need to re examine the entire system of data collection to further capture more live data. Also it will be worthwhile to have the baseline reworked through an independent third party source for a more robust integrity and reliability of the data. Finally the budget and expenditure component of the data became tedious on account of change in the legal ownership after devolution in view of the weak accounting and reporting system. Hence, effort has been made to use officially published data which, however, continues to suffer from issues of consistency. In Sindh the primary education refers to class $1-5$ in the age group 5-9 years, while middle education refers to class $6-8$ in the age group 10-12. The primary and middle together constitute elementary education covering class 1-8. Secondary education (13-14 years) comprises class $9-10$.

There are presently, 44,522 primary schools in Sindh and against these, there are only 2505 middle schools and 1641 secondary schools, which together 
constitute less than 10 percent of primary schools. The most interesting aspects of school portfolio are that about 56 percent of schools are mixed i.e. these are attended by both girls and boys.

Figure 3-4 : Class Wise Enrolments

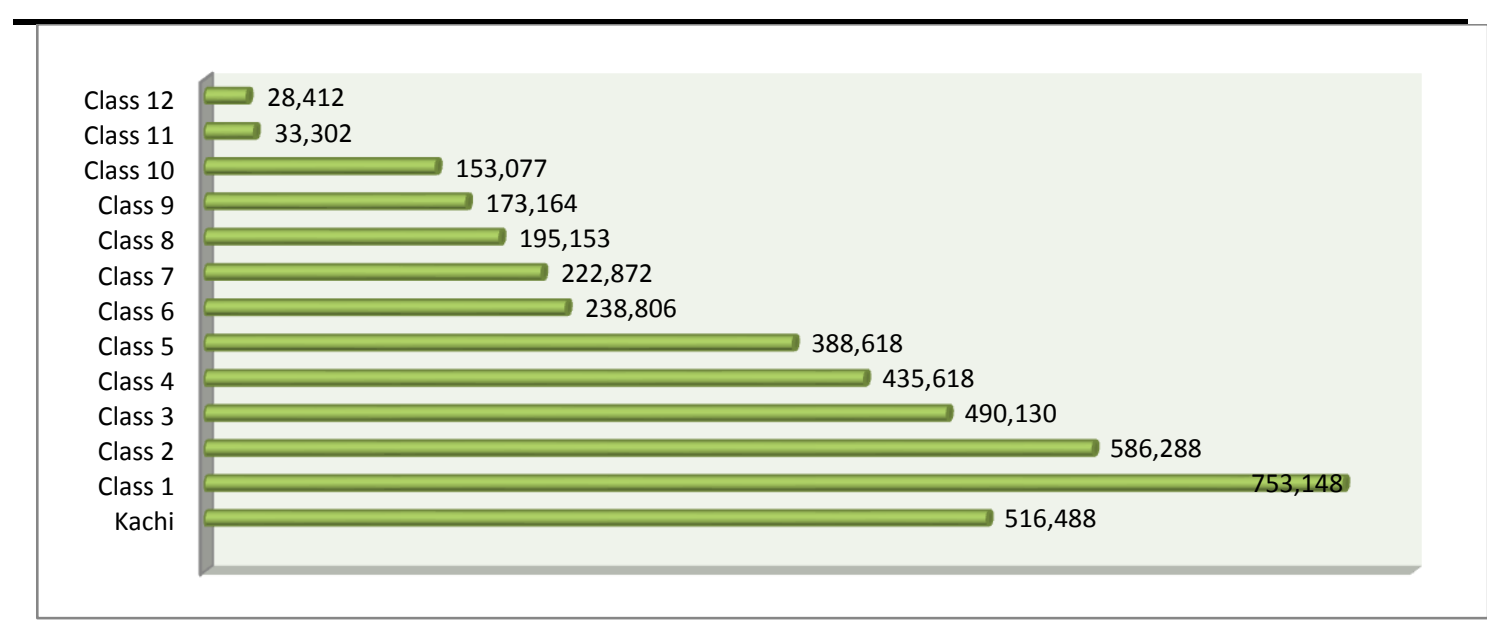

Source : SEMIS Statistical Bulletin 2010-11, p.18.

This is despite the fact that the entire education portfolio across the country is segregated on gender lines. However, the presence of 56 percent of schools which cater to both boys and girls contradicts the official segregation which has led to considerable inefficiencies including the unnecessary spread of school portfolio. Another peculiar feature of Sindh is the prevalence of various mediums of schools, including Urdu, Sindhi, and English and mixed. Majority of the schools (73 percent) are of Sindhi medium and the majority of which (93 percent) are in the primary, 15 percent schools are Urdu medium, 11 percent of schools have mixed languages namely Sindhi, English and Urdu while only 1 percent are English medium schools.

As per SEMIS (2010-11) report, of the 48,914 total schools in Sindh, 5039 schools are closed, of which almost 90 percent are primary schools. The closed schools' phenomenon has remained a regular feature of school education in Sindh and it is an off-shoot of skewed planning which over the years has been 
determined on political grounds rather than a proper on-ground needs assessment and scientific planning. Total school enrolment (pre-primary to class-10) in Sindh is $4,402,993$ and this has somewhat remained static since last 3 years. Presently, the total male enrolment is 2,589,148 (59 percent), and

Table 3-3 : Schools, Enrolments \& Teachers; 4- Years Comparison

\begin{tabular}{lcccccccccccc}
\hline & \multicolumn{4}{c}{ Schools } & \multicolumn{1}{c}{ Enrolment } & \multicolumn{4}{c}{ Teachers } \\
\cline { 2 - 11 } & $\mathbf{2 0 0 7}$ & $\mathbf{2 0 0 8}$ & $\mathbf{2 0 0 9}$ & $\mathbf{2 0 1 0}$ & $\mathbf{2 0 0 7}$ & $\mathbf{2 0 0 8}$ & $\mathbf{2 0 0 9}$ & $\mathbf{2 0 1 0}$ & $\mathbf{2 0 0 7}$ & $\mathbf{2 0 0 8}$ & $\mathbf{2 0 0 9}$ & $\mathbf{2 0 1 0}$ \\
\hline Prim & 44315 & 44518 & 45044 & 44522 & 3335171 & 3326734 & 3402391 & 3291974 & 95852 & 100999 & 101944 & 102061 \\
Mid & 3097 & 2787 & 2668 & 2505 & 230882 & 218341 & 228832 & 237003 & 10192 & 10586 & 9610 & 9959 \\
Secy & 1601 & 1604 & 1662 & 1641 & 577966 & 586583 & 630337 & 620951 & 26016 & 26889 & 25550 & 25598 \\
H Sec. & 198 & 216 & 231 & 246 & 187956 & 209316 & 227649 & 253065 & 5947 & 6621 & 6530 & 6992 \\
\hline Total & 49,211 & 49,125 & 49,605 & 48,914 & $4,331,975$ & $4,340,974$ & $4,489,209$ & $4,402,993$ & $\mathbf{1 3 8 , 0 0 7}$ & $\mathbf{1 4 5 , 0 9 5}$ & $\mathbf{1 4 3 , 6 3 4}$ & $\mathbf{1 4 4 , 6 1 0}$ \\
\hline Source: Compiled from SEMIS Statistical Bulletin 2007-8 to 2010-11.
\end{tabular}

female enrolment is $1,813,845$ (41percent). Out of total 144,610 teachers, 69 percent are male and 31 percent are female teachers. Three -fourth of enrolment is in primary schools; 5.38 percent in middle schools and 14 percent in secondary schools (table 3.3). Figure 3.4 illustrates class wise enrolment. The system does not officially recognize kachi (pre primary) classes; however, there were 516,488 children in this component in $2010-11$. This is a decrease of $20 \%$ compared to the year before when there were over 700,000 children at this level. The highest enrolment in class- 1 constituting over $17 \%$ of total enrolment is reflective of the presence of a robust demand for education which many fail to appreciate and there is considerable funding for communication dissemination through the media for strengthening public demand for education in Pakistan. The major issue is that the system is not able to retain the children and the drop-outs begin from class 2 onwards. Approximately 28 percent children fallout from class 1 to 2 and second major fall comes from class 5 to 6 
when compared to class 1 enrolment only 31 percent move to grade 6 . Finally by class 10 only about 20 percent children are in the system and 80 percent have dropped out.

There are innumerable factors which are responsible for this situation and these all can be termed to be issues of 'supply side' where from school infrastructure; teachers; management and inputs together suffer from inefficiencies and weaknesses leading to systematic losses on account of inability to retain children. Table 3-3 presents a four year analysis of schools, enrolment and teachers.

It may be seen that the number of schools increases and then decreases, it reflects an overall decrease of 1.39 percent from 2009 to 2010 . The overall enrolment shows a decrease of 1.92 percent from 2009 to 2010 . The teachers' data reflect that there are currently 144,610 teachers as against 138,007 , three years ago depicting a 7.7 percent increase in this period.

Table 3-4 : Student - Teacher Ratio (STR)

\begin{tabular}{lcccc}
\hline School Level & $2006-07$ & $2007-08$ & $2009-10$ & $2010-11$ \\
\hline Primary & 34.13 & 34.08 & 32.94 & 33.38 \\
Middle & 20.42 & 22.65 & 20.63 & 23.81 \\
Secondary & 21.43 & 22.22 & 21.81 & 24.67 \\
Higher Sec. & 28.45 & 31.61 & 31.61 & 34.86 \\
\hline
\end{tabular}

Source: SEMIS various issues.

In the context of school characteristics table 3-4 provides the STR reported in Sindh's ACS from 2006-07 to 2009-10.It can be seen that on an average primary and higher secondary levels have high STR compared to middle and secondary level. However, over the years STR at primary level has improved slightly from 34.13 to 33.38 percent, whereas in case of middle levels, the STR has increased from 20.42 percent in $2006-07$ to 23.81 percent in $2009-10$. At the secondary level, it has increased from 21.43 percent in $2006-07$ to 24.67 percent in 2009-10 and higher secondary levels the STR increased from 28.45 
in 2006-7 to 34.86 percent in 2009. Sindh has an overall teacher / student ratio of $1: 32$. This again is a very broad average.

Table 3-5 : Student - Classroom Ratio (SCR)

\begin{tabular}{ccccc}
\hline School Level & $\mathbf{2 0 0 6 - 0 7}$ & $\mathbf{2 0 0 7 - 0 8}$ & $\mathbf{2 0 0 8 - 9}$ & $\mathbf{2 0 0 9 - 1 0}$ \\
\hline Primary & 44.00 & 44.21 & 43,58 & 43.85 \\
Middle & 23.74 & 26.54 & 26.06 & 27.62 \\
Secondary & 43.67 & 43.80 & 45.42 & 49.23 \\
Higher Sec. & 61.76 & 65.15 & 67.26 & 73.67 \\
\hline Source: Compiled from SEMIS data $2006-2010$ & &
\end{tabular}

ource: Compiled from SEMIS data 2006-2010.

As mentioned earlier, the teacher deployment suffers from inefficiencies and more than often transfer postings happen on the basis of patronage rather than on the basis of a need or a given strategy. This results in regions with insufficient staff and regions with a high concentration of teachers. Generally big cities like Karachi and other urban centers get a considerably greater proportion of teaching staff. This patronage based deployment coupled with high frequency of teacher absenteeism renders the general STR calculations quite misleading in many cases. Another characteristic which sheds light on school characteristics is the student class room ratio (SCR), which is used to measure the number of classrooms in relation to the size of the student enrolled in the class. It is generally assumed that a low SCR signifies smaller cohorts of students in class, which enables the teacher to pay more attention to individual students, which may in the long run result in a better performance of the students. In Sindh higher SCR is mostly at the secondary and higher secondary level reflecting higher demand and low availability of infrastructure. This is also evident from the number of middle and high schools in Sindh. In 2006-07 the SCR of higher secondary schools was 61.76 percent which increased to 73.67 percent in 2009-10 with 49 students per class in 2009-10. 


\subsubsection{School enrolments and retention}

The state of gross and net enrolment rates in Sindh compared to other provinces in Pakistan is presented below. The situation is gloomy as despite

Table 3-6 : Gross Enrolment Rate Primary Level (5-9) Excluding Kachi Class

\begin{tabular}{|c|c|c|c|c|c|c|c|c|c|c|}
\hline & \multicolumn{3}{|c|}{ Urban } & \multicolumn{3}{|c|}{ Rural } & \multicolumn{3}{|c|}{ Total } & Total \\
\hline & Male & Female & Total & Male & Female & Total & Male & Female & Total & \\
\hline Pakistan & 109 & 103 & 106 & 96 & 75 & 86 & 100 & 83 & 92 & 91 \\
\hline Punjab & 111 & 108 & 109 & 100 & 88 & 94 & 103 & 93 & 98 & 97 \\
\hline $\begin{array}{l}\text { Sindh } \\
\text { Khyber }\end{array}$ & 107 & 99 & 103 & 87 & 55 & 72 & 94 & 72 & 84 & 84 \\
\hline Pakhtunkhwa & 105 & 96 & 100 & 100 & 73 & 87 & 101 & 76 & 89 & 87 \\
\hline Balochistan & 117 & 84 & 102 & 85 & 43 & 66 & 92 & 52 & 74 & 75 \\
\hline \multicolumn{11}{|c|}{ Net Enrolment Rate Primary (5-9) } \\
\hline & \multicolumn{3}{|c|}{ Urban } & \multicolumn{3}{|c|}{ Rural } & \multicolumn{3}{|c|}{ Total } & Total \\
\hline & Male & Female & Total & Male & Female & Total & Male & Female & Total & \\
\hline Pakistan & 67 & 65 & 66 & 57 & 48 & 53 & 60 & 53 & 56 & 57 \\
\hline Punjab & 69 & 69 & 69 & 60 & 55 & 58 & 62 & 59 & 61 & 62 \\
\hline $\begin{array}{l}\text { Sindh } \\
\text { Khyber }\end{array}$ & 63 & 62 & 63 & 54 & 39 & 47 & 57 & 48 & 53 & 54 \\
\hline Pakhtunkhwa & 63 & 58 & 61 & 56 & 43 & 50 & 57 & 45 & 51 & 52 \\
\hline Balochistan & 69 & 58 & 64 & 53 & 29 & 42 & 56 & 35 & 47 & 44 \\
\hline
\end{tabular}

having a much larger economy than the two smaller provinces in Pakistan (KPK and Balochistan); its indicators on primary education are quite low especially as compared to KPK. Also there is little movement in last few years. The GER and NER data presented at table 3.6 to 3.8 relate to the entire public and private sector schools.

The GER for primary level is static from $2008-09$ to $2010-11$ at 84 percent and the NER reflects a decrease of 1 percent in this period from 54 percent to 53 percent. The overall GER in Punjab at this level is significantly higher than Sindh at 98 percent. What is highly conspicuous in the case of Sindh is that the overall indicators of rural areas and especially rural females are very poor. The urban Sindh enrolments both the gross and net figures are comparable with the overall national figures though even these are on the lower side; however the rural enrolments are way below. The total gross and net enrolment in rural area 
in Pakistan in 2010-11 is 86 and 53 percent and as against this the enrolments

Table 3-7 : Gross Enrolment Rate Middle Level (11-13)

\begin{tabular}{|c|c|c|c|c|c|c|c|c|c|}
\hline \multirow[b]{2}{*}{ Unit } & \multicolumn{3}{|c|}{ Urban } & \multicolumn{3}{|c|}{ Rural } & \multicolumn{3}{|c|}{ Total } \\
\hline & Male & Female & Total & Male & Female & Total & Male & Female & Total \\
\hline Pakistan & 78 & 79 & 78 & 64 & 43 & 55 & 68 & 54 & 62 \\
\hline Punjab & 75 & 82 & 78 & 64 & 52 & 58 & 67 & 61 & 64 \\
\hline $\begin{array}{l}\text { Sindh } \\
\text { Khyber }\end{array}$ & 78 & 78 & 78 & 56 & 24 & 42 & 66 & 50 & 59 \\
\hline Pakhtunkhwa & 92 & 66 & 79 & 78 & 42 & 61 & 80 & 46 & 64 \\
\hline Balochistan & 87 & 72 & 81 & 50 & 12 & 35 & 58 & 26 & 45 \\
\hline \multicolumn{10}{|c|}{ Net Enrolment Rate Middle Level (11-13) } \\
\hline \multirow[b]{2}{*}{ Unit } & \multicolumn{3}{|c|}{ Urban } & \multicolumn{3}{|c|}{ Rural } & \multicolumn{3}{|c|}{ Total } \\
\hline & Male & Female & Total & Male & Female & Total & Male & Female & Total \\
\hline Pakistan & 46 & 49 & 48 & 34 & 24 & 29 & 38 & 32 & 35 \\
\hline Punjab & 46 & 51 & 48 & 34 & 29 & 31 & 37 & 36 & 37 \\
\hline $\begin{array}{l}\text { Sindh } \\
\text { Khyber }\end{array}$ & 46 & 50 & 48 & 34 & 14 & 26 & 39 & 32 & 36 \\
\hline Pakhtunkhwa & 50 & 38 & 44 & 38 & 22 & 30 & 40 & 25 & 33 \\
\hline Balochistan & 47 & 35 & 42 & 30 & 7 & 21 & 34 & 13 & 25 \\
\hline
\end{tabular}

Source: PSLM, 2010-11.

in Sindh are 72 and 47 percent. Though the participation level of rural females is one of the lowest in Pakistan however, the participation level of rural males at primary level on the basis of GER and NER is also low. As against the national GER and NER of 96 percent and 57 percent for rural males; the figures for Sindh rural males are 87 and 57 percent respectively. The situation on rural female participation levels is worst. As against rural female gross and net enrolment of 75 and 48 percent respectively at national level; the gross and net enrolments in Sindh are 55\% and 39\% respectively.

In terms of gross enrolment levels, there is a difference of about 20 percentage. Points between national level rural female enrolment and Sindh's rural female enrolment, which is a very pronounced difference reflecting upon the extent of backwardness and under development and gender disparity in Sindh. The pattern seen at the level of primary is also visible at the middle school level to certain extent. Sindh's urban middle school enrolments are quite comparable with the national enrolments as well as that of Punjab at this level both on gross 
enrolments as well as net. The situation on rural enrolments unfortunately remains much behind the national level figures both for males as well as females. If we look at Sindh's GER for rural females it is 24 percent compared to the national GER for rural females of 43 . Similarly the net enrolment of Sindh's rural females is 14 percent compared to 24 at national level.

Under the secondary education as well the status of urban enrolments is in conformity with the overall national level status on urban enrolments though slightly behind. The gross rural enrolment at the secondary level in Sindh is 42 percent whereas it is 58 percent in Punjab and 61 percent in KPK. Balochistan's indicators continue to be significantly behind all the provinces. Sindh's GER of rural females is 24 compared to 42 at national level. The net

Table 3-8 : Gross Enrolment Rate Secondary Level (14-15)

\begin{tabular}{|c|c|c|c|c|c|c|c|c|c|}
\hline & \multicolumn{3}{|c|}{ Urban } & \multicolumn{3}{|c|}{ Rural } & \multicolumn{3}{|c|}{ Total } \\
\hline & Male & Female & Total & Male & Female & Total & Male & Female & Total \\
\hline Pakistan & 75 & 75 & 75 & 54 & 34 & 45 & 61 & 48 & 55 \\
\hline Punjab & 78 & 83 & 80 & 56 & 43 & 50 & 63 & 56 & 59 \\
\hline $\begin{array}{l}\text { Sindh } \\
\text { Khyber }\end{array}$ & 74 & 69 & 72 & 41 & 14 & 30 & 56 & 42 & 50 \\
\hline Pakhtunkhwa & 70 & 56 & 63 & 67 & 31 & 50 & 67 & 35 & 52 \\
\hline Balochistan & 67 & 48 & 59 & 40 & 5 & 26 & 46 & 16 & 34 \\
\hline \multicolumn{10}{|c|}{ Net Enrolment Rate Secondary Level (14-15) } \\
\hline & \multicolumn{3}{|c|}{ Urban } & \multicolumn{3}{|c|}{ Rural } & \multicolumn{3}{|c|}{ Total } \\
\hline & Male & Female & Total & Male & Female & Total & Male & Female & Total \\
\hline Pakistan & 32 & 34 & 33 & 21 & 15 & 18 & 24 & 21 & 23 \\
\hline Punjab & 32 & 38 & 35 & 21 & 19 & 20 & 24 & 25 & 25 \\
\hline Sindh & 35 & 32 & 33 & 19 & 7 & 14 & 26 & 20 & 23 \\
\hline KPK & 29 & 27 & 28 & 22 & 12 & 17 & 23 & 14 & 19 \\
\hline Balochistan & 28 & 13 & 21 & 19 & 2 & 12 & 21 & 4 & 14 \\
\hline
\end{tabular}

Source: PSLM, 2010-11.

enrolment status of rural females is highly dismal at 14 percent compared to 24 at national level, for the secondary education. Closely connected with the enrolment is the student retention in the school followed by school completion rates. The dropout rate is one of the key indicators for analyzing and projecting student flows from class to class within the educational cycle. This is calculated 
by subtracting the sum of promotion rate and repetition rate from 100 of the given class in the given school year. The trend in dropouts of boys and girls shows similar trends, hence only the total drop-out figures have been analyzed. One of the important indicators of an efficient schooling system is the survival rate to class 5 , which tells that for every 100 students enrolled in grade 1 , only about 50 percent or so survive till class 5 and approximately 30 percent survive till class 6 (this is the highest dip in elementary education) ( see table at appendix 6-B). The target for MTDF was 80 percent and EFA target requires the survival rate to be 100 percent by 2015 . Survival rates in Sindh have always been lower than national averages; for example, in 2008-09 survival rates at the national level averaged 54.6 percent, while in Sindh these were 42.56 percent. In the wake of the floods, there has been a further drop in the school survival rates, to 39.4 percent (between 2010 and 2011). It was estimated that some 21,460 students were not able to reach to class 5 in 2010 alone. By the time children reach class 10 , there are only 20 percent or so who have survived till this stage. The major reason behind the sharp dropout from class 5 to 6 is largely due to issues related to transition from primary to middle level school, especially on account of non -availability of middle level schools nearby for children graduating from class 5 . The total numbers of middle and high schools together make up for less than 10 percent of the primary schools hence other than several other Table 3-9 : Gender Parity Index 2006-07 - 2009-10

\begin{tabular}{|c|c|c|c|c|c|}
\hline & & & & & \\
\hline \multirow{2}{*}{ aspects including culture with } & School Level & $2006-07$ & $2007-08$ & $2009-10$ & $2010-11$ \\
\hline & Primary & 0.67 & 0.67 & 0.67 & 0.69 \\
\hline \multirow{3}{*}{ reference to girl child, the big } & Middle & 0.88 & 0.76 & 0.87 & 0.95 \\
\hline & Secondary & 0.64 & 0.67 & 0.64 & 0.67 \\
\hline & Higher Sec. & 0.65 & 0.63 & 0.58 & 0.55 \\
\hline
\end{tabular}
gap on non availability of Source : SEMIS Statistical Bulletin various issues. middle and high schools is a very obvious reason for the sharp dropouts after 
class 5 . The gender parity index (GPI) measures progress towards gender parity in education participation and /or learning opportunities available for women in relation to those available to men. It also reflects the level of women's empowerment in society. A GPI equal to 1 indicates parity between females and males. In general, a value less than 1 indicates a disparity in favor of boys and a value greater than 1 indicates in favor of girls. According to the figures in table 3-9 the GPI in the public sector schools of Sindh during 2006-07 to $2009-10$ has increased slightly except higher secondary level where it has decreased significantly. The statistical bulletin (2010) of the Education department, government of Sindh reports that the MTDF target for gender parity at primary level was 0.94 by the year 2010 . The GPI for Sindh is lower than the national average of 0.83 . Gender parity, like other indicators, also sharply improves with mother's education and wealth index. Thus some districts have achieved gender parity and done better than other districts in enrolling more girls. Gender disparity is quite widespread in Sindh, particularly in the less-developed districts, however, disadvantage of girls is slightly less pronounced in major cities or urban centers, which includes Hyderabad (0.98) and Karachi (1.27), than compared to rural areas where the parity index for primary schools drops to 0.61 .

\subsubsection{School infrastructure}

The subject of school infrastructure has over the years assumed a highly complex and intriguing context. Alike other components of education, the school construction and maintenance suffers from issues of weak and centralized planning where more than often the school identification is undertaken on political considerations. This has by now created a situation 
where the public schools come out as disorganized, poorly maintained and inadequate portfolio. A part of the chaos is probably an offshoot of the bid for "universal schooling" as when the policy makers decided to expand the school infrastructure under the donor led social action program (SAP- I). Initially, the massive gap led them to plan one room and two room structures all over the province.

Table 3-10 : Room wise Distribution of Schools

\begin{tabular}{|c|c|c|c|c|c|}
\hline District & Shelter less & $1-4$ room & 5-9 rooms & $\begin{array}{c}10 \text { or more } \\
\text { rooms }\end{array}$ & Total \\
\hline Badin & 953 & 1993 & 161 & 52 & 3159 \\
\hline Benazirabad & 586 & 1900 & 164 & 86 & 2736 \\
\hline Dadu & 417 & 1466 & 180 & 73 & 2136 \\
\hline Ghotki & 598 & 1183 & 169 & 51 & 2001 \\
\hline Hyderabad & 25 & 626 & 280 & 149 & 1080 \\
\hline Jacobabad & 495 & 899 & 130 & 37 & 1561 \\
\hline Jamshoro & 26 & 697 & 125 & 41 & 889 \\
\hline Kambar- & 285 & 1218 & 121 & 56 & 1680 \\
\hline Karachi & 61 & 850 & 1789 & 912 & 3612 \\
\hline Kashmore & 763 & 635 & 72 & 32 & 1502 \\
\hline Khairpur & 602 & 2630 & 314 & 134 & 3680 \\
\hline Larkana & 148 & 878 & 231 & 95 & 1352 \\
\hline Matiari & 56 & 815 & 119 & 36 & 1026 \\
\hline Mirpurkhas & 618 & 1392 & 170 & 71 & 2251 \\
\hline Naushero Feroze & 574 & 1562 & 263 & 83 & 2482 \\
\hline Sanghar & 1004 & 2032 & 216 & 93 & 3345 \\
\hline Shikarpur & 206 & 932 & 170 & 73 & 1381 \\
\hline Sukkur & 216 & 831 & 225 & 101 & 1373 \\
\hline T Allah Yar & 86 & 625 & 103 & 25 & 839 \\
\hline T M Khan & 152 & 812 & 74 & 18 & 1056 \\
\hline Tharparkar & 1317 & 2630 & 150 & 38 & 4135 \\
\hline Thatta & 550 & 2556 & 147 & 53 & 3306 \\
\hline Umarkot & 524 & 1647 & 125 & 36 & 2332 \\
\hline Total & 10262 & 30809 & 5498 & 2345 & 48914 \\
\hline
\end{tabular}

The portfolio was expanded without examining the dynamics of school operations and as to how would such proliferated portfolio be managed? The situation by now has become grave. The size of the portfolio has expanded exponentially where the overall number of schools has reached 48,914 . The reality however, is that: of these 48,914 schools, about 10,262 are shelter less 
and over 30,000 are one, two, three or four-roomed schools located all across Sindh (see table $3-10$ ). Together these 41,000 or so schools constitute $84 \%$ of the total public school portfolio having approximately 2.4 million children (about 55 percent of total enrolment). 30,000 of the 44,522 primary schools have either one or two teachers and as such when that teacher is absent; the oneteacher schools obviously close down.

Total teachers in these one/two room schools are 66,268. Most of these 41,000 schools are remotely located and given the location and minimum infrastructure; locating quality teachers and other teaching resources is probably not feasible. For instance around 10,000 of these schools with the bare minimum infrastructure have an enrolment of less than 35 . This is also a reported enrolment but in reality the enrolment in these schools can vary between any figures of less than 35. Maintaining the physical infrastructure, ensuring availability of teachers and students remains a huge challenge in these schools. Further there is a question mark as to what would be the learning outcomes of these 2.4 million children in these schools with scanty infrastructure and teaching resources. As already mentioned, nearly 11 percent of all primary schools in Sindh are closed. This number rises to 11.6 percent for rural primary schools (the rate is only 2 percent in urban areas) and to 19.5 percent of rural girls' schools). Various reports suggest that schools are closed because of a lack of teachers and infrastructure problems however there could be numerous other reasons, generally clubbed under the 'governance issue'. Also the number of closed and non- functional schools keeps on varying from time to time. Another important aspect relating to school infrastructure is the overall up-keep of these schools. This status is presented in table 3.11 
reflecting that an alarmingly high number, 19,545 which constitute about $52 \%$ of school buildings require immediate repairs.

Another 6141 are in a dangerous condition. SEMIS (2011) report reveals further that half of the primary schools do not have toilets, drinking water or boundary wall. The overall Table 3-11: Condition of School Buildings

percentage of schools without electricity is $74.23 \%$, schools without toilet facilities are $42.33 \%$, those without drinking water are $49.07 \%$

\begin{tabular}{c|c|c}
\hline $\begin{array}{c}\text { School Building } \\
\text { Condition }\end{array}$ & No of Schools & \% of Total \\
\hline Satisfactory & 11970 & $31.79 \%$ \\
\hline Repairable & 19545 & $51.90 \%$ \\
\hline Dangerous & 6141 & $16.31 \%$ \\
\hline
\end{tabular}
Source : Statistical Bulletin 2010-11, p.27. and $45.14 \%$ of schools have no boundary walls. This brings forward an important issue of access to school as especially girls in the rural areas may not go to a school which has no boundary wall or toilet and drinking water facilities.

\subsubsection{Education financing and expenditure in Sindh}

The last decade has witnessed a progressive increase in successive education allocations in annual budgets, signifying an overall commitment of the Sindh government to education. This premise of increased budgetary allocations has its fault lines; however it reflects a consistent commitment to meeting education targets. Subsequent to devolution of education along with other subjects at district level from 2001 to 2010, the education budgeting and expenditure compilation was being undertaken at the district level and throughout these years compilation of aggregate accounts and expenditure data has remained a major challenge. In the initial few years, considerable effort and time was spent in deployment of manpower and their capacity development. However, despite these efforts the availability of aggregate information remains difficult. 
In Sindh the total public expenditure on education as a share of Provincial GDP has remained static since last few years', however, compared to 2001-02 it has increased from $1.18 \%$ in $2001-02$ to $2 \%$ in $2012-13$. Total public expenditure allocated to education as a proportion of total government expenditure remained in the range of 20 percent approximately from the year

Table 3-12 : Education Expenditures ( FY 2009-10 to 2011-12)

(Rs. in millions)

\begin{tabular}{|c|c|c|c|c|c|c|c|c|c|}
\hline & \multicolumn{3}{|c|}{ FY 2009-10 } & \multicolumn{3}{|c|}{ FY 2010-11 } & \multicolumn{3}{|c|}{ FY 2011-12 } \\
\hline & Provincial & District & Total & Provincial & District & Total & Provincial & District & Total \\
\hline Salary & 15,137 & 35,481 & 50,617 & 8,606 & 44,306 & 52,912 & 11,365 & 52,983 & 64,348 \\
\hline Non-Salary & 9,429 & 807 & 10,235 & 10,818 & 3,316 & 14,134 & 11,397 & 4,109 & 15,506 \\
\hline Total A & 24,566 & 36,287 & 60,853 & 19,424 & 47,622 & 67,046 & 22,762 & 57,093 & 79,854 \\
\hline Dev B & 5,708 & 4,188 & 9,896 & 7,082 & 2,449 & 9,531 & 7,733 & & \\
\hline total $(A+B)$ & 30,274 & 40,475 & 70,749 & 26,506 & 50,071 & 76,578 & 30,495 & 57,093 & 79,854 \\
\hline Prov. Budget & & & 327,183 & & & 422,251 & & & 457,547 \\
\hline Prov GDP & & & $4,104,681$ & & & $\begin{array}{c}4,556,1 \\
96\end{array}$ & & & $5,057,378$ \\
\hline $\begin{array}{l}\text { Edu as \% of } \\
\text { Prov Budget }\end{array}$ & & & $22 \%$ & & & $18 \%$ & & & $17 \%$ \\
\hline $\begin{array}{l}\text { Edu \% of } \\
\text { Prov GDP }\end{array}$ & & & $2 \%$ & & & $2 \%$ & & & $2 \%$ \\
\hline
\end{tabular}

2000 onwards and was 20.7 percent in 2004-05; 20.26 in 2005-06. It reached $22 \%$ in $2009-10$ and then declined to $17 \%$ by $2011-12$. The annual budget of the department of Education, government of Sindh, can be disaggregated into three major components: (i) recurrent budget which comprises of salary and non-salary components; (ii) development budget (iii) special activities, which are part of the non salary recurrent budget. The recurrent budget covers the on-going cost of providing education while development budget handles the expansion of facilities. At times the difference is blurred with the maintenance and repair budget too being covered under development budget. A line item of special activities was created to cater to the special needs of the education sector such as funding for undertaking annual school census; free textbooks; stipends for girl child' for improving their retention levels; funds relating to teacher 
trainings and other special activities including third party validations etc. These components have remained protected under the Sindh Education Reform Program (SERP) which was implemented with the support of World Bank and European Union grant from 2006 to 2011. The salary budget is almost inelastic as it covers teachers and other education staff salaries. In the absence of any system of relating teacher salaries with their performance or even regular attendance, this aspect of the budget has consistently increased after factoring in annual increments as well as across the board pay increases announced by the government.

The share of recurring budget as a percentage of the total education budget stood at 92.4 percent in the year 2001-02. The decade witnessed a progressive decrease in the recurrent budget which was 76.5 percent in 2012-13. A further zoom-in at annual recurrent expenditure reveals that with recurrent budget there has been a more rational shift between salary and non-salary expenditure.

The Annual Development Program (ADP) mostly covers infrastructure related activities, and to some degree it also incorporates activities like teacher training, capacity building of district officials and other related activities. The infrastructural interventions cater to four main areas i) construction of shelter less schools ii) up gradation of primary to middle and middle to high schools iii) addition of classrooms and iv) provision of missing facilities like boundary wall, toilets, etc. A look at budget allocation for this area shows a consistent increase since 2007-08. The composition and focus of development budgets can be seen in table 3-13. Government of Sindh embarked upon a reform path in the early years of the last decade 
with the overall objective of improving access to quality through improving governance including making expenditures more effective. These reforms were evolved and implemented with the support of donors.

Table 3-13 : Comparison of ADP 2010-11 and 2011-12

\begin{tabular}{l|c|c|c}
\hline Sub-Sector & $\begin{array}{c}\text { ADP 2010-11 } \\
\text { (Rs. in millions) }\end{array}$ & $\begin{array}{c}\text { ADP 2011-12 } \\
\text { (Rs. in millions) }\end{array}$ & $\begin{array}{c}\text { Increase/ } \\
\text { Decrease \% }\end{array}$ \\
\hline Elementary Education & 436.000 & 257.997 & -40.83 \\
Teacher Education & 28.562 & 81.800 & 186.39 \\
Sindh Education Foundation & 897.793 & 1468.323 & 63.55 \\
Special Education & 5.000 & 0 & -100.00 \\
Secondary Education & 654.767 & 1162.627 & 77.56 \\
College Education & 2299.176 & 3976.238 & 72.94 \\
Miscellaneous & 239.202 & 786.015 & 228.60 \\
Total & $\mathbf{4 5 6 0 . 5 0 0}$ & $\mathbf{7 7 3 3 . 0 0 0}$ & $\mathbf{6 9 . 5 6}$ \\
\hline Source : Planning and Development Department, GoS, ADP , 2010-11,2011-12.
\end{tabular}

Sindh was committed US $\$ 360$ million and of which major assistance was provided by the World Bank through an IDA credit of US\$300 million for financing a multi-year Sindh Education Reform Program (SERP) in Sindh. The remaining US\$ $60 \mathrm{~m}$ are grants, and of this biggest share was provided by the European Union. Apart from this, USAID has been providing support through various programs targeting various education components mainly focusing on teachers' professional development and management of the sector. As stated the major support has been extended by the World Bank under the SERP which remained under implementation from 2006-11. The objectives of the program were to improve participation, retention, and transition; reduce gender and regional disparities; and improve the quality in elementary and secondary education (class 1-10). The reform program was built on four complementary pillars; i) fiscal, financial management, and procurement reforms aimed at strengthening provincial finances and the effectiveness of public expenditures while increasing education and other poverty - related expenditures; ii) second 
pillar included strengthening capacity and accountability of provincial and district education management in line with devolution objectives; to provide incentives to district governments to improve service delivery; and to strengthen the role of school management committees in school development and monitoring; iii) third pillar aimed at improving access to quality schooling, with a particular focus on rural areas and girls, by improving the quality and utilization of school physical infrastructure and the implementation of incentive programs (free textbooks and girls' stipends), and by launching partnerships with the nongovernment / private sector to increase access and quality; iv) fourth pillar aimed to improve the quality of teaching and learning through instituting merit-based recruitment, establishing a competency-based system of teacher education and continuous professional development and through strengthening the assessment of student achievement in the provincial education system. There have been a few system improvements however these do not reflect any major gains on school functionality. The government of Sindh and the World Bank are now finalizing SERP II which is built on the lessons learnt under SERP I and entails a tougher set of reforms. Lately the US AID has also pledged a robust US\$150 million to support education in Sindh. Similarly, the DFID has also entered the education sector in Sindh for the first time under a different strategy targeting to reach out to the children through private sector organizations under businessmen led board.

\subsection{EDUCATION INDICATORS - A COMPARISON BY DISTRICT}

An analysis of data collected through the annual school census (ASC) by SEMIS, Education department, and government of Sindh over the last six years for public schools is presented here. The indicators used in this comparative 
analysis cover the census years 2005-06 to 2010-11, a six year time series data to study trends in education inputs and impacts on a set of indicators especially the enrolment rates. The indicators used in this analysis include both demand and supply side of education, including institutions, and teachers at district level. Following is the district wise situation analysis.

\section{DISTRICT BADIN}

Table 3-14 provides an overview of the education indicators in district Badin from 2005 to 2010. The primary Table 3-14 : District Badin

schools in this period have increased from 3120 to 3159 . This is again reflective of skewed planning as there are already a large number of small primary schools, which are either shelter less or one / two room schools with very small enrolment. Approximately 30 percent of total schools in the district are shelter less

\begin{tabular}{|c|c|c|}
\hline & 2005 & 2010 \\
\hline \multicolumn{3}{|c|}{ Primary Level } \\
\hline Enrolment & 153439 & 108797 \\
\hline Expenditure & $575,000,000$ & $900,000,000$ \\
\hline School & 3120 & 3159 \\
\hline STR & 36 & 22 \\
\hline SSR & 49 & 34 \\
\hline SCR & 40 & 22 \\
\hline \multicolumn{3}{|l|}{ Middle Level } \\
\hline Enrolment & 17745 & 25458 \\
\hline Expenditure & $180,000,000$ & $330,000,000$ \\
\hline School & 150 & 133 \\
\hline STR & 67 & 77 \\
\hline SSR & 118 & 191 \\
\hline SCR & 47 & 66 \\
\hline \multicolumn{3}{|c|}{ Secondary Level } \\
\hline Enrolment & 7196 & 10723 \\
\hline Expenditure & $150,000,000$ & $580,000,000$ \\
\hline School & 55 & 50 \\
\hline STR & 10 & 16 \\
\hline SSR & 131 & 214 \\
\hline SCR & 17 & 29 \\
\hline
\end{tabular}
and 93 percent of schools in the district are less than 5 rooms. What is however, disturbing is that fact that the enrolments have decreased by more than 27 percent at the primary level. The district expenditure reflects an increase of 57 percent in this period from Rs. 575 million to Rs.900 million. Hence more teachers and schools / classrooms have led to improvement in the STR and SCR at this level. In case of the middle level education there is an increase of 43 percent in enrolment; whereas the expenditure in this period has risen by 83 percent. The STR and SCR have worsened and STR is now 77 
students to a teacher. In case of the secondary education, the expenditure has increased by $287 \%$ and the enrolment at this level has increased by 49 percent. What is surprising is that the number of middle and secondary schools has decreased in these years. The STR at the secondary level has increased from 10 to 16 and also there are only 29 students per class against only 17 per class earlier.

\section{DISTRICT DADU}

Dadu's enrolment over a period of 6 years reflects a cumulative decrease of

Table 3-15 : District Dadu

\begin{tabular}{lcc}
\hline Dadu & $\mathbf{2 0 0 5}$ & $\mathbf{2 0 1 0}$ \\
\hline Primary Level & & \\
Enrolment & 167424 & 142659 \\
Expenditure & $555,000,000$ & $1,500,000,000$ \\
School & 1934 & 2136 \\
STR & 32 & 26 \\
SSR & 87 & 67 \\
SCR & 45 & 30 \\
Middle Level & & \\
Enrolment & 21851 & 25668 \\
Expenditure & $180,000,000$ & $510,000,000$ \\
School & 81 & 72 \\
STR & 64 & 82 \\
SSR & 270 & 357 \\
SCR & 73 & 117 \\
Secondary Level & & \\
Enrolment & 10717 & 13366 \\
Expenditure & $190,000,000$ & $800,000,000$ \\
School & 54 & 50 \\
STR & 11 & 13 \\
SSR & 198 & 267 \\
SCR & 24 & 27 \\
\hline Source : SEMIS Data; various issues
\end{tabular}

15 percent whereas in this period the cumulative expenditures have risen by 170 percent at the primary level. The primary level schools have increased from 1934 to 2136. Consequently, with a greater number of teachers and decrease in enrolment, the STR, SSR and SCR have all improved in this period. The STR has improved to $26: 1$ from the earlier $32: 1$ and the SCR is now 30 students per class. In case of middle level education, the enrolment has risen by 17 percent though the expenditure at this level has increased by 183 percent. The STR has worsened from 64 students to a teacher to 82 students; whereas the SCR has deteriorated to 117 students per class, which is physically non tenable. At the secondary level, there is an increase of $29 \%$ in the enrolment however the secondary level expenditure has increased by $320 \%$ from Rs. 190 million to Rs. 800 million. The schools at this level have decreased from 54 to 50 and the STR, SSR and SCR have 
resultantly increased in ratio. The STR is however only $13: 1$, reflecting hefty presence of teachers, whereas SCR is 27 students per class. The massive increase in expenditures has probably been on account of increase in salary spending due to salary rises and recruitment of additional teachers. The SCR reflects availability of adequate space for greater number of students at the secondary level.

\section{DISTRICT GHOTKI}

District Ghotki's data reflects a decrease of 1 percent in the enrolment at the primary level, whereas the Table 3-16 : District Ghotki

expenditure has increased by 195 percent cumulatively in this period under review. The primary level schools in this period have increased from 1633 to 2001 i.e 23 percent increase. The STR and SCR have resultantly improved. In case of the middle level education there is an increase of 66 percent in enrolment and the expenditure has

\begin{tabular}{|c|c|c|}
\hline Ghotki & 2005 & 2010 \\
\hline \multicolumn{3}{|c|}{ Primary Level } \\
\hline Enrolment & 131555 & 130039 \\
\hline Expenditure & $475,000,000$ & $1,400,000,000$ \\
\hline School & 1633 & 2001 \\
\hline STR & 43 & 37 \\
\hline SSR & 81 & 65 \\
\hline SCR & 47 & 33 \\
\hline \multicolumn{3}{|l|}{ Middle Level } \\
\hline Enrolment & 16899 & 28044 \\
\hline Expenditure & $140,000,000$ & $450,000,000$ \\
\hline School & 89 & 98 \\
\hline STR & 67 & 88 \\
\hline SSR & 190 & 286 \\
\hline SCR & 56 & 92 \\
\hline \multicolumn{3}{|c|}{ Secondary Level } \\
\hline Enrolment & 7368 & 12145 \\
\hline Expenditure & $150,000,000$ & $480,000,000$ \\
\hline School & 32 & 33 \\
\hline STR & 13 & 20 \\
\hline SSR & 230 & 368 \\
\hline SCR & 20 & 31 \\
\hline
\end{tabular}
Source : SEMIS Data; various issues

increased by 221 percent in the same period. The number of schools has also increased from 89 to 98 however the STR and SCR have worsened most probably in response to increase in enrolment. STR of $88: 1$ is extremely high reflecting shortage of teachers and the SCR of 92 students per class is also physically not possible. In case of the secondary level education; expenditure has increased by 220 percent and the enrolment increased by 65 percent in 
this period. The STR at this level is only $20: 1$ reflecting the presence of excess teachers at this level. The SCR of 31 students per class is also significantly better than the situation at the middle school level. There is a very visible fall in the enrolments both at the middle and secondary level especially in comparison to primary enrolment. As against 131555 or 130,000 children in primary (for the years 2005 and 2010), the enrolment at the middle level is in the range of 16,000 to 28,000 and this further decreases to $7000-12000$ range at the secondary level; reflecting a sharp decline in the retention and completion rates.

\section{DISTRICT HYDERABAD}

Hyderabad is a predominantly urban district having a significant share of private sector schools. The data reflects

Table 3-17 : District Hyderabad

that in these six years; the primary

schools increased from 887 to 1080 ; and

the school expenditures increased by

142 percent from Rs. 455 million to Rs.

1.1 billion. Despite such improvement in

resources, there is a decrease of 22

percent in the primary enrolment in this

period. Hence, the data reflects that a

\begin{tabular}{|c|c|c|}
\hline \multicolumn{3}{|c|}{ Hyderabad } \\
\hline \multicolumn{3}{|c|}{ Primary Level } \\
\hline Enrolment & 118187 & 927345 \\
\hline Expenditure & $455,000,000$ & $1,100,000,000$ \\
\hline School & 887 & 1080 \\
\hline STR & 22 & 17 \\
\hline SSR & 133 & 86 \\
\hline SCR & 39 & 19 \\
\hline \multicolumn{3}{|l|}{ Middle Level } \\
\hline Enrolment & 30517 & 34420 \\
\hline Expenditure & $230,000,000$ & $520,000,000$ \\
\hline School & 80 & 81 \\
\hline STR & 58 & 62 \\
\hline SSR & 381 & 425 \\
\hline SCR & 79 & 92 \\
\hline \multicolumn{3}{|c|}{ Secondary Level } \\
\hline Enrolment & 17352 & 20096 \\
\hline Expenditure & $320,000,000$ & $1,400,000,000$ \\
\hline School & 85 & 82 \\
\hline STR & 8 & 9 \\
\hline SSR & 204 & 245 \\
\hline SCR & 17 & 22 \\
\hline
\end{tabular}

Source : SEMIS Data; various issues expenditure. Also the STR of 17 students per teacher shows that a very large number of teachers are available in the district; in fact it shows a disproportionate availability of teachers. There are only 19 students per class gain reflecting the availability of huge infrastructure lying underutilized. At the 
middle level, enrolments show an increase of 13 percent; whereas the expenditure has increased by 126 percent cumulatively in six years. The SSR and SCR reflect a pressure which is visible as against over 900 primary schools; the number of middle schools is just 81 . The SCR of 92 students per class is however physically not possible. The secondary level expenditure exhibits an increase of 338 percent and it is obvious that this is on account of teacher salaries. The enrolment in this period has increased by only 16 percent. An STR of 9 reflects a highly disproportionate number of teachers' availability in the district. Also the SCR of 22 students per class exhibits availability of considerable physical infrastructure lying underutilized.

\section{DISTRICT JACOBABAD}

The primary schools expenditure in Jacobabad increased by 136 percent in six

Table 3-18 : District Jacobabad

\begin{tabular}{|c|c|c|}
\hline \multirow{2}{*}{\multicolumn{3}{|c|}{$\begin{array}{l}\text { Jacobabad } \\
\text { Primary Level }\end{array}$}} \\
\hline & & \\
\hline Enrolment & 85730 & 99806 \\
\hline Expenditure & $635,000,000$ & $1,500,000,000$ \\
\hline School & 1471 & 1561 \\
\hline STR & 27 & 28 \\
\hline SSR & 58 & 64 \\
\hline SCR & 38 & 35 \\
\hline \multicolumn{3}{|l|}{ Middle Level } \\
\hline Enrolment & 14429 & 17364 \\
\hline Expenditure & $230,000,000$ & $480,000,000$ \\
\hline School & 62 & 69 \\
\hline STR & 60 & 42 \\
\hline SSR & 233 & 252 \\
\hline SCR & 66 & 72 \\
\hline \multicolumn{3}{|c|}{ Secondary Level } \\
\hline Enrolment & 5195 & 7614 \\
\hline Expenditure & $110,000,000$ & $490,000,000$ \\
\hline $\begin{array}{l}\text { School } \\
\text { STR }\end{array}$ & $\begin{array}{c}32 \\
8\end{array}$ & $\begin{array}{l}27 \\
15\end{array}$ \\
\hline SSR & 162 & 282 \\
\hline SCR & 18 & 37 \\
\hline
\end{tabular}

Source : SEMIS Data; various issues years from 2005 to 2010; the number of schools increased from 1471 to 1561 in this period. The primary school enrolments increased by 16 percent cumulatively in this period. As in case of other districts, here also large part of expenditure has been pre- empted by salary expenditures. An SSR of 68 students per school reflects that most of the primary schools must be one/two

room schools. The STR and SCR are almost static with 28 students to a teacher and 35 students per class. At the middle school level, the expenditure has increased by 109 percent and 7 additional schools have been added in this 
period. The enrolment at this level has increased by only 20 percent over a period of 6 years. There is an improvement in the STR from 60 students to a teacher to now 42 students to a teacher. The SSR and SCR reflect a pressure at the middle school level with 72 students to a class. At the secondary school level, the expenditure shows an increase of 345 percent and the enrolments show an increase of 47 percent. But the total number of students at the secondary level is just 7614 as against 99,800 in the primary level. As against more than 1561 primary schools, there are only 96 middle and secondary schools. The STR at this level is only 15 reflecting the availability of excess teachers.

\section{DISTRICT JAMSHORO}

In Jamshoro, the primary schools in this period have increased from 803 to 889 and the expenditure has increased from

Rs. 265 million to Rs. 600 million; a 126 percent increase. Enrolment in this period has declined by 23 percent in this period. Expenditure alike other districts, in most probability has been consumed by teacher salaries. The STR accordingly shows an improvement from 32 to 24 . Given the fact that enrolments have

\begin{tabular}{|c|c|c|}
\hline Jamshoro & 2005 & 2010 \\
\hline \multicolumn{3}{|c|}{ Primary Level } \\
\hline $\begin{array}{l}\text { Enrolment } \\
\text { Expenditure } \\
\text { School }\end{array}$ & $\begin{array}{c}63118 \\
265,000,000 \\
803\end{array}$ & $\begin{array}{c}48518 \\
600,000,000 \\
889\end{array}$ \\
\hline $\begin{array}{l}\text { STR } \\
\text { SSR } \\
\text { SCR }\end{array}$ & $\begin{array}{l}32 \\
79 \\
33\end{array}$ & $\begin{array}{l}24 \\
55 \\
19\end{array}$ \\
\hline \multicolumn{3}{|l|}{ Middle Level } \\
\hline $\begin{array}{l}\text { Enrolment } \\
\text { Expenditure } \\
\text { School } \\
\text { STR } \\
\text { SSR } \\
\text { SCR }\end{array}$ & $\begin{array}{c}8619 \\
79,000,000 \\
30 \\
67 \\
287 \\
76\end{array}$ & $\begin{array}{c}11041 \\
230,000,000 \\
30 \\
107 \\
368 \\
100\end{array}$ \\
\hline \multicolumn{3}{|c|}{ Secondary Level } \\
\hline $\begin{array}{l}\text { Enrolment } \\
\text { Expenditure } \\
\text { School } \\
\text { STR } \\
\text { SSR } \\
\text { SCR }\end{array}$ & $\begin{array}{c}4639 \\
120,000,000 \\
31 \\
12 \\
150 \\
23\end{array}$ & $\begin{array}{c}4801 \\
370,000,000 \\
34 \\
9 \\
141 \\
18\end{array}$ \\
\hline
\end{tabular}
fallen; the SCR also shows a decrease from 33 students to a class, to 19 students per class in 2010 . The total number of middle and secondary schools in the district is just 64. Enrolment at the middle level has increased by 28 percent but the enrolment at the secondary 
level is almost static over a period of six years. This is a highly unusual feature; given the fact that there are already small numbers of students at this level. The expenditure at the middle and the secondary level has gone up by 190 and 201 percent respectively in these 6 years. The STR,SSR and SCR figures for middle school are on extremely high side. There are 107 students per teacher and 100 students per class, which is physically quite impossible. Conversely, the STR at secondary level is just 9 students to a teacher; reflecting the availability of excess teachers at secondary level; and an SCR of 18 students per class also reflects availability of infrastructure.

\section{DISTRICT KAMBAR}

The primary level schools in Kamber, in this period have increased from 1511

Table 3-20 : District Kamber

\begin{tabular}{|c|c|c|}
\hline $\begin{array}{l}\text { Kambar-S } \\
\text { hahdadkot }\end{array}$ & 2005 & \\
\hline \multicolumn{3}{|c|}{ Primary Level } \\
\hline Enrolment & 100304 & 120016 \\
\hline Expenditure & $385,000,000$ & $900,000,00$ \\
\hline School & 1511 & 1680 \\
\hline STR & 32 & 36 \\
\hline SSR & 66 & 71 \\
\hline SCR & 38 & 32 \\
\hline \multicolumn{3}{|l|}{ Middle Level } \\
\hline Enrolment & 15639 & 23340 \\
\hline Expenditure & $130,000,000$ & $310,000,00$ \\
\hline School & 71 & 67 \\
\hline STR & 76 & 124 \\
\hline SSR & 220 & 348 \\
\hline SCR & 60 & 101 \\
\hline \multicolumn{3}{|c|}{ Secondary Level } \\
\hline Enrolment & 7470 & 10164 \\
\hline Expenditure & $120,000,000$ & $380,000,00$ \\
\hline School & 33 & 32 \\
\hline STR & 14 & 19 \\
\hline SSR & 226 & 318 \\
\hline SCR & 21 & 34 \\
\hline
\end{tabular}

Source : SEMIS Data; various issues to 1680 and the expenditure has risen by 134 percent. The primary enrolment however, has risen by only 20 percent in this period. This spending does not seem to have impacted the STR much; as the students to teacher has increased from 32 to 36 in this period. The SCR is almost static whereas SSR reflects a little increase at the primary level. At middle and secondary level the enrolments have risen by 40 and 34 percent respectively in the 6 year period; whereas the expenditure at these levels has gone up by 138 and 217 percent respectively. The total number of schools at middle and secondary level is only 99 as against 1680 primary schools; depicting a serious constriction. Alike 
district Jamshoro; the STR and SCR at middle level are extremely high. STR reflects an increase from 76 students to a teacher to 124 . SCR of 101 at the middle school level is physically untenable. At the secondary level; the STR is only 19 students to a teacher reflecting availability of excess teachers and the SCR of 34 students per class. In reality, other than the separate middle schools, the middle and the secondary school students in many instances are housed in the high schools together hence there is sharing of teachers and infrastructure.

\section{DISTRICT KARACHI}

Karachi is the financial and trade hub of the country and it houses a large number of private sector schools. The Table 3-21 : District Karachi

6 year data on the state of public schools reflects multiple inefficiencies.

Karachi City

2005 2010 Primary Level Enrolment 383669 310887 The primary enrolment has decreased Expenditure $1,995,000,000$ School STR 2642

24 145

SCR 30

by 19 percent; whereas the

Middle Level

expenditure has increased by 35 Enrolment

145277
$0,000,000$

Expenditure

School STR

percent. The STR is 21 students per teacher and the SCR is 122 students

SSR

\section{Secondary Level}

Enrolment

Expenditure

per class; which is impossible. At the

School

middle level, the enrolment has fallen

$$
\text { STR }
$$

SSR

by 7 percent and at the secondary

\begin{tabular}{ccc} 
SCR & 137 & 131 \\
\hline
\end{tabular}

Source : SEMIS Data; various issues

level it has marginally increased by 4 percent. The expenditures at the middle level show a slight decrease of 7 percent and an increase of 288 percent at the secondary level. In reality a large number of the middle school students are in the high schools which house both these tiers and here the teachers and 
other resources are shared. Hence an STR of 46 and 9 at these two tiers is misleading as in all probability these teachers together cater to grade 6 to 10 in the high schools. Being a big metropolis, the teachers from across the province try to get themselves transferred here. There are over 26,094 teachers in Karachi out of a total 144,000 teachers in the province. The expenditure rise is mostly reflecting the increase on teacher salaries on three counts; increase in salaries; fresh recruitments and teacher transfers. The decrease in enrolments is reflective of preference for private sector schooling.

\section{DISTRICT KASHMORE}

District Kashmore is one of the highly

under developed district of Sindh. The

education indicators are also

reflective of this under development.

The primary enrolment in the district

has decreased drastically by 28

percent in the 6 year period under

review. The expenditure however has

risen by 128 percent, which in all

\begin{tabular}{lcc}
\multicolumn{3}{c}{ Table 3-22 : District Kashmore } \\
Kashmore & \multicolumn{2}{c}{2005} \\
Primary Level & \multicolumn{3}{c}{2010} \\
Enrolment & 95076 & 68535 \\
Expenditure & $245,000,000$ & $560,000,000$ \\
School & 1409 & 1502 \\
STR & 39 & 31 \\
SSR & 67 & 46 \\
SCR & 60 & 35 \\
\hline Middle Level & & \\
Enrolment & 11160 & 12296 \\
Expenditure & $54,000,000$ & $210,000,000$ \\
School & 59 & 47 \\
STR & 47 & 60 \\
SSR & 189 & 262 \\
SCR & 61 & 79 \\
Secondary Level & \multicolumn{3}{c}{} \\
Enrolment & 3960 & 6787 \\
Expenditure & $54,000,000$ & $360,000,000$ \\
School & 29 & 23 \\
STR & 8 & 21 \\
SSR & 137 & 295 \\
SCR & 16 & 39 \\
\hline Source : SEMIS Data; various issues
\end{tabular}

probability has been consumed in

teacher salaries. The STR has improved from 39 students to a teacher to 31 and the SCR has improved from 60 students to a class to 35 by 2010 . This has occurred on account of decrease in the enrolment. An SSR of 46 students per school reflects the prevalence of one / two room schools across the district. In case of the middle level education there is only an increase of 10 percent in this period; though the expenditure has gone up from Rs. 54 million to Rs.210 
million; a more than 288 percent increase. The situation on STR and SCR has worsened as there are only 47 schools catering to over 12,296 students. The situation on the secondary side is also grim on the resources side as here also there are only 29 schools. The district has only a total of 70 middle and secondary schools reflecting severe shortage of schools beyond primary level. The expenditure at the secondary level has increased from Rs. 54 million to Rs. 360 million which is 567 percent increase however this is due to a smaller original base. The enrolment at secondary level has gone up by 71 percent; however the total enrolment at this level is only 6787 against over 68500 children at primary level.

\section{DISTRICT KHAIRPUR MIRS}

Table 3-23 provides an overview of the education indicators in district Khairpur

Table 3-23 : District Khairpur Mirs

\begin{tabular}{lcc} 
Khairpur Mirs & 2005 & 2010 \\
Primary Level & & 175084 \\
Enrolment & 180173 & $1,600,000,000$ \\
Expenditure & $655,000,000$ & 3679 \\
School & 3362 & 28 \\
STR & 30 & 48 \\
SSR & 54 & 22 \\
SCR & 32 & \\
Middle Level & \multicolumn{3}{|c}{} \\
Enrolment & 39081 & 49851 \\
Expenditure & $280,000,000$ & $610,000,000$ \\
School & 194 & 195 \\
STR & 57 & 65 \\
SSR & 201 & 256 \\
SCR & 70 & 72 \\
Secondary Level & \multicolumn{2}{|}{} \\
Enrolment & 16406 & 23845 \\
Expenditure & $290,000,000$ & $1,300,000,000$ \\
School & 101 & 97 \\
STR & 9 & 14 \\
SSR & 162 & 246 \\
SCR & 21 & 25 \\
\hline Source : SEMIS Data; various issues \\
\multicolumn{2}{l}{}
\end{tabular}

48 students to a school reflects

considerable presence of one/ two room structures in the district. The SCR of 22 students to a class exhibits availability of huge school infrastructure in the 
district. In case of the middle level education there is an increase of 28 percent in the enrolment and the expenditure at this level has risen by 118 percent. The STR and SCR have both risen in this period to 65 students to a teacher and 72 students per class. At the secondary level, enrolments have risen by 45 percent whereas the expenditure has jumped from Rs. 290 million to Rs. 1.3 billion; this is 348 percent increase. The STR was earlier only 9 students to a teacher reflecting a disproportionate availability of teachers at this level. This has increased to 14 students per teacher showing availability of excess teachers. The SCR at this level is 25 students to a class, which again reflects the presence of robust physical infrastructure in the district.

\section{DISTRICT LARKANA}

Table 3-24 : District Larkana

Table 3-24 provides an overview of

the education indicators in district

Larkana from 2005 to 2010. The

primary level schools in this period

have increased from 1214 to 1351 .

The enrolments at primary school

level have increased marginally by 7

percent cumulatively in the 6 year

period; whereas the expenditure

has risen from Rs. 275 million to Rs. Larkana

Enrolment

Expenditure

School

STR

SSR

\section{Middle Level}

Enrolment

Expenditure School

STR

SSR

SCR 2010

Secondary Level

Enrolment

Expenditure School

STR

SSR

SCR
135054

$275,000,000$

1214

33

111

48

26621

$88,000,000$

68

95

391

94

12911

$84,000,000$

51

13

253

29
2005

144225

$1,200,000,000$

1351

29

107

34

37287

$460,000,000$

67

136

557

139 18399

$750,000,000$

51

18

361

38

1.2 billion; a 336 percent increase. The STR has improved slightly. SSR of 107

children per school reflects the availability of better infrastructure in the district.

In case of middle level; the enrolment has increased by 40 percent in this timeframe and at this level, expenditure has increased from Rs. 88 million to 
Rs.460 million; a 423 percent increase. The STR of 136 students per teacher and SCR of 139 children per class are physically untenable. The number of middle schools is static and the SSR and SCR figures reflect a strong need for expanding middle school level infrastructure in the district. The secondary level expenditure has also increased from Rs. 84 million to Rs. 750 million and as against this enrolments show an increase of 43 percent. The STR at the secondary level is only 18 students to a teacher reflecting the availability of excess teachers. Alike other districts this dichotomy is covered up on account of presence of the high schools which house the middle and the secondary level children together. This balances the teachers as well as infrastructure for both levels of education.

\section{DISTRICT MATIARI}

The primary level schools in this period have increased from 932 to 1026 . The

\begin{tabular}{|c|c|c|}
\hline Matiari & 2 & 2010 \\
\hline \multicolumn{3}{|c|}{ Primary Level } \\
\hline Enrolment & 72992 & 56074 \\
\hline Expenditure & $315,000,000$ & $590,000,000$ \\
\hline School & 932 & 1026 \\
\hline STR & 28 & 20 \\
\hline SSR & 78 & 55 \\
\hline SCR & 36 & 20 \\
\hline \multicolumn{3}{|l|}{ Middle Level } \\
\hline Enrolment & 10024 & 14536 \\
\hline Expenditure & $89,000,000$ & $250,000,000$ \\
\hline School & 37 & 45 \\
\hline STR & 113 & 96 \\
\hline SSR & 271 & 323 \\
\hline SCR & 90 & 102 \\
\hline \multicolumn{3}{|c|}{ Secondary Level } \\
\hline Enrolment & 4786 & 6815 \\
\hline Expenditure & $77,000,000$ & $260,000,000$ \\
\hline School & 30 & 32 \\
\hline STR & 10 & 12 \\
\hline SSR & 160 & 213 \\
\hline SCR & 19 & 25 \\
\hline
\end{tabular}
enrolments at primary school level have declined by 23 percent whereas the expenditure at this level has risen from Rs. 315 million to Rs. 590 million; an 87 percent increase. The STR and SCR have improved to 20 students per teacher and 20 students per class respectively. This is on account of the drastic fall in enrolment at primary level. The SSR is 59 students per school. The STR data is reflective of a higher number of teacher presence at this level in the district. 
At the middle level; the enrolment has increased by 45 percent in 6 years and the expenditure has increased from Rs. 89 million to Rs.250 million; an increase of 181 percent. The STR of 96 students per teacher and SCR of 101 children per class are physically untenable. The secondary level expenditure has also increased significantly from Rs. 77 million to Rs. 260 million. The secondary school enrolments show an increase of 42 percent. The STR at this level is only 12 students to a teacher and the SCR is also low with 25 students to a class. This is in stark contrast to the middle school level STR and SCR. Alike other districts', these dichotomies get handled through the high schools which cater to both levels and balance out the shortages. The major worrying aspect is that the enrolment at primary level has fallen drastically and as against about 56000 children at primary level, only 6800 or so reach to the secondary level.

\section{DISTRICT MIRPURKHAS}

In district Mirpurkhas, the primary

Table 3-26: District Mirpurkhas

level schools have increased from

1919 to 2251 . The enrolments at

Mirpur Khas

Enrolment

2005

Expenditure

101448

School

$415,000,000$

104384

STR

primary school level have declined by

SSR

1919

$000,000,000$

25

2251

24

Middle Level

3 percent whereas the expenditure at

Enrolment

32

46

24

$20772-24372$

this level has risen from Rs. 415

Expenditure

$150,000,000$

$380,000,000$

School

STR

SSR

million to Rs. 1 billion; an increase of

SCR

69

91

301

123

75

Secondary Level

141 percent. The STR of 24 students

Enrolment

88

198

Expenditure

10718

79

School

per teacher is an ideal ratio and it

STR

SSR

$210,000,000$

13026

12
179

$690,000,000$

reflects greater availability of $\frac{22}{\text { Source }: \text { SEMIS Data; various issues }}$

teachers in the district at primary level. SSR is 46 students per school 
exhibiting presence of one / two room schools across the district. In case of middle level education there is an increase of 17 percent in the enrolment in this period of 6 years and at this level the expenditure has increased from Rs. 150 million to Rs.380 million; reflecting an increase of 153 percent. The STR of 75 students per teacher and SCR of 79 children per class are slightly on the higher side. The number of middle schools has risen from 69 to 123 . The secondary level expenditure has also spiraled from Rs. 210 million to Rs. 690 million and as against this enrolments show an increase of 22 percent. The STR at the secondary level is only 17 students to a teacher, showing excess availability of teachers. The SCR of 30 students to a class is also reflective of greater availability of school infrastructure. Alike other districts, the STR and SCR are most probably being balanced on account of high schools, housing both middle school children as well as the secondary students.

\section{DISTRICT NOUSHEROFEROZE}

Table 3-27 provides an overview

Table 3-27 : District Nausheroferoze Naushero Feroze
Primary Level

\begin{tabular}{lcc} 
Enrolment & 130543 & 119722 \\
Expenditure & $665,000,000$ & $1,300,000,000$ \\
School & 2181 & 2476 \\
STR & 28 & 25 \\
SSR & 60 & 48 \\
SCR & 32 & 21 \\
Middle Level & & \\
Enrolment & 31465 & 42203 \\
Expenditure & $320,000,000$ & $530,000,000$ \\
School & 152 & 189 \\
STR & 52 & 61 \\
SSR & 207 & 223 \\
SCR & 59 & 70 \\
Secondary Level & & \\
Enrolment & 13947 & 19573 \\
Expenditure & $240,000,000$ & $860,000,000$ \\
School & 62 & 48 \\
STR & 12 & 23 \\
SSR & 225 & 408 \\
SCR & 24 & 45 \\
\hline SOurce : SEMIS Data & vaious &
\end{tabular}

Source : SEMIS Data; various issues district Nausheroferoze from

2005 to 2010 . The primary level schools in this period have increased from 2181 to 2476. The enrolments at primary school level have declined by 8 percent whereas the expenditure at this level has risen from Rs. 665 million to Rs. 1.3 billion; an 
increase 95 percent. The STR and SCR have improved to 25 students per teacher and 21 students per class respectively. SSR is 48 students per school. The STR data is quite ideal, though it is reflective of a higher number of teachers' presence at this level in the district. In case of the middle level education there is an increase of 34 percent in the enrolment in this 6 year period and at this level the expenditure has increased from Rs. 320 million to Rs.530 million; reflecting an increase of 65 percent. The STR of 61 students per teacher and SCR of 70 children per class are considerably high. The number of middle schools has risen from 152 to 189 . The secondary level expenditure has increased from Rs. 240 million to Rs. 860 million, whereas the enrolments show an increase of 40 percent. The STR at this level is 23 students per teacher, which is on the lower side. The SCR is 45 students per class. Here also the disbalance at the middle and the secondary level resources is in all probability being balanced through high schools, which cater to both the levels of education.

\section{DISTRICT SANGHAR}

District Sanghar's data shows that in the period from 2005 to 2010; the primary schools increased from 3116 to 3345 and there has been an increase of 12 percent in the primary school enrolment. In this period the primary level school expenditure has risen from Rs. 545 million to Rs. 1.5 billion; reflecting an increase of 175 percent. Both the STR and the SCR have increased slightly to 23 students per teacher and 37 students per class respectively. SSR is 49 students per school. The STR data; both the 2005 as well as 2010 are reflective of higher number of teacher presence at this level in the district. In case of the middle level education, there is an increase of 12 percent in the 
enrolment in this period. The expenditure at this level has increased from Rs. 220 million to Rs.510 million; reflecting an increase of 132 percent. The STR of 74 students per teacher and SCR of 78 children per class are slightly on the higher side. The number of middle schools has risen from 164 to 113.

The secondary level expenditure has also increased from Rs. 190 million to Rs. 880 million; whereas the enrolment at this level has increased by 34 percent. The STR at this level has increased from 10 students to a teacher to 15 Sanghar Table 3-28 : District Sanghar

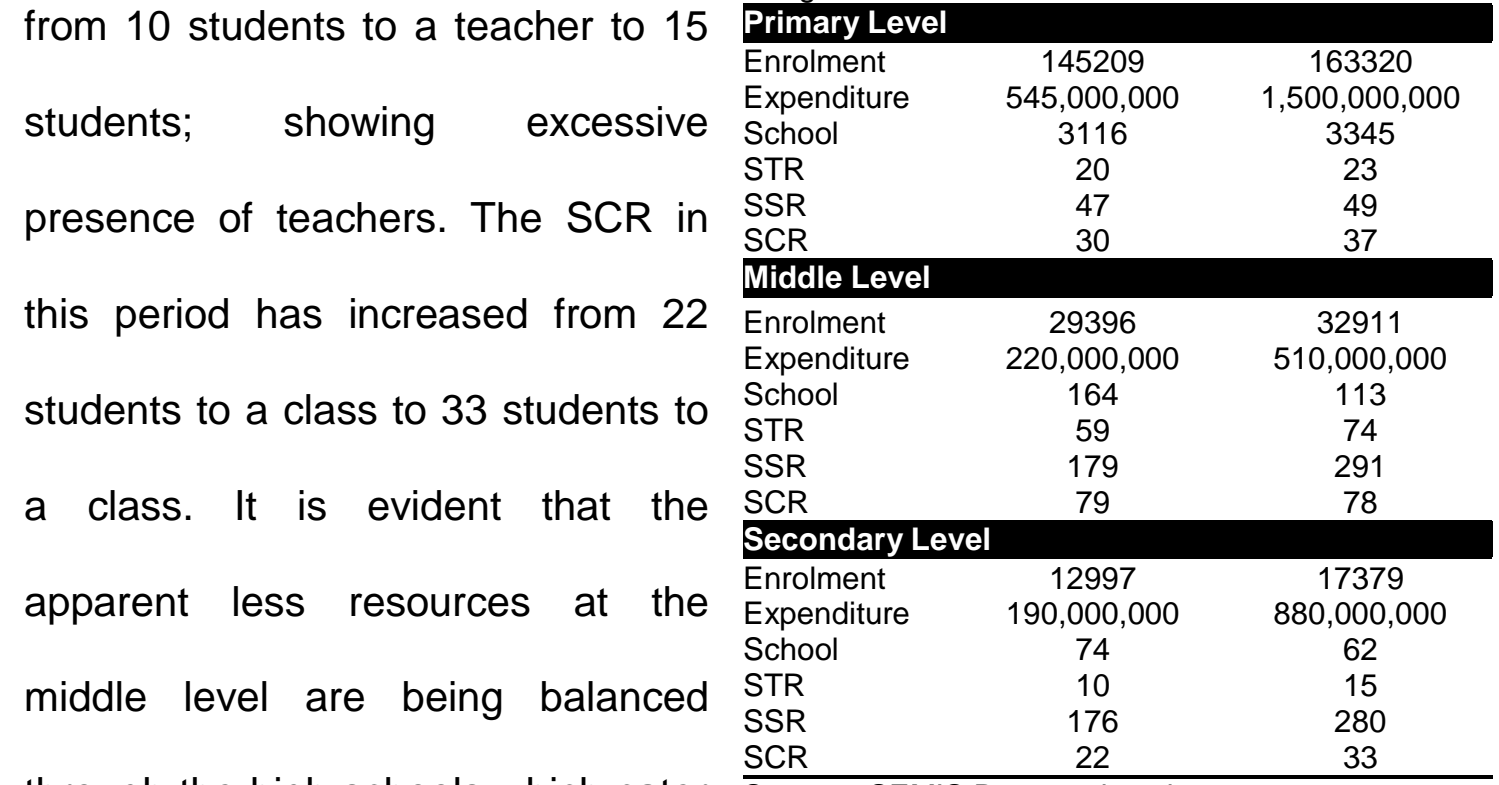
through the high schools which cater Source : SEMIS Data; various issues to both levels of education.

\section{DISTRICT SHAHEED BENAZIRABAD}

District Shaheed Benazirabad data shows that the primary schools have increased from 2398 to 2736 in this period from 2005 to 2010 . The enrolment however has fallen by 3 percent at the primary level. There were 110583 students in $2005-06$ and these dropped to 107,261 by $2010-11$. The district expenditure reflects a very large increase from Rs. 435 million to Rs.1.1 billion; an increase of 153 percent. The STR which was earlier 28 students to a teacher has reduced to 22 students to a teacher and similarly the SCR has 
decreased from 29 students to a class to now 20 students to a class. This is apparently on account of the fall in enrolment and increase in teacher and school resources.

At the middle level, there is a 25

Table 3-29 : District Shaheed Benazirabad

percent increase in enrolment, whereas the expenditure has increased by 156 percent in this period. The STR at 70 students to a teacher and SCR at 67 students to a class are quite high. In case of secondary level, the expenditure increased by 292 percent. The increase in enrolment at this level

\begin{tabular}{lcc} 
Sh Benazirabad & 2005 & 2010 \\
Primary Level & & \\
Enrolment & 110583 & 107261 \\
Expenditure & $435,000,000$ & $1,100,000,000$ \\
School & 2398 & 2736 \\
STR & 28 & 22 \\
SSR & 46 & 39 \\
SCR & 29 & 20 \\
Middle Level & & \\
Enrolment & 21401 & 26765 \\
Expenditure & $160,000,000$ & $410,000,000$ \\
School & 111 & 121 \\
STR & 67 & 70 \\
SSR & 193 & 221 \\
SCR & 63 & 67 \\
Secondary Level & & \\
Enrolment & 9515 & 12685 \\
Expenditure & $130,000,000$ & $510,000,000$ \\
School & 52 & 59 \\
STR & 14 & 19 \\
SSR & 183 & 215 \\
SCR & 22 & 23 \\
\hline Source :SEMIS Data; & &
\end{tabular}

is about 33 percent. The STR at this level is only 19 students to a teacher and the SCR is also 23 students to a class reflecting the availability of excess resources of teachers and infrastructure at the secondary level; in contrast to the middle school. As a large proportion of middle school children are housed in high schools together with secondary; in reality most of these resources are shared.

\section{DISTRICT SHIKARPUR}

Table 3-30 provides an overview of the education indicators in district Shikarpur from 2005 to 2010 . The primary level schools in this period have increased from 1284 to 1380; however the enrolment has declined by 6 percent in this period. The expenditure at this level has risen from Rs. 455 million to Rs. 900 million; a 98 percent increase. The STR has improved slightly from 29 to 25 
students per teacher. The SCR has improved from the earlier 34 students to a class to now 23 students to a class.

\begin{tabular}{|c|c|c|}
\hline \multicolumn{3}{|c|}{ Table 3-30 : District Shikarpur } \\
\hline Shikarpur & 2005 & 2010 \\
\hline \multicolumn{3}{|c|}{ Primary Level } \\
\hline Enrolment & 90075 & 84960 \\
\hline Expenditure & $455,000,000$ & $900,000,000$ \\
\hline School & 1284 & 1380 \\
\hline STR & 29 & 27 \\
\hline SSR & 70 & 62 \\
\hline SCR & 34 & 23 \\
\hline \multicolumn{3}{|l|}{ Middle Level } \\
\hline Enrolment & 16091 & 20793 \\
\hline Expenditure & $160,000,000$ & $350,000,000$ \\
\hline School & 64 & 68 \\
\hline STR & 72 & 93 \\
\hline SSR & 251 & 306 \\
\hline SCR & 66 & 79 \\
\hline \multicolumn{3}{|c|}{ Secondary Level } \\
\hline Enrolment & 7293 & 10077 \\
\hline Expenditure & $68,000,000$ & $630,000,000$ \\
\hline School & 49 & 47 \\
\hline STR & 8 & 12 \\
\hline SSR & 149 & 214 \\
\hline SCR & 16 & 25 \\
\hline
\end{tabular}

At the middle level, the enrolment has

increased by 29 percent cumulatively in this period of 6 years and at this level the expenditure has increased from Rs. 160 million to Rs.350 million; reflecting an increase of 119 percent. The STR of 93 students per teacher and SCR of 79 children per class is extremely high. This however is Source:SEMIS Data; various issues balanced by the excess resource availability on the secondary level of education. At the secondary level, the STR is 12 students to a class and the SCR is 25 students to a class. This excess availability of teachers and classrooms caters to those middle school students, who are housed in the high schools together with the secondary school students. Further, at the secondary level; the enrolment exhibits an increase of 38 percent in this period. The expenditure has also increased from Rs. 68 million to Rs. 630 million; an over 800 percent increase. Though the enrolment at the middle and secondary level reflects some increases however these are considerably low compared to the primary enrolment.

\section{DISTRICT SUKKUR}

Table 3-31 provides an overview of the education indicators in district Sukkur from 2005 to 2010 . The primary level schools in this period have increased from 1044 to 1373 . The enrolments at primary school level have declined by 5 
percent whereas the expenditure at this level has risen from Rs. 385 million to Rs. 900 million; an increase of 134 percent.

The STR has marginally improved to 30 students per teacher from the earlier

\begin{tabular}{|c|c|c|}
\hline \multicolumn{3}{|c|}{ Table 3-31: District Sukkur } \\
\hline Sukkur & 2005 & 2010 \\
\hline \multicolumn{3}{|c|}{ Primary Level } \\
\hline Enrolment & 101209 & 95915 \\
\hline Expenditure & $385,000,000$ & $900,000,000$ \\
\hline School & 1044 & 1373 \\
\hline STR & 32 & 30 \\
\hline SSR & 97 & 70 \\
\hline SCR & 42 & 23 \\
\hline \multicolumn{3}{|l|}{ Middle Level } \\
\hline Enrolment & 18468 & 26092 \\
\hline Expenditure & $140,000,000$ & $350,000,000$ \\
\hline School & 72 & 74 \\
\hline STR & 39 & 57 \\
\hline SSR & 257 & 353 \\
\hline SCR & 54 & 67 \\
\hline \multicolumn{3}{|c|}{ Secondary Level } \\
\hline Enrolment & 8327 & 13018 \\
\hline Expenditure & $240,000,000$ & $970,000,000$ \\
\hline School & 53 & 63 \\
\hline STR & 6 & 11 \\
\hline SSR & 157 & 207 \\
\hline SCR & 13 & 20 \\
\hline
\end{tabular}
32 students to a teacher. The SCR has also improved from the earlier 42 students to a class to 23 students. In case of middle level education there is an increase of 41 percent in the enrolment in this period of 6 years and at this level the expenditure has increased from Rs. 140 million to Rs.350 million; reflecting an increase of 150 percent. The STR of 57 students per teacher and

SCR of 67 children per class

reflect shortage of teacher and classrooms at this level. In contrast the STR at the secondary level is only 11 students to a class. Similarly the SCR at the secondary level is 20 students to a class. Here also, the middle school level pressure gets addressed to a large extent as the high schools cater to significant proportion of the middle school students. At the secondary level, the enrolment has increased from 8327 to 12639 , reflecting an increase of 56 percent and in this period the secondary level expenditure has increased from Rs. 240 million to Rs. 970 million; a 304 percent increase.

\section{DISTRICT TANDO ALLHAYAR}

In district Tando Allahyar, the primary schools in this period have increased from 687 to 837 . However, the enrolment in this period has decreased by $13 \%$ 
at the primary level. There were 40772 students in 2005-06 and these decreased to 33152 by $2010-11$. The Table 3-32 : District T.A Yar
TAY 2005
Primary Level $\begin{array}{lll}\text { Primary Level } & & \\ \text { Enrolment } & 42772 & 37152\end{array}$ Expenditure $\quad 305,000,000 \quad 210,000,000$ primary level expenditure has surprisingly decreased in this district from Rs. 305 million to Rs. 210 million; School $\begin{array}{lll}\text { STR } & 30 & 25\end{array}$ $\begin{array}{lll}\text { SSR } & 62 & 44\end{array}$ MCR Enrolment Expenditure School an over 30 percent decrease. The STR at this level has improved to 25 students STR SSR SCR Enrolment to a teacher from the earlier 30 STR Expenditure School STR SCR 26 $\begin{array}{cc}7833 & 11023 \\ 98,000,000 & 140,000,000\end{array}$ $43 \quad 37$ $82 \quad 125$ $182 \quad 298$ $\begin{array}{ll}182 & 298 \\ 57 & 93\end{array}$

\begin{tabular}{cc}
3666 & 4994 \\
$50,000,000$ & $240,000,000$ \\
22 & 22 \\
15 & 18 \\
167 & 227 \\
26 & 31 \\
\hline
\end{tabular}
students. The SCR has decreased from Source : SEMIS Data; various issues 30 students to a class to 17 students per class. This reflects excess availability of teachers as well as space for higher enrolments at primary level. In case of the middle level education there is an increase in enrolment from 7833 students to 11,023 in this period; a 41 percent increase. The education expenditure has increased at this level from Rs. 98 million to Rs.140 million; an increase of 40 percent. As regards other indicators, the STR has worsened from 82 students to a teacher to 125 students, which is extremely high. The SCR has worsened to 93 students per class. In contrast the secondary level STR is only 18 students to a class and SCR at this level is just 31 students to a class. Here also these dichotomies are addressed to a large extent due to high schools which cater to both levels of education. At the secondary level, the district expenditure increased by 380 percent and the enrolment increased from 3666 to 4994 ; an increase of 36 percent.

\section{DISTRICT TANDO MOHAMMAD KHAN}

The primary level schools in this period have increased from 953 to 1056. The 
enrolments at primary school level have declined by 19 percent whereas the expenditure at this level has risen from Rs. 305 million to Rs. 340 million; an increase of 11 percent. The STR has improved to 22 students per teacher against the earlier 30 students to a teacher. The SCR has reduced to now just 19 students to a class against the earlier 33 students to a class. The STR data is reflective of a higher number of

Table 3-33 : District T.M Khan

\begin{tabular}{|c|c|c|}
\hline \multirow{2}{*}{$\begin{array}{l}\text { TMK } \\
\text { Primary Leve }\end{array}$} & \multirow[t]{2}{*}{2005} & \multirow[t]{2}{*}{2010} \\
\hline & & \\
\hline Enrolment & 47397 & 38252 \\
\hline Expenditure & $305,000,000$ & $340,000,000$ \\
\hline School & 953 & 1056 \\
\hline STR & 30 & 22 \\
\hline SSR & 50 & 36 \\
\hline SCR & 33 & 19 \\
\hline \multicolumn{3}{|l|}{ Middle Level } \\
\hline Enrolment & 5731 & 5850 \\
\hline Expenditure & $74,000,000$ & $140,000,000$ \\
\hline School & 24 & 31 \\
\hline STR & 94 & 44 \\
\hline SSR & 239 & 189 \\
\hline SCR & 70 & 52 \\
\hline \multicolumn{3}{|c|}{ Secondary Level } \\
\hline Enrolment & 1578 & 2497 \\
\hline Expenditure & $28,000,000$ & $260,000,000$ \\
\hline School & 21 & 37 \\
\hline STR & 8 & 8 \\
\hline SSR & 75 & 67 \\
\hline SCR & 11 & 12 \\
\hline
\end{tabular}
teacher presence at this level in the district. The SCR also shows availability of space in schools which can cater to higher levels of enrolment at primary level in the district. In case of middle level education there is an increase of just 2 percent in enrolment in this period of 6 years and at this level the expenditure has increased from Rs. 74 million to Rs.140 million; an increase of 89 percent. The STR is 44 students per teacher and SCR is 52 children per class. The secondary level expenditure in this district reflects an increase from Rs. 28 million to Rs. 260 million; 828 percent increase. The enrolments show an increase of 58 percent. The STR at the secondary level has declined to just 8 students to a teacher and the SCR is only 12 students to a class. This reflects complete contrast compared to the situation at the middle school level. Again this is because of showing separate resources for middle and secondary schools when in reality a large proportion of middle school students are in high schools which cater to both levels of education. 


\section{DISTRICT THARPARKAR}

Table 3-34 provides an overview of the education indicators in district Tharparkar from 2005 to 2010.

Table 3-34 : District Tharparkar

The primary level schools in this period have increased from 3702 to 4152 . The enrolment at primary level have increased by 56 percent in this period whereas the expenditure has risen from Rs. 615 million to Rs. 1.6 billion; an increase of 160 percent. The STR and SCR have increased due to the increase

\begin{tabular}{lcc} 
Tharparkar & 2005 & 2010 \\
Primary Level & & \\
\hline Enrolment & 119556 & 186113 \\
Expenditure & 615000000 & 1600000000 \\
School & 3702 & 4152 \\
STR & 31 & 40 \\
SSR & 32 & 45 \\
SCR & 32 & 34 \\
Middle Level & & \\
Enrolment & 13768 & 21559 \\
Expenditure & $180,000,000$ & $430,000,000$ \\
School & 297 & 234 \\
STR & 37 & 60 \\
SSR & 46 & 92 \\
SCR & 30 & 45 \\
Secondary Level & \multicolumn{2}{|c}{} \\
Enrolment & 2975 & 8252 \\
Expenditure & $53,000,000$ & $380,000,000$ \\
School & 33 & 40 \\
STR & 8 & 20 \\
SSR & 90 & 206 \\
SCR & 11 & 28 \\
\hline Source : SEMIS Data; various issues
\end{tabular}
in the enrolment. The STR has Source : SEMIS Data; various issues

increased to 40 students to a teacher and the SCR is 34 students to a class from the earlier 32 students to a class. SSR is just 48 students per school reflecting the presence of a large number of scattered and small schools. At the middle level; the enrolment has increased by 57 percent in this period of 6 years and at this level the expenditure has increased from Rs. 180 million to Rs.430 million; reflecting an increase of 139 percent. The STR of 60 students per teacher and SCR of 45 children per class is quite high. The secondary level expenditure has increased from Rs. 53 million to Rs. 380 million; an increase of 617 percent. The enrolment shows an increase of 177 percent. The STR and SCR at this level is considerably low with STR of 20 students to a teacher and 28 students per class. It is evident from this data that there is a need to add more middle as well as high schools for enabling greater enrolment at this level. This is a perennial issue which needs policy attention. 


\section{DISTRICT THATTA}

In district Thatta, the primary schools in this period have increased from 2971 to 3306 . The enrolments at primary school level have declined by 19 percent whereas the expenditure at this level has risen from Rs. 625 million to Rs.1.6 billion; a 156 percent increase. The STR has resultantly decreased from the earlier 36 students to a teacher to now 28 students to a teacher. The SCR has come down from 38 students to a class to now 23 students to a class. SSR is 39 students per school, reflective of presence of a large number of small and scattered schools. In case of middle level education there is an increase of 19

\begin{tabular}{lcc}
\multicolumn{3}{c}{ Table 3-35: District Thatta } \\
Thatta & 2005 & 2010 \\
Primary Level & \multicolumn{3}{l}{} \\
Enrolment & 157820 & 127356 \\
Expenditure & $625,000,000$ & $1,600,000,000$ \\
School & 2971 & 3306 \\
STR & 36 & 28 \\
SSR & 53 & 39 \\
SCR & 38 & 23 \\
Middle Level & & \\
Enrolment & 12026 & 14286 \\
Expenditure & $160,000,000$ & $450,000,000$ \\
School & 93 & 72 \\
STR & 57 & 97 \\
SSR & 129 & 198 \\
SCR & 38 & 69 \\
Secondary Level & \multicolumn{3}{l}{} \\
Enrolment & 4584 & 6626 \\
Expenditure & $110,000,000$ & $430,000,000$ \\
School & 61 & 62 \\
STR & 7 & 10 \\
SSR & 75 & 107 \\
SCR & 12 & 16 \\
Source : SEMIS Data; various issues \\
\hline
\end{tabular}

percent enrolment in this period of 6 years and at this level the expenditure has increased from Rs. 160 million to Rs.450 million; reflecting an increase of 181 percent. The STR of 97 students per teacher and SCR of 69 children per class is on the higher side. The number of middle schools has decreased from 93 to 72 . The secondary level expenditure has increased from Rs. 110 million to Rs. 430 million and as against this enrolments show an increase of 45 percent. The STR at this level is extremely low with only 10 students per teacher. Also there are only 16 students per class. The mismatch is greatly on account of treating middle school separate from the secondary as physically both these levels are catered 
through high schools to a large degree. The major issue at the middle and secondary level is low enrolment due to high dropouts and inability of the system to retain children.

\section{DISRICT UMERKOT}

In district Umerkot, the primary schools in the period from 2005 to 2010 have increased from 1845 to 2329 . The Table 3-36 : District Umerkot

enrolments at primary school level

\begin{tabular}{lcc} 
Umerkot & 2005 & 2010 \\
\hline Primary Level & & \\
\hline Enrolment & 73140 & 91996 \\
Expenditure & $305,000,000$ & $660,000,000$ \\
School & 1845 & 2329 \\
STR & 27 & 29 \\
SSR & 40 & 40 \\
SCR & 29 & 24 \\
Middle Level & &
\end{tabular}

has risen from Rs. 305 million to Rs.

Enrolment

Expenditure

660 million; an increase of

116

School

STR

percent. SSR of 40 reflects the

SCR

Secondary Level

presence of small and scattered

Enrolment

Expenditure

$\begin{array}{cc}11238 & 16064 \\ 81,000,000 & 240,000,000\end{array}$

schools across the district. The STR

88

$88-83$

SCR

SCR 153

\begin{tabular}{cc}
4744 & 7207 \\
$120,000,000$ & $280,000,000$ \\
31 & 46 \\
19 & 25 \\
153 & 157 \\
25 & 29 \\
\hline
\end{tabular}

middle school level enrolment has Source: SEMIS Data; various issues

increased by 43 percent cumulatively in 6 years. At this level the expenditure has increased from Rs. 81 million to Rs.240 million; an increase of 196 percent. Alike other districts, the middle school level exhibits high levels of STR and SCR. The STR of 130 students per teacher and SCR of 70 children per class are physically not possible. At the secondary level the STR is 25 the SCR is 29 . As the high school infrastructure and resources cater to secondary school students and a large proportion of the middle school students together, as such the secondary level resources are in reality shared. The secondary level expenditure has increased from Rs. 120 million to Rs. 280 million; whereas the enrolment at the secondary level shows an increase of 52 percent. 


\subsection{CONCLUSION}

Sindh is confronted with serious challenges on the front of economic growth and development and unfortunately it continues to underperform on education despite the fact that there is already a considerable gap on account of past non performance. The state of education in Sindh continues to be a matter of grave concern on many aspects including serious issues of access to education and the inability of the system to retain children in school. The overall indicators remain dismal and those of rural children especially females are one of the worst in the country. Sindh's children remain victim of weak performance in the sector and the situation has seemingly remained stagnant even during the devolution framework and the high growth periods. The broken down data at the district level throws further light on the issues of quality of planning; operations and the overall education management exhibiting an institutional framework which has largely become dysfunctional. 


\section{CHAPTER 4 : LITERATURE REVIEW}

\section{Abstract}

This paper presents a survey of large empirical literature that has sought to examine the relationship between educational expenditures and outcomes in both the developed and the developing countries. Availability of more comprehensive and credible education data through annual school census, the development of new statistical and econometric methodologies and computing capacities has led to a huge increase in scientific evaluations of the determinants of education quality in recent years. There is, however, debate in the education literature about whether production theory provides a reasonable theoretical underpinning for statistical models estimating the determinants of student performance. There are methodological problems with standard education production function estimates. The outcomes of different studies often yield contradictory results owing to different regional or national focus, different methodologies, or different data sets. The best way of using this approach is to understand the basic value of the method with an explicit framework, defining the goals of an education system against which outcomes can be judged and performance quantified.

This section reviews the extensive literature interface economics and education that has analyzed the relationship between educational expenditure and outcomes. This section is organized as follows. First, the relevant literature is reviewed and then a definition of the educational production function and the cost function is provided. Next a detailed discussion of the production function and the cost function with its genesis is presented. A comparative analysis of studies by well known authors / scholars on production and cost functions are produced. This was followed by a detailed analysis of efficiency measurement with emphasis on stochastic frontier analysis and data envelopment analysis. Next, panel data model, its estimation, advantages and limitations discussed. To support the theoretical discussions specific studies of panel data regression models with DEA and SFA estimations giving empirical results are presented. Finally, literature and select case studies reviewed in the context of Pakistan are presented. 


\subsection{SCHOOL EFFECTIVENESS RESEARCH AND PRODUCTION FUNCTION}

According to Scheerens (2000) School effectiveness is a difficult concept to define, and, once defined, is of a nature that is difficult to measure. The author finds different strands of educational-effectiveness research which have concentrated on different types of variables to answer this question. Economists have concentrated on resource inputs, such as per-pupil expenditure. Instructional psychologists have investigated classroom management, such as time on task and variables associated with instructional strategies. General education experts and educational sociologists have looked at the aspects of school organization, such as leadership style (p.19). He describes the effectiveness as the extent to which the desired level of output is achieved and efficiently as the desired level of output against the lowest possible cost. In other words, "efficiency is the effectiveness with the additional requirement that this is achieved in the cheapest possible manner" (p.21).

Lockheed and Hanushek (1994) opined that the term efficiency is used in many ways in educational discussions and the general lack of a consistent definition at times produces very misleading discussions and policy recommendations. They find a straightforward rationale behind efficiency concepts, that when there are limited resources - as there always are - those resources should be used to promote the society's objectives as fully as possible. "This is efficiency" (Lockheed and Hanushek, 1994, p.1). There are different perspectives to the concept of efficiency and effectiveness of education systems. A recent work by Mandl et al. (2008), outlines the conceptual framework and different methods used for cross-country comparisons of the efficiency and effectiveness of public spending. They are of the view that educational efficiency is frequently 
confused with educational effectiveness, and at times the two terms are (inappropriate) used interchangeably. They consider educational effectiveness as a specific set of resources having a positive effect (or otherwise) on achievement and, if so, how large this effect is. Clearly, "since effectiveness does not directly compare resources or costs, what is effective is not necessarily what is most efficient" (p.2). They say that the analysis of efficiency and effectiveness is about the relationships between inputs, outputs and outcomes, where the outcome is often linked to welfare or growth objectives and therefore, may be influenced by multiple factors (Mandl et al., 2008, p.3). They further point out that effectiveness shows the success of the resources used in achieving the objectives set, which implies that efficiency and effectiveness are not always easy to isolate. They contemplate that an education system is said to be efficient if maximum output is obtained from a given input, or if a given output is obtained with minimum possible input. They conclude, "effectiveness is more difficult to assess than efficiency, since the outcome can be influenced political choice" (Mandl et al., 2008, p.3). Guoxing (2007) traces the evolution of SER and state that most of school effectiveness research studies have traditionally come from the USA and Europe, in particular, the Netherlands. These studies emerged in the mid-1960s. Since then, there are three distinct but interrelated branches of school effectiveness research, namely, (a) school effects research-I. e. Scientific properties of school effects, e.g. the size of school effects, (b) effective schools research-I. e. Process-oriented study of characteristics of effective schools, and (c) school improvement research-focusing and limiting its test of specific models of effective schools (Guoxing, 2007, p.3). He identifies and briefly discusses a few 
studies done in the context of school effectiveness research. Gist of some of these studies as taken from Guoxing ( 2007, pp.6-12) are given below:

Jansen (1995) identified two generations of SER in developing countries: the first generation emerged in the 1970s focusing on econometric estimation; the second generation evolved in the 1980s using more sophisticated statistical techniques such as Stochastic Frontier Analysis. Lockheed and Levin (1993) argue that creating effective schools in developing countries requires necessary inputs in terms of curriculum, instructional materials, quality time for learning, and teaching practice promoting students active learning. Fuller and Clarke (1994) review of SER studies showed significant positive associations between academic achievement and school input as well as process. Similarly, Hanushek (1995) finds that SER in developing countries has been much concerned with the econometric notion of cost - effectiveness. Heneveld (1996) propose a conceptual framework of school effectiveness (Heneveld 1994; Heneveld and Craig 1996) which consists of an interrelated network of various factors that influence student outcomes which are characterized in four ways; participation, academic achievement, social skills and economic success. Kellaghan and Greaney (2004) postulate that assessing and monitoring student academic progress/achievement is considered an important factor in promoting school effectiveness in both developed countries and developing countries. From the perspectives of developing countries, Kellaghan and Greaney (1992; $2001 ; 2004)$ have been the key proponents of singling out the use of assessment / examination reforms to engineer change in the levels of educational policy and teaching practice to enhance the quality. Scheerens (2000a; 2000b; 2001a), in a series of reviews comparing the findings of SER studies in 
developing and developed countries, on behalf of the World Bank and UNESCO IIEP, draws three major conclusions (2001a: 361cited in Guoxing, 2007,p.12).

- Considerably larger school-variation in developing than developed countries

- A more consistent and stronger positive effect of material and human resource input factors in developing countries

- Inconclusive and weak evidence on the effect of instructional factors that have received empirical support in industrialized countries.

The production function has been used as an important tool of economic analysis in the neoclassical tradition (description at appendix 4-A). The discussion on education economics has started between the late 1950s and early 1960s with the developing conversation on human capital. The basis of human capital lies in the theories of Theodore Schultz, who produced his ideas of human capital in the early 1960s as a way of explaining the advantages of investing in education to improve agriculture output. The contemporary economic approach to education started developing from the late 1950s onwards with Jacob Mincer's application of human capital theory to the measurement of the economic return to education. Teixeira (2007) asserts that, Mincer's dissertation(finished in 1957 and published in the Journal of Political Economy in 1958) was the first analytical contribution to the development of human capital theory, his research opened the way for very important work to be carried out on patterns of lifetime earnings, labor force participation, and investments in human capital, and his development and econometric estimation of the human capital earnings function became a centerpiece of modern labor research. Becker (1962), built on Schultz's theories, concentrated on 
developing a theory of investment in human capital, "with an emphasis on empirical implications rather than on formal generalization" and is concerned with activities that influence future real income through the embedding of resources in people," this is called investing in human capital" (pp.49 and 9). He explains the concept that, they are called human capital, because people cannot be separated from their knowledge, skills health or values in the way they can be separated from their financial and physical assets. Building on the human capital theory, other economists and other social scientists produced a large body of empirical evidence determining the more time spent in school, the higher the income of a person. This necessitated designing a model explaining the relationship between educational output and school resources. This resulted into developing an educational production function based on theory of human capital. According to Glewwe and Kremer (2005), a useful assumption to understand the impact of education policies of years of schooling and skills learned, to employ in order that each household (in particular, the parents of the child) maximizes, subject to constraints, a (life-cycle) utility function. They further contend that "the constraints in the process or the production of learning, the impact of years of schooling and of skills obtained on the future labor incomes of children, a life-cycle budget constraint, and perhaps some credit constraints" (p.11). The production function of learning is a structural relationship and these ideas developed into these educational production functions :(Glewwe and Kremer, 2005, p.12)

$$
A=a(S, Q, C, H, I) \quad \ldots . .
$$

Where $\mathbf{A}$ is skills learned (achievement), $\mathbf{S}$ is years of schooling, $\mathbf{Q}$ is a factor of school and teacher characteristics (quality), $\mathbf{C}$ is a vector of child 
characteristics (including "innate ability"), $\mathbf{H}$ is a vector of household characteristics, and I am a vector of school inputs under the control of parents, such as children's daily attendance and purchases of textbooks and other school supplies.

Many researchers trace the origins of the production function approach to the Coleman Report (1996) done in the United States to investigate equal opportunity issues during the 1960s. The Coleman Report stirred up considerable controversies by coming to the surprising conclusion that variations in schools resources did not explain much of the variation in students' achievement. The majority of Education Production Function studies was conducted in the United States and tend to reinforce Coleman's most controversial finding, that variation in achievement is more closely tied to family background than to school resources, although evidence from countries with very low per capita income sometime suggest contexts where student outcomes tend to be more sensible to the availability of school resources (Gamoran and Long, 2006, cited in Nascimento, 2008, p.20). Despite several criticisms about the methodologies used and the inferences made, that report is even now considered the first major study of education production function (Hanushek, 1986 and a reference point for both education production functions (hereafter called EPF) and school effectiveness research (Levacic, 2005, cited in Nascimento, 2008, p.19). Quoting Levacic (2005) Nascimento (2008) contemplates that EPFs are an analogy made by economists between the learning process and the production process that takes place in a firm: schools are then seen as the place where educational resources (teachers, books, buildings, equipments, etc., and the students themselves) interact to produce 
an output, which is the student outcomes, normally expressed in terms of test scores. However, there is criticism on EPF efficacy. Worthington (2001) attributes four key reasons for educational production function failure. The first questions the validity of the educational production function framework itself. It is argued that many empirical studies are ad hoc in their selection of methodology, and in particular, choose input and output variables that are at odds with the production function approach it. The second centers on the possibility that public policy does not have any measurable impact on educational outcomes. The third follows from Mayston's (1996) argument that the lack of a positive relationship between educational outcomes and educational expenditure is the result of schools balancing of demand-side considerations of 'willingness to pay' for additional educational attainment against supply-side factors related to the genuine underlying production function (Worthington, 2001, p.246).

He concludes: "The associated econometric problems that follow from the neglect of the demand side transpires that one cannot legitimately interpret an estimated single equation between test scores and expenditure per pupil as telling us directly about the true underlying education production function" (Mayston 1996, p. 141, cited in Worthington, 2001, p.246). The fourth touches the assumption that the educational production function approach relies on an assumption of efficiency. It is generally assumed that all institutions in a given context are able to transform educational inputs into academic outputs at the same rate. If this is not the case, and inefficiencies are present in the educational process, then the empirical application of the conceptual model may collapse (Hanushek, 1986, reported in Worthington, 2001, p.246). 


\subsection{PRODUCTION AND COST FUNCTIONS FOR PUBLIC EDUCATION}

Studies of education production functions (also referred to as "input-output" analyses or"cost-quality" studies) examine the relationship among the different inputs into and outcomes of the educational process (Hanushek, 1986, p. 1148). He regards these studies as systematic, quantitative investigations relying on econometric methods for understanding the various factors influencing students' performance. According to Yinger (2007), there are two closely related tools which are being used for analyzing production of a good or service: production functions and cost functions. He makes a distinction between two and says, "a production function shows the outputs that can be produced with various combinations of inputs and a cost function shows how much it costs to produce various output levels given input prices" (Yinger, 2007, p.1). The comparison of these two tools leads to a conclusion that a cost function is derived from a production function, but these two tools have different strengths and weaknesses in studying education. He further explains that production functions are ideally suited to studying the impact of school programs on performance in the sample of individual students, like classroomlevel inputs while cost functions, which require information on spending but not on inputs, are ideally suited to studying educational production at the school district level.

Gronberg et al. (2004), contend that a cost function relates district spending to student performance, prices of inputs, student characteristics, and other relevant characteristics of districts. Then they touch upon a very important aspect employed in efficiency measurement, 'the estimated cost function', which is used to predict the level of spending needed to reach a particular 
performance standard, given prices, student characteristics and other district characteristics. Differences in predicting spending provide insight into the extent to which factors outside of a district's control affect the cost of education and such insights can be particularly helpful to policymakers interested in integrating performance standards into the school finance formula, and ensuring that school districts have the resources needed to meet those standards (Gronberg et al., 2004,p.2).

Imazeki (2006) estimated costs for California districts to meet the achievement goals set out for them by the state and examine how these costs vary across districts with different student characteristics. She used an econometric cost function approach in this study. She defines the cost of education as, "the minimum amount of money that a school district must spend in order to achieve a given educational outcome, such as reading at a grade appropriate level" (p.2). She further elaborates that the cost function, or 'econometric', approach utilizes data on a per-pupil school expenditures, student performance, and various characteristics of students and school districts, from all school districts within the state. She sums up that using regression techniques; the researcher estimates an equation that best fits the available data. Generically, a cost function can be represented by the following equation : (Imazeki, 2006, p.5). $S_{i t}=h\left(T_{i t}, P_{i t}, Z_{i t}, F_{i t}, \varepsilon_{i t}, u_{i t}\right), \ldots \ldots$

Where per -pupil expenditure in district $i$ in year $t\left(S_{i t}\right)$ are specified as a function of public school performance $\left(T_{i t}\right)$, a vector of input prices $\left(P_{i t}\right)$, the characteristics of the student body $\left(Z_{i t}\right)$, other characteristics of the school district $\left(\varepsilon_{i t}\right)$ and a random error term $\left(u_{i t}\right)$. district-level data for a given state. The resulting coefficients indicate the contribution of various district 
characteristics to the cost of education, holding constant the level of performance. She then uses the cost function for predicting the cost of any given level of performance (this is done by multiplying the cost function coefficients by the actual values of the student and district characteristics while setting the performance variables equal to the desired level). In this way, for each district, the minimum amount of money necessary to achieve various educational performance goals can be predicted. Cost functions are 'black boxes' that do not illuminate how districts should organize their resources (Imazeki 2006, p.6). However, with a word of caution she concludes that, cost functions are also limited by the same problems that can plague any statistical analysis, including errors in estimation and the availability of high-quality data.

Golebiewski (2008) provides a review of the cost function studies done in the United States. His review contains information on twenty-six cost function studies conducted in nine different states (appendix 4-B). These studies have used a variety of variables in their cost function models which are Student Performance Measures in Education Cost Models, Salary Variable, Cost Variables, Control for Efficiency, Economies of Quality Scale Teacher Salaries, Student in Poverty, Students with Disabilities. The results of the cost function studies show cost differentials to vary by the specification of the model by the choice of variables and instruments, and by the state due to certain statespecific conditions. The cost function studies face difficult challenges because of the nature of the data and production process being examined. Groenberg et al. (2004), lists three important advantages to using cost function approach as identified by Duncombe (1995), in a study of education costs in New York. The cost function offers a sound statistical approach to estimating the variation in 
required spending across districts. It uses actual data on factors affecting spending to develop estimates of the costs of performance standards. Furthermore, the cost function allows a relatively straightforward calculation of alternative cost estimates for policy analysis. The cost function approach has a number of desirable technical properties. They iterate that it is reasonable to expect that a school has a number of desirable technical properties and schools will be evaluated with respect to multiple outcomes, and the cost function framework accommodates this requirement handily. Second, the cost function approach is applicable as long as firms are minimizing costs. Public schools may attempt to provide education services at minimum cost, but they are certainly not profit maximizing as must be presumed in some other methodologies. Hence a cost function approach has often been employed in studies of non-profit institutions, both in the public sector and in the private sector. Finally, a cost function-based approach encourages or even forces researchers and policy analysts to be explicit about what outcomes are being studied and what inputs are being considered, as well as what assumptions are being made regarding the behaviour of decision makers at the school or district under analysis. The advantages described above can only be obtained with good data and an appropriate statistical model. If the data are poor measures of the relevant outcomes, prices, and environment of a district, then it is hard "to make a silk purse out of a sow's ear." (p.3). If the estimation model is poorly specified, then the statistical results may-even with the best of data-provide a distorted picture of the true cost relationships. They find usual econometric concerns in the cost function approach, from the possibility of simultaneous equations bias to concerns about misspecification and structural change. They 
assert that at its theoretical foundation, the cost function approach presumes that school districts are attempting to provide the designated outcomes at minimum cost. Statistical methods allow us to accommodate school districts that are inefficient, but even this approach requires that school districts are trying to minimize costs, they sum up, "if school districts are not trying to minimize costs, then cost function analysis may be misleading" (p.4).

They also criticize the cost function approach owing to its technical complexity which makes it difficult to communicate to the policy - making community. Another related criticism they point out is that the cost function does not directly inform how school districts should spend their money, as it only provides a predicted cost, for a district to achieve given outcomes standards but does not identify what districts need to do to reach those performance standards.

\subsection{PREVIOUS WORK DONE IN AREA OF STUDY AND FINDINGS}

The most well-known surveys mapping education inputs to student achievement have been conducted by Hanushek (1986, and his frequent reappraisal). According to Hanushek (2003) most analysis of education production function have directed their attention at a relatively small set of resource measures, and this makes it easy to summarize the results. There have been at least 187 studies estimating the educational production function, and he presents two series of results pertaining to the United States and developing countries. He states that "the 89 individual publications that appeared before 1995 and that form the basis for this analysis, contain 376 separate production estimates" (p.75). Educational outcomes considered are test scores in three quarters of the estimates, and other outcomes such as a continuation in school or dropout behaviour in the rest of the estimates. 
Resources considered are real classroom resources (teacher-pupil ratio, teacher education, teacher experience, financial aggregates (teacher salary, expenditure per pupil), other resources (facilities, administration, teacher, test scores). The display of the results in table 4.1 distinguishes between statistically insignificant and significant estimates, and among the latter, between positive and negative ones. The number of estimates by school resource variables varies from 41 to 276 and 53 to 86 percent of the estimates are insignificant. The negative and significant are 5 to 14 percent and only 9 to

Table 4-1: Production Function estimates

\begin{tabular}{|c|c|c|c|c|c|c|c|c|}
\hline \multicolumn{5}{|c|}{ United States sample of 376 PF Estimates } & \multicolumn{4}{|c|}{ Developing Countries $96 \mathrm{PF}$} \\
\hline \multirow[b]{2}{*}{ Resources } & \multirow{2}{*}{$\begin{array}{l}\text { Number } \\
\text { of estimate }\end{array}$} & \multicolumn{2}{|c|}{ S. sig $(\%$} & \multirow{2}{*}{$\begin{array}{c}\text { S.insig } \\
(\%)\end{array}$} & \multirow{2}{*}{$\begin{array}{l}\text { Number } \\
\text { of } \\
\text { estimates }\end{array}$} & \multicolumn{2}{|c|}{ S.sig. (\%) } & \multirow[b]{2}{*}{ S.insig (\%) } \\
\hline & & $+\mathrm{ve}$ & -ve & & & $+\mathrm{ve}$ & -ve & \\
\hline Teacher/Pupil Ratio & 276 & 14 & 14 & 72 & 30 & 27 & 27 & 46 \\
\hline Teacher education & 170 & 9 & 5 & 86 & 63 & 56 & 3 & 41 \\
\hline Teacher experience & 206 & 29 & 5 & 66 & 46 & 35 & 4 & 61 \\
\hline Teacher salary & 118 & 20 & 7 & 73 & 13 & 31 & 15 & 54 \\
\hline Expenditure per pupil & 163 & 27 & 7 & 66 & 12 & 50 & 0 & 50 \\
\hline Facilities & 91 & 9 & 5 & 86 & 34 & 65 & 9 & 26 \\
\hline Teacher test scores & 41 & 37 & 10 & 53 & 34 & 65 & 9 & 26 \\
\hline
\end{tabular}

Source: Hanushek, 2003,pp.76 and 78.

37 are significant and positive. A higher proportion of the estimated effects of teacher experience are positive and statistically significant (29\%). However, 71 percent still indicates either worsening performance with experience or less confidence in any positive effect. In sum, "the vast number of estimated real resource effects gives little confidence that just adding more of any of the specific resources to schools will lead to a boost in student achievement" (p.76). Similarly for financial provision he got weak empirical support for leading to improved student performance, as only $27 \%$ of the estimated coefficients are positive and statistically significant in the case of per pupil expenditure. Existing analyses in less developed countries have shown a similar 
inconsistency of estimated resource effects as that found in the US. The second half of table 4-1 provides 96 estimates for developing countries pertaining to the following variables: teacher-pupil ratio, teacher education, experience and salary, expenditure per pupil and school facilities. There are 12 to 63 estimates per variable, and the results are much more varied than those of the US sample. First, there are less insignificant estimates, the proportion varying between 26 and 61 percent, second, among significant estimates, a majority is positive for all variables, and the proportion of negative estimates is below 10 percent except for the teacher-pupil ratio and teacher salary. Third, an absolute majority of the estimates are significant and positive for teacher education. Hanushek (2007) in his most recent paper, 'education production functions: developed country evidence', provides some conclusions and implications saying that the existing research suggests inefficiency in the provision of schooling, but clarifies that it does not indicate that schools do not matter nor does it indicate that money and resources never impact achievement. He pronounces that "the accumulated research surrounding estimation of education production functions simply says there currently is no clear, systematic relationship between resources and student outcomes" (p.9). Following select studies are a series of rebuttal and replies by Hanushek and others on Hanushek's basic findings. These are: 1) Hanushek, (1989). "The impact of differential expenditures on school performance". 2) Hedges, Laine, Greenwald, (1994). "Does money matter? A meta-analysis of studies of the effects of differential school inputs on student outcomes”;3) Hanushek.(1994) "Money might matter somewhere: A response to Hedges, Laine, and Greenwald"; 4) ) Hedges, Laine, Greenwald (1994). "Money does matter 
somewhere: A reply to Hanushek"; 5) Dewy, Husted and Kenny (2000). "The ineffectiveness of school inputs: a product of Misspecification"? And, 6) Krueger, (2000). "Economic considerations and class size". Hanushek (1989) conducted a meta-analysis of 38 studies conducted between $1967 \& 1987$ that examined the relationship between economic resources and student achievement and found 187 effect sizes. He finds no statistically significant relationships between class size or teacher educational attainment and student outcomes. He finds only a marginally stronger relationship between teacher experience and student outcomes, but he said this may be a result of selection effects (experienced teachers choosing to teach in classrooms/schools with better students). He concluded that there were no strong or systemic relationship between the educational inputs examined and school outcomes. Hedges, Laine and Greenwald (1994) postulate that over the last decade a series of influential reviews of literature on the education production function have suggested that there is no systematic relation between resource inputs and school outcomes. They believe that the inference procedure used in these reviews, vote counting, is known to be problematic. Their study titled "A Metaanalysis of studies on the effects of differential school inputs on student outcomes", is a reanalysis of data from these earlier reviews, using more sophisticated synthesis methods. Authors reviewed the studies from Hanushek's Meta-analysis. They argued that the original study lacked statistical power and rigor, specifically the analytical tools and the way evidence across the studies were combined. They question the validity of Hanushek's results and survey methodology. The HLG critique is two pronged. First, they point out there are more positive than negative results in Handshake's sample. If the 
chance of being positive or negative were even, the odds of observing so many positive estimates would be less than one in a million. HLG's results provide strong support for a robust positive relation between student achievement and various inputs in the educational process. In particular, they found expenditure per pupil to be a robustly significant factor and that the mean coefficient was sufficiently large to be of practical importance. Of the other factors analyzed, teacher experience was found to be the most consistently significant measured input. Furthermore, pupil-teacher ratios and teacher salaries gave mixed but generally significant results.

Hanushek (1994) provides a rebuttal on Meta-analysis of the test score literature by HLG and their reported claim of finding strong effects of school resources. According to him, HLG's simple summary is that "using more sophisticated synthesis methods show a systematic positive relation between resource inputs and school outcomes". Two main points he makes (a)" more sophisticated " is not synonymous with corrections, and (b) their interpretation is potentially very misleading when it come to policy matters (p.5). He further says that his summary provides a tabulation of findings about how major items of resource use are related to student performance. HLG set out to show that Hanushek's original statement "there is no strong or systematic relationship between school expenditure and student performance (Hanushek, 1989) is incorrect. A key element of their critique actually hangs on the interpretation of the words "strong and systematic". They were meant to summarize the situation in which a vast majority of studies on the relationship between specific resources and student performance gives no real confidence that there is any relationship while HLG implicitly use a very different definition of these 
summary terms (p.5). Hanushek questions the validity of the technique used by Hedges et al., on several grounds. In particular, he notes that if their estimate of the impact of school resources were accurate, and then test scores in the United States should have skyrocketed during the 1970's and 1980's when spending per pupil rose significantly. In reality, student achievement in the United States improved very little over this period. Hedges, Laine, Greenwald (1994). "Money does matter somewhere: A reply to Hanushek", is a quick response to Hanushek's rebuttal. HLG's reply on Hanushek's above mentioned rebuttal includes three general points and several specific ones. They say, first Hanushek seems to question the validity of meta-analysis, we, and many other scientists and statisticians, disagree, they emphasized. They refer to a report of a committee of the Mathematical Sciences Board of the National Research Council (1992), which concludes that, "Meta-analysis offers a powerful set of tools for extracting information from a body of related research" (p.9). Second, Inference Procedures must have performance properties that are reasonably well understood if their results are to be credible. They claim that Hanushek misunderstands the inference problem in research synthesis in a subtle but important way. The failure to distinguish the pattern of observed results (estimates) from the parameter structure that generates them is a mistake that has led to a great deal of confusion in research synthesis (e.g., to the appeal of vote-counting), and Hanushek seems to make this mistake. Third, Hanushek attributes to them the statement that none of their samples of "estimates [is] appropriate for the statistical methodology" because none are completely independent, which they contradict as they had used the full multivariate procedure in their meta-analysis to deal more efficiently with 
dependence. On a specific point they point out contradiction in Hanushek's own statement, wherein Hanushek complains about the lack of independence among the studies that HLG examined, but then criticizes them for creating subsets of the data that are independent. On the methodological aspect they lament and say, "Perhaps the data are flawed as Hanushek now admits, if so, policy recommendations based on them should be held in abeyance" (p.10). Dewey, Husted and Kenny (DHK: 2000) examine the production of knowledge before the child leaves the nest and ensure comparability, they examine cognitive skills, as measured by a score on a standardized test. The study by Dewey, Husted and Kenny (DHK: 2000) affirms Hedges et al.'s criticism of

Table 4-2:Comparison between Hanushek and DHK studies

\begin{tabular}{l|c|c|c|c}
\hline & \multirow{2}{*}{ Hanushek $^{\mathrm{a}}$} & \multicolumn{3}{|c}{$\begin{array}{c}\text { Dewey, Husted, and Kenny meta re- } \\
\text { analysis }\end{array}$} \\
\cline { 3 - 5 } & & All & Good & Bad \\
\hline Teacher education & 46.4 & 67.2 & 66.7 & 67.3 \\
Teacher experience & 69.1 & 68.8 & 65.2 & 70.7 \\
Teacher salary & 66.7 & 59.1 & & 59.1 \\
Other teacher & & 86.8 & 94.7 & 84.2 \\
characteristics & & & & \\
Teachers per pupil & 37.4 & 74.2 & 70.6 & 75.6 \\
$\begin{array}{l}\text { Expenditure per pupil } \\
\text { School size }\end{array}$ & 70.4 & 81.3 & 84.6 & 80.0 \\
Total & & 45.8 & 71.4 & 37.1 \\
\hline
\end{tabular}

${ }^{a}$ Hanushek (1986). Coefficients listed as having unknown sign are excluded. Source: Dewey et al.2000, p.33.

Hanushek's findings. DHK use a more recent sample than that considered by Hanushek (1986), including127 regressions taken from 46 papers, while analysis of Hanushek (1986) is based on 147 regressions from 33 publications (p.30). DHK argued that the inclusion of income, because it is a demand-side factor, leads to inappropriate specifications, and that this is an important factor driving the lack of relationship in previous work. The inclusion of the demand variable 'family income' creates serious statistical problems that should make it 
more difficult to conclude that school inputs are significant. Under these two weak criteria (failure to include a measure of parental inputs and inclusion of income or socioeconomic status), 92 of the 127 studies, nearly three-quarters, were labeled as bad. Income or socioeconomic status was included in 85 studies; seven of these also did not have variable specifically measuring parental inputs. Seven other studies were labeled as bad due to the omission of any parental input measure. Misspecification, particularly the inclusion of income as a regressor, thus appears to be a serious problem in this literature (p.29).

Table 4-3: Comparison between Hanushek and DHK studies (Sig. +ve)

\begin{tabular}{l|c|c|c|c}
\hline & \multirow{2}{*}{ Hanushek $^{\mathrm{a}}$} & \multicolumn{3}{|c}{$\begin{array}{c}\text { Dewey, Husted, and Kenny meta re- } \\
\text { analysis }\end{array}$} \\
\cline { 3 - 5 } & & All & Good & Bad \\
\hline Teacher education & 8.7 & 17.2 & 25.0 & 15.4 \\
Teacher experience & 35.1 & 42.2 & 52.2 & 36.6 \\
Teacher salary & 25.0 & 31.2 & & 31.2 \\
$\begin{array}{l}\text { Other teacher } \\
\text { characteristics }\end{array}$ & & 43.4 & 52.6 & 40.4 \\
Teachers per pupil & 9.9 & 17.7 & 17.6 & 17.8 \\
Expenditure per pupil & 24.1 & 48.9 & 30.8 & 56.7 \\
School size & & 18.1 & 38.1 & 11.3 \\
Total & 20.3 & 30.2 & 38.1 & 27.5 \\
\hline
\end{tabular}

a Significant at the $2.5 \%$ level using a one-tail test.b Hanushek (1986). Coefficients listed as having unknown signs are excluded.

Source: Dewey et al.2000, p.33.

Table 4-3, gives results which are further summarized by sign and significance level, respectively, and compared with Hanushek's summaries (Hanushek, 1986). Over $68.8 \%$ of coefficients suggest the expected positive sign that school inputs have a positive impact. Over $81 \%$ of the coefficients for expenditure per pupil and for other teacher characteristics are positive, but less than half the coefficients for school size are so. Hanushek, on the other hand, found only $56.1 \%$ of the coefficients to be positive in the studies he examined. 
The coefficients on teacher education, teachers per pupil, and expenditure per pupil were much less often positive. Thirty-seven percent of the 414 coefficients are significantly positive at a $5 \%$ (one-tail) significance level. To facilitate comparison with Hanushek (1986), table 4-3 reports Hanushek's summary was less favorable to educational inputs than DHK. Only $20.3 \%$ of his coefficients were significant. For each of the five input categories, his coefficients were less often significant than where the coefficients in DHK re-analysis.

The biggest difference was in spending; his were half as likely as DHK's coefficients to be significant. DHK suggests that good studies have been 39 percent more often more significant than were bad studies. The correctly specified studies were much more likely to find that school size and various indicators of teacher quality were significant. They agree with Hanushek and others that "it does matter how the money is spent on education; simply spending more will not guarantee higher achievement in all cases and the evidence on productivity is stronger for some inputs than for others" (p.42). Another notable criticism of Hanushek's methodology, focusing on the 1997 paper, came from Krueger (2000). Hanushek (1997) argues, "Given the small confidence in Just getting noticeable improvements [from school resources], it seems somewhat unimportant to investigate the size of any estimated effects" (p. 144). On this statement Krueger (2000) is of the view that the size of the effect would seem worth considering now since Hanushek's classification of studies in the literature does provide evidence of a systematic relationship between school inputs and student performance. But he cautions," Moreover, if the estimates in the literature are Imprecise, they all could be statistically insignificant and unsystematic (p. 20)".Imprecise, they all could be statistically 
insignificant and unsystematic (p. 20). Krueger's main point is that counting estimates, as opposed to studies, to compute the proportions of positive, negative and significant results gives more weight to studies from which large numbers of estimates are drawn. Krueger provides some evidence that there Table 4-4: Krueger's Reanalysis of Hanushek's (1997) Class Size Studies

\begin{tabular}{lcccc}
\hline \multicolumn{1}{c}{ Results } & $\begin{array}{c}\text { Hanushek's } \\
\text { weights }\end{array}$ & $\begin{array}{c}\text { Studies equally } \\
\text { weighted }\end{array}$ & $\begin{array}{c}\text { Studies } \\
\text { weighted by } \\
\text { journal impact } \\
\text { factor }\end{array}$ & $\begin{array}{c}\text { Regression- } \\
\text { adjusted } \\
\text { weights }\end{array}$ \\
\hline Positive \& stat. sig. (\%) & $(1)$ & $(2)$ & $(3)$ & $(4)$ \\
Positive \& stat. insig. (\%) & 14.8 & 25.5 & 34.5 & 33.5 \\
Negative \& stat. sig. (\%) & 13.4 & 27.1 & 21.2 & 27.3 \\
Negative \& stat. insig. (\%) & 25.3 & 10.3 & 6.9 & 8.0 \\
Unknown sign \& stat. insig. & 19.9 & 23.1 & 25.4 & 21.5 \\
Ratio positive to negative & 1.07 & 14.0 & 12.0 & 9.6 \\
p-value* & 0.500 & 0.059 & 0.034 & 2.06 \\
\hline Source: Krueger. & & & & 0.009 \\
\hline
\end{tabular}

Source : Krueger,2000, p.38.

is indeed a negative correlation between the number of estimates per study and the proportion of positive estimates. He then compares Hanushek's tabulation with three alternative tabulations which give equal weight to all studies ('one study, one vote' rather than 'one estimate, one vote') as given in table 4-4. While Hanushek's tabulation yielded a proportion of 14.8 percent (13.4 \%) positive (negative) and significant results, Krueger's tabulation yielded 25.5 percent (10.3 \%) 34.5 percent $(6.9 \%)$ and 33.5 percent (8.0\%).Positive estimates thus are in a large majority, although the proportion of insignificant estimates remains high? Krueger concludes that 'studies with positives studies are twice as likely as studies with negative results; the probability of observing at this many studies with positive results by chance is less than one in hundred' (p.44).

\subsubsection{Determinants of learning in developing countries}

The success since 1960 in expanding the quantity of education in most developing countries has shifted attention to education quality, especially as 
measured by student performance on academic tests. Glewwe and Kremer (2005) opine that most empirical studies of the determinants of years of schooling and learning in both developed and developing countries are retrospective studies, based on data generated by ordinary (non-experimental) variation across schools and households. Hence, both economists and other social scientists have used retrospective data to investigate the impact of school and teacher characteristics on learning. The authors claim that the most significant recent retrospective studies of the determinants of learning in developing countries since 1990s are: the research on Ghanaian middle schools by Glewwe and Jacoby (1994); the study of Jamaican primary schools by glue and others (1995); the investigation of grade 8 students in India by Kingdon (1996); and the paper on Philippines primary schools by Tan and others (1997). The study by Glewwe and Jacoby (1994) on Ghana have examined student achievement in 1988-89, using scores on reading (English and Mathematics) in Ghanaian middle schools (grades 7 to 10). Eighteen schools and teacher variables were examined, but most estimated effects were small and statistically insignificant. The only statistically significant teacher variable was teaching experience, but its effect was indirect, in contrast, school facilities had larger impacts (Glewwe and Kremer, 2005, p.30). A study by Glewwe and others (1995) used Jamaican data collected in 1990 to examine the performance of primary school students in reading (English) and mathematics. More than 40 schools and teacher characteristics were examined, including pedagogical processes and management structure. Most variables had statistically insignificant effects. The school variables with significant positive impacts were administration of eye examinations (reading 
only), teacher training within the past 3 years (mathematics), routine academic testing of students (reading and mathematics), and the use of textbooks in class (reading). The size of these estimated impacts (in standard deviations of the test score variable) was lower than those for Ghana (Glewwe and Kremer,2005,p.31). Kingdon's(1996) study of India is based on data collected in 1991. Tests in reading (Hindi and English) and mathematics were given to students in "class 8" (grade 8). Kingdon examined five teacher variable (years of general education, years of teacher training, marks received on official teacher exams, years of teaching experience, and salary) and three school variables (Class size, hours per week of academic instruction, and an index of 17 physical characteristics). The teacher variable with significant effects were teacher exam marks, which had significant positive impacts on both mathematics and reading scores, and teachers' year of education, which had a significantly positive impact on reading scores (Glewwe and Kremer,2005,p.31).

Tan, Lane and Coustere (1997), using data from 1990 and 1991, investigate the impact of school and teacher variables on the mathematics and reading scores of 2,293 first graders in the Philippines. Of the teacher variables, the score on the subject knowledge test in reading had a positive impact on students' reading scores: a one standard deviation increase in the teacher's score raised student learning by 0.12 standard deviations. The same is true for mathematics scores: a one standard deviation increase in the teacher's score raised student learning by 0.10 standard deviations. Turning to school characteristics, the impact of textbooks was unstable for both subjects, in some cases significantly negative. The only other school variable significant at the 5 
percent level was the lack of adequate furniture, which was associated with a drop of -0.32 standard deviations in math and 0.29 standard deviations in reading (Glewwe and Kremer, 2005, p.31).

In all four studies, most school and teacher variables were not significantly different from zero, although this could reflect both low sample sizes (163 students in Ghana and 355 in Jamaica) and high correlation among many of these variables. While each study did find that one or more teacher variable had statistically significant impacts. They differed widely across the studies. Similarly, three of the four studies finds significant impacts of physical inputs (the exception being the Jamaica study), but again the specific inputs vary across different studies. Part of this variation could reflect differences in the variables available in the data, and part could reflect large socioeconomic differences across countries but, whatever the reason for this variation, the conclusion is that there is no general result regarding which teacher and school variables raise learning in developing countries (Glewwe and Kremer, 2005, p.32). The offshoot of the above discussion assumes that the estimated impact of these four retrospective studies are accurate, but also provides many reasons to worry about biases in such estimates. Perhaps the underlying relationship that is more motivated teachers, principals, and parents were more likely to keep the building in good repair. The inability to observe certain children and household characteristics such as the child's innate ability and parental tastes for education also leaves lingering doubts. Finally, it is likely that schools variables are measured with a large amount of error-examples have been presented in Tanzania (distance to schools) and the Philippines (books per pupil). The random measurement error could explain why these variables 
are often statistically insignificant (Glewwe and Kremer, 2005, p. 34). Nascimento (2008) quoting Hanushek and Hedges and Greenwald, on the variation in output, says that findings often point in opposite directions, fuelling endless controversies on whether "there is not strong or consistent relationship between school resources and student performance" (Hanushek, 1997, p.148) or "school resources are systematically [and sufficient] related to student achievement $[\ldots]$ to be educationally important"(Hedges and Greenwald, 1996, p.90). He sums up, "indeed, the degree of influence of school resources on student achievement seems to vary widely depending on the sample taken, the level of aggregation of the data, and methodology used" (Nascimento, 2008, p.26).

\subsection{METHODOLOGICAL ISSUES}

Vignoles et al. (2000) present an extensive discussion of methodological issues and review the findings of the recent studies from the USA and the United Kingdom in the context of the impact of various inputs on educational outcomes. In the US, they find that the evidence of aggregate expenditure is not reliable, so that one needs to consider different inputs separately. They say higher quality studies do find a significant impact on class-size reduction on student achievement, but this impact would be too small to justify the implied increase in expenditure on cost-efficiency grounds. The evidence on teacher characteristics is also rather ambiguous. They found teacher experience to have a positive impact on achievement, but this is non-linear, as only the first few years of experience are associated with significant, positive coefficients. However, they say that, there is some robust evidence of a positive impact of teacher salaries, but none concerning teacher education, interests, and more 
precise estimates are found when using detailed input measures (e.g.

Distinguishing between initial and further years of teaching experience, or teacher qualifications by subject areas) rather than less informative summary measures.

Table 4-5: Effect of Key Variables

\begin{tabular}{|c|c|c|c|}
\hline Author & Location & Input & $\begin{array}{l}\text { effect of } 1 \% \text { inc. in } \\
\text { expenditure }\end{array}$ \\
\hline Angrist and Lavy (1999) & Israel & Class Size & $3.6 \%, 1.7-1.9 \%$ \\
\hline \multirow[t]{2}{*}{ Barro and Lee (1996) } & C. Country & Class Size & $2.70 \%$ \\
\hline & C. Country & Teacher Salary & Insignificant \\
\hline \multirow[t]{3}{*}{ Cooper and Cohn (1997) } & US & Class Size & $1-4 \%$ \\
\hline & US & Teacher Experience & Insignificant \\
\hline & US & $\begin{array}{l}\text { Teacher } \\
\text { Qualification }\end{array}$ & $0.5-2.5 \%$ \\
\hline \multirow[t]{4}{*}{ Dewey et al.(2000) } & US & Expenditure & $0.15 \%-0.12 \%$ \\
\hline & US & Teacher Experience & $0.008 \%-0.04 \%$ \\
\hline & US & $\begin{array}{l}\text { Teacher } \\
\text { Qualification }\end{array}$ & Insignificant \\
\hline & US & Teacher Salary & $0.04 \%$ \\
\hline Figlio (1977) & US & Expenditure & $2.5-6.4 \%$ \\
\hline \multirow[t]{3}{*}{ Gold Haber et al. (1999) } & US & Class Size & $-6.6 \%$ to $-7.2 \%$ \\
\hline & US & $\begin{array}{l}\text { Teacher } \\
\text { Qualification }\end{array}$ & $2.30 \%$ \\
\hline & US & Teacher Salary & Insignificant \\
\hline Gupta et al. (1999) & C. Country & Expenditure & $3.30 \%$ \\
\hline \multirow[t]{4}{*}{ Hanushek et (1998) } & US & Class Size & $0.001-0.05 \%$ \\
\hline & US & Teacher Experience & $-7 \%$ to $-15 \%$ \\
\hline & US & $\begin{array}{l}\text { Teacher } \\
\text { Qualification }\end{array}$ & $-4 \%$ \\
\hline & US & Teacher Salary & $0.76-1.2 \%$ \\
\hline Hoxby (1999) & US & Class Size & Insignificant \\
\hline \multirow[t]{3}{*}{ Karuger (1999) } & US & Class Size & $7-9 \%$ \\
\hline & US & Teacher Experience & $3 \%$ \\
\hline & US & $\begin{array}{l}\text { Teacher } \\
\text { Qualification }\end{array}$ & Insignificant \\
\hline Kirjavainen and Loikkanen (1998) & Finland & Class Size & $25 \%$ of inefficient \\
\hline Kruger Whitmore(1999) & US & Class Size & $20 \%$ \\
\hline Marlow (2000) & US & Expenditure & -0.01 to +0.002 \\
\hline
\end{tabular}

They find UK studies as typical of the literature pertaining to other developed countries than the US, with relatively few methodologically strong studies. They further contemplate that it is also patchy and lacks both depth and breadth of coverage with respect to the different phases of education and data sets used. The research has been restricted by the lack of suitable and accessible data 
[....]' (p.36).Their review of the selected studies related to three major inputs; expenditure per pupil; class size and teacher characteristics are given in table 4.5 , which summarizes the results of 26 studies. Four studies examine the expenditure as an independent variable. Dewey et al. (2000), found positive results between expenditure per pupil and SAT scores. Figlio's results indicate that expenditure reduction were harmful to student achievement in mathematics, reading, science and social studies. Gupta et al. (1999), get a positive response for countries that invest a greater proportion of national income in education have higher enrolment rates.

Marlow (2000) focuses mainly on the effect of competition on school performance, where competition is measured by an index based on the number and concentration of different school districts within a particular country. His premise is that a larger number of school districts, with more equal shares of the market, will stimulate greater competition in that country and raise performance. They conclude, "Overall, sufficiently significant concerns about that data and methodological tools employed in the four papers examined suggest that the 'Hanushek view'- that increased expenditure in itself does not raise student achievement - cannot be seriously challenged by the results of these studies" (p.22). Nine studies examine class size as an independent variable. The issue of class size remains contested one owing to conflicting findings. Hanushek (1997) suggested that smaller class sizes do not systematically lead to improve student achievement. Similarly, Hoxby (1998) while using two quasi-experimental techniques in panel framework to examine the influence of class size on test scores in Connecticut district school finds insignificant impact of class size on student achievement. Examining the 
National Educational Longitudinal Study (NLES) of 1998, Goldhaber and Brewer (1997) found that class size was significant but had the 'wrong sign', i.e. suggesting that largest classes are associated with better student outcomes. In a subsequent paper using the same data, Goldhaber, Brewer, and Anderson (1999) found a similar result. On the other hand, Cooper and Cohn (1997), using stochastic frontier estimation, found that smaller class sizes reduce student test scores. However, three studies reflected in the above table do find a positive link between smaller classes and student achievement; two are from the US (Krueger, 1999; Hanushek, Kain, and Rivkin, 1998), and the third one from Israel (Angrist and Lavy, 1999). Krueger found that the most substantial gains occurred in the initial year of class size reduction, with the difference between children in small and large classes increasing by a single percentage point in subsequent years. A subsequent analysis by Krueger and Whitmore (1999) suggests that the student achievement associated with the STAR experiment had permanent effects. Krueger's analysis suggests that a 1 percent decrease in class size would lead to a-level gain of 4 percent followed by a 1 percent growth per annum, which appears to be an upper bound on the potential return from reducing calls size (Vingoles et al., 2000, p.26). Hanushek, Kain, and Rivkin (1998) provide alternative estimates of class size effects using the Harvard / UTD Texas Schools Project database. Hanushek et al. (1998), finds that class size effects are statistically significant for $4^{\text {th }}$ and $5^{\text {th }}$ formers but not for $6^{\text {th }}$ formers. However, although significant, the magnitude of the effects was considerably smaller than those obtained by Krueger (1999), and account for less than $0.1 \%$ of the total variation in student achievement. The third study that finds robust gains in student achievement from smaller 
classes, is an examination of class size reductions in Israel in the early 1990s by Angrist and Lavy(1990).

For teacher characteristics, they examined three most popularly employed measures of teacher quality viz; teacher experience; teacher education and teacher salary in three studies. A summary of these studies is given in table 4-5 which will be seen in comparison to Hanushek (1997a) survey which gives the percentage of studies finding significant results for the most commonly included teacher characteristics teacher's education (9\% positive and significant), experience $(29 \%)$, and salary $(27 \%)$. In the context of teachers experience they consider three studies for analyzing the input - teacher experience and its impact on student achievement. Hanushek et al. (1998), found a significant and positive effect on achievement for teachers with up to 2 years experience, as compared to teachers with no experience (with the exception of $4^{\text {th }}$ and $5^{\text {th }}$ form mathematics). However, no effects were found from greater levels of teacher experience. As summarized in table 6-5, other studies surveyed in this paper (other than Dewey et al.) all found that teacher experience lacked explanatory power. However, these alternative studies do not directly contradict Hanushek et al. In the context of teacher education, they refer to six studies done to examine the effect of teacher qualification on student achievement. For teacher education, only three studies find significant results. In particular Goldhaber and Brewer (1997) detect robust results that being taught by a teacher with a degree in mathematics has a positive impact on pupils' mathematics scores. By contrast however, Hanushek et al. (1998), found that $4^{\text {th }}$ form students appear to suffer through having more highly educated teachers. Neither study found that, outside mathematics, there is any discernible relation between teacher 
education and outcomes-results that are consistent with Goldhaber et al's recent re-examination of the NLES database. The only paper that appears to have had some success with an 'aggregate' teacher education variable is Cooper and Cohn (1997), however, their results are not robust at all the specifications. In the context of impact of teacher salary on student achievement they present four studies. Hanushek et al. (1999), found that when student fixed effects and teacher mobility are accounted for, a higher salary exert a positive influence on student achievement. Dewey et al. (2000), obtain positive and robust results that relative salary differentials matter in determining student outcomes. Other analyses, summarized in table 4-5 find no significant relationship. They sum up, "there is some robust evidence that teacher experience and teachers' salaries have significant effects but that teacher's education level (with the exception of teacher with a qualification in mathematics) do not" (Vingoles et al., 2000, p.32).

\subsection{EFFICIENCY MEASUREMENT}

Modern efficiency measurement beings with Farrell (1957) who drew upon the work of Debreu (1951) to define a simple measure of firm efficiency which could account for multiple inputs. Worthington (2001) identifies three main measures of efficiency; technical, allocative and economic. Technical efficiency refers to use of productive resources in the most technologically efficient manner - the maximum possible output from a given set of inputs. Within the context of education, technical efficiency may then refer to the physical

relationship between the resources used (say, capital, labor and equipment) and some education outcome. These educational outcomes may either be defined in terms of intermediate outputs (generally standardized test score) or a 
final education outcome (such as graduate employment rates, starting salaries or acceptance rates into higher education) (p.245). Allocative efficiency is concerned with choosing between different technically efficient combinations of inputs used to produce the maximum possible outputs. Finally and when taken together, allocative efficiency and technical efficiency determine the degree of productive efficiency (also known as total economic efficiency) (p.245). Based on the above description and when applied to the education sector it can be said that, first, efficiency is about allocating efficiently between different kinds of resources - e.g., between teachers and blackboards, or between more teachers per student and better-qualified teachers - that is, about choosing the most efficient input mix (allocative efficiency). Second, efficiency is also about using each resource efficiently, that is, making the best use of each given input (technical efficiency).

A number of analytical techniques have been developed to estimate the form of cost and production frontier and associated inefficiency of individual organizations. Green (1993) while giving an overview of techniques for econometric analysis of technical (production) and economics (cost) efficiency describes two broad paradigms for measuring economic efficiency. One based on an essentially nonparametric, programming approach to analysis of observed outcomes, and the other one based on an econometric approach to estimation of theory-based models of production, cost, or profit. He further elaborates that the empirical estimation of production and cost functions is a standard exercise in Econometrics. He says, "the frontier production function or production frontier is an extension of the familiar regression model, based on the theoretical premise that a production function, or its dual, the cost function, 
or the convex conjugate of the two, the profit function, represents an ideal, the maximum output attainable given a set of inputs, the minimum cost of producing that output given the prices of the inputs, or the maximum profit attainable given the outputs, and prices of the inputs" (p.92-93).

Thus, resultantly there are two basic approaches to the measurement of efficiency: the statistical (or econometric) approach and the non-statistical (or programming approach). The distinction between the two approaches derives from the underlying assumptions. In summary, a method for measuring efficiency can be statistical or no statistical, parametric or non-parametric, deterministic or stochastic. Of the eight possible permutations of these characteristics, the most common methods fall into one of three of these categories: statistical parametric methods (deterministic or stochastic) and deterministic non-statistical non-parametric methods (Johnes, 2004, p.625). According to Zamorano (2004) the choice of estimation method has been an issue of debate, with some researchers preferring the parametric and others the non parametric approach. In his opinion, no approach is strictly preferable to any other measurement of efficiency in education is definitely a complicated issue. Several methodological approaches have been used to overcome problems in educational efficiency measurement. They all have their advantages and shortcomings. The early studies of educational production function mostly used least-squares regression techniques. From the 1980s the use of non-stochastic Data Envelopment Analysis (DAE) has become quite common. DEA is a programming technique that envelopes the observed data to determine the best practice frontier. This technique has become popular in evaluating technical efficiency in the public sector because it easily handles 
multiple outputs, is nonparametric, and does not require input prices. An alternative econometric approach (parametric and statistical techniques) has progressed from ordinary least squares (OLS) regression to Stochastic Frontier Analysis, where the simple ratio of one output to one input have been replaced by composite ratios of efficiency derived from linear programming (LP) methods.

\subsubsection{Parametric techniques}

Parametric techniques use econometric methods to estimate the parameters of a specific functional form of cost or production function. There are a number of methods that fall directly under this heading, including ordinary least squares regression analysis and stochastic frontier analysis. Ordinary least squares (OLS) are one of a variety of techniques that fall under the heading of regression analysis. It involves the identification of a statistical relationship between variables. OLS regression analysis fits a line of best fit to these points, such that the line minimizes the sum of the squared vertical distances of the observed country's coasts. The line of best fit can be written as follows:

$$
C_{i}=\alpha+B L_{i}+U_{i}
$$

Where i represent the observations for different institutions, $\alpha$ is the fixed cost involved, $\beta$ is the cost of educating another student, and $\mu \mathrm{i}$ is the regression residual (the difference between actual costs and those predicted by the line of best fit).

A stochastic production frontier model were first introduced by Aigner et al. (1977) and Meeusen and Van den Broeck (1977) and has been a significant contribution to the econometric modeling of production and the estimation of technical efficiency of firms. The Stochastic frontier involved two random 
components, one associated with the presence of technical efficiency and the other being the traditional random error (Battese and Coelli, 1992, p.149). In contrast OLS regression models implicitly assume that the whole of the residual for a particular observation (in this context a country) is the result of genuine inefficiency. This decomposition of residuals between 'error' and 'genuine efficiency' provides a more accurate reflection of the true level of inefficiency. A number of studies have used these approaches to estimate the efficiency of educational institutions. These include Sengupta (1987), Barrow (1991), Deller and Rudnicki (1933), Cubbin and Zamani (1996), Bates (1997), Moomaw and Adkins (2005) and Kirjavainen (2007), details of last two are presented in the later part of this chapter.

\subsubsection{Non-parametric techniques}

Non-Parametric techniques place no conditions on the functional form and use observed data to infer the shape of the frontier. Most non-parametric methods take the form of data envelopment analysis (DEA) and its many variants. DEA essentially calculates the economic efficiency of a given organization relative to the performance of other organizations producing the same good or service, rather than against an idealized standard of performance. It is a nonstochastic method in that it assumes all deviations from the frontier are the result of inefficiency. It can be used as an alternative to regression-based techniques. It does not involve statistical estimation, but instead makes use of linear programming or some other form of mathematical programming methods to characterize the set of efficient producers and then derive estimates of efficiency for inefficient observations based on how far they deviate from the most efficient ones. Charnes, Cooper and Rhodes (1981), Sengupta and Sfeir 
(1988), Ganely and Cubbin (1992), Beasley (1995) and Haksever and Muragishi (1998) and others (for details see appendix 4-C) have applied these approaches to educational institutions (Worthington, 2001, p.250).

\subsection{PANEL DATA MODEL}

Panel regression models are based on panel data. Panel data are repeated measures of one or more variables on one or more persons (repeated crosssectional time-series). Gujarati (2003) states that panel data have space as well as time dimensions. Frees et al. (2001), opine that Panel data analysis is a statistical methodology that has been developed in the biological health and social science literatures. The idea of a panel data set is that a cross-section of observational units, typically individuals or economic entities, is selected and a response (dependent variable) and explanatory (independent) variables are observed for each unit. This is the usual regression setup. The key distinguishing feature of panel data is that observational units are followed over time, thus allowing researchers to study the dynamics of a problem (p.25).

Panel, or longitudinal, data analysis has become an important tool for empirical researchers in the social and biological sciences. To illustrate, an index of over 800 scholarly and trade journals in business and economics, ABI/INFORM, provides references to 192 articles that include the phrase "panel data" in their title or abstract over 1997-98. The Science Citation Index, a broad index of science journals, refers to 646 articles that include the phrase "longitudinal data" in their title or abstract over 1997-98. As an econometric technique, panel data methods are primarily used for inference to assess the effect that one or more (exogenous) explanatory variables may have on a response, controlling for other explanatory variables (p.25). 
Hsiao (2006) states that there is a proliferation of panel data studies be it methodological or empirical. In 1986, when Hsiao's (1986) first edition of Panel Data Analysis was published, there were 29 studies listing the key words: "panel data or longitudinal data", according to Social Sciences Citation index. By 2004, there were 687 and by 2005, there were 773. The growth of applied studies and the methodological development of new econometric tools of panel data have been simply phenomenal since the seminal paper of Balestra and Nerlove (1966). He further asserts that there are at least three factors contributing to the geometric growth of panel data studies. (i) data availability, (ii) greater capacity for modeling the complexity of human behavior than a single cross-section or time series data, and (iii) challenging methodology. Hsiao (2003) contemplates that panel data models have become increasingly popular among applied researchers due to their heightened capacity for capturing the complexity of human behavior as compared to cross-sectional or time-series data models.

\subsubsection{Benefits and limitations of panel data}

Hsiao (2003) and Klevmarken (1989) list several benefits from using panel data. (Cited in Baltagi , 2005, pp. 4-6).It controls for individual heterogeneity. By combining time series of cross-section observations, panel data give "more informative data, more variability, less collinearity among variables, more degrees of freedom and more efficient."Panel data are better able to study the dynamics of adjustment. Panel data enables us to study more complicated behavioral models. According to Baltagi limitations of panel data include: Design and data collection problems. Distortions of measurement errors. Selectivity problems. This includes self-selecting, non-response and attrition. 
Short time-series dimension and Cross-section dependence. Macro panels on countries or regions with long time series that do not account for the crosscountry dependence may lead to misleading inference. They also caution that Panel data is not a panacea and will not solve all the problems that a time series or a cross-section study could not handle.

\subsection{FIXED AND RANDOM EFFECTS MODEL}

There is a vast literature in Econometrics that suggests models and estimators to overcome many but not all of these limitations, as discussed in the preceding paras. Gujarati (2003) suggests that as data involve both cross-section and time dimensions, problems that plague cross-sectional data (e.g., heteroscedasticity) and time series data (e.g., autocorrelation) need to be addressed. There are several estimation techniques to address one or more of these problems. The two most prominent are (1) the fixed effects model (FEM) and (2) the random effects model (REM) or error component model (ECM) ( $p$. 652). In Econometrics, a fixed effects model is a statistical model that represents the observed quantities in terms of explanatory variables that are treated as if the quantities were non-random. This is in contrast to the random effects model in which either all or some of the explanatory variables are treated as if they arise from random causes.

Gujarati (2003) gives a detailed description about FEM and ECM; in FEM the intercept in the regression model is allowed to differ among individuals in recognition of the fact that each individual or cross-sectional unit may have some special characteristics of its own. To take into account the differing intercepts, one can use dummy variables, while in ECM it is assumed that the intercept of an individual unit is a random drawing from a much larger 
population with a constant mean value. The individual intercept is then expressed as a deviation from this constant mean value. ECM is appropriate in situations where the (random) intercept of each cross-sectional unit is uncorrelated with the regressors. He further refers to conducting the Hausman test which is used to decide between FEM and ECM. But he sums up, "despite its increasing popularity in applied research, and despite the increasing availability of such data, panel data regressions may not be appropriate in every situation. One has to use some practical judgment in each case" (p.652). Vignoles et al. (2010) discuss fixed and random effects models in the context of educational research and set out the assumptions behind the two approaches. They conclude that a fixed effects approach will be preferable in scenarios where the primary interest is in policy-relevant inference of the effects of individual characteristics. Brand and Bollen (2010) state that fixed and random effects models for longitudinal data are common in sociology. Their primary advantage is that they control for time-invariant omitted variables. Henderson (2003) in surveying the developments and extensions of technical efficiency measurement using panel data, primarily focuses on both deterministic and stochastic production functions and examines both time invariant and time variant measures of technical efficiency. To obtain the production frontier, he uses a linear programming method. Subsequently, this method forms the basis of the Data Envelopment Analysis (DEA) method by Charnes, Cooper and Rhodes (1978). The alternative to the deterministic frontier, the stochastic frontier, originated by Meeusen and van den Broeck (1977) and Aigner, Lovell and Schmidt (1977), use econometric methods to estimate the frontier. According to him "these models concentrate on cross-sectional data and 
estimate technical efficiency using maximum likelihood estimation (MLE)" (p.2). Schmidt and Sickles (1984), cited in Henderson, 2003, point out three main difficulties concerning the maximum likelihood (ML) methods and consistency of estimates from using cross-sectional data. First, technical efficiency of a particular firm can be estimated, but not consistently. Next, distributional assumptions are required about technical efficiency in order to estimate the model and separate technical efficiency from statistical noise. Finally, it may be incorrect to assume that efficiency is independent of the regressors. Each of these difficulties is potentially avoidable if a "satisfactory" panel data set is available. The potential gains from using panel data to measure technical efficiency appear to be quite large. A panel obviously contains more information about a particular firm than does a cross-section of the data. Moreover, Schmidt and Sickles (1984) suggest that panel data will enable one to relax some of the strong assumptions that are related to efficiency measurement in the cross-sectional framework. Pitt and Lee (1981) extend the cross-sectional Maximum Likelihood (ML) technique to analyze a panel data set. Branching from this, Schmidt and Sickles (1984) apply random and fixed effects procedures on a panel toward the estimation of a stochastic production frontier in order to estimate time-invariant technical efficiency.

\subsection{APPLICATION OF SFA AND DEA IN EDUCATION}

Most of the studies of technical inefficiency in education have used Data envelopment analysis (DEA). Perhaps the best-known and earliest work in the area of measuring education production was conducted by Bessent et al.,1982 (Worthington,2001,p.255). Studies using stochastic frontier analysis (SFA) are in the minority compared to applications of DEA in the context of measuring the efficiency of school institutions. Most of these studies have 
used cross section data. Some studies have used panel data and compared the results of SFA and DEA models. Following are some of the studies using SFA, DEA models and a study comparing the results of both SFA and DEA models with same data sets.

\subsubsection{Efficiency measurement using DEA}

Chakraborty (2001) used Data Envelopment Analysis to examine the relationship between school districts' spending and various school and nonschool factors including productive efficiency (using three years panel data from unified school districts in Kansas). An average cost function and a production function of education were estimated and an efficiency index constructed and the total factor productivity measured.

Borrowing from Duncombe and Yinger (2000), this study estimates a cost function expressed as: ( Chakraborty 2001, p.25)

$$
C=\alpha+\beta_{1} X+\beta_{2} P+\beta_{3} N+\beta_{4} F+\beta_{5} D+\varepsilon
$$

Where $\mathrm{C}$ is the expenditure per student in the district; $\mathrm{X}$ is the various measures of students' performance (math and reading scores); $\mathrm{P}$ is the price of various inputs the district pays, such as teachers' salaries; $\mathrm{N}$ is the district size; F is the students' socioeconomic status; $D$ is the other student characteristics; and $\varepsilon$ is the unobserved district characteristics. In the measure of technical efficiency a school district is considered technically efficient if it achieves the highest possible output (i.e., achievement score) from a given amount of resources used or, conversely, uses minimum resources to produce a given level of output (p.26). One of the crucial unobserved factors in the above equation is district efficiency. Holding other things constant, a more efficient district most likely would spend less per student to achieve the same standard. 
In order to capture the effect of unobserved factors on district spending, an efficiency index is included as one of the independent variables in the cost function. Initially, the linear models for panel data, both fixed effect and random effect models were applied to estimate the cost function, but based on the Hausman test, he found a two-way fixed effect model more appropriate to estimate the cost function. Accordingly he modified the model and the modified cost function equation is produced below: (Chakraborty,2001,p.26)

$C_{i t}=a_{0}+a_{i}+\gamma_{t}+\beta_{k} \Sigma z_{i t}+\varepsilon_{i t}$

Where $i$ is the number of districts; $t$ is the number of periods; $a_{i}$ is the group effect; $\gamma_{t}$ is the time effect; $\beta_{k}$ Are the unknown coefficients to be estimated; vector $Z$ represents original variables $X, P, N, F$, and $D$ from the equation (1). $Z$ also includes an efficiency index for each district for each year under study. The educational production function uses math and reading scores as two outputs; and operating expenditure per student, teacher-student ratio, teachers' salary, and percent of student qualified for free and subsidized lunch (AFDC) as inputs.

Table 4-6 : Summary of Mean Technical Efficiency

\begin{tabular}{l|c|c|c|c|c|c|c}
\hline $\begin{array}{c}\text { Mean } \\
\text { Efficiency }\end{array}$ & $\begin{array}{c}\text { Nos } \\
\text { USD }\end{array}$ & $\begin{array}{c}\text { Percent } \\
\text { Growth } \\
\text { EFFCH }\end{array}$ & $\begin{array}{c}\text { Nos } \\
\text { USD }\end{array}$ & $\begin{array}{c}\text { Percent } \\
\text { Growth } \\
\text { TECHCH }\end{array}$ & $\begin{array}{c}\text { Nos } \\
\text { USD }\end{array}$ & $\begin{array}{c}\text { Percent } \\
\text { Growth } \\
\text { TFPCH }\end{array}$ & $\begin{array}{c}\text { Nos } \\
\text { USD }\end{array}$ \\
\hline 1.000 & 4 & $1.134-1.109$ & 6 & $104.5-100.1$ & 18 & $1.134-1.109$ & 6 \\
$0.999-0.950$ & 53 & $1.108-105.0$ & 39 & - & & $1.108-105.0$ & 19 \\
$0.949-0.900$ & 87 & $114.9-100.1$ & 125 & - & $104.9-100.1$ & 83 \\
$0.899-0.850$ & 90 & 1.000 & 12 & - & 1.000 & 0 \\
$0.845-$ Below & 70 & $1.000-0.892$ & 122 & $1.000-0.964$ & 286 & $1.000-0.939$ & 196 \\
AVG $=0.892$ & 304 & AVG $=1.006$ & 304 & AVG $=0.979$ & 304 & AVG $=0.985$ & 304 \\
\hline
\end{tabular}

USD-unified school district;EFFCH-efficiency change;TECHCH-technological progress/change TFPCH-total factor productivity change * Source: Chakraborty, 2001,p.28.

A summary of the efficiency scores given in table 4-6 shows that technical efficiency for 53 districts is between 99.9 and 95.0 percent and only 4 out of 304 districts were found fully efficient. The study found that, on average, 
districts are 89.2 percent efficient. He further explains the indices for efficiency change, technological progress, and total factor productivity change, for any of these ratios a value less than one implies deterioration and greater than one denotes improvement.

Table 4-7 : Educational Cost Function Estimates

\begin{tabular}{lcc}
\hline Variables & Coefficient & t-statistics \\
\hline Math Composite $\left(4^{\text {th }}, 7^{\text {th }}\right.$, and $\left.10^{\text {th }}\right)$ & 0.00111 & $2.447^{*}$ \\
Reading Composite $\left(3^{\text {rd }}, 7^{\text {th }}\right.$, and $\left.10^{\text {th }}\right)$ & 0.00129 & $2.122^{*}$ \\
$\operatorname{Ln}()$ & -2.03889 & $-11.061^{*}$ \\
$\operatorname{Ln}()^{2}$ & 0.10829 & $7.135^{*}$ \\
Ln(teacher's salary) & 0.03738 & 0.896 \\
Percent of students receiving Free and subsidized & 0.00030 & 0.670 \\
lunch (AFDC) & -0.00216 & $-6.516^{*}$ \\
Efficiency (percent) & 16.91 & $23.87^{*}$ \\
Constant & 0.9882 & \\
R-square & 280 & \\
Hausman test statistics & &
\end{tabular}

*-indicates significant at 5 percent or below level

Source : Chakraborty , 2001, p.28.

Comparison of total factor productivity (TFP) change across district time showed significant differences across districts however, on average most of the districts experienced a decrease in TFP growth (p. 29). The regression results from the cost function that accounts for efficiency differences indicate that it costs less per students for efficient districts to achieve a set of standards. As described earlier for estimating educational cost function he used a two- way fixed effect model (using district and time dummy variables) and overall, the regression equation has a good fit.

Table 4-7 presents the coefficient estimates from the cost function showing the coefficients on all explanatory variables have expected sign. Positive coefficients on the variable math and reading score (measure of outputs) suggest that it costs more to generate a higher level of output. Highly significant and negative coefficient on enrolment and the positive and 
significant coefficient on enrolment-squared suggest per student expenditure decreases initially reaching a minimum as enrolment increases, and then increases as enrolment increases. The elasticity for teachers' salary is 0.3 , which implies that a one percent increase in teachers' salary would cause a 0.3 percent increase in expenditure per student. The negative and the highly significant coefficient on the efficiency variable suggests an inverse relationship between districts' efficiency and per student expenditure. He concludes, "districts with low technical efficiency at the beginning of the period experienced the highest growth in TFP at the end" and "the regression results from the cost function that accounts for efficiency differences indicate that it costs less per students for efficient districts to achieve a set of standards" (pp.35 - 36).

\subsubsection{Efficiency analysis using DEA}

In this paper Tyagi et al. (2005), used Data Envelopment Analysis (DEA) to assess the technical efficiency and efficiency differences among 348 elementary schools of Uttar Pradesh state in India. Data collected from the survey namely National Achievement Survey of class $\mathrm{V}^{\text {th }}$ students, which have been conducted by National Council of Educational Research and Training (NCERT) in the year 2000. A cross sectional data aggregated to the school level comprised 348 schools in 7 districts in Uttar Pradesh. Inputs were characterized in two parts as school related variables and home related variables. In this category \% available teaching facilities (PTF), \% available physical facilities (PPF) and \% available ancillary facilities (PAF) were included. PTF included the availability of maps, globes, charts, play material, games equipments, primary science kit, mathematics kit, books for the 
library. PPF includes the availability of things like school bell, musical instrument, blackboard, chalk-duster, dust-bin, furniture for the schools. PAF included availability of facilities like safe drinking water, toilet, TV, electric connection, computer and play ground etc. (p. 3).

Table 4-8 : Variable used in the DEA efficiency measurement

\begin{tabular}{lcccc}
\hline Inputs/outputs & Model1 & Model2 Model3 & Model 4 \\
\hline Inputs & & & & \\
\hline \%available teaching facilities (PTF) & $\checkmark$ & $\checkmark$ & $\checkmark$ & $\checkmark$ \\
\hline \%available physical facilities (PPF) & $\checkmark$ & $\checkmark$ & $\checkmark$ & $\checkmark$ \\
\hline \% available ancillary facilities (PAF) & $\checkmark$ & $\checkmark$ & $\checkmark$ & $\checkmark$ \\
\hline Teacher qualification index (TQI) & $\mathbf{x}$ & $\checkmark$ & $\checkmark$ & $\checkmark$ \\
\hline Teacher experience index (TEI) & $\mathbf{x}$ & $\checkmark$ & $\checkmark$ & $\checkmark$ \\
\hline Number of students per teacher (SPT) & $\mathbf{x}$ & $\mathbf{x}$ & $\checkmark$ & $\checkmark$ \\
\hline Average attendance of students in school(ASS) & $\mathbf{x}$ & $\mathbf{x}$ & $\checkmark$ & $\checkmark$ \\
\hline Parents education occupation index(EOI) & $\mathbf{x}$ & $\mathbf{x}$ & $\mathbf{x}$ & $\checkmark$ \\
\hline Outputs & $\checkmark$ & $\checkmark$ & $\checkmark$ & $\checkmark$ \\
\hline Average marks in EVS (AME) & $\checkmark$ & $\checkmark$ & $\checkmark$ & $\checkmark$ \\
\hline Average marks in mathematics (AMM) & $\checkmark$ & $\checkmark$ & $\checkmark$ & $\checkmark$ \\
\hline Average marks in language (AML) & & & & \\
\hline Source: Tyagi et al., 2005, p.8. & & & $\checkmark$ \\
\hline
\end{tabular}

They summarized Teacher's characteristics in four variables; Teacher qualification index (TQI); Teacher experience index (TEI); Number of students per teacher (SPT) and average attendance of students in school (AAS.) Similarly, in Home related variable Parent's education occupation index (EOI) was included. Resultantly three outputs were: Average marks in EVS (AME); Average marks in Mathematics (AMM) and Average marks in Language (AML).

To assess the intuitive picture of performance and to measure the dependency of efficiency on different variables they considered four models with different input-output setting. The guiding principle in construction of models was to proceed from simple one (with less number of input-output variables) to more complicated ones (with greater number of variables). This strategy of running four models enabled them to test the robustness of results 
also as their methodology DEA is not a statistical method with which the theoretically based hypothesis can be tested with classical tests. The input and output variables included in the four models are shown in table 4-8 above.

This study estimated the relative efficiency scores under the assumption of constant returns to scale (CRS). Table 4-9 offers basic information on the distribution of efficiency scores. There are differences in efficiency scores of schools for different models. In model 1, efficiency scores range from 9.83 percent to 100 percent. When teachers' characteristics

Table 4-9: The average efficiency and the percentage share of efficient schools

\begin{tabular}{lccccc}
\hline & Model 1 & Model 2 & Model 3 & Model 4 \\
\hline Mean score & 43.84 & 61.69 & 66.59 & 70.58 \\
Minimum score & 9.83 & 15.17 & 18.62 & 19.44 \\
Maximum score & 100 & 100 & 100 & 100 \\
Number of efficient schools & 11 & 33 & 51 & 67 \\
$\begin{array}{l}\text { Percentage shareof efficient } \\
\text { school }\end{array}$ & 3.16 & 9.48 & 14.65 & 19.25 \\
\hline
\end{tabular}

Source: Tyagi et al., 2005, p.9.

are added into model 1, efficiency scores range from 15.17 percent to 100 percent. On this result they argue that it shows teachers' characteristics are more effective in performance evaluation than providing facilities. In model 3 , which consists of variables of model 2 and students' attendance, the efficiency scores vary from 18.62 percent to 100 percent. The average efficiency in model 1 is 43.84 percent, indicating an average saving potential of 56.16 (100-43.84) percent in use of resources when assuming outputs are given. Under the assumption of CRS, the efficiency scores remain same in both input orientation (input minimization) and output orientation (output maximization). The average efficiency in model 4 is 70.58 percent which is higher for all four models. The share of fully efficient schools (score 100 
per cent), i.e. schools determining the efficiency frontier, increased from 9.83 percent in model 1 to 15.17 percent in model 2 and 19.44 percent in model 4. The number of efficient schools in model 1, 2, 3 and 4 are 11, 33, 51 and 67 respectively. The efficiency scores of model 1 are clearly below the other three models. The addition of variables related to teachers' characteristics shifted the efficiency distribution remarkably upwards, whereas the efficiency distributions of model 2 and 3 are close to each other. Thus, the addition of variables students per teacher (SPT) and average attendance of students (AAS) did not have a large influence on the efficiency score distribution. The addition of variable measuring the education and occupation of students' parents (model 4) again shifted the distribution slightly upwards, which indicates some impact of the home environment on schools' performance. Finally, they claim, that their methodology is helpful in suggesting the enhancement in outputs and the reduction in inputs for inefficient schools (efficiency scores $<100 \%$ or 1 ) to become efficient and they can develop a school-wise planning form to get better performance (p. 7).

\subsubsection{Efficiency measurement using SFA}

Studies using SFA are in the minority compared to applications of DEA in the context of measuring the efficiency of school institutions. Moomaw and Adkins (2005) in this paper estimated a Stochastic Production Frontier, which likes other such estimates, finds that economic resources matter for performance. Borrowing from Battese and Coelli (1995) they proposed a stochastic frontier model for use with panel data in which the inefficiencies can be expressed as specific functions of explanatory variables. The data (from the academic years 1990-1991 
through 1994-1995) included 418 school districts in the state of Oklahoma. They used test scores to measure school output. Output is measured as the district average of the lowa Test of Basic Skills (ITBS) for grades 3 and 7, and of the Test of Achievement and Proficiency (TAP) for grades 9 and 11 . Maximum likelihood estimates of the production function and its stochastic frontiers are given at appendix 4-D. District (ADM) was measured as the average daily membership in the school district for the year rounded to the nearest whole number. It was calculated by dividing the total days of membership throughout the year by the number of days taught. Instructional expenditures per student $(I \$ / S)$ are the total expenditures for the school district devoted to instruction divided by ADM. Other expenditures $(\mathrm{O} \$ / \mathrm{S})$ were the expenditure per student devoted to administrative and other school operations. Salary (SALARY) was the average by dividing the gross salaries and fringe benefits of the district by the number of full-time equivalent (FTE) teachers for the school year. The MLEs (Maximum Likelihood estimates) were obtained using each of 4 output measures: 3 rd grade, 7 th grade, 9 th grade and 11 th grade test scores. The coefficient estimates and their corresponding t-ratios for the frontier production functions are presented in appendix 6-D.

Table 4-10: Elasticities of test scores

\begin{tabular}{l|c|c|c|c|c}
\hline & Grade 3 & Grade 7 & Grade 9 & Grade 11 & $\begin{array}{c}\text { Grade 11 } \\
\text { W/ 9th g. } \\
\text { score }\end{array}$ \\
\hline$(\mathrm{I} / \mathrm{S})$ & 0.2854 & 0.1570 & 0.1864 & 0.2270 & 0.0397 \\
Standard Error & 0.0276 & 0.0223 & 0.0239 & 0.0254 & 0.0281 \\
$(\mathrm{O} \$ \mathrm{~S})$ & 0.0801 & 0.1031 & 0.0785 & 0.0728 & 0.0484 \\
Standard Error & 0.0193 & 0.0157 & 0.0155 & 0.0167 & 0.0201 \\
\hline
\end{tabular}

Source: Moomaw and Adkins ,2005,p.23. 
Output elasticities have been computed based on the mean values of $L n(I \$ / S)$ and $\operatorname{Ln}(\mathrm{O} \$ / \mathrm{S})$ and are summarized in table 4-10. According to Moomaw and Adkins (2005) there was wide variation in the efficiency with which districts use available resources to educate students. Large districts tend to be more efficient than small ones. Similarly the elasticities of test scores with respect to instructional and non- instructional spending were statistically positive at the $5 \%$ level. They have found that a one percent higher level of instructional spending is predicted to increase third grade test scores by 0.29 percent and the other test scores from 0.16 to 0.23 percent. According to their estimates increasing teacher salary reduces inefficiency by statistically significant amounts in all grades considered. Likewise, increasing the percentage of faculty with advanced degrees improves technical efficiency in all grades. Years of experience increase technical efficiency in all grades, except for grade 3. Larger student/teacher ratios reduce technical inefficiency in grade 3,7 and 9 . Studies of education production and its efficiency suggest that: (a) schools or school districts matter (Deller and Rudnicki 1993); (b) principals matter (Chubb and Moe 1990); teachers matter (Ferguson and Ladd 1996); class size matters (Krueger 1997); computers matter (Betts 1995), and so on. Teacher experience, advanced degrees, and salary also matters, they conclude.

\subsubsection{Efficiency measurement using SFA}

In this paper Kirjavainen (2007) has analyzed the efficiency of Finnish upper secondary schools using different stochastic frontier models. A five year (20002004) panel data was used for estimating education production functions (an unbalanced data, consisting of 436 schools and the number of schools varied 
from 424 to 427 depending on the year). School resources are measured by two variables: teaching expenditures per student and other current expenditures per student. Teaching expenditure consists of teachers' and principals' salaries, teaching materials and other costs that can be directly attributed to teaching. Kirjavainen calculated that they contribute some 75 percent of the total expenditures. Other expenditures consist of the costs of meals, health care and counseling, administration, and rents for the school properties. There were quite considerable differences in teaching expenditures per pupil across schools. In 2000, the average teaching expenditure was some 3300 euros. It varied, however, between 1800 and 13000 euros. In 2004, the average teaching expenditures per student were some 3700 euros. The differences had somewhat diminished since the expenditures varied between 2200 and 9200 euros (p.11). Both teaching expenditures per student and student - teacher ratio were tested as measures of teaching resources. School output is measured by compulsory grades in matriculation examination. Students' socioeconomic status is measured with three different variables: Education level of parents, share of white-collar workers, and share of single parents. Other controls for the students of each school include the shares of female and Swedish speaking students. Five different stochastic frontier models were estimated using an unbalanced panel data. They were pooled stochastic frontier model, random effects (RE) model, fixed effects (FE) model and true random effects (TRE) and true fixed effects (TFE) model (Greene, 2005a, b). In addition, there were two alternative models. In Model A teaching resources were measured with teaching expenditures per student. In Model B this variable was replaced with student - teacher ratio. The latter model was 
estimated with a smaller sample (p.16). He found, heteroscedasticity related to school size in idiosyncratic error term fit in both the models.

The results were therefore heteroscedasticity corrected for those models. The correction had only minor effects on the results. For the choice between random or fixed effects models, Hausman specification test was performed.

Table 4-11:Average inefficiency in panel data models

\begin{tabular}{|c|c|c|c|c|c|}
\hline Model A & $\begin{array}{l}\text { Pooled } \\
\text { panel }\end{array}$ & $\begin{array}{l}\text { Random } \\
\text { effects }\end{array}$ & True Random effects & $\begin{array}{l}\text { Fixed } \\
\text { effects }\end{array}$ & $\begin{array}{l}\text { True fixed } \\
\text { effects }\end{array}$ \\
\hline Mean & 0.037 & 0.064 & 0.027 & 0.154 & 0.056 \\
\hline $\begin{array}{l}\text { Standard } \\
\text { deviation }\end{array}$ & 0.015 & 0.041 & 0.010 & 0.046 & 0.014 \\
\hline MM. & 0.008 & 0.002 & 0.005 & 0.000 & 0.020 \\
\hline $\begin{array}{l}\text { Max. } \\
\text { Model B }\end{array}$ & 0.123 & 0.250 & 0.103 & 0.295 & 0.143 \\
\hline Mean & 0.026 & 0.065 & 0.030 & 0.179 & 0.057 \\
\hline $\begin{array}{l}\text { Standard } \\
\text { deviation }\end{array}$ & 0.008 & 0.042 & 0.013 & 0.063 & 0.014 \\
\hline MM. & 0.009 & 0.002 & 0.006 & 0.000 & 0.020 \\
\hline Max. & 0.068 & 0.209 & 0.121 & 0.341 & 0.146 \\
\hline
\end{tabular}

Source: Kirjavainen, 2007, p.23.

The results of the test supported fixed effects models. Despite of this affirmation for the fixed effects model, he also ran the random effects model owing to the fact that the panel was fairly short (five years) and some of the explanatory variables of interested stay constant through time.

The stochastic frontier model was found to be appropriate for the description of the production technology since the lambda coefficient was statistically significant in all the models. The efficiency results show that most of the explanatory variables in these models have the expected sign. Comprehensive school GPA affects positively on matriculation examination scores. Both teaching expenditures and other expenditures per student have statistically significant coefficients in TRE model. Teaching expenditures are also statistically significant in TFE model. He explained this resultant statistically 
significant teaching expenditure because of unmeasured heterogeneity across schools which was captured in the model, teaching expenditure turned out to be statistically significant. As regards the average length of the studies affects he found that on average the longer studies do not contribute to increased performance in matriculation examination. School size affects the performance of their students negatively, and the coefficient is statistically significant in pooled panel data, RE and TFE models. The size of the coefficient is, however, quite small. There were clear differences in the inefficiency of schools between the different stochastic frontier models (see table 4-11).

Traditional FE model, by labeling all school specific fixed effects as inefficiency, produces clearly the highest average inefficiency, some 15 percent in the Model A. As a consequence of taking into account school specific fixed effects and separating it from inefficiency, inefficiency decreases to 6 percent. Therefore, interpreting whole school specific fixed effects as inefficiency most likely overestimates its magnitude. The same pattern applied to RE and TRE models although the average inefficiency is lower in both cases compared to fixed effects models. The clear difference in average inefficiency between random and fixed effects models highlighted the importance of the choice of an appropriate model. As for the variation in inefficiency scores across schools, it was also highest in FE model, whereas TRE model produces the lowest variation each year. The results of pooled panel data and TFE model were also very close to that of TRE model (pp.17-18). In this study, new variant of stochastic frontier models for panel data were used to evaluate the efficiency of Finish upper secondary schools, which allows separation of random and fixed effects from inefficiency. He found the estimation results similar to previous 
studies, like variables related to students' earlier school success and family background were the strongest predictor of performance in matriculation examination. Similarly, in most of the models, the effect of school resources (teaching expenditure per student) was not statistically significant. The inefficiency vary depending on the stochastic frontier model. Fixed and random effects models produce different estimates for efficiency. Therefore, he argued that the choice of model matters and the advantage of true random effects and true fixed effects models was, however, that they allow the separate identification and investigation of time constant effects and inefficiency. He concluded, "the puzzle by choosing the appropriate model remains partly unresolved" (pp. 17-18).

\subsection{LITERATURE REVIEW IN THE CONTEXT OF PAKISTAN}

The aggregate human capital investments in Pakistan are low relative to other countries of similar per capita income levels (see chapter 1). Studies across countries show that human capital investments in Pakistan are performing poorly: the school enrolment rate is low, school dropouts are widespread, and there is a distinct gender gap in education (Sawada, 1997, p.695). This low level of education in Pakistan may have a strong negative effect on the country's long-term macroeconomic growth. Birdsall, Ross and Sabot's (1993) regression results indicate substantial forgone income gains for Pakistan due to lower investments in schooling over the last three decades. Their simulations revealed that Pakistan would have increased the current per capita income by 25 percent if it had had Indonesia's 1960 primary school rates, and by 16 percent if as many girls as boys had attended primary school in 1960 (cited in Sawada,1997,p.698). The high levels of drop-out at the primary, middle and 
secondary school level remain the elusive path to school education in Pakistan. The resources spent on dropouts are an educational wastage, because the limited literacy and numeracy skills acquired at less than primary level are lost by the dropouts (see chapter 6 for efficiency / wastage analysis in the context of Sindh).In their study in the context of rural Pakistan Alderman et al. (1996), found that the primary explanation for gender differences was for differences in access to suitable schools. However, this is not as much a concern in urban areas. They further explain that lack of single gender schools has also been a major deterrent to the girl's continuation into the middle and high schools. In their study on the learning effects and dropouts, Bilquees and Saquib ( 2004) refer to various studies done in this context. They refer to a study by Chaurd and Mingat (1996) which is based on a sample of 8000 students in the Punjab and the NWFP (Renamed as Khyber Phukhtukhawa) provinces on the learning effects and dropout rates at the primary level only. This study covers three types of educational institutions; private, public, mosque schools over a thirteen month period in 100 schools at two level grade I and grade IV. The main findings of the study are that at the level I dropouts are lowest for private schools, and higher for mosque schools, however, at level IV the dropouts are lower and do not differ significantly between the three categories of schools. At the regional level, in the rural areas dropouts are not affected by multigrade or single grade teaching or even if the schools do not offer all levels of primary schooling. The drop out among the girls was higher than boys in all sampled schools. Aged school teachers and their qualification were contributing factors to drop out. Similarly, they cite a study by Kemal and Maqsood (2000) using the data from study by Chaurd and Mingot endorsed the earlier results that 
teacher qualification and age contribute to the dropout. The drop out in public schools was higher than the private schools. Sawada and Lokshin (2001) for their study on Household Schooling Decisions in Rural Pakistan, conducted field surveys in 25 Pakistani villages and integrated their field observations, economic theory, and econometric analysis to investigate the sequential nature of education decisions because current outcomes depend not only on current decisions but also on past decisions. They found that accessibility to a primary school within the village seems to contribute to about $18 \%$ increase in a girls' primary school entry probability, and that the female primary school dropout will decline by about 16 percent. They report a consistently positive and significant coefficient of father's and mother's education at all levels of education except at the secondary school level. They observed that dropouts at the primary and secondary exit levels are also associated with negative income and health shocks. They further point out that households do not discriminate against all daughters; while the older daughters might have to bear the brunt of resource constraint as the domestic labor provided by elder girls and their early marrying, infact release household resources for younger siblings including younger daughters. A household's human and physical assets and changes in its income significantly affect children's education patterns. Birth order affects siblings' competition for resources (Sawada and Lokshin, 2001, p1). Lloyd et al. (2005), report that in rural Pakistan, retention decisions are responsive to school quality. In the case of, the share of teachers residing in the community - a fact easily known to parents-was found to have a particularly important effect on girls'; in the case of retention, attending a government school rather than a private school-government schools typically 
have a lower rank on most dimensions of school quality-tends to significantly increase the chance that a girl will drop out of school. Arif and Saqib (2003) measure cognitive skills in the primary grades for public, private and nongovernmental organization (NGO) schools. They administered questionnaires to grade 4 (primary school) pupils, their parents, teachers and school heads. In total, 50 schools were sampled across the country yielding 965 primary school boys and girls. Test of numeracy, literacy and life-skills /general knowledge were administered to all pupils to obtain measures of cognitive skills. Private school pupils are found to perform significantly better than those in government schools while this was not true for NGO school students.

There are very few surveys that document learning outcomes and monitor quality of education being delivered by the public sector in Pakistan. Amongst those are; the national education assessment system (NEAS), (2005-09), the Punjab learning and educational achievement Schools (LEAPS) survey (2006), Sindh education assessment system survey (PEAS, 2006 and 2010), the World Bank rural school survey (2006) and the Annual Status of Education Report (ASER), 2010 and 2011 - bring out a dismal picture of any positively significant relationship between the resources spent and the progress achieved - all have arrived at similar conclusions: children are not learning in school what they are expected to know. One can argue that analyzing the relationship between overall spending and outcomes is a limited analytical tool. Some things work, and others do not - but what works and what does not is a perennial question in this sort of analysis. An ineffective allocation of resources by a district might not show results, whatever the mode and means of spending were. On the flip side of such analysis is another version measuring cognitive achievements 
indicates short-term changes in students' performance on standardized tests but resultantly ignores long-term outcomes.

In an extensive study, Holmes (2003) measures the determinants of school completion in Pakistan at the primary, middle, and high school levels. She finds that overall females receive less education than males. They tend to drop out, or withdraw, earlier for economic and social-cultural reasons. The opportunity cost of sending female children to school in rural areas, where girls are married quite early, is high because the benefits of their schooling will not accrue to their parental household. In the context of the impact of parent's education, Holmes finds a positive and significant impact on child schooling. She suggests that the gender gap in illiteracy can be reduced by 40 percent in rural Pakistan if gender gaps in primary education were eliminated. Holmes finds the distance to primary schools was not significant as a cause of dropout; however, the distance to middle and high schools affected the schooling of both the sex. This study does not endorse the findings of an earlier study by Sathar and Llyod (1994) who concluded that school distance of $1 \mathrm{Km}$ have significant impacts on the primary school attendance in rural girls. Aslam and Kingdon (2006) investigate whether the intra-household allocation of educational expenditure in Pakistan favors males over females. They posit two potential channels of gender bias: bias in the decision whether to enrol / keep both sons and daughters in school, and bias in the decision of education expenditure conditional on keeping both sons and daughters. In junior and secondary school ages, evidence points to significant pro-male biases in both the enrolment decision as well as the decision of how much to spend is conditional on enrolment. However, in the primary school age-group only the former 
channel of bias applies. Household fixed effects estimation suggests that the observed strong gender difference in education expenditure is a within rather than an across household phenomenon.

A recent study by Aslam (2007) titled 'the relative effectiveness of government and private schools in Pakistan' highlights a significant pro-male bias within households in the allocation of education expenditure. In estimating achievement production functions, findings reveal that boys are indeed more likely to be sent to private schools than girls within the household, so that differential school-type choice is an important channel of differential treatment against girls. Private schools are also found to be of better quality - they are more effective than government schools in impacting mathematics and literacy skills.

Khan and Kiefer (2007) postulate that NGO schools perform dramatically better than government or private schools in rural Pakistan (details of this study are given in the latter part of this section). Alderman et al. (2001), conducted household-level and school-level surveys. Tests of Urdu and Mathematics were administered to a subset of III age children. The authors found that, controlling for home background and school inputs, children in private schools performed better than their government school counterparts. The study demonstrates that schooling choices of poor households are very sensitive to school fees, proximity, and quality. They conclude, "rather than being exploited by private schools, evidence suggests that strong demand for private schools is in response to better quality and learning opportunities offered by private schools"(p.19). The findings from the three studies in the context of Pakistan reported above suggest that in urban and rural Pakistan private school pupils 
outperform public school counterparts, at least at the primary level. In contrast to above three referred studies which looks at the qualitative aspects of private sector schooling, Cynthia, Cem Mete, and Monica (2007) look at the recent and dramatic shifts in the distribution of the public and the private sectors from another angel. They believe that there is a need to have a deeper understanding of the factors that may contribute to the multiple educational disadvantages that poor rural girls continue to face in Pakistan as the percentage of poor rural girls enrolled in school remain low. This finding may be partially explained by the fact that school choice has expanded most in richer communities and in communities in which gender disparities are narrow, that is in communities in which girls' rates were higher to begin with. As a result, many of the poorest communities and the communities with the highest gender disparities still lack a girls' school. It thus appears unlikely that the expanding private sector can fully substitute for the public sector in addressing the educational needs of poor rural girls, they conclude. Similarly Behrman et al. (2008), say, "for the conditions facing Pakistan in the early 1990s, our estimates of "social rates" of return indicate that improving the quality of primary schooling was preferable of increasing access to middle schooling : the rate of return to improving the quality of primary schooling is substantially greater than the rate of return to increasing access to middle school, although it is somewhat lower than the rate of return to expanding in low-quality primary schools"(p.100). It turns out to be that productivity and equity concerns, both pointed towards expanding primary schools, even if they are of lower quality. In explaining the relatively large and persistent countrywide gender gap in schooling, literature has highlighted both demand- and supply-side constraints. 
These include poverty and parental concerns about the safety and mobility of their daughters on the demand side and under investment in girls' schooling on the supply side. Sawada (1999) finds that transitory income shocks (including deaths of household members, deaths of animals, and deviations from average rainfall) affect children significantly, with a greater impact for girls. Father and mother's education variables have consistently positive and significant coefficients in all levels of schooling except at the secondary school exit level (p.18). According to Behrman et al (2001), the focus on primary school is justified by the fact that universal primary schooling remains an elusive goal in Pakistan, where large numbers of children, particularly girls, still never enroll in school, despite the very high estimated rates of return to primary completion. This got affirmation by Behrman et al. (2008), in a recent study on estimating rates of returns from rural Pakistan. The results indicate that rates of return were much higher for investing in primary school quality than for investing in middle schools and, at the primary school level, somewhat higher for expanding low quality schools than for increasing quality in existing schools. Recent literature on the financial aspect of education, in particular the impact of education expenditure demonstrates that public sector expenditure does not equally benefit all groups of the population. Benefit of these expenditures can vary with respect to income, age, gender and/or region. In a study on public provision of education and government spending in Pakistan, Khan and Akram (2007) examine the inequalities in resource distribution and service provision in relation to the government education expenditure. They found rural areas of Pakistan are the more disadvantaged in the provision of the education facilities. They seem satisfied with the overall expenditure on the education sector to be 
progressive, both at the regional and the provincial levels. However, variation exists in the shares of different income groups' benefit from the provision of educational facilities created by public expenditure, they admit. Economic literature frequently corroborates the positive impact of education on economic performance, with higher returns to primary education than to secondary and/or tertiary education. Examining government expenditure on education in Pakistan, Sabir (2003) finds government subsidies directed toward primary education are pro-poor while Husain, et al. (2003), found no disparities in the allocation of funds to the education sector, however, the SPDC Report (2004) shows that the expenditure on primary and secondary education has a progressive benefit incidence. Teacher absence, which is most prevalent in government girls' schools because of their lower level of amenities and their reliance on non-local female teachers, reduces school access for girls. Ghuman and Lloyd (2007) in a study titled "Teacher absence as a factor in gender inequalities in access to primary schooling in rural Pakistan", examine the impact of teacher absenteeism as a further barrier to schooling for girls. According to their results absence rates among the all-female teachers in government girls' schools are substantially higher than among the all-male teachers in government boys' schools. Teacher absence, which is most prevalent in government girls' schools because of their lower level of amenities and their reliance on non-local female teachers, reduces school access for girls. At the time of the school visit, 25 percent of girls enrolled in rural Pakistan did not have a teacher present in the classroom.

Swada and Lokshin (2008) in a study titled "obstacles to school progression in rural Pakistan", investigate the sequential educational investment process of 
Pakistani households by integrating field observations, economic theory, and econometric analysis. According to their descriptive statistics and econometric analysis, one of the most striking aspects of rural Pakistani education revealed through the data collected are the high educational retention rate of girls. Hence, gender-specific progression rates are converging. Interestingly, while the father's education influence primary school entry, school progression after primary school is more influenced by the mother's education. This analysis demonstrates the important dynamic of the gender difference in education and the significance of shock variable, household wealth effects, and intrahousehold resource allocation of educational decision making. "Therefore, the cost-effectiveness of providing primary education can be improved by directing the allocation of funds to recurring expenditures for the construction of girls' school and the employment of more female teachers. These supply-side policy interventions have the potential to significantly reduce gender biases in human capital investment in Pakistan" (p.347).

In a recent study Bari and Sultana (2011) reiterate the supply side factors that girls' education is constrained by multiple impediments including too far away school, associated transportation cost with the far off school, insecure environment including poor infrastructure. In another recent study SDPI \& HDF (2011) tried to explore the reasons for lack of primary schooling in eight regions of the country. The study verified the earlier reasons that poor socioeconomic status, corporal punishment, teachers' qualification and behavior towards children, child labor, school distance, poor investment by parents and cultural constraints are the significant reasons. 


\subsubsection{Education cost and production function studies in Pakistan}

The literature on the effectiveness of public expenditure on education shows that there is a variable impact across regions, as well as within countries at a similar stage of development. The efficiency literature points to institutional factors that affect the level and quality of public services. There is inadequate work done in Pakistan on the efficiency and effectiveness of public expenditure in different provinces and in Pakistan as a whole. There is one instance of a study examining the differences in the cost of primary education by gender and by province, done in the early 90 s. However, after that there are a number of studies evaluating internal efficiency in the education sector in Pakistan, not a substantial number though. Their findings are also open to debate. On the efficiency aspect, recent research has introduced non-parametric techniques for social sector expenditure. However, such studies have still not been conducted in Pakistan at the state level. Following two studies are presented in the context of Pakistan.

\subsubsection{Gender differentials in the cost of primary education}

In this study Ismail (1996) examines the differences in the cost of primary education by gender and by province in Pakistan. He is of the view that different approaches can be adapted for deriving the cost function for the primary education of provincial governments. One approach is to view the provincial governments as of engaging in cost minimization behavior, given knowledge of the production function of enrolments with respect to inputs like schools, teachers, etc. In this view unit costs are the minimum average costs for achieving a target ratio. The other one is when provincial governments operate in an overall resource constrained framework, both for recurring and 
development expenditures, and that given the overall quantum of resources available in the recurring budget and the annual development program (ADP), funds are allocated to primary education on the basis of inter-sectoral priorities. According to this view then the actual choice of level of inputs need not correspond to the cost minimizing combination. As such some inputs are likely to be overused while others remain at sub-optimal levels. His theoretical framework subscribes to the latter view. Accordingly the number of teachers, T, and the number of schools, S, is given exogenously by the size of current recurring and development expenditure (past and present) allocation for primary schools. The total cost of primary education to provincial governments is given by the following equation where $U_{t}$ is the rental price of capital and includes a depreciation component for the opportunity cost of capital.

$$
C_{t}=W_{t} \overline{T_{t}} \mathrm{U}_{t} \bar{K}_{t}\left(S_{t}\right) \quad \ldots \quad \ldots \quad \ldots \quad \ldots
$$

Where

$\mathrm{C}_{t}=$ Unit Capital Cost per school

$\mathrm{W}_{\mathrm{t}}=$ Average wage rate of teacher

$T_{t}=$ Number of Teachers

$\mathrm{K}_{\mathrm{t}}=$ Capital Stock in year $\mathrm{t}$

The production function of primary education is represented as

$$
E_{t}=f_{t}\left(\bar{T}_{t}, \bar{S}_{t}, Z_{t}\right) \quad \ldots \quad \ldots \quad \ldots \quad \ldots
$$

Where $E_{t}=$ enrolments and $Z_{t}$ a vector of variables on the demand side determining the rate of utilization of educational facilities. The general specification of the average cost function (with respect to enrolment ) of primary education for the provincial government is given by Equation (3). For econometric estimation he scales the number of schools by the school going age population in the age group of five to nine years. The latter variable reflects potential demand. Similarly, the number of teachers is scaled by the number of 
schools, to yield the input mix. The resulting equation may be estimated as follows; (Ismail, 1996, p. 1):

$$
A \mathbf{C}_{t}=\boldsymbol{\beta}_{0+} \boldsymbol{\beta}_{1}\left(\frac{\bar{S} t}{A t}\right)+\boldsymbol{\beta}_{2}\left(\frac{\bar{S} t}{A t}\right)^{2}+\boldsymbol{\beta}_{3}\left(\frac{\bar{S} t}{A t}\right)^{3}+\beta_{4}\left(\frac{\bar{T} t}{\bar{A} t}\right)
$$

$+\boldsymbol{\beta}_{5}\left(\frac{\bar{T} t}{\bar{S} t}\right)^{2}+\boldsymbol{\beta}_{6}\left(\frac{\bar{T} t}{\bar{S} t}\right)^{3}+\boldsymbol{\beta}_{7} Y_{\mathrm{t}}+\boldsymbol{\beta}_{8} U_{\mathrm{t}}+\boldsymbol{\beta}_{9} \mathrm{l}_{\mathrm{t}}+\epsilon \quad \ldots \ldots$

Where

$\bar{A}_{t}=$ school going age population in year $t$

It $=$ real per capita income

$U_{t}=$ extent of urbanisation

$I_{t}=$ relative price index for wages to construction cost

$Y_{t}$ is included to capture the real wage effect (inclusive of labor into school construction) and a possible demand effect. $U_{t}$ is a demand related variable. It derives the cost implications of a divergence between inflation in wages and construction costs.

\begin{tabular}{|c|c|c|c|c|}
\hline Variable $e^{\star \star \star}$ & Girls Coefficient & $t$-ratio & Boys Coefficient & t-ratio \\
\hline$\overline{\left(\bar{S} / \hat{A}_{t}\right)}$ & -1231.099 & $-1.035 * *$ & -5430.697 & $-5.638^{*}$ \\
\hline$\left(\overline{\left.S / \hat{A}_{t}\right)^{2}}\right.$ & 2293.720 & $7.368^{*}$ & 700.412 & $8.163 *$ \\
\hline$\left(S / \hat{A}_{t}\right)^{2}$.DSP & -2191.407 & $-11.951 *$ & -221.149 & $-14.168 *$ \\
\hline$\left(\overline{T_{t}} / \overline{S T_{t}}\right)$ & 5742.642 & $5.079 *$ & 25887.877 & $7.853 *$ \\
\hline$\left(\overline { T _ { t } } \longdiv { S T _ { t } }\right)^{2}$ & -1407.147 & $-3.476^{*}$ & -7784.920 & $-5.063 *$ \\
\hline$\left(\overline{T_{t}} / \overline{S T_{t}}\right)^{3}$ & 89.609 & $2.634 *$ & 780.281 & $3.465^{*}$ \\
\hline$U_{t}$ & -21518.984 & $-1.932 * *$ & -8172.684 & $-3.826^{*}$ \\
\hline$Y_{t}$ & 0.603 & $1.571 * *$ & 0.369 & $2.036 * *$ \\
\hline $\mathrm{I}_{\mathrm{t}}$ & -6209.950 & $-4.317^{*}$ & -6049.055 & $-6.750 *$ \\
\hline DUMBAL & 5857.647 & $7.889 *$ & 4605.334 & $19.003 *$ \\
\hline$R^{2}$ & 0.956 & & 0.987 & \\
\hline $\mathrm{F}$ & 121.325 & & 429.087 & \\
\hline $\begin{array}{l}\text { Degree of } \\
\text { Freedom }\end{array}$ & & 49 & & 49 \\
\hline
\end{tabular}

Table 4-12: Result of Regressions

Source; Ismail, 1996,p.846.

DUMBAL $=1$ for Balochistan; zero otherwise. DPS $=1$ for Punjab and Sindh; zero otherwise. ${ }^{*}$ Significant at 1 percent level. ${ }^{* *}$ Significant at 5 percent level. ${ }^{* *}$ Significant at 10 percent level.

Equation (3) is estimated separately for genders on pooled time-series data for the four provinces for the period, 1976-77 to 1990-91. The results are given in table 4-12 above. The estimated equation demonstrates that there are some significant inter-regional differences in these coefficients, which Punjab and Sindh following into one group and N.W.F.P and Baluchistan into another group. He says that for all provinces the equation indicates that the average cost falls initially and then rises subsequently with an increase in $\left(\overline{S_{t}} / \hat{A}_{t}\right)$, the 
ratio of schools to school-going age population. Therefore, there exists for each province an optimal $(\bar{S} / \hat{A})$, which minimizes the unit cost. With regards to teachers per school, there observed a rise in cost initially and then a fall with the increase in $\bar{T} / \bar{S}$ up to a level beyond which the cost rise again (p.846). He also found that there is under provision generally of teachers ${ }^{10}$. It appears that their role in raising quality and demand for primary education has not been fully recognized. The result also indicates that the inputs of teachers per school are above cost minimizing levels only in the context of girls in the Punjab. He concludes that cost effectiveness of provision of primary education can significantly be enhanced if the allocation of funds is shifted towards recurring expenditures for employment of more teachers away from development allocations for construction of new schools in the context of boys' education at the primary level (p.848).

\subsubsection{Educational production function for rural Pakistan}

Khan and Kiefer (2007) used a production function approach to identify the impact of student, parent, teacher, and school policy variables on student performance as measured by test scores. The statistical analysis is conducted in a comparative institutional context that includes government, private and non-governmental organization schools. Their fieldwork involved 10 questionnaires, prepared to get information about students, teachers, households, and communities. Two customized tests have also been administered for assessing student skill in mathematics and comprehension. Student test scores are highest at NGO schools and lowest at government schools. Appendix 4-E \& 4-F presents selected results study for students and

${ }^{10}$ Note: This is not the case now as at present STR is 1:31 
their teachers (p.331). They collected subjective field evaluations of each school from a team of trained evaluators; table 4-13 summarizes their findings indicating that only seven out of 43 government schools have been viewed as successful confirming the conventional wisdom that the state of government basic education in Pakistan is abysmal and urgently in need of reform. NGO Schools are judged to be most successful, followed by private schools. These evaluations are one measure of institutional effectiveness (p.333).

Following Glewwe and Kremer (2005), they formalized academic achievement A, as measured by mathematics and comprehension tests scores, according to the structural relation: (Glewwe and Kremer, (2005,p.334).

$A=a(Q, C, I)$,

Where $Q$ is a vector of school quality characteristics (e.g., school type or teacher experience), C, a vector of child and in 43 villages, 1998

household characteristics

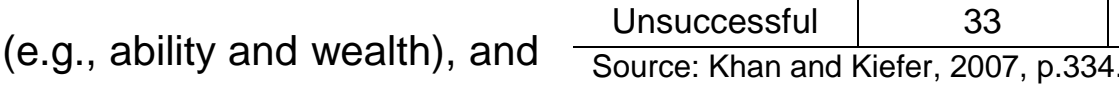

Table 4-13: Comparative tally of the field evaluations

\begin{tabular}{c|c|c|c} 
& Government & Private & NGO \\
\hline Successful & 7 & 23 & 33 \\
\hline Mixed & 3 & 3 & 1 \\
\hline Unsuccessful & 33 & 17 & 9 \\
\hline \multicolumn{2}{l}{ Source: Khan and Kiefer, 2007, p.334. }
\end{tabular}

I, a vector of school inputs under the control of parents (e.g., daily attendance).Educational input prices $P$ (e.g., school fees or distance from school) is another important set of variables. Under the assumption that school quality and parent-controlled inputs are exogenous, they estimate a simple linear version of the structural production function equation (4) in table 4-14 for 2051 observations. The dependent variable is the vector of student comprehension and mathematics scores.

School type is the only school characteristic and the student's absentee rate is the only input under the control of parents. The only student characteristics 
are gender and their province of residence, with Punjab as the reference; clearly, provincial variables can have an ethnic rather than a student interpretation. Consistent with the raw scores reported at appendix 4-E, the results suggest that government school students learn the least by a significant margin when compared with private and NGO students.

There are also significant regional effects; on average, the best results for the Table 4-14: production functions estimates

\begin{tabular}{l|c|c|c|c}
\hline \multicolumn{2}{l}{ Student comprehension score (out of 1000) } & \multicolumn{2}{l}{$\begin{array}{l}\text { Student mathematics score } \\
\text { (out of 1000) }\end{array}$} \\
\hline & Coefficient & t Statistic & Coefficient & t Statistic \\
\hline Government school & 43.75 & 34.69 & 39.76 & 36.25 \\
Private school & 58.18 & 43.16 & 45.49 & 38.81 \\
NGO school & 66.67 & 53.77 & 47.19 & 43.77 \\
Male & -1.01 & -0.95 & 7.18 & 7.72 \\
Sindh Province & -3.20 & -2.65 & -4.34 & -4.15 \\
Balochistan Province & -5.67 & -2.36 & -11.45 & -5.49 \\
North West Frontier & 12.26 & 7.93 & 8.90 & 6.62 \\
\% of days absent & -0.07 & -2.61 & -0.09 & -4.09 \\
R $^{2}$ & 0.85 & & 0.84 & \\
\hline
\end{tabular}

Source: Khan and Kiefer ,2007, p.335

comprehension test are reported in the Punjab, and for the mathematics test in the North West Frontier province. Furthermore, they conclude that male students do better in mathematics, and that student attendance is beneficial. NGO schools perform dramatically better than government or private schools in rural Pakistan.

\subsubsection{Cost function of school education in Punjab}

Social policy and development center (SPDC) conducted an analysis of certain districts of Punjab in the year 2006 in the context of budget expenditure and its impact on educational outcomes. According to SPDC (2006-07) the relatively rapid growth in expenditure by local governments in recent years (after decentralization implemented and bulk of activities transferred to district governments) in line with macroeconomic buoyancy raises the issue as to 
whether the enhanced outlays for delivery of services are characterized by higher or lower levels of cost-efficiency. This has been examined in the context of the principal local service, primary and secondary education. The analysis looked at the increased education expenditure been accompanied by a corresponding growth in student enrolments or not. They looked at two key variables. The first variable is the level of cost effectiveness achieved in the delivery of services (in this particular context 'delivery of services' refers to the growth in student enrolment). The second variable comprises the relative increase in the technical efficiency of the district governments of the Punjab in providing primary and secondary education. Finally, it looked to see if there is any trade-off between efficiency and equity, if, at the margin, more resources are allocated for education to relatively backward districts. The current education expenditure by a district government was taken as a function of enrolment (primary and secondary, respectively) as well as the characteristics of a district, like the extent of urbanization and geographical area (see appendix 4-G). These factors determine the predicted level of expenditure. A district is considered to be more efficient if its actual expenditure is less than the predicted level of expenditure (on the basis of regression analysis). Alternatively, if actual expenditure exceeds predicted expenditure, then the district is considered less efficient (p.87).

In order to calculate the predicted value they estimated the following cost function.

EDUPun $=f$ (PRIMPun, MHIGHPun, AREAPun, URBPun) $:($ SPDC,200607,p.133).

Where

EDUPun = Punjab Education Recurring Expenditures PRIMPunD= Punjab Primary School Enrolment 
MHIGHPunD = Punjab Middle + High School Enrolment

AREAPun = Punjab Area per Square Kilometre

URBSIND = Punjab Urbanization

Dependent Variable EDUPUN, Method: Least Square

Table 4-15: Level of Efficiency in Education Expenditure Punjab

\begin{tabular}{|c|c|c|c|c|c|}
\hline & & $\begin{array}{l}\text { District Ranking } \\
\text { in Development }\end{array}$ & $\begin{array}{c}\text { Level of } \\
\text { Efficiency (actual } \\
\text { to Predicted } \\
\text { Expenditure) }\end{array}$ & $\begin{array}{c}\text { Enrolment per } \\
\text { School } \\
\text { (primary) }\end{array}$ & $\begin{array}{c}\text { Enrolment per } \\
\text { Teacher } \\
\text { (primary) }\end{array}$ \\
\hline \multicolumn{6}{|c|}{ S.\# $\quad$ Five Most Efficient Districts } \\
\hline 1 & Mandi Bahuddin & 1 & 0.95 & 117 & 39 \\
\hline 2 & Gujrat & 2 & 0.99 & 98 & 32 \\
\hline 3 & Layyah & 3 & 0.99 & 94 & 34 \\
\hline 4 & Pakpatan Sharif & 4 & 1.00 & 120 & 39 \\
\hline 5 & Attock & 5 & 1.03 & 98 & 34 \\
\hline S.\# & \multicolumn{5}{|c|}{ Five Least Efficient Districts } \\
\hline 1 & Rajanpur & 30 & 1.46 & 87 & 31 \\
\hline 2 & Bahwalnagar & 31 & 1.47 & 72 & 29 \\
\hline 3 & Rawalpindi & 32 & 1.55 & 80 & 27 \\
\hline 4 & Hafizabad & 33 & 1.89 & 83 & 32 \\
\hline 5 & Lahore & 34 & 2.20 & 111 & 26 \\
\hline
\end{tabular}

The results of the spatial variation in efficiency of education expenditure are perhaps unexpected in character. Table 4-15 indicates the top five and the bottom five districts of Punjab in terms of the level of efficiency, measured as the ratio between actual and predicted expenditure. It appears that the more efficient districts are relatively underdeveloped, including Layyah, one of the most backward districts of Punjab. Contrary to this, the least efficient districts include Rawalpindi and Lahore, Which are considered among the most developed districts of Punjab. This implies an important conclusion that there is likely to be no trade-off between efficiency and equity if, at the margin, more resources are allocated for education to relatively backward districts (p.88).

\subsection{CONCLUSION}

The crux of this literature review is that there is a lack of consensus about the results of standard studies using the 'education production function' conceptual 
framework, whether at the macro or at the micro level. Numerous studies have attempted to identify the importance of different school characteristics like student / teacher ratio, teacher education, teacher salary, expenditure per pupil, facilities - in the production of cognitive achievement. But, the success story of the relative influence of the various dimensions of school quality is quite limited, as is evident from the survey of 96 studies for developing countries (Harbison and Hanushek, 1992) none of the six common input measures listed in that study have statistically significant positive effects for more than two-thirds of the studies. The reasons why such techniques at the end have produced only limited evidence as to the way schools around the world function probably stems from the deficiencies of the conceptual framework it has used. Although this statistical technique has been in use for a long time, skepticism about its value has also persisted. In the wake of these powerful arguments of critics Khan and Kiefer (2007) suggest policy-makers nonetheless need advice on effective ways of allocating resources and say that the abandonment of the production function method may be too extreme a response to its limitations. Following Fortune (1993) or Monk (1992), they state, "we accept the basic value of the method, acknowledge its flaws, and attempt corrections with better data and most appropriate statistical methods" (p. 328).

The literature on the effectiveness of public expenditure on education shows that there is variable impact across regions. The efficiency literature points to institutional factors that affect the level and quality of public services. Although the finding of various studies differs depending on the peculiar country specific situation but rural-urban divide, gender bias, distance to school and variance in cognitive achievement appear to be the common elements in all the studies. 


\section{Abstract}

The studies on efficiency in education differ widely, with respect to both content and methodology. Among the existing methods for measuring productivity and efficiency, there are a number of techniques employed in empirical studies, including production frontier analysis. To develop the production frontier, both parametric (econometric) and nonparametric methods can be applied. The most commonly used approaches to parametric (stochastic frontier) analysis of efficiency in panel data, are the random effects and the fixed effects models and later is applied in this study. Among other analyses, the study also presents a ranking based comparison of the productive efficiency of the education systems of 23 districts in the province of Sindh. The rankings were produced using a form of the 'fixed effects,' stochastic frontier methodology. The data analyzed in this econometric study were a six year (2005-2010) panel.

The purpose of this chapter is to develop the general stochastic frontier production function, which will be used in the estimation of technical efficiency for school education in Sindh. The chapter then lays down the methodological assumptions, describes sources of data and variables used in this study. This section presents the estimation technique of the fixed effects model and framework of the stochastic frontier model that is estimated in an effort to determine the preferred functional form of production functions.

\subsection{ESTIMATION METHOD}

The data we use to estimate the stochastic frontier production function is a panel data with 6 years of data for each of the 23 education districts. The stochastic frontier production has generally been estimated by Maximum Likelihood (ML) estimates. This will provide the correct results provided the likelihood function is correctly specified, and more important, there are no measurement errors in the variables. When there are errors in the variables and these are not taken into account in estimation, the coefficient estimates will be biased, hence the frontier will also be measured with error. It is therefore 
important to use estimation methods that are robust to the existence of measurement errors if one suspects the existence of such errors. There are many capital inputs, such as libraries and laboratory equipment that we are not able to account for. Finally, the output variables are measured as gross enrolment while the inputs are aggregates for all school, teacher and student specific variables. A major problem with the production functions is the possibility that the quantity of input used by districts are themselves endogenous, especially in countries where local districts determine school inputs through local property taxes. Failure to account for the endogeneity of these inputs will result in inconsistent or, at best, biased coefficient estimates. The usual way of solving this problem is to estimate a simultaneous system of equations that include the output equation and a set of input demand equations in order to account for the endogeniety of inputs. In the case of Sindh, there are reasons to suspect that the problem of endogenously determined inputs may not arise. First, the inputs we use-teachers and physical capital-are generally provided by the provincial government through the department of education. While there exist student teachers association which may provide additional resources, these are generally very small relative to overall resources of the school and they never involve teachers or the construction of physical facilities. Second, for political reasons, the provincial government cannot provide school resources that vary systematically across districts or regions, especially when measured on per student basis. This implies that we could, potentially, treat the school inputs are exogenously determined. It is possible that some school districts may get relatively large resources because the school's administration is more successful at lobbying the provincial 
administration for resources or because government decision makers come from this particular constituency.

To capture the part of heterogeneity that is unobserved, we exploit the panel data structure of the data by including school type, year, and district-fixed effects in the estimation. We observe 3 different school levels ;( primary, middle and secondary). District fixed effects are included, as there is a large dispersion in school enrolments across districts. School resources are summarized in terms of four relatively homogenous categories:

management personnel; (2) teaching personnel; (3) supporting personnel; and (4) material supplies. 'Capital', in the sense of school building infrastructure is not accounted for owing to data constraints. Most of the costs are spent on teaching personnel, followed by material, management personnel, and, lastly, supporting personnel. Besides teaching, a teacher has some management and administrative responsibilities. The different tasks within one function are not officially reported. We assume that there is a homogenous distribution of these different tasks within one function, between teachers both within one school and across district.

\subsubsection{Log-linear regression model}

The choice between a linear regression model or a log-linear regression model is a perennial question in empirical analysis (Gujarati, 2003, p. 282). An equation that specifies a linear relationship among the variables gives an approximate description of some economic behavior. An alternative approach is to consider a linear relationship between log-transformed variables; this is a log-log model where the dependent variables as well as all explanatory variables are transformed to logarithms. Many econometric models make use 
of variables measured in logarithms: sometimes the dependent variable, sometimes both dependent and independent variables. Wooldridge (2009) says that using the "double log" transformation (of both $\mathrm{Y}$ and $\mathrm{X}$ ) we can turn a multiplicative relationship, such as a Cobb-Douglas production function, into a linear relation in the (natural) logs of output and the factors of production. Different functional forms give parameter estimates that have different economic interpretation. The parameters of the linear model have an interpretation as marginal effects. The elasticities will vary depending on the data. In contrast the parameters of the log-log model have an interpretation as elasticities. So the log-log model assumes a constant elasticity over all values of the data $\operatorname{set}^{11}$.

Regression diagnostics provides to verify whether data meet the assumptions of linear regression. Here, we will focus on the issue of normality. Some researchers believe that linear regression requires that the outcome (dependent) and predictor variables be normally distributed. We just looked at

Figure 5-1: Histogram and Kernel density of primary enrolment distribution

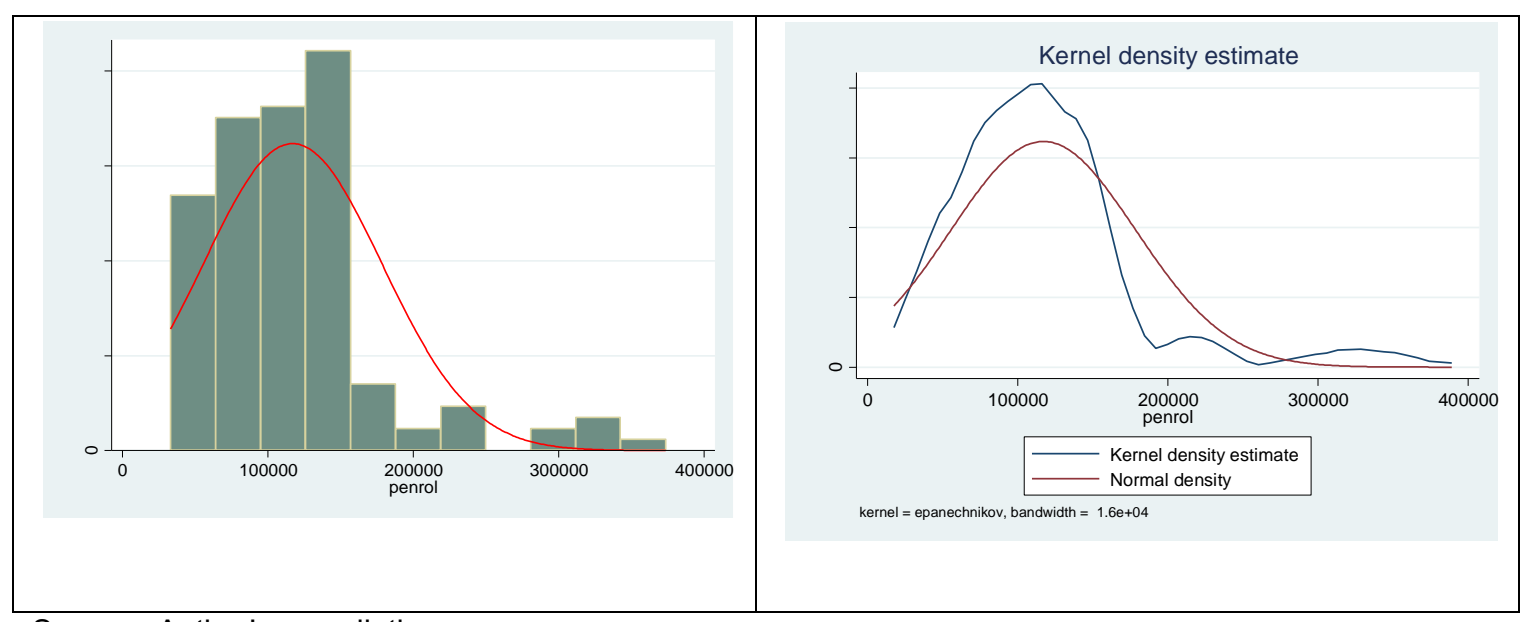

Source : Author's compilation

the distribution of outcome variable, primary enrolment by making a histogram

\footnotetext{
${ }^{11}$ http://shazam.econ.ubc.ca/intro/olslog.htm (accessed August 24, 2013).
} 
of the variable penrol, and also by the kernel density plot, which approximates the probability density of the variable. Both histogram and the kernel density plot indicate that the variable penrol does not look normal (fig 5-1). Hence, penrol transformed to the log form. A look at fig- 5-2 indicates that the

Figure 5-2: Histogram and Kernel density of primary enrolment (log) distribution

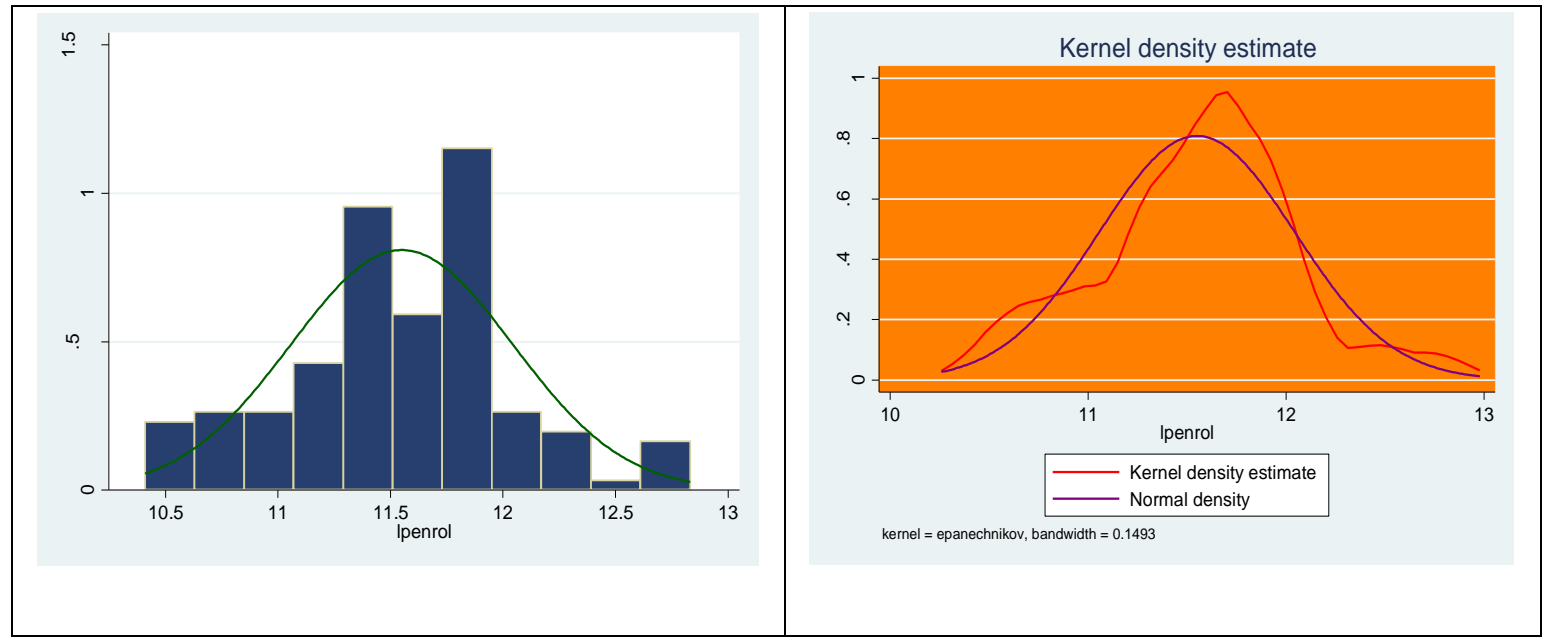

Source : Author's compilation

log transformation would help to make penrol more normally distributed. It can be seen that penrol looks quite normal. Similar was the case for middle and secondary enrolment. Also, in case of middle and secondary education the variables were accordingly transformed into logarithmic form. According to Wooldridge (2009) variables such as population, total number of employees and number of school often appear in logarithmic form; these have a common feature of being large integer values. In a heterogeneous analysis of this nature, heteroscedasticity is one of the major problems and log-log model takes care of this by transforming both dependent and independent variables in logarithms to scale down the variation.

For this study, the econometric approach uses panel data on education along with some macro data; with the model specification based on the district situation and the literature. The approach shows how public spending and other 
interventions have influenced education enrolment through the years. Education is a multifaceted phenomenon. As such, a wide variety of methods are used to measure different aspects of education. These include, among others, ratios, education attainment indicators, quality of education indicators and measures of absolute and relative dispersion of education. I find two important aspects in this scenario. Set in above background, I use student, school and teacher characteristics data along with geographical area and education expenditure to measure the efficiency of public sector education programs in terms of the impact of education expenditure on the actual number of students in a district school. Data are analyzed for all (twenty three) districts for six years from 2005-06 to $2010-11$. The sample period is constrained by the availability of consistent data series for all the variables considered in this model.

\subsection{THEORITICAL FRAME WORK}

The fixed effects model explores the relationship between predictor and outcome variables within an entity (districts, students, schools, etc.). Each entity has its own individual characteristics that may or may not influence the predictor variables. When using fixed effects we assume that something within the individual may impact or bias the predictor or outcome variables and we need to control for this. This is the rationale behind the assumption of the correlation between entity's error term and predictor variables. Fixed effects model removes the effect of those time-invariant characteristics from the predictor variables so we can assess the predictors' net effect. Another important assumption of the FE model is that those time-invariant characteristics are unique to the individual and should not be correlated with 
other individual characteristics. Each entity is different therefore the entity's error term and the constant (which captures individual characteristics) should not be correlated with the others. The fixed-effects model controls for all timeinvariant differences between the individuals, so the estimated coefficients of the fixed-effects models cannot be biased because of omitted time-invariant characteristics...[like culture, religion, gender, race, etc]. A time-invariant characteristic cannot cause such a change, because it is constant for each person. The basic fixed-effects model focuses on the mean response and assumes: no serial correlation (correlation over time) and no cross-sectional (contemporaneous) correlation (correlation between subjects). Hence, no special relationship between subjects and time is assumed. Typically, the number of subjects, $n$, substantially exceeds the maximal number of time periods, T. Typically; the heterogeneity among subjects explains a greater proportion of variability than the heterogeneity among time periods.

Thus, we begin with the "basic" model $y_{i t}=a_{i}+\mathbf{x}_{i t}{ }^{\prime} \mathbf{b}+e_{i t}$.

This model allows explicit parameterization of the subject-specific heterogeneity. The common effects of the explanatory variables are dictated by the sign and magnitude of the betas (b's). These are the parameters of interest. The intercept parameters vary by subject and account for different behavior of subjects. The intercept parameters control for the heterogeneity of subjects. Two different models were useful to construct the model used in this paper. The former by Gupta et al. (2002) examines the impact of public expenditure across countries, while the latter by Kaur and Misra (2003) analyzes the impact of public expenditure across states in India. Gupta et al. use the following model to evaluate the effectiveness of government spending 
on education and health care in a cross-sectional study across 50 developing and transition countries. Kaur and Misra use a similar model to evaluate the impact of public expenditure across states in India.

$\mathrm{Y}_{\mathrm{i}}=f\left(\mathrm{X}_{1} \mathrm{i}, \mathrm{X}_{2} \mathrm{i}, \mathrm{Z}_{\mathrm{i}}\right)$ Gupta et al. (2002)

where $Y_{i}$ is a social indicator reflecting education attainment or health status for a country $i, X_{1 i}$ the aggregate public spending on education or health care as a share of GDP; $\mathrm{X}_{2 \mathrm{i}}$ is allocations to different programs within the sector (i.e., primary education and primary health care) as a share of total sectoral spending; and $Z_{i}$ is a vector of socioeconomic variables. Four measures of education attainment are used: gross enrolment in primary and upper-primary education, gross enrolment in secondary education, persistence through Grade IV, and primary school drop-out rates. The gross enrolment rate (GER) represents the number of students enrolled in a level of education as a percentage of total number of students of proper age for that specific level. The GER measure includes under-age and over-age children, as well as grade repeaters.

$Y_{i t}=f\left(E_{i t}, G S D P_{i t}, X_{i t}\right)$ Kaur and Misra (2003)

where $\mathrm{Y}$ is a social indicator, $\mathrm{E}$ denotes social sector spending, GSDP is defined in per capita terms, $\mathrm{X}$ is the vector of other control variables. $\mathrm{i}$ denotes states in the sample, and t denotes time period. The model is estimated for two measures of education attainment: (a) gross enrolment in primary and (b) gross enrolment in secondary education.

\subsection{EDUCATION ENROLMENT EQUATION}

As stated above, the approach here is based on panel data regressions for primary, middle and secondary education enrolments. From the analysis and 
the discussion above, the following equation is used to assess the relationship between educational expenditure and the main outcome being the enrolment in the estimations. Therefore, this model allows for the identification of the channels through which district wise government expenditure on education affect enrolment over time in the province of Sindh.

Drawing upon some previous studies including Gupta et al. (2002), Kaur and Misra (2003) and Baldacci et al. (2008), all the main variables are logged and fixed effects are utilized. Here, we have taken three equations separately to illustrate three models for primary education, middle education and secondary education. These equations of model (M1, M2 and M3) examine the direct impact of education spending on the enrolment after controlling for other variables like number of schools, class rooms, teachers and the percent proportion of urban population, along with the density of population (primary and secondary education level) and literacy rate. The following models (M-1,M2 and $M-3$ ) estimates the impact of public expenditure on primary, middle and secondary education.

MODEL 1: Education enrolment equation: Primary education: ( M1)

$\operatorname{Ln}($ penrol $)=\alpha+\beta_{1}{ }^{*} \ln ($ pexp $)+\beta_{2}{ }^{*} \ln ($ pschool $)+\beta_{3}{ }^{*} \ln ($ pclass $) \beta_{4}{ }^{*} \ln ($ pteacher $)+$ $\beta_{5}{ }^{*} \ln ($ pden $)+\beta_{6}{ }^{*}$ pprate $+\beta_{7}{ }^{*}$ litrate $+\beta_{8}{ }^{*}$ urban $+u \ldots$

Where penrol is the Primary enrolment ( Class I to V), pexp is the education expenditure at the primary level, pschool the number of schools at the primary level, pclass is the number of classrooms at the primary level, pteacher is the number of teachers at the primary level, pprate is the primary participation rate, litrate is the literacy rate, pden is the population density for primary level education, urban is the percent proportion of urban population, $u$ is the Error 
term, $\alpha$ is district specific effect and In is the natural Log.

MODEL 2: Education enrolment equation: Middle education: (M2)

$\operatorname{Ln}($ menrol $)=\alpha+\beta_{1}{ }^{*} \ln (\operatorname{mexp})+\beta_{2}{ }^{*} \ln ($ mschool $)+\beta_{3}{ }^{*} \ln ($ mclass $)+\beta_{4}{ }^{*}$

$\ln ($ mteacher $)+\beta_{5}{ }^{*}$ litrate $+\beta_{6}{ }^{*} u r b a n+u \quad \ldots$

Where menrol is the middle enrolment (Class VI to VIII), mexp is the education expenditure at the middle level, mschool the number of schools at the middle level, mclass is the number of classrooms at the middle level, mteacher is the number of teachers at the middle level, litrate is the literacy rate, urban is the percent proportion of urban population in a district, while $u$ is the Error term , $\alpha$ is district specific effect and In is the natural Log.

MODEL 3: Education enrolment equation: Secondary education: (M3)

$\operatorname{Ln}($ senrol $)=\alpha+\beta_{1}{ }^{*} \ln (\operatorname{sexp})+\beta_{2^{*}} \ln ($ sschool $)+\beta_{3}{ }^{*} \ln ($ sclass $)+\beta_{4}{ }^{*} \ln ($ steacher $)+\beta_{5}{ }^{*} \ln$ (sden) $+\beta_{6}{ }^{*}$ litrate $+\beta_{7^{*}}($ urban $)+u$

Where senrol is the secondary enrolment ( Class XI to X), sexp is the education expenditure at the secondary level, sschool the number of schools at the secondary level, sclass is the number of classrooms at the secondary level, steacher is the number of teachers at the secondary level, , sden is the population density for secondary level education, litrate is the literacy rate of the district, urban is the percent proportion of urban population in a district, while $u$ is the Error term , $\alpha$ is district specific effect and In is the natural Log. In the above education regressions, primary, middle and secondary enrolment are used as the dependent variables. The explanatory variables include 
primary, middle and secondary education expenditure, number of schools, number of classrooms, number of teachers, literacy rate, participation rate, density of population and the percent of urban proportion of population living in districts. A school in a district is considered technically efficient if it achieves the highest possible output (in this case enrolment) from a given amount of resources used or, conversely, uses minimum resources to produce a given level of output.

\subsection{ESTIMATION OF THE MODEL}

Availability of a richer set of information in panel data allows us to consider a more realistic characterization of the inefficiencies. Pitt and Lee (1981) were first to propose the ML estimation of Normal-Half Normal SF model and Kumbhakar (1990) was the first to propose the ML estimation of a time-varying SF Model. Greene (2005a) approached this issue through a time-varying SF Normal-Half Normal model with unit-specific intercepts. As pointed out by Greene (2005b), neither formulation is a priori completely satisfactory nor should the choice be driven by the features of the data at hand. According to Atella et al. (1998), as far as panel data analysis is concerned, the social Stata xtfrontier command allows the estimation of a Normal-Truncated Normal model with time-invariant inefficiency (Battese and Coelli 1988) and a time-varying version, named as "time decay" model, proposed by Battese and Coelli (1992). The literature on panel data estimation of frontier models also addresses the fundamental question of how and whether inefficiency varies over time, and how econometric models can be made to accommodate the theoretical propositions. Panel data estimator programmed in STATA 11 using Xtfrontier command fits stochastic production or cost frontier models for panel data. 


\subsection{THE SELECTED MODEL}

Given the nature of the data, I expect individual district-specific heterogeneity to exist within the model. Districts are likely to vary systematically in terms of infrastructure, production efficiencies, and institutional factors and so on. As mentioned earlier, in order to capture the cross-sectional parameter of heterogeneity, two types of models are generally proposed in the literature. The random effect model treats the district-specific variables as time-invariant random variables, which are independent of the explanatory variables of the model. The fixed effects model (the within, or least squares dummy variable estimator), on the other hand, allows individual effects to be correlated with the regressors. The choice of the model can be based solely upon a priori assumption. Vignoles et al. (2010), suggest that different approaches are appropriate in different contexts, and suggest that the fixed effects approach will be preferable in scenarios where the primary interest is in policy relevant inference. Perhaps the most frequent suggestion is to rely on the Hausman test, which is designed to assess whether there is a significant difference between the estimates of the two models (p. 29).

In this study estimations have been carried out using fixed effects (within) regression procedure as given in the STATA statistical package. I conducted the Hausman test in STATA to determine whether fixed effects or random effects should be used to estimate the model, for primary, middle and secondary level education. As the $\mathrm{x}^{2}$ test statistic was 147 for primary, 39 for middle and 15 for secondary education level models and the Prob>chi2 were less than 0.05 (i.e. Significant) (for primary, middle and secondary education) the calculated test statistic rejected the null hypothesis at the 5 percent 
significance level, implying that random effects method would yield inconsistent estimates. This justified the use of the fixed effects model and seems more realistic as it cannot be assumed that all unobserved fixed effects are uncorrelated with the regressors in the data set.

The second issue in the estimation was of heteroscedasticity. Heteroscedasticity arises as a consequence of differences in the conditional variance of the dependent variable for given distinct levels of an independent variable or variables. In aggregate, as well as in micro data, the possibility exists that these conditional distributions do not share the same variance due to heterogeneity in the unit of analysis. After fitting the model, two test statistics: BP test and White's general test. Breusch-Pagan / Cook-Weisberg test were calculatet the null hypothesis that the error variances are all equal versus the alternative that the error variances are a multiplicative function of one or more variables. White's general test is a special case of the Breusch-Pagan test, where the assumption of normally distributed errors has been relaxed. The Breusch-Pagan test indicates the presence of heteroscedasticity (estimated chi-squared value $>$ critical value). A large chi-square would indicate that heteroscedasticity was present. In our model, the chi-square value was large, indicating heteroscedasticity was a problem ( Appendix 7-A). Taking logs of dependent and explanatory variables have reduced the problem. Castilla (2008) argues that there is a lack of evidence as to whether standard tests for heteroscedasticity can be applied to panel data models; the White and Breusch-Pagan tests are widely used to detect heteroscedasticity in crosssectional data, though their feasibility and performance of fixed-effects models has been assumed but not shown. 


\subsection{ESTIMATING EFFICIENCY}

For the purposes of clarity, this efficiency has been analyzed at three levels:

First, internal efficiency of the existing portfolio with baseline year 2005-06 has been calculated in terms of wastage; Second, management comparison of public and private sector schools were carried out. Finally in chapter seven, variations in the relative technical efficiency in providing school education have been analyzed for which econometric techniques have been used.

In Sindh, student-teacher ratios show considerable inefficiency because low student - teacher ratios imply that more teachers are used to service relatively few students. To add to this dimension of inefficiency, Sindh is witnessing another trend of increasing number of schools across all the districts leading to a low student to school ratio, further skewing the system toward a compounded case of wastage. Despite decades of research on public - private management debate, there still exists uncertainty regarding the extent to which public and private management differ, and which factors play a role in such differences. A survey was carried out to compare the public and the private management pattern. Results suggest that a mixed phenomenon in both public and private sector schools was found regarding management practices. In the literature review, we find conflicting results in assessment of the production function and cost efficiency. As a consequence, conflicting advices have been given to policy makers by economists. Hence, following aims and objective of this research paper will try to answer some of the issues which have plagued education in Sindh.

* To estimate the technical efficiency of the districts of Sindh in providing primary, middle and secondary education. 
* To analyze the factors those explain variations in the relative technical efficiency or inefficiency in providing school education at the provincial level in Sindh.

* To examine the structural issues and institutional weaknesses which hamper improvements in education in Sindh.

\subsection{DATA COLLECTION AND CONSTRAINTS}

After reviewing the literature I realized that only two methods of data collection were appropriate for my study. These were primary data source and a very small portion of online questionnaires focusing on 23 Executive District Officers Education (EDOs) in the province of Sindh. A panel dataset for 23 districts of Sindh from 2005 to 2010 was compiled for this research. All data series are annual data.

Data for the study was collected from the Sindh Education Management Information System (SEMIS). An annual school census (ASC) exists in Pakistan. Such a census constitutes an important mechanism for the collection of information on schools so that there is a sound basis for arguing for better budgets /planning and changing policies. Given the federal structure of the country, the ASC has primarily been implemented by provinces, with the federal level playing a coordinating and standards setting role. Following the devolution of powers to districts after 2001, EMIS cells were established in districts partly in order to perform the data entry functions of the ASC, and partly to allow for the utilization of ASC data at the district level to support the new district functions. Sindh Education Management Information System (SEMIS) served as the basis for understanding expenditure effectiveness district wise. The other data source included PSLM Survey (2004-11), Federal Bureau of Statistics (renamed as Pakistan Bureau of Statistics in the year 
2011), Government of Pakistan, giving details on household income and the individual expenditures on education. All the relevant data on education expenditure is taken from the Auditor General, Sindh and finance department, government of Sindh. Total developmental expenditures in different sectors of education were taken from the annual budget and annual development program, planning and development department and finance department, government of Sindh.

Our study is limited to public schools rather than both the private and public schools. Three reasons account for excluding private schools. First, the public sector provides an overwhelming share of education in Pakistan. Hence limiting the study to the public sector does not mean that the study is less representative than it would be if we included the private schools. Second and the most practical reason was that, we only have education data on the public sector but not for the private sector. Third, while all public sector schools may have the objective of providing instructions in academic subjects, and therefore teaching towards universalizing education and meeting the goals of education for all (EFA), private schools may have additional objectives, such as religious education, that public schools may not be concerned with. Finally, because private schools are free from the directions of federal and provincial education bureaucracies, they may combine school inputs in ways that are different from those of the public sector in order to achieve their objectives. Public sector schools do not have that luxury. This means that the production technology in public and private schools may be different. Concentrating on public schools allows us to assume a given underlying production technology for all schools. Although the Net Enrolment Rate (NER) is a better estimator of enrolment rate 
than the Gross Enrolment Rate (GER), it is still not a completely accurate measure of the number of children who actually attend primary school. Large enrolment rates measured at the start of the school year can mask nonattendance and / or dropout later in the school year. Thus, regression results for NER should be interpreted with some caution. Next, a governance indicator has not been included in this analysis since a reliable measure of the quality of governance across districts is difficult to obtain. Lastly, this research would also have benefited by adding a health variable to explain differences in outcomes across richer and poorer districts. A healthier population is more likely to invest in education and some previous cross-country studies (Gupta et al., 2002; Baldacci et al., 2008) use under-5 child mortality rates as a proxy for the stock of health capital in a country. However, in Sindh, the availability of data regarding the health and nutritional status of school students at the district level is extremely limited, and hence, despite considerable efforts, the health variable could not be used as an additional explanatory variable.

Serious data constraints have been faced in the course of this study. As explained earlier, despite the institution of annual school census, significant system improvements and third party verifications the system still suffers from issues of inconsistency. Also, the data sets relating to budgets and expenditures are extremely hard to obtain. Considerable time and effort have been spent on gathering data from different appropriation accounts. The effect of various school and teacher characteristics relating to individual districts (which are very difficult to compare) have somewhat rendered the use of most of the financial variables considerably weak. When combined with the differences in the concept of efficiency itself, the results so obtained need to be 
used with caution. Data is taken mainly in whole figures (original unit of measures) for each variable. However, for the estimation, all the main variables have been transformed into their natural log transformations, due to which these variables are interpreted in proportional terms.

\subsection{CONCLUSION}

This chapter presented the methodology of the research. In this chapter the research design, estimation method, tool of research, selected model and its estimation, education equation, procedure for data collection and constraints were discussed. The studies on efficiency in education show that besides differences in contents, there are methodological differences between efficiency studies. These methodological differences between efficiency studies do not necessarily influence the quality of the studies, but do influence outcomes and interpretation of results.

This study determines educational efficiency of 23 districts of Sindh using Stochastic Frontier analysis and regression analysis. Variables commonly researched in the scholarly literature as well as factors unique to Sindh education were considered in the methods and analyses. Comparison groups of peer districts were observed using the theoretical framework to determine relative efficiency and effectiveness based on student enrolment as outcomes. Concurrently, sources influencing the relative efficiency of districts surfaced through the data analyses and the variables determined to effect district efficiency were discovered at the provincial level. Preliminary analyses are presented in chapter 6 and econometric results are presented in chapter 7 . Discussion, conclusion and recommendations are presented in Chapter 8 . The current study has provided a replicable model for measuring district efficiency. 


\title{
CHAPTER 6 : PRELIMINARY ANALYSIS
}

\begin{abstract}
In Sindh over $90 \%$ of recurrent expenditure goes to teachers' salaries, resources spent for operations and maintenance are minimal. Two inter related issues discussed in this chapter ; first is the internal efficiency of education delivery and second comparing this management skill between public and private sector schooling system. Two dimensions of internal efficiency has been examined; unnecessary inputs and undesirable output for the year 200506. Student - teacher ratios show great inefficiency as there are more teachers for fewer students. These resources could be saved by using fewer teachers and employ the saved resources to buy inputs, such as textbooks and other learning resources that improve achievement. To add to this dimension of inefficiency, Sindh is witnessing another trend of increasing numbers of schools across all the districts leading to a low school to student ratio, further skewing the system toward a compounded case of wastage. Despite decades of research on public - private management debate, there still exists uncertainty regarding the extent to which public and private management differ, and which factors play a role in such differences. A survey was carried out to compare the public and the private management pattern. Results suggest that a mixed phenomenon in both public and private sector schools was found regarding management practices.
\end{abstract}

\subsection{INTERNAL EFFICIENCY}

According to Lockheed and Hanushek (1994) educational efficiency is frequently confused with educational effectiveness, and at times the two terms are used interchangeably. They state that educational effectiveness is whether or not a specific set of resources has a positive effect on achievement and, if so, how large this effect is. Clearly, since effectiveness does not directly compare resources or costs, what is effective is not necessarily what is most efficient, they conclude (p. 2).

The term 'internal efficiency' of education refers to a comparison of learning (a non-monetary outcome of education) to the cost of educational inputs; the analysis typically employed is cost effectiveness (Lockheed and Hanushek, 1994, p. 5). Internal efficiency addresses the question of how funds within the education sectors should be best allocated. External efficiency, refer to what is 
often the topic of cost-benefit analyses: that is, the ratio of monetary outcomes to monetary inputs (p. 6). They make a distinction between efficiency and effectiveness, which are dependent on the form of the inputs: efficiency refers to monetary inputs whereas effectiveness refers to non- monetary inputs. Efficiency typically also encompasses the relationship between non-monetary inputs and non-monetary outputs in the form of technical efficiency.

An effort has been made to look at education system in Sindh from both dimensions of unnecessary inputs as well as undesirable output. Under the category of unnecessary inputs redundancy of teachers and schools have been discussed which tend to skew the system toward the input-heavy side. While on account of undesirable outputs drop-out of the system and primary completion rate have been taken as indicators. In order to get an idea of the extent of waste, the financial data with respect to budget allocations for education has been used to compute some understanding of monetary aspect of the waste. The data set used here has been taken for the year 2005-06, in an effort to trail the cohort admitted in grade I in the year 2005 to see the impact on class $V$ in the year 2010.

\subsubsection{Dimension of unnecessary inputs}

The two pronged analysis of inputs related system waste takes following two indicators: student - teacher ratio across the Sindh; student - school ratio in Sindh. An effort has been made to build a case based on the data pertaining to 2005-06, whereby both infrastructure and human resource inputs have been examined.

Student - teacher ratio (STR) is the number of students in a school or district 
compared to the number of teaching professionals. STR is interconnected with class size which is described as 'the number of students for whom a teacher is primarily responsible during a school year'. Hanushek (1998) admits that 'pupil-teacher ratios are not the same as class sizes', and that 'data on pupilteacher ratios reflect the total number of teachers and the total number of students at any time, not the utilization of these....'(p. 12). There is a general perception that a low student-teacher ratio and teachers' high qualifications result in better performance in school. However, studies have indicated that on the basis of available data no optimum class size can be scientifically established as a function of educational benefits.

Figure 6-1 : Student-teacher ratio (STR) - Districts of Sindh

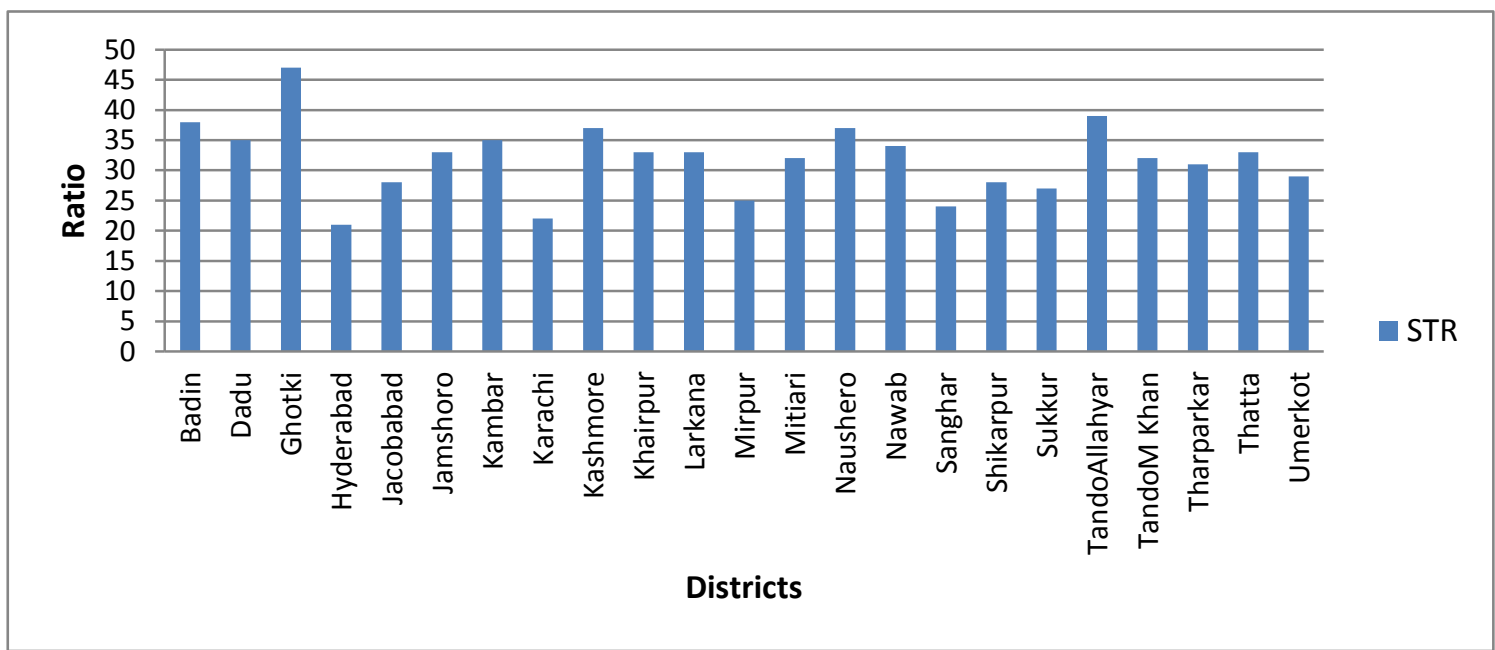

Source: SEMIS 2005-06, p.44.

Many policy oriented interventions and research studies consider a 40:1 ratio reasonable in developing countries. I have taken this benchmark to apply to Sindh to understand the dynamics of waste in school education system.

Teacher remuneration and school construction and maintenance costs, together with costs of schemes for encouraging enrolment such as school feeding and girls' stipend programs, and provision of free textbooks is the largest areas of incremental costs. The analysis demonstrates that there is a 
great potential for significant cost savings if the available resources are used efficiently. It is also apparent that the under utilization of teachers and schools are the main causes of wastage of resources in Sindh. In both areas of wastage, there are historical baggage issues which make reduction of wastage in the short term a difficult proposition. Redeploying well-qualified teachers in underserved areas, for example, are notoriously difficult and may mean that increasing the student teacher ratio is only feasible in the medium to long term, when locally recruited teachers can replace part of the teacher stuck in an overserved area. Similarly, in case of wastage resulting from an excessive number of schools, a long term strategic vision may be needed to weed out redundancy and rationalize school placement using technology based solutions.

SEMIS (2005-06) shows Sindh as having particularly low STRs in primary school (29:1) and especially in Middle School (11.9:1), making it extremely difficult to project costs for future realistically. This is because when STRs are so far from the target level, the assumption made is not reliable. Accordingly the calculations for teachers needed and resulting costs that quite overwhelms the effects of increased student enrolment. They demonstrate in any case the importance for cost purposes (and for purposes of freeing resources for more important uses) of using teachers efficiently. In other words, we make the arbitrary assumption that the costs of the additional teachers needed to handle increased enrolment will be balanced by an increase in efficiency of use of the existing workforce. An alternative way of interpreting the same assumption is that on average, the new enrolment would be absorbed by the present teaching force. The numbers of teachers that might be needed to teach the additional numbers enrolled vary greatly depending on the assumptions made about the 
existing STR and how it changes over time. However, in case if the whole primary teaching force could be used more efficiently, starting from the current STR of $29: 1$ and gradually reaching the target STR of $40: 1$ by say $2010-11$, the cumulative additional needs over the period imply a small reduction in the present teaching force (Appendix-6-A).

Another important dimension of wastage seen in education scenario is the ratio of the student to school. At present this ratio stands at about 90 students per school in Sindh. Although a global generalization usually masks demographic, geographic and other social considerations for rationalizing new schools, still this aspect of wastage cannot be underestimated as it carries a spillover effect on other areas of resource allocation. At the disaggregated level, we see differentials among districts but getting further down to school level the inefficiency becomes starker. This calls for a policy action that needs to use available technology of Global Positioning System to further study into the phenomenon and come up with consolidation and rationalization of interventions. A significant but mostly overlooked dimension of wastage in Sindh has been a low student to school ratio. The year 2005-06 provides an overall student: school ratio of 89 students per school. At disaggregated level, this ratio comes to around 77 for primary schools, 76 for middle schools and 399 for high and higher secondary schools. The wastage appears highest at primary level (only 15 students are in each grade on average). However, when looked from per class students, the ratio of 33 even at the high school level indicates a less than optimal outputs.

The structure of the pay scales for teachers in Pakistan is one with many steps, by which (we believe) the salaries that individual teachers are paid increase 
annually, independent of an increase applied to the salary scale. Thus if few teachers leave in any year, average salaries are likely to increase.

However, given that the process of recruitment to the teaching force has not been taking place for many years, the age and salary structures of the teaching force are likely to be skewed towards the upper end. On the other hand, we note that at least one province has a policy of recruiting primary teachers from candidates with degrees; these new teachers would be recruited at a pay level considerably above those who only have teaching certificates, so that perhaps the average salary might increase.

Total teacher remuneration is by far the largest part of total education recurrent expenditure; it is over 95 percent of the total education budget. Also, total teacher remuneration can change significantly from year to year, independent

Figure 6-2: Basic Facilities in public schools of Sindh

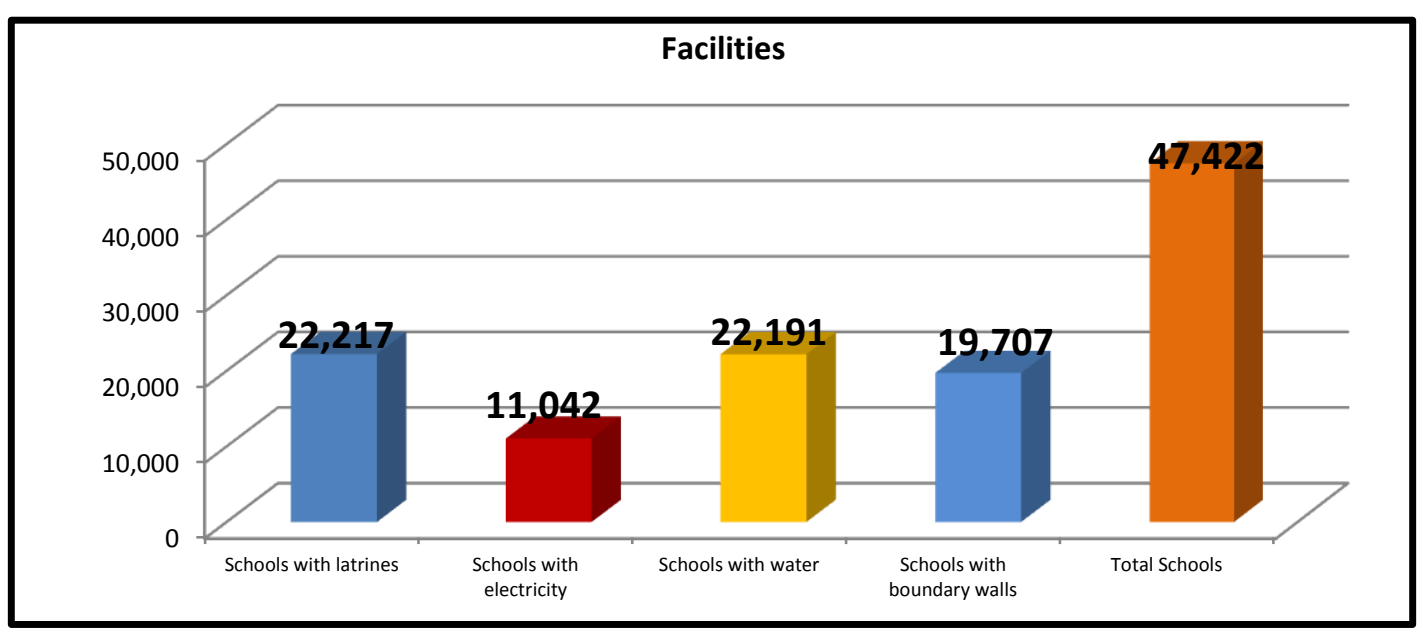

Source: SEMIS, 2005-06, p .23.

of what is happening to enrolment. Thus, improvement in the efficiency of use of existing teachers, particularly at the primary stage, can have an impact that swamps the additional number needed to provide for increased enrolment. Schools with necessary facilities have great impact on the quality of education. A student studying in schools with all basic facilities will have a different 
learning environment, then the schools with missing basic facilities. School environment has a major impact on the teaching learning environment. The status of facilities in public schools in Sindh is not very desirable. Even if we talk about some basic but critical facilities, the Sindh public school system provides a dismal scenario. According to annual school census (ASC) 2005-06, there were 47,422 schools in Sindh province out of which only 22,217 (47\%) are schools which have a latrine facility (latrine is one of the basic facility, especially in girls' schools), Similarly, only 11,042 (23\%) schools have a legal electrical connection, provision of drinking water facility is only in 22,191 (47\%) schools, schools with boundary walls are only available in 19,707 (42\%). If we drill down the state of missing facilities, the provision of facilities in rural districts is very poor as compared to the urban districts, as is evident from figure 6-3.

Figure 6-3: District wise School Facilities

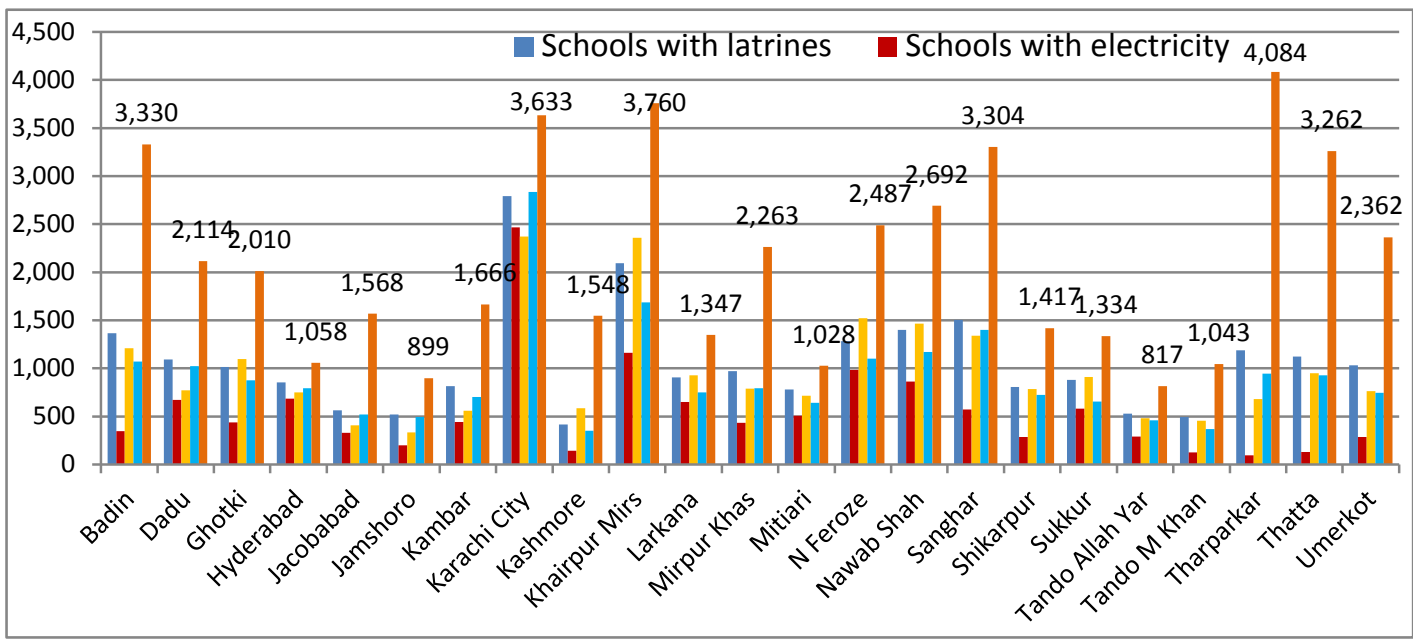

Source: SEMIS 2005-06, p. 43.

\subsubsection{Allocative efficiency model}

The allocative efficiency model estimation is based on two elements separately; one is based on taking student - teacher ratio (STR) and the other based on the student - school ratio (SSR). It calculates efficiency premium by taking the 
present STR of 29:1 to a more rationalized ratio of $40: 1$.

It calculates wastage as follows: the present number of teachers employed; total salary expenditure being incurred; the average salary cost per teacher; the cost cut by taking the STR to rationalized ratio and factoring in the cost saving from the saving from schools.

Table 6-1 : District wise Efficiency Premium Calculations

( Rs. In millions)

\begin{tabular}{|c|c|c|c|c|c|c|c|}
\hline District & $\begin{array}{c}\text { Total } \\
\text { Enrolment }\end{array}$ & $\begin{array}{c}\text { Total } \\
\text { Teachers }\end{array}$ & STR & $\begin{array}{c}\text { Total salary } \\
\text { budget }\end{array}$ & $\begin{array}{c}\text { Per Unit } \\
\text { cost of } \\
\text { teacher per } \\
\text { year }\end{array}$ & $\begin{array}{c}\text { Cost of } \\
\text { teacher at } \\
40: 1\end{array}$ & $\begin{array}{l}\text { Efficiency } \\
\text { Premium }\end{array}$ \\
\hline Tharparkar & 141889 & 4629 & 31 & $569,390,000$ & 123,004 & $436,322,863.00$ & $133,067,137$ \\
\hline Badin & 201131 & 5283 & 38 & $764,460,000$ & 144,701 & $727,596,420.00$ & $36,863,580$ \\
\hline Dadu & 235301 & 6729 & 35 & $785,200,000$ & 116,688 & $686,420,077$ & $98,779,923$ \\
\hline Ghotki & 189270 & 4006 & 47 & $506,000,000$ & 126,310 & $597,667,342$ & $(91,667,342)$ \\
\hline Hyderabad & 176992 & 8610 & 21 & $1,027,570,000$ & 119,346 & $528,082,180$ & $499,487,820$ \\
\hline Jacobabad & 119568 & 4227 & 28 & $557,040,000$ & 131,781 & $393,919,765$ & $163,120,235$ \\
\hline Jamshoro & 86819 & 2662 & 33 & $409,330,000$ & 153,767 & $333,747,429$ & $75,582,571$ \\
\hline Kambar & 139666 & 4007 & 35 & $489,470,000$ & 122,153 & $426,515,522$ & $62,954,478$ \\
\hline Karachi & 635703 & 29386 & 22 & $4,809,160,000$ & 163,654 & $2,600,883,469$ & $2,208,276,531$ \\
\hline Kashmore & 122233 & 3299 & 37 & $278,470,000$ & 84,410 & $257,942,188$ & $20,527,812$ \\
\hline Khairpur & 301125 & 9017 & 33 & $1,283,270,000$ & 142,316 & $1,071,372,637$ & $211,897,363$ \\
\hline Larkana & 195252 & 5842 & 33 & $349,980,000$ & 59,907 & $292,424,039$ & $57,555,961$ \\
\hline Mirpur & 140619 & 5598 & 25 & $692,880,000$ & 123,772 & $435,117,371$ & $257,762,629$ \\
\hline Mitiari & 101927 & 3217 & 32 & $400,370,000$ & 124,454 & $317,130,571$ & $83,239,429$ \\
\hline Naushero & 248108 & 6666 & 37 & $1,270,650,000$ & 190,616 & $1,182,333,863$ & $88,316,137$ \\
\hline Nawab & 178383 & 5171 & 34 & $694,430,000$ & 134,293 & $598,889,705$ & $95,540,295$ \\
\hline Sanghar & 228344 & 9343 & 24 & $1,160,630,000$ & 124,224 & $709,145,126$ & $451,484,874$ \\
\hline Shikarpur & 123034 & 4464 & 28 & $588,330,000$ & 131,794 & $405,378,574$ & $182,951,426$ \\
\hline Sukkur & 141162 & 5251 & 27 & $729,190,000$ & 138,866 & $490,065,057$ & $239,124,943$ \\
\hline T.A Yar & 69720 & 1803 & 39 & $236,160,000$ & 130,981 & $228,299,883$ & $7,860,117$ \\
\hline T.M Khan & 60637 & 1871 & 32 & $179,950,000$ & 96,178 & $145,798,634$ & $34,151,366$ \\
\hline Thatta & 179341 & 5478 & 33 & $618,030,000$ & 112,820 & $505,831,290$ & $112,198,710$ \\
\hline \multirow[t]{2}{*}{ Umerkot } & 93841 & 3275 & 29 & $465,590,000$ & 142,164 & $333,520,298$ & $132,069,702$ \\
\hline & 4110065 & 139834 & 29 & $18,865,550,000$ & & $13,704,404,303$ & $5,161,145,697$ \\
\hline
\end{tabular}

Source: Self compiled ( from SEMIS and various budget documents ,GoS,2005-06 ).

The unit salary has been calculated at basic level and has not taken into account tiered salary differentials on the basis of the pay scale and length of service. Other costs which will increase as the system expands, such as costs of administration, have not been included, although they may also increase significantly. One common feature of teacher deployment was the 
concentration of teaching staff in urban and semi urban school while remote area schools were poorly catered for. The reason for this over saturation in urban areas was the proximity of their homes. And, in case of remote area non availability of transport and female teachers because of customs it would not find it advisable to serve in such areas. This is one of the biggest reasons for closure of schools and appearance of ghost school (a school which only exists on papers).

Based on these statistics we can justifiably say that more teachers to fewer students would lead to inefficiency. This is because low enrolment in a class would lead to underutilization of resources. Since the demand of primary education is on the increase and the cost of education is high, if the student: teacher ratios are increased, participation in education is likely to be boosted. This would be done without extra costs.

\subsection{A MODEL OF ALLOCATIVE EFFICIENCY BASED ON THE SSR}

The basic constituents of this model are; the present number of schools available; developing an understanding of the cost of one school including both capital and recurrent cost; the cost cut by taking the student school ratio to rationalized ratio and factoring in the cost saving from the saving from rationalizing teachers' strength.

Table 6-2 : Allocative Efficiency SSR Model

\begin{tabular}{|c|c|c|c|c|}
\hline $\begin{array}{l}\text { Number of } \\
\text { Schools }\end{array}$ & $\begin{array}{l}\text { Total expenditure on } \\
\text { schools per year* }\end{array}$ & $\begin{array}{l}\text { Per Unit cost of } \\
\text { school per year }\end{array}$ & $\begin{array}{l}\text { Per unit cost of school at 175 } \\
\text { students per school per year }\end{array}$ & Efficiency premium \\
\hline 47,422 & $\begin{array}{c}2,775+886+ \\
3,890=\text { Rs.7.551 billion }\end{array}$ & Rs. $1,59,229$ & Rs. 79,614 & Rs. $\mathbf{3 . 7 7 5 5}$ billion \\
\hline
\end{tabular}

Note: * It includes; development + non-development+ school management committees' budgets.

Source: Author's compilation

Related to this aspect is the issue of the teacher to school ratio that also provides huge differentials aspect is the issue of the teacher to school ratio 
across district ranging from 8 teachers per school in Hyderabad to 1.1 teachers per school in Tharparkar. Under following paragraphs, an effort is being made to look into factual position in different districts in Sindh against interconnected dimensions of wastage that has reflected in the internal inefficiency of the education system in Sindh in addition to other indicators of entry, drop out, and completion rates.

DISTRICT THARPARKAR (2005-06) provides us with a classic case where the absence of any long term planning within a holistic framework has led to chronic inefficiencies reflecting in school closure and less than optimum use of available resources. Tharparkar has a total of around 141,889 (boys and girls) in around 3,689 schools with a teacher force of about 4,629. This leads to a student teacher ratio of about 31 which is on the lower side, also when looked from another dimension of student per school ratio coming at around 38 students per school, wastage of resources is compounded. This situation leads to less than optimal effectiveness by the sheer fact that teacher to school ratio comes down to 1.3 teachers per school. Despite being home to tribal culture in a desert based geographical setting, there are some genuine factors calling for expanded coverage of schools, however, the main reasons for this inefficient resource allocation are attributed to the absence of any planning and resource allocation which has led to villages with clusters of schools in proximity.

DISTRICT BADIN (2005-06) has a total enrolment of around 201,131 with a work force of 5,283 , giving an STR of 38 . The total number of schools in Badin is around 2,964, providing 67 students per school defying any criterion of efficiency of resources. Compounding the problem with illusory effectiveness is the abysmal allocation of 1.7 teachers per school. 
DISTRICT DADU (2005-06) has a total enrolment of 235,301 and a teaching force of 6,729 , giving an STR of 35.The total number of schools in Dadu are 2,078.This provides us with 113 students per school. The teachers' allocation per school comes to around 3.2 in district Dadu.

DISTRICT GHOTKI (2005-06) has a total enrolment of 189,270 while the number of the teaching force is around 4,006. This gives us STR of around 47.The total number of schools in district Ghotki is 1,749 which provides a ratio of around 108 students per school. The teacher allocation per school comes to 2.3 teachers per school.

DISTRICT HYDERABAD (2005-06) has a total enrolment of around 176,992 with a teaching force of 8,610 giving an STR of 21 . The total number of schools in Hyderabad is 1,056 . This gives a ratio of around 167 students per school. The allocation of teacher per school comes to around 8.1 which probably rank highest in the province.

DISTRICT JACOBABAD (2005-06) has a total enrolment of 119,568 while the teaching force in the district is 4,227 giving an STR of around 28. The total number of schools in the district is 1,563 ; this gives a ratio of 76 students per school. The ratio of teacher per school comes to around 2.7 teachers. DISTRICT JAMSHORO (2005-06) has a total enrolment of 86,819 while the teaching force in the district is around 2,662, thus giving an STR of around 33.The total number of schools in the district is 866.The student per school ratio comes to around 100 while the teacher per school ratio comes to around 3.0. So 3 teachers are allocated per school.

DISTRICT KARACHI (2005-06) has a total enrolment of 635,703 with a teaching force of around 29,386, thus giving an STR of around 22 students per 
teacher. The total number of schools in Karachi is 3,750.This gives us an average of 169 students per school. The allocation of teacher per school comes to around 7.8.

DISTRICT KASHMORE (2005-06) has a total enrolment of around 122,233 with a teaching force of 3,299 giving an STR of 37 in the district. The total number of schools in Kashmore is 1,497 which gives an average of 83 students per school. The teachers per school ratio come out to be 2.2.

DISTRICT KHAIRPUR MIRS (2005-06) has a total enrolment of 301,125 with a teaching force of about 9,017 giving an STR of 33.The total number of schools in Khairpur districts are 3,600.This gives us a student per school ratio of 84 . The teacher per school ratio comes out to be 2.5 teachers per school.

DISTRICT LARKANA (2005-06) has a total enrolment of 195,252 with a teaching force of 5,842 giving an STR of 33 in the district. The number of schools in the district is 1,335 , which gives a ratio of 146 students per school. The teacher to school ratio in district Larkana is around 4.3.

DISTRICT MIRPUR KHAS (2005-06) has a total enrolment of 140,619 with a teaching force of 5,598 giving an STR of 25 . The total number of schools in the district is 2,056 , which gives a ratio of 68 students per school. The ratio of teachers per school is around 2.45 .

DISTRICT MITIARI (2005-06) has a total enrolment of around 101,927 with a teaching force of 3,217 , giving an STR of around 32 . The total number of schools in the district is 1,002 , which gives student to school ratio of 102.The allocation of teachers per school comes to around 3.1.

DISTRICT NAUSHERO FEROZE (2005-06) has a total enrolment of around 248,108 with a teaching force of about 6,666 giving an STR of about 37 . The 
total number of schools in the district is 2,352, which gives a ratio of 106 students per school. The teacher per school ratio comes to around 2.8.

DISTRICT NAWAB SHAH (2005-06) has a total enrolment of around 178,383 with a teaching force of about 5,171 giving an STR of about 34 . The total number of schools in the district is 2,442 , which gives a ratio of 73 students per school. The teacher per school ratio comes to around 2.1.

DISTRICT SANGHAR (2005-06) has a total enrolment of 228,344 with a teaching force of 9,343 . This gives an STR of around 24. The total number of schools in district Sanghar is 3,289 , which gives a ratio of 69 . The teacher to school ratio comes to 2.8 .

DISTRICT SHAHDADKOT (2005-06) has a total enrolment of around 139,666 with a teaching force of 4,007 giving an STR of around 35. The total number of schools in the districts is 1,623 , which gives a ratio of 91 students per school. The teacher to school allocation comes to around 2.3.

DISTRICT SHIKARPUR (2005-06) has a total enrolment of 123,034 with a teaching force of 4,464 giving an STR of about 28 . The total number of schools in the district is 1,404 . This gives us a ratio of 88 students per school. The teacher per school ratio comes to around 3.2.

DISTRICT SUKKUR (2005-06) has a total enrolment of 141,162 with a teaching force allocation of 5,251 which gives an STR of 27.The total number of schools in Sukkur is 1,175 . The ratio of students per school is around 120 . The allocation of teacher per school is around 4.4.

DISTRICT TANDO ALLAH YAR (2005-06) has a total enrolment of 69,720 with 1,803 teachers giving an STR of around 39. The total number of schools is 755. The ratio for student per school is 92 while teacher per school is 2.3 . 
DISTRICT TANDO MUHAMMAD KHAN (2005-06) has a total enrolment of 60,637 with a teaching force of 1,871 giving an STR of around 32 . The total number of schools in the district is 980 , which gives the ratio of 62 students per school while teacher allocation per school is 1.9 .

DISTRICT THATTA (2005-06) has a total enrolment of 179,341 with a teaching force of 5,478 giving an STR of around 33. The total number of schools in the district is 2,862 . The ratio for student per school is 63 , while teacher allocation per school is 1.9 .

DISTRICT UMERKOT (2005-06) has a total enrolment of 93,841 with a teaching force of 3,275. This gives a student teacher ratio ( STR) of around 29. The total number of schools in the district is 1,971 . The ratio for student per school 48 while teacher allocation per school is 1.6.

With respect to Sindh, the figures provided above, mask some realities, one major being that no school level capital expenditure numbers are available. The development expenditure is diverted to other complementary development schemes like teacher development, private school support besides used for capital expenditure for schools. However, given the natural political economic dimension it could be safely assumed as indicated by historical expenditure available that a bulk of it goes to school construction, up gradation or rehabilitation of existing school structures. Looking at the overall expenditures, it becomes very obvious that per unit expense of school other than teacher salary is very minimal. One result of rationalizing the number of schools in Sindh could be improving the schools within the same budget. Following few indicative aspects fortify the argument given above, which is more indicative of a better number of class rooms than to have more dispersed school buildings. 


\subsubsection{Undesirable output dimension of wastage/internal efficiency}

The second dimension of system waste takes into account the internal efficiency of the education system in Sindh from the perspective of its effectiveness in processing efficiency and emphasizes on two indicators:

1. Dropout rate of the system

2. Primary completion rate

The issue of dropout signals a structural malady in an education system reflecting its inability to retain students which it loses either to another system or back to illiteracy fold. The tables in appendix $6-\mathrm{B}, \mathrm{C}, \mathrm{D} \& \mathrm{E}$ provide a synopsis of different dimensions of the problem both across grades as well as gender boundaries. Primary completion rate out of any educational system signify a tangible product output of the first stage of the system working having a bearing on the external efficiency / effectiveness of that system. It is the end product after factoring in of the wastage occurred that occurred across grades in a primary cycle.

\subsubsection{Monetary aspect of wastage}

An effort has been made to roughly calculate the extent of wastage in monetary term resulting from a low completion rate in Sindh.

Following are the assumptions.

- A basic per child cost has been calculated by dividing total enrolment by the budget allocated for that year.

- All the students graduating to grade 5 were assumed completing the cycle.

- The number of class 5 students was taken from the year 2009-10 in an effort to trail the cohort admitted in grade 1 in the year 2005-06. 
- The percentage of completion rate drops significantly (to around $29 \%$ as given in the table providing completion rate) if the calculations are done based on enrolment in grade 6. This however, is fraught with risk of losing the reality as other factors like short supply of middle schools, compulsions of labor market and social-cultural factors also play a significant role in the progression from primary to secondary levels.

- The Sindh education scenario is complex with an interplay among diverse forces where geographic, demographic and socio cultural factors may necessitate some inefficient allocation of resources especially teachers and schools. The above analysis signals structural weaknesses in the educational edifice that is causing substantial loss to already constrained education resource pool.

Table 6-3 : Allocative Efficiency CR Model

\begin{tabular}{|c|c|c|c|c|c|c|}
\hline $\begin{array}{c}\text { Enrolment } \\
\text { Class1 }\end{array}$ & $\begin{array}{c}\text { Enrolment } \\
\text { Class V }\end{array}$ & $\begin{array}{c}\text { Completion } \\
\text { Rate }\end{array}$ & $\begin{array}{c}\text { \# of Students not } \\
\text { completed the } \\
\text { primary cycle }\end{array}$ & $\begin{array}{c}\text { Budget } \\
\text { Allocated }\end{array}$ & $\begin{array}{c}\text { Budget per } \\
\text { Child per year }\end{array}$ & $\begin{array}{c}\text { Efficiency } \\
\text { Loss per year }\end{array}$ \\
\hline 806,162 & 341,128 & $42 \%$ & 465,034 & $\begin{array}{c}\text { Rs. } 31.103 \\
\text { billion }\end{array}$ & RS. 7,568 & Rs.3,519 billion \\
\hline
\end{tabular}

Sindh government is incurring an annual loss to the tune of Rs. 8.9 billion on account of inefficient and redundant resource allocation of two major inputs i.e. teachers and schools. This amount could be saved, provided that the teacher recruitment and school construction had been done under some rational policy framework. This upfront loss is further compounded by the internal inefficiency of the system not able to retain enrolled student to complete primary cycle. This is causing an annual loss of around Rs. 3.5 billion by losing the students only at the primary level. This however, does not include the massive drop outs at the middle and secondary levels of education. 


\subsection{ANALYSIS OF PUBLIC AND PRIVATE SCHOOLS MANAGEMENT}

There are different perspectives on public administration as to differences in planning and management practices across sectors. Despite decades of research on public - private management discussion, there still exists a gap in understanding the extent to which public and private organizations differ, and contributing factors which play a role in such differences. In this study, we have surveyed members of the Reform Support Unit (RSU) ${ }^{1}$ in the Education Department, Government of Sindh and Private School Management in the Province of Sindh.

In general, privately managed schools tend to have more freedom, better resources, better school climate and better performance levels than public sector schools. There has been a tremendous increase in the share of education in the private sector in the urban areas. However, there has been little work done on this subject, largely due to a lack of reliable national data either on private schools or the population (as there was no population census done in Pakistan between 1981 and 1998 and after 1998 till 2012). Public sector organizations show a much greater level of internal and external linkages as compared to the private sector organizations. This leads to more procedural steps and delays, which is usually described by social scientists as bureaucratic "red tapism". Managers in the private sector organizations are more inwardly focused while public sector managers are concerned with linkages outside the organization. The greater levels of hierarchical structure present in the public sector organizations require layers of interaction and approval. This multi-layer structure results into taking longer to complete projects in the public sector organizations. In the light of above, the following 
hypotheses were developed comprising three categories; first was regarding data collection and their team members, second for consultation in the planning process and third was on budget utilization and timely completion of projects.

Table 6-4: List of variables for Chi-Square test

\begin{tabular}{|c|c|c|}
\hline Variable & & $\mathbf{N}$ \\
\hline H1: Data reliability & (Yes/No) & 237 \\
\hline $\mathrm{H} 2$ : Objectives of the education plans for data collectors & (Yes/No) & 237 \\
\hline H3: Authentic and correct data for education plans & (Yes/No) & 237 \\
\hline H4: Data flaws do not invalidate results & (Yes/No) & 237 \\
\hline H5: Consultation with administrator & (Yes/No) & 237 \\
\hline H6: Consultations with educationists & (Yes/No) & 237 \\
\hline H7: Target of interventions across localities & (Yes/No) & 237 \\
\hline H8: Maximization of cost-effectiveness & (Yes/No) & 237 \\
\hline H9: Trained monitoring officers & (Yes/No) & 237 \\
\hline H10: Co-ordination among various agencies & (Yes/No) & 237 \\
\hline H11: Non utilization of funds & (Yes/No) & 237 \\
\hline H12: Projects go over- budget & (Yes/No) & 237 \\
\hline H 13: Projects are delayed & (Yes/No) & 237 \\
\hline H 14: Guidance from foreign experts in planning & (Yes /No) & 237 \\
\hline
\end{tabular}

Source : Author's compilation

Table 6-5 provides a list of variables used to perform the chi-square tests to test the differences between performance of private and public sector organizations.

The purpose of this study is to analyze productivity differences among public and private-schools using the non-parametric approach. Thus, a nonparametric technique- Chi-square test has been employed. To test these hypotheses, a descriptive, cross sectional study was conducted to collect information from administrators, managers, monitoring officers, educationists, and district officers Sindh Education Management and Information System $(\text { SEMIS })^{12}$. The survey questions were designed to collect information in three categories; first was regarding data collection and their team members, second for consultation in the planning process and the third was on budget utilization

${ }^{12}$ SEMIS is a part of RSU and only exists for public sector schools 
and timely completion of projects. Convenience sampling was used to draw the sample i.e. the schools were selected by a random draw, and the questionnaires were handed out to the respondents at random, depending on who was available at that given point in time. The questionnaire was administered to 250 respondents and 237 filled in questionnaire were returned. Out of a total of 237 respondents 48 percent were male and 52 percent female, of which 40 percent carried the title of educationists and administrators and 40 percent belong to RSU in different capacities while teachers comprised around 19 percent and managers 24 percent. In terms of education, 50 percent held a master degree and 46 percent had a bachelor's degree. The sample consisted of 51 percent respondents from the private sector organizations and 49 percent from the public sector organizations. The survey was pilot-tested by four deputy program managers in the RSU for its validity. Hence, these were made clear, which was integrated into the final questionnaires.

\subsection{RESULTS}

To test the differences between private and public sector schools, a series of chi-square tests were performed. The hypothesis tested was whether or not two different types of schools are different enough in some characteristic. The association between two variables would lead to the significance of chi-square tests inferring that there is a relationship between the two variables under discussion.

For hypothesis , $\mathrm{H} 1$, the chi-square test showed that there was no association between sectors of the organization and whether the data collected for educational planning are more reliable in case of private sector schools. Of the public schools, 76.9 percent did respond with affirmative while 30 percent of the 
private sector schools did so. Chi- square and Cross tabulation at appendix 6F. For hypothesis, H2, the chi-square test showed that there was no association between sectors of the organization and whether the objectives of the education plans are clear to the data collectors in the case of private sector schools and public sector schools. Of the public schools, 35.9 percent did respond with affirmative while 68.3 percent of the private sector schools did so. Chi- square and Cross tabulation at appendix 6-G. For hypothesis, $\mathrm{H} 3$, the findings are not significant, there is actually a 27.4 percent chance that these differences could have just risen as a quirk of random sampling rather than reflecting a real underlying difference in the population as a whole. Chi- square and Cross tabulation at appendix $6-\mathrm{H}$. For hypothesis, $\mathrm{H} 4$, It can be seen that the findings are not significant, there is actually a 85.3 percent chance that these differences could have just risen as a quirk of random sampling rather than reflecting a real underlying difference in the population as a whole. Chisquare and Cross tabulation at appendix 6-I. For hypothesis, H5, the chisquare test showed that there was no association between sectors of the organization and their likelihood of involving administrators in the educational planning process. Of the public schools, 23.9 percent did respond with affirmative while86. 7 percent of the private sector schools did so. Chi- square and Cross tabulation at appendix 6 -J. For hypothesis, $\mathrm{H} 7$, the chi-square test showed that there was no association between sectors of the organization and their likelihood of consulting educationists in the educational planning process. Of the public schools, 32.5 percent did respond with affirmative while 64.2 percent of the private sector schools did so. Chi-square and Cross tabulation at 
at appendix 6-K. For hypothesis, $\mathrm{H} 7$, the chi-square test showed that there was no association between sectors of the organization and their likelihood of targeting interventions. Of the public Sector organizations, 17.1 percent were on target while 81.7 percent of the private sector organizations did the target intervention across localities. Therefore, there is no evidence to suggest that public sector organizations are more likely target intervention across localities than private sector organizations. Chi- square and Cross tabulation at appendix 6-L. For hypothesis 8 , the chi-square test showed that there was no association between sectors of the organization in terms of their maximization of cost effectiveness. Chi- square and Cross tabulation at appendix 6-M. For hypothesis 9 , it can be seen that the findings are not significant there is actually a 16.3 percent chance that these differences could have just risen as a quirk of random sampling rather than reflecting a real underlying difference in the population as a whole. Chi- square and Cross tabulation at appendix 6-N. For hypothesis 10 , the chi-square test showed that there was no association between sectors of the organization and whether there was coordination amongst various tiers. Of the public sector organizations, 89.76 percent did show coordination while 75.8 percent of the private sector organizations did so. Therefore, there is no evidence to suggest that public sector organizations are more likely to be more coordinated than private sector organizations. Chisquare and Cross tabulation at appendix 6-O. For hypothesis 11, the chisquare test showed that there was no association between sectors of the organization in their likelihood of utilizing the funds properly. Of the public sector organizations, 88 percent did not utilize budget as compared to 18.3 percent in the private sector schools. Chi- square and Cross tabulation at 6-P. 
For hypothesis 12, the chi-square test showed no association between sectors of the organization and whether the project was completed within budget. Of the public sector organizations, 49.6 percent did not complete projects within earmarked budget while 36.7 percent of the private sector organizations did not. Therefore, there is no evidence to suggest budget over run in case of the public sector organizations. Chi- square and Cross tabulation at appendix 6-Q. For hypothesis 13 , the chi - square test showed that there was an association between sectors of the organization and on schedule delivery in case of private sector organizations was 59 percent while for public sector organizations only 36.7 percent. The results provide support for the hypothesis. Chi- square and Cross tabulation at appendix 6-R. For hypothesis 14, the survey produced no evidence of any difference between public and private schools in terms of their opinion regarding reasons for project failures. Chi- square and Cross tabulation at appendix 6-S.

This initial study of the planning process and project management in public and private schools has shown similarity in most of the cases. Both sectors face the same level of budget overrun, however, public sector schools show more time overrun due to more vertical and horizontal constituents.

\subsection{CONCLUSION}

The objective of this chapter was to analyze education sector in Sindh at the level of internal efficiency, the management practices in the public and private As such, a wide variety of methods are used to measure different aspects of education. These include, among others, ratios, education attainment indicators, quality of education indicators and measures of absolute and relative dispersion of education. The internal efficiency premium calculations 
clearly demonstrate system wastes. An effort has been made to roughly calculate the extent of wastage in monetary term. The Sindh education scenario is complex with an interplay among diverse forces where geographic, demographic and socio cultural factors may necessitate some inefficient allocation of resources especially teachers and schools, however the above analysis signals structural weaknesses in the educational edifice that is causing substantial loss to the already constrained resource pool allocated to education in Sindh which has barely touched 1.4 percent of provincial GDP. The Sindh government is incurring an annual loss to the tune of Rs. Rs. 8.9 billion on account of inefficient and redundant resource allocation of two major inputs i.e. teachers and schools. This amount could be saved provided that teacher recruitment and school construction had been done under some rational policy framework.

In part two non-parametric approache has been used for analyzing productivity differences among public and private-schools. The personnel from both the organizations use similar teaching and management strategies. Public sector organizations show a much greater level of interdependence across organizational boundaries as compared to private sector organizations. This greater interdependence leads to greater oversight which leads to more procedural steps and delays. Managers in the private sector organizations are more concerned with internal coordination while public sector managers are concerned with linkages outside the organization. The greater level of oversight present in public sector organizations requires increased coordination and additional levels of approval. Because of the increased number of constituents, it is more costly and takes longer to complete projects. 
CHAPTER 7 : ECONOMETRIC RESULTS

\begin{abstract}
The efficiency of public education has been examined using the most commonly used approaches to parametric (stochastic frontier) analysis of efficiency in panel data that is the fixed effects model. Empirical estimation uses six years (2005-06 to 2010-11) panel data from 23 school districts in Sindh. An efficiency index is constructed for district ranking. Evidence from this study finds weak impact of education expenditure on the primary level enrolment. Though the coefficient on public expenditures is positive and statistically significant but indicates a small impact on enrolment at primary level. The impact of education expenditures on the middle level and the secondary level is more pronounced. The coefficients for both these levels are statistically significant as well. There is a lot of variation in the efficiency of the districts at the three levels of education with the mean efficiency of 0.39 at primary level; a mean efficiency of 0.64 at the middle level and a mean efficiency of 0.75 at the secondary level of education. This study will contribute to the educational research on selecting Stochastic Frontier Analysis as a primary estimation method for analyzing the district efficiency of school education. It will additionally provide a resource to stakeholders in making data driven decisions regarding school funding and spending.
\end{abstract}

\title{
7.1. DESCRIPTIVE ANALYSIS
}

Despite decades of intensive study, there is no general consensus regarding the effectiveness of monetary educational inputs for student outcomes. In particular, papers that summarize the debate on the effects of public education expenditures often advocate conflicting views. The aim of this paper is to explore whether differences in the resources allocated to education can explain differences in educational access across districts in Sindh. The paper therefore seeks to contribute to the discussion on the role of government expenditure on education in Sindh, by analyzing linkages between such education expenditure and school education enrolments and to draw some policy implications. For that purpose, a district panel data set was put together for econometric testing, using public education expenditure and other school, student and teacher related characteristics as inputs. Gross primary, middle and secondary 
education enrolments are the outcomes. On the basis of the evidence from these tests, conclusions are drawn on the relative relevance of public education expenditure for policy-making purposes.

Given the complex structure, system and multiple levels of planning and administration of education in Sindh, it is not surprising that multiple inputs including better funding, infrastructure and teacher resources do not lead to desired results on a range of outputs especially enrolment and completion rates. In fact, politicized planning, patronage based recruitment and deployment systems have resulted in a school structure which is not only unwieldy but has largely become dysfunctional. Before producing some descriptive statistics and proceeding to the regression analysis, it will be useful to present bivariate relationships between key variables; education expenditure and enrolment, using simple scatter plots. Figures 7-1, 7-2 and 7-3 show positive relationship between both key indicators.

Figure 7-1: Mean Primary Enrolment and Expenditure (in logs) in Sindh

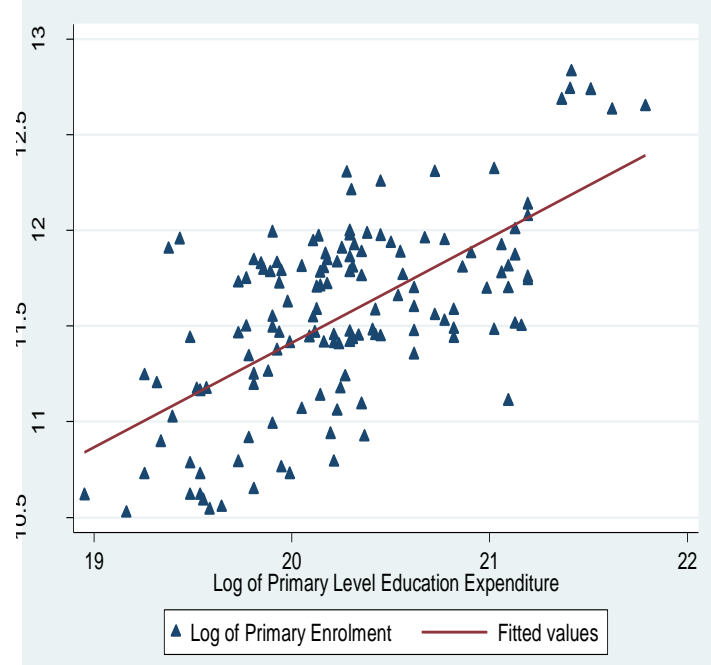

Figure 7-2: Mean Primary Enrolment and Expenditure ( in logs) in Sindh

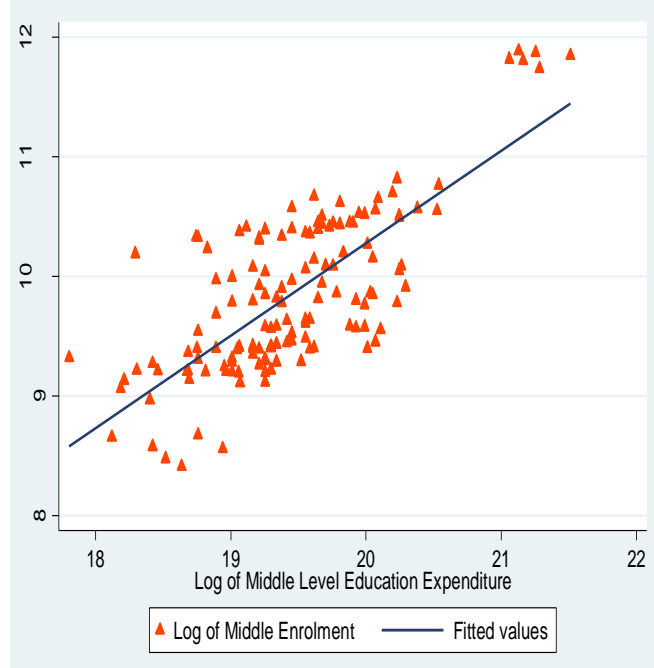

Source: Author's Compilations 
The bivariate results (Fig 7-1 and 7-2) indicate a positive relationship between education expenditure and school enrolment, whereas the multivariate analysis does not support this relationship.

Fig. 7-3: Mean Secondary Enrolment (log) and Mean Expenditure (Log) in Sindh

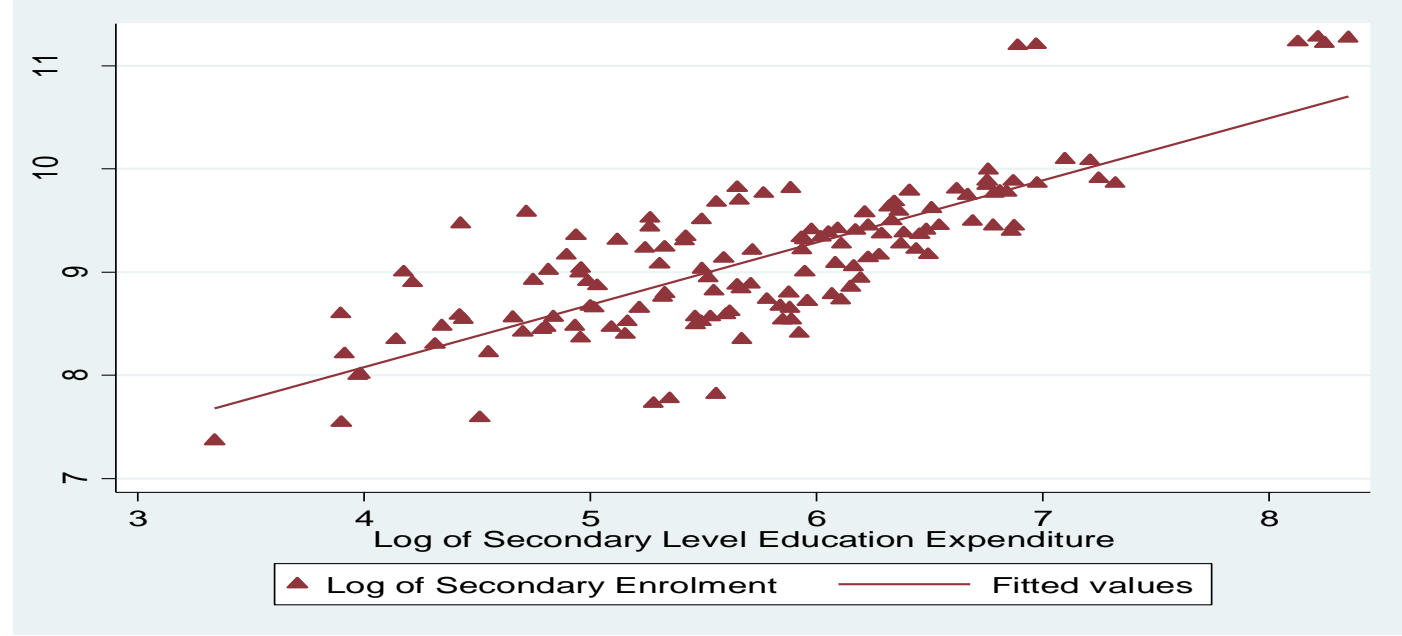

Source: Author's Compilations

This variation results from the fact that while the bivariate results show the direct relationship between these two variables, the multivariate analysis also simultaneously takes into account the effects of a number of variables believed to be relevant to variation in enrolment rates at the primary, middle and secondary school levels. Thus, it is imperative to go beyond the simple assumption of just a positive relationship.

The preceding bivariate analysis is purely descriptive and of limited use when trying to draw conclusions as to the generative mechanisms of school out comes. Given that many theoretically important variables are highly correlated with each other, it is often misleading to draw inference from these bivariate distributions. The unconditional correlation between two variables will often fall away when other variables are controlled for, indicating that some variables are merely proxying other important variables, and due to their correlation with those important variables, there seems to be a strong relationship. 
Multivariate analysis can go some way to account for these correlations and provide some indication of the true generative mechanisms. Some noteworthy findings emerge from observing the summary statistics in table 7-1. The

Table 7-1: Descriptive Statistics Primary Level Education

\begin{tabular}{lcccc}
\hline Variable & Mean & Std. Dev. & Min & Max \\
\hline Enrolment & 120590.2 & 61638.37 & 37152 & 383669 \\
Expenditure & $7.49 \mathrm{E}+08$ & $4.85 \mathrm{E}+08$ & $1.70 \mathrm{E}+08$ & $2.90 \mathrm{E}+09$ \\
No of Schools & 1958.761 & 915.94 & 687 & 4152 \\
No of Class rooms & 3459.812 & 2039.684 & 1220 & 12925 \\
No of Teachers & 4308.355 & 2722.571 & 1393 & 15904 \\
Student-School ratio & 66.03076 & 25.82316 & 30.16201 & 145.2191 \\
Student-Class room ratio & 36.59608 & 11.46492 & 17.06569 & 121.9643 \\
Student teacher ratio & 29.2577 & 5.527209 & 17.37512 & 45.13208 \\
Literacy rate & 54.4058 & 1057102 & 31 & 84 \\
Participation rate & 55.92499 & 0.1205715 & 0.160153 & 0.873277 \\
Population density & 108.5172 & 167.9453 & 19.18 & 886.49 \\
\hline
\end{tabular}

Source: Author's compilation from SEMIS data.

expenditure on primary education per district ranges from Rs. 170 million to Rs. 2900 million across districts, with a mean of Rs. 749 million. Primary enrolment varies from 37152 to 383669 . The mean student - classroom ratio (SCR) is 36.59 with a standard deviation of 11.4 , while the mean student- school ratio (SSR) is 66.03 , with a minimum of 30 and maximum of 145 students per school. The mean student - teacher ratio (STR) is 29.25 with a standard deviation of 5.5 ; this adjusts well with SCR.

It is pertinent to mention that the area of districts vary widely for example district Hyderabad has an area of $975 \mathrm{Km}^{2}$ while district Thatta has an area of $17355 \mathrm{Km}^{2}$ which obviously makes it difficult to manage the education sector with such huge distances. Schools, class rooms and teachers are in the absolute numbers while participation rate, literacy rate and population density are measured in percentage.

In the case of middle level education (class VI - VIII) the expenditure per district 
ranges from Rs. 54 million to Rs. 2200 million across districts, with a mean of Rs. 359 million. Middle level enrolment ranges between 4491 to 145,277 . The mean SSR is 234 with a standard deviation of 93 , with a minimum of 46 and

Table 7-2: Descriptive Statistics Middle Level Education

\begin{tabular}{lcccc}
\hline Variable & Mean & Std. Dev. & Min & Max \\
\hline Enrolment & 25749.42 & 25678.93 & 4491 & 145277 \\
Expenditure & $3.59 \mathrm{E}+08$ & $3.30 \mathrm{E}+08$ & $5.40 \mathrm{E}+07$ & $2.20 \mathrm{E}+09$ \\
No of schools & 119.1087 & 97.58797 & 24 & 550 \\
No of class rooms & 379.2391 & 463.1478 & 64 & 2941 \\
No of teachers & 434.7826 & 586.0469 & 42 & 3666 \\
Student-school ratio & 234.2823 & 93.02767 & 46.3569 & 556.5224 \\
Student-class room ratio & 75.96386 & 24.31461 & 30.12691 & 147.8261 \\
Student-teacher ratio & 71.73277 & 22.97522 & 33.28697 & 135.5891 \\
\hline
\end{tabular}

Source: Author's compilation from SEMIS data.

maximum of 556 students per school. The mean SCR is 75 and mean STR is 71.73 with a standard deviation of 22.97 this adjusts well with SCR ratio.

In the case of secondary education (table 7-3), there is a stark contrast compared to the primary level of education. At this level there is a minimum enrolment of 1578 to a maximum of 80483 . This reflects the need for

Table 7-3: Descriptive Statistics Secondary Level Education

\begin{tabular}{lcccc}
\hline Variable & Mean & Std. Dev. & Min & Max \\
\hline Enrolment & 12765.97 & 14621.86 & 1578 & 80483 \\
Expenditure & $4.20 \mathrm{E}+08$ & $5.84 \mathrm{E}+08$ & $2.80 \mathrm{E}+07$ & $4.05 \mathrm{E}+09$ \\
No of schools & 70.36232 & 109.0535 & 21 & 586 \\
No of class rooms & 595.0435 & 1031.017 & 1206 & 81 \\
No of teachers & 1145.145 & 1737.847 & 197 & 9324 \\
Student-school ratio & 202.1546 & 66.63513 & 62.5 & 407.77 \\
Student-class room ratio & 25.94529 & 7.999644 & 11.19 & 44.69 \\
Student-teacher ratio & 13.15992 & 4.213945 & 6.390637 & 26.53846 \\
Population density & 19.35152 & 38.3284 & 2.41504 & 199.156 \\
\hline
\end{tabular}

Source: Author's compilation from SEMIS data. 
expanding the infrastructure and resources both for the middle and the secondary education.

The education expenditure at the secondary level is, from a minimum of Rs. 28 million to a maximum of Rs. 4 billion. The school-student ratio is from a minimum of 62 to a maximum of 407 , while student-class room ratio is from a minimum of 11 to a maximum of 44 . In case of secondary level education the teacher deployment is on subject basis.

The variation between the resources of middle and the secondary education is slightly skewed and is not capturing the position on ground. In reality a significant number of middle school children are in the high schools which cater to both the levels and the resources of teachers and classrooms are shared between these levels.

\subsection{ESTIMATION RESULTS}

In this study, a fixed effect (within) regression model has been applied to education data of districts in the province of Sindh. I have used the equations $(5.1,5.2$ and 5.3) to examine the effects of education expenditure on enrolment in 23 districts of Sindh for the period 2005-06 to $2010-11^{13}$. The results of the education equations are presented in table 7-4 (primary education enrolment), table 7-5 (middle education enrolment) and table 7-6 (secondary education enrolment). Regression results confirm the role of public spending as a determinant of enrolment rates. The coefficient for public education spending is positive and statistically significant in all of the estimated models and specifications. There are two variables that I use to proxy schooling infrastructure. The first is the number of schools and the second is the number

\footnotetext{
${ }^{13}$ Note: The data show financial year 2005-06 and 2010 -11 and are shown as 2005 and 2010 .
} 
of class rooms in the school in the district. The per capita availability of schools in a community might affect individual schooling outcomes directly because of rationing of school spaces, or indirectly via its (inverse) association with the "market" price of schooling and average proximity to schools (both of which would in turn influence the demand for schooling). The other community variable that is included is the number of teachers. The student- teacher ratio is often used as an indicator of school quality in the education literature. If the quality of schooling services is an important determinant of their utilization, improvements in quality could lead to greater utilization and improved schooling outcomes. Since the denominator of the student-teacher ratio is the number of enrolled students in the schools, there could be a spurious inverse correlation between the probability of school enrolment and the student-teacher ratio. Hence, I used the number of school teachers as an indicator of the supply of teachers. An important caveat, that I implicitly assume, is that the spatial placement of schools and teachers across Sindh districts is exogenous to the household's child schooling decisions. If schools and teachers are allocated across districts on the basis of unobserved education conditions, the estimated effects of school availability and student-teacher ratios on individual schooling outcomes may be spurious. However, this problem is not likely to be important in the current context for two reasons. First, teachers in Sindh are supposed to be assigned to various districts in accordance with budget book provision (based on number of school and an agreed number of teachers, not on the basis of current enrolments neither any relevance to house hold expenditure. Second, the primary focus of this paper is on how the marginal effects of school facilities and student-teacher ratios on school enrolments vary across districts 
of different eco-geographical backgrounds. The results obtained here throw light on the frequent dilemma facing policy makers in developing countries on the choice between expanding school facilities (quantity) and the teacher student ratio (quality). The empirical results presented here suggest that the two interventions have diametrically opposite effects on school districts. An expansion of school facilities would conventionally increase the enrolment of children and on the other hand, an improvement in the number of class rooms increases the enrolment rate. However, the results suggest a negative impact of numbers of school in the districts on school enrolments but positive impact in the case of increase in the number of class rooms in a district. One reason for the decline in enrolment of the districts might be that constructing more schools often take place at the expense of other schooling inputs, such as stipends and other teaching aid materials. Another reason may be that school constructions are often selected on whims of elected representatives and there are no rationale criteria for selecting a site. So schools are constructed where these are not required. Hence, in Sindh, policies that serve to expand the number of class rooms may make more sense than interventions that increase the number of schools.

The dependent variable in table 7-4, primary enrolment (in logs) is regressed on (i) expenditure on primary school education (in logs) (ii) number of schools (in logs), (iii) number of classrooms (in logs), (iv) number of teachers (in logs), (v) literacy rate, (vi) participation rate, (vii) population density ( in logs) and proportion of urban population. The main regressor, education expenditure reflects the investments and costs associated with education. It covers public contributions to the full range of expenses, including school construction and 
maintenance, teacher salaries, learning materials, as well as stipends and free text books.

Table 7-4: Summary of significant findings using the fixed effects model

\begin{tabular}{|c|c|}
\hline \multicolumn{2}{|l|}{ Dependent Variable $=$ Log of primary enrolment (Class I to V) } \\
\hline Independent variables & Coefficient estimate \\
\hline Log of primary education expenditure & $\begin{array}{c}0.018403 \\
(2.68)^{* * *}\end{array}$ \\
\hline Log of number of primary schools & $\begin{array}{c}-0.03599 \\
(-0.88)\end{array}$ \\
\hline Log of number of classrooms & $\begin{array}{l}0.022099 \\
(2.36)^{* *}\end{array}$ \\
\hline Log of number of teachers & $\begin{array}{c}0.032981 \\
(1.13)\end{array}$ \\
\hline Log of population density & $\begin{array}{l}0.962809 \\
(10.21)^{* * *}\end{array}$ \\
\hline Primary participation rate & $\begin{array}{l}1.604634 \\
(49.49)^{* * *}\end{array}$ \\
\hline Literacy rate & $\begin{array}{c}0.007828 \\
(0.15)\end{array}$ \\
\hline Percent of urban population & $\begin{array}{l}-2.80221 \\
(5.58)^{* * *}\end{array}$ \\
\hline Constant & $\begin{array}{l}6.967519 \\
(22.31)^{* * *}\end{array}$ \\
\hline rho $=.99952855 \quad$ (sigma_u $0.821 \quad$ sigma_e $=0.017)$ & No of obs.138 \\
\hline Hausman:chi2 $(8)=147.08$ & \\
\hline
\end{tabular}

The intra class correlation of 0.999 percent suggests that 99 percent of the variance is due to differences across panels. According to Van der Berg (2008) the rho value for a country "expresses the variance in performance between schools as a proportion of overall variance" (p.3). With reference to the intraclass correlation coefficient in Sindh, given the exceptionally high degree of inequality in the country, it would be reasonable to expect that this would filter through to the education system, creating a highly unequal schooling system. The errors ui (0.821) are correlated with the regressors in the fixed effects model. The $F$ test is less than conventional 0.05 confirming the soundness of the model, $\mathrm{t}$-values test the hypothesis that each coefficient is different from 0 . Two-tail p-values are less than 0.05 percent for five independent variables 
concluding significant influence on the dependable variable, Ipenrol. The coefficients bear a positive sign for six variables and negative sign for two variables (number of schools and urban proportion of population). The results indicate positive relationship between public expenditure and primary enrolment with statistically significant coefficient.

Among the most salient results from the model are the following: in case of primary level education enrolment in Sindh, the coefficient on public expenditures is positive but indicating small impact on enrolment. Expenditure is significant at $1 \%$ level, indicating that by increasing 1 percent in the government expenditure on education would improve enrolment by only 0.01 percent in the province. The results are in conformity with Al-Samarrai (2003), who finds that enrolment in basic education appears to have stagnated, and there are signs that enrolment in many types of government recognized primary schools is beginning to decline despite the fact that government resources devoted to education have increased considerably in real terms.

The model here is:

Ipenrol $=6.96+.018^{*}$ Ipexp $-.035^{\star}$ Ipschool $+.022^{*}$ Ipclass $+.032^{*}$ Ipteacher $+0.96^{*}$ Ipden $+1.60^{*}$ pprate $+.007^{*}$ litrate $-2.80^{*}$ urban $+\ldots$

The higher the number of schools, means ideally more students in the school. Surprisingly more schools have resulted into decrease in enrolment, though not that substantial decrease. This can be seen from the results that public primary schools has a negative coefficient, which is not significant at the traditional levels of $1 \%$ or $5 \%$ indicating that 1 percent increase in the number of schools leads to 0.03 percent decrease in the primary level enrolment. This is probably on account of presence of a large number of dysfunctional schools and many of 
which lie wholly or partially underutilized. The number of teachers has a positive impact on enrolment, but not significant at the traditional levels of $1 \%$ or $5 \% \%$ and shows that a 1 percent increase in this number will lead to 0.03 percent increase in the primary level enrolment. In the context of the impact of number of classrooms on enrolment, the coefficient bears a positive sign and is significant at $5 \%$ level, indicating that if the classroom gets crowded by 1 percent more, the enrolment rate will increase by 0.02 percent. The coefficient of other two explanatory variables, literacy rate is only significant at the $15 \%$ level, implying that it is insignificant at the traditional $5 \%$ level, while another explanatory variable participation rate is positive and significant at $1 \%$ level. The coefficient of the participation rate indicates that if the participation rate goes up by 1 percent, on an average a district enjoys a 1.6 percent increase in enrolment. The population density is also showing a positive and statistically significant coefficient at the level of $1 \%$, which indicates that there is an increase of 0.96 percent in enrolment with 1 percent increase in population density. The urbanization variable for primary level enrolment has a negative coefficient, which is significant at the $1 \%$ level, indicates that 1 percent increase in the urbanization leads to a 2.8 percent decrease in the enrolment. According to Gupta et. al, (2002), urbanization levels can affect outcomes, as the private cost of education (e.g., transportation costs) may be lower for urban households, they are more inclined to send their children to school. The results here are not in conformity with Gupta et al.'s referred statement as the urban proportion of the population has a negative sign (-2.8 percent) on primary school enrolment in Sindh. This is clearly because of the growth of private sector schooling in the urban areas on account of quality aspects - a demand 
factor which pulls middle class and others to private schooling and is now a widespread phenomenon.

In case of middle level education (table $7-5$ ) the intra class correlation of 0.963 percent suggests that 96 percent of the variance is due to differences across panels. The errors ui $(0.427)$ are correlated with the regressors in the fixed effects model.

Table 7-5: Summary of significant findings using the fixed effects model

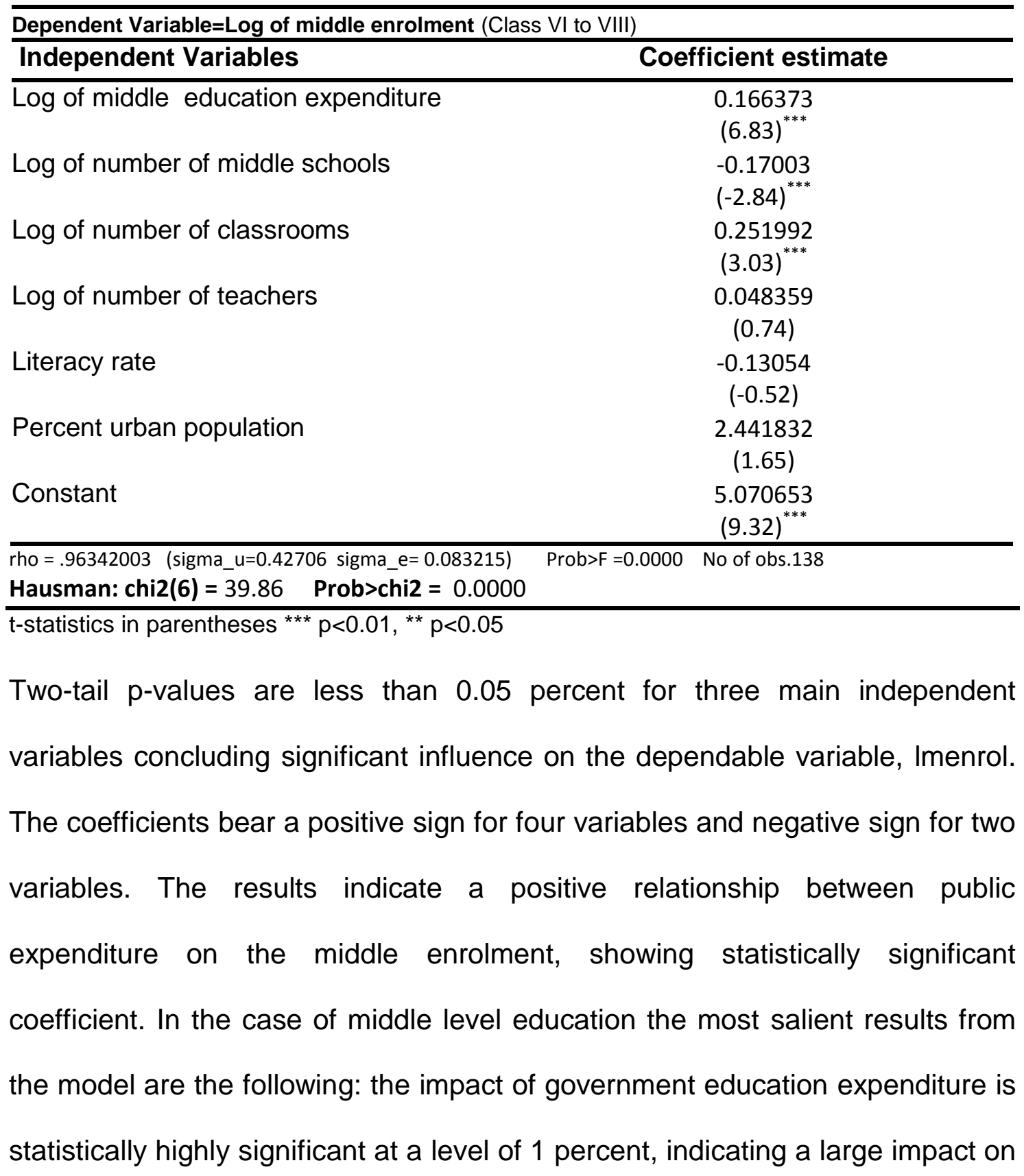


enrolment. This implies that with 1 percent increase in expenditure, enrolment increases by 0.16 percent. This demand is predominantly because of serious shortage of middle schools; which are only 2505 compared to 44,522 primary schools.

The model here is:

Imenrol $=5.07+.166^{\star} I$ mexp $-.170^{\star}$ Imschool $+.251^{\star}$ Imclass $+.048^{*}$ Imteacher $-.130^{*}$ litrate $+.2 .44^{*}$ urban $\ldots .$.

In the context of the impact of number of schools on enrolment the coefficient bears a negative sign and the result is significant at $1 \%$ level; it says that if the schools get crowded by 1 percent more, the enrolment will decrease by 0.17 percent. However, the number of classrooms has a significant and positive coefficient at a level of $1 \%$; it says that if the classroom gets crowded by 1 percent more, the enrolment will increase by 0.25 percent. The number of teachers has a positive impact on enrolment, but not significant at the traditional levels of $1 \%$ or $5 \% \%$ indicates that 1 percent increase in the number of teachers will lead to 0.04 percent increase in the middle level enrolment. Most strikingly, the literacy rate is not associated with improved enrolment. Urbanization levels could potentially affect outcomes as well. As the private cost of education (e.g., transportation costs) may be lower for urban households, they are more inclined to send their children to school (Gupta et. al, 2002), indicating that a 1 percent increase in urbanization would lead to 2.4 percent increase in middle enrolment in Sindh. However the result is not significant at the traditional levels of $1 \%$ or $5 \% \%$. This result is in conformity with Gupta et al.'s referred statement. In the case of secondary level education (table 7-6) the intra class correlation of 0.916 percent suggests that 91 percent 
of the variance is due to differences across panels. The errors ui (0.353) are correlated with the regressors in the fixed effects model.

Table 7-6: Summary of significant findings using the fixed effects mode

\begin{tabular}{lc}
\hline Dependent Variable= Log of secondary enrolment $($ Class IX to X) & \\
\hline Independent Variable & Coefficient estimate \\
\hline Log of secondary education expenditure & 0.177992 \\
Log of number of secondary schools & $(2.68)^{* * *}$ \\
& 0.450935 \\
Log of number of classrooms & $(2.96)^{* * *}$ \\
Log of number of teachers & -0.28689 \\
& $(-2.45)^{* *}$ \\
Log of population density & 0.145646 \\
& $(0.95)$ \\
Literacy rate & 0.089537 \\
Percent of urban population & $(0.55)$ \\
Constant & 0.042384 \\
& $(0.13)$ \\
& 1.018273 \\
\end{tabular}

Rho $=.91634761$ (sigma_u $=0.353887$ sigma_e $=0.106924) \quad$ Prob $>F=0000$

No of Obs.138

Hausman: $\operatorname{chi2}(7)=15.33$ Prob $>$ chi2 $=0.0000$

t-statistics in parentheses ${ }^{* * *} p<0.01,{ }^{* *} p<0.05$

As already mentioned above that the intra-class correlation coefficient in context of education in Sindh, given the exceptionally high degree of inequality in the province, would expect to be high, creating a highly unequal schooling system. The $F$ test is less than conventional 0.05 confirming the soundness of the model, t-values test the hypothesis that each coefficient is different from 0 . Two-tail P-values are less than 0.05 percent for three independent variables concluding insignificant influence on the dependent variable, Isenrol. However, it is more than 0.05 percent for remaining four. The main predictor expenditure on the secondary level education, showing statistically highly significant coefficient. The coefficients bear a positive sign for all the variables except for the impact of number of class rooms. The results indicate a statistically 
significant and positive relationship between public expenditure and enrolment at the secondary level of education.

In case of secondary level education, the model here is:

Isenrol $=4.13+.177^{\star}\left|\operatorname{sexp}+.450^{\star}\right|$ sschool $-.286^{\star} \mid$ sclass $+.145^{\star} \mid$ steacher

$+.042^{*}$ litrate $+.089^{*}$ Isden $+1.01^{*}$ urban $\ldots$

All explanatory factors bear a positive sign except the number of class rooms. The panel regression results for secondary level education indicate that public expenditure on education at the secondary level has been generally productive, and the effect of education expenditure is statistically highly significant at $1 \%$ level. A 1 percent increase in government education expenditure increases secondary education enrolment by 0.17 percent. The secondary education results are consistent with those of Gupta et al. (1999). The bigger the number of schools, which is to say that more students in a school means there is high enrolment. The result is significant at $1 \%$ level, indicating that a 1 percent increase in this number will lead to 0.45 percent increase in enrolment. However, the number of classrooms has a negative coefficient. The result is significant at $5 \%$ level; it says that if the classroom gets crowded by 1 percent more, the enrolment will decrease by 0.28 percent. The possible explanation for this negative relationship could be the distribution of classrooms amongst the middle and secondary students in the high schools which cater to both the middle as well as secondary students. Teachers' placement in a secondary school is on a subject basis; although there is a shortage of subject specialists, there are quite sufficient numbers of teachers in secondary schools. The result indicates that teachers influence the enrolment with a 1 percent increase in number of teachers, leads to an increase in the enrolment by 0.14 percent; 
however it is not significant at the traditional $5 \%$ level. The other three explanatory variables; population density, literacy rate and percent of urban population have a positive impact but coefficients are only significant at the $55 \% ; 13 \%$ and $44 \%$ level, implying that it is insignificant at the traditional $5 \%$ level.

\subsection{EFFICIENCY FRONTIERS}

As stated earlier stochastic frontier models have become a popular subfield in Econometrics. Richmond (1974) as cited in Coelli, et al. (1998), suggested that the parameters of the stochastic frontier production function, can be estimated by using either the maximum likelihood (ML) method or the corrected ordinary least squares (COLS) method. The stochastic frontier model was further extended to accommodate panel data first by Schmidt and Sickles (1984) who modeled technical inefficiency as time-invariant then by Battese \& Coelli (1992) who modeled the technical inefficiency as time variant.

To measure efficiency, I have adopted the stochastic production frontier approach at the individual (district) level and have used the panel data estimator, programmed in STATA11. On the basis of the inputs previously mentioned and the enrolment as an output, an efficiency analysis has been implemented by attributing an efficiency score to each district. Time invariant efficiency estimations have been found to be inconsistent and not feasible in case of primary level education. Hence, time-varying decay model has been applied. However, in the case of middle and secondary level education time invariant efficiency estimations have been found to be consistent and feasible, which have accordingly been applied. Examining the results of the time-varying decay model and time invariant decay model, it is observed contrary to what is 
expected, the coefficients of the proportion of the urban population are negative in case of secondary and primary level education, while it is positive for the middle level education. The coefficients of other main variables are positive in case of all three stages of education. For the primary level education (appendix 7-B) the variance parameter, is approximately 0.99 . This implies that of the total variation captured by sigma squared $(0.61824)^{14}, 99$ percent is as a result of the technical inefficiency in production processes while 01 percent could be attributed to other stochastic errors. For middle level education (appendix 7-C) the variance parameter, is approximately 0.95 . This implies that of the total variation captured by sigma squared $(0.161244) 95$ percent is as a result of the technical inefficiency in production processes while only 5 percent could be attributed to other stochastic errors. Similarly, for the secondary level education (appendix 7-D), the variance parameter, is 0.96 . This implies that of the total variation captured by sigma squared $(0.294728) 96$ percent is as a result of the technical inefficiency in production processes while only 4 percent could be attributed to other stochastic errors. As described earlier, in measurement of technical efficiency a district is considered to be technically efficient if it achieves the highest possible output (enrolment) from a given amount of resources used or, conversely, uses minimum resources to produce a given level of output. The efficiency is measured by the ratio of actual observed output to maximal potential output. The ratio can take the values between zero and one; one being perfectly efficient. Here, a clarification is necessary that an efficient district does not necessarily produces the maximum level of output given set of inputs, it is comparatively best managed. On the other hand, a

\footnotetext{
${ }^{14} \mathrm{Sigma}^{\mathrm{U}^{2}}$ is the sum of sigma-u squared and sigma-v squared, 0.617941 and 0.000301 , respectively
} 
less efficient district does not necessarily need a higher resource input to match the performance standard of efficient districts as there may be other inefficiency parameters which impinge upon the performance. And, also an efficient district in case of primary level education may not necessarily be efficient in case of middle level education or secondary level education. Hence, the varied efficiency is dependent upon that specific level of education.

\subsection{RESULTS OF THE STOCHSATIC FRONTIER ANALYSIS}

The efficiency is calculated through the Stochastic Frontier Analysis, which tells us, that from the given inputs of expenditure, school and teacher characteristics among other variables, the enrolment (the output in the model) of that district is good or not. Higher the efficiency better would be the net enrolment from a given set of inputs. In case of primary level education, the results show an overall mean efficiency of 39.53 ; in case of middle level education, the results show an overall mean efficiency of 64.16 and in case of secondary level education, the results show an overall mean efficiency of 75.50. The results indicate that it costs less for efficient districts to improve enrolment. Table 7-7 gives the district efficiency ranking for the primary level education for 23 districts in the province of Sindh. It is evident from the table below that Sukkur (mean efficiency 0.98), Karachi (mean efficiency 0.98) and Khairpur (mean efficiency 0.96) districts are the most efficient districts in terms of generating enrolment at the primary level with the given resources that we used as input in our model. The results show that only seven districts (30 percent) are on the frontier in case of primary level education.

Around two thirds of the school districts have an efficiency score of less than 39 percent. District Matiari (mean efficiency 0.10), district T.A.Yar (mean efficiency 
0.09),) and district T.M.Khan (mean efficiency 0.09) are the least efficient districts for primary level of education.

Five districts are clustered around the mean efficiency of 0.39 while 11 districts are way below the mean efficiency of 39 percent. We can say that there is a lot of variation in the efficiency of the districts at the primary level of education as

Table 7-7: District Mean Efficiency (Primary Education)

\begin{tabular}{|c|c|c|c|c|c|}
\hline $\begin{array}{c}\text { Efficiency } \\
\text { Ranking }\end{array}$ & District & $\begin{array}{c}\text { Primary } \\
\text { mean }\end{array}$ & $\begin{array}{c}\text { Efficiency } \\
\text { Ranking }\end{array}$ & District & $\begin{array}{c}\text { Primary } \\
\text { mean }\end{array}$ \\
\hline 1 & Sukkur & 0.983005 & 13 & Ghotki & 0.274704 \\
\hline 2 & Karachi & 0.980997 & 14 & Kambar-Shahdadkot & 0.274231 \\
\hline 3 & Khairpur & 0.969598 & 15 & Larkana & 0.272228 \\
\hline 4 & Thatta & 0.809407 & 16 & Kashmore & 0.264028 \\
\hline 5 & Dadu & 0.545807 & 17 & Naushero Feroze & 0.250186 \\
\hline 6 & Sanghar & 0.495867 & 18 & Jacobabad & 0.225357 \\
\hline 7 & Tharparkar & 0.420553 & 19 & Hyderabad & 0.206431 \\
\hline 8 & Badin & 0.348133 & 20 & Shikarpur & 0.203362 \\
\hline 9 & Umerkot & 0.337241 & 21 & Matiari & 0.102061 \\
\hline 10 & Jamshoro & 0.325888 & 22 & T. A. Yar & 0.096461 \\
\hline 11 & Mirpur Khas & 0.306587 & 23 & T.M.Khan & 0.09536 \\
\hline 12 & Shaheed Benazirabad & 0.305335 & \multicolumn{2}{|c|}{ Average Mean } & 0.39534 \\
\hline
\end{tabular}

Source: Author's computation

the lowest efficiency is for T.M. Khan district (mean efficiency 0.09 ) and the highest efficiency is for Sukkur district (mean efficiency 0.98).

In case of middle level education the results show an overall mean efficiency of 64 percent. It can be seen from table 7-8 that Khairpur (mean efficiency 0.95), Sanghar (mean efficiency 0.95) and Larkana (mean efficiency 0.94) are the most efficient districts in terms of generating enrolment at the middle Level with the given resources that were used as input in this model.

Thatta, Sukkur and T. M.Khan are the least efficient districts for middle level of education. Most of the other districts are clustered around the mean efficiency of 0.64 . We can say that there is a lot of variation in the efficiency of the districts at the middle level of education as the lowest efficiency is for T.M. 
Table 7-8 :District Mean Efficiency (Middle Education)

\begin{tabular}{|c|c|c|c|c|c|}
\hline $\begin{array}{c}\text { Efficiency } \\
\text { Ranking }\end{array}$ & District & $\begin{array}{c}\text { Middle } \\
\text { mean }\end{array}$ & $\begin{array}{c}\text { Efficiency } \\
\text { Ranking }\end{array}$ & District & $\begin{array}{c}\text { Middle } \\
\text { mean }\end{array}$ \\
\hline 1 & Khairpur & 0.956919 & 13 & Umer kot & 0.607175 \\
\hline 2 & Sanghar & 0.952933 & 14 & Mirpur Khas & 0.556044 \\
\hline 3 & Larkana & 0.947062 & 15 & Matiari & 0.544008 \\
\hline 4 & Naushero Feroze & 0.855479 & 16 & Hyderabad & 0.52042 \\
\hline 5 & Ghotki & 0.817163 & 17 & Tando Ala Yar & 0.473871 \\
\hline 6 & Karachi & 0.808366 & 18 & Kashmore & 0.460014 \\
\hline 7 & Badin & 0.792578 & 19 & Jacobabad & 0.458887 \\
\hline 8 & Dadu & 0.738065 & 20 & Jamshoro & 0.451992 \\
\hline 9 & Shaheed Benazirabad & 0.728437 & 21 & Thatta & 0.425903 \\
\hline 10 & Kambar-Shahdadkot & 0.715063 & 22 & Sukkur & 0.422653 \\
\hline 11 & Tharparkar & 0.616949 & 23 & T.M.Khan & 0.298288 \\
\hline 12 & Shikarpur & 0.609781 & & Average Mean & 0.641654 \\
\hline
\end{tabular}

Source: Author's computation

Khan district (0.29) and the highest is for Khairpur district ( mean efficiency 0.95).

In case of the secondary level education the results show an overall mean efficiency of 75 percent. According to the results shown in table 7-9 for the secondary level of education, Larkana district (mean efficiency 0.96 ), is the

Table 7-9 : District Mean Efficiency (Secondary Education)

\begin{tabular}{|c|c|c|c|c|c|}
\hline $\begin{array}{c}\text { Efficiency } \\
\text { Ranking }\end{array}$ & District & $\begin{array}{c}\text { Secondary } \\
\text { mean }\end{array}$ & $\begin{array}{c}\text { Efficiency } \\
\text { Ranking }\end{array}$ & District & $\begin{array}{c}\text { Secondary } \\
\text { mean }\end{array}$ \\
\hline & & & 13 & Kashmore & 0.721038 \\
\hline 1 & Larkana & 0.969933 & 14 & Shikarpur & 0.6462369 \\
\hline 2 & Khairpur & 0.955487 & 15 & Badin & 0.646237 \\
\hline 3 & Naushero Feroze & 0.950661 & 16 & Hyderabad & 0.644676 \\
\hline 4 & S.aheed Benazirabad & 0.946284 & 17 & T.A. Yar & 0.639331 \\
\hline 5 & Kambar-Shahdadkot & 0.939499 & 18 & Matiari & 0.63469 \\
\hline 6 & Ghotki & 0.937264 & 19 & Tharparkar & 0.632963 \\
\hline 7 & Sukkur & 0.865412 & 20 & Jacobabad & 0.629748 \\
\hline 8 & Karachi & 0.853094 & 21 & Jamshoro & 0.598610 \\
\hline 9 & Umerkot & 0.849291 & 22 & Thatta & 0.552033 \\
\hline 10 & Sanghar & 0.843897 & 23 & T.M.Khan & 0.319509 \\
\hline 12 & Mirpur Khas & 0.801812 & & Average Mean & 0.755071 \\
\hline
\end{tabular}

Source: Author's computation

most efficient district of Sindh in terms of a secondary level of education 
provided, followed by Khairpur (mean efficiency 0.95) and Nausheroferoz (mean efficiency 0.95 ) out of the maximum of 1.0 . However, 12 districts are above the mean efficiency level of 0.75 which is comparatively high when compared to primary and middle level of education efficiency. Jamshoro (mean efficiency 0.59) Thatta (mean efficiency 0.55) and T.M.Khan (mean efficiency 0.31) are the least efficient districts in providing secondary level education, however the mean efficiency of the least performing districts in the case of secondary level education is much more than the mean efficiency of least performing districts at the primary level of education. It can be seen that district Khairpur stands out as the only district, which consistently appears in the top three most efficient districts, at all the three levels of education. District Khairpur is at number one in efficiency ranking at the middle level of education and at number 2 in case of secondary level education and at number three in case of primary education. Similarly for less efficient districts, district T.M.Khan appears at all three levels of education as the least efficient district. It may be pertinent to note that district T.M.Khan was carved out as an independent district in the year 2005 from the district Hyderabad. As such the best statistics of urban character of Hyderabad gave some support to district T.M.Khan which however, as an independent district has gone. Hence, T.M.Khan couldn't improve upon its performance alone.

\subsection{CONCLUSION}

The purpose of this study was to examine the efficiency of Sindh public school districts through Stochastic Frontier Analysis. The school year 2005-06 to 2010-11 was selected to provide the panel data set. The SFA estimation method calculated and assigned efficiency scores to each of the 23 districts 
considered in the study. This study sought to identify variables which impact school district efficiency. Amongst the eight variables selected for regression analysis at the primary education level, five statistically significant variables were identified as impacting the district efficiency of school districts in Sindh. Similarly in case of middle out of six variables, four were indentified impacting middle education enrolment. And for secondary education out of seven selected variables, six could impact upon secondary enrolment. Indeed, the model presented and estimated in this paper improves upon previous studies at the macro level in terms of including a richer palette of explanatory variables within an estimation strategy that explicitly takes into account unobservable district specific factors in the province of Sindh. Results show that educational spending improves enrolment in Sindh; the impact is more pronounced at middle and secondary level of education. Of the three school related characteristics the number of class rooms and teachers have a positive impact while the effect of schools is negative. Such heterogeneous effects of educational spending illustrate the importance of analysis at more localized levels, and bring into question some cross-country studies that assume outcome homogeneity across entire country. 
CHAPTER 8 : DISCUSSION, CONCLUSION AND RECOMMENDATIONS

\begin{abstract}
The previous chapters have empirically analyzed the technical efficiency of Sindh's 23 districts' school education system using parametric models based on a panel data set on performance index and educational inputs of primary, middle and secondary schools for the period 2005-06 to-2010-11. Accordingly the education outcomes have been examined through an inter-district evaluation of Sindh's districts. This evaluation is consistent with the literature and allows for the identification of the process through which government expenditure and other policy interventions affect education enrolment over time. The research focuses on identifying variables which explains the variations in the relative technical efficiency or inefficiency in providing school education at the provincial level in Sindh. The estimated coefficients of the stochastic frontier production function calculate indices of technical efficiency for each district in the province.
\end{abstract}

These results are expected to provide new evidence of a systematic relationship between measured school inputs and student enrolment. The approach shows how public spending and other linked interventions influence education enrolment at different levels of education. However, the major question is as to how substantial these effects are? Although the results are statistically significant, but impact is weak in case of primary level enrolment.

By examining and analyzing technical efficiency during a six-year period from 2005-06 to 2010-11, this research has systematically addressed the following three questions: a) To estimate the technical efficiency of the districts in Sindh in providing primary, middle and secondary education especially in the context of enrolments at these levels; b) To analyze the factors which explain the variations in the relative technical efficiency or inefficiency in providing school education at the provincial level in Sindh; and c) To examine the structural and institutional weaknesses which hamper improvements in education in Sindh.

This chapter summarizes the key findings for each of these research questions and draws conclusions, as follows: Section 8.1 recaptures the 
provincial and district contexts and ambit of the thesis; Section 8.2 summarizes the study and the main findings from the previous chapters; Section 8.3 discusses policy implications from the empirical findings; Section 8.4 highlights the specific contributions of this study; Section 8.5 outlines some of this study's limitations; and Section 8.6 gives conclusion and recommendations.

\subsection{RECAPTURE OF THE PROBLEM AND CONTEXT}

\subsubsection{Provincial context}

Sindh is the most urbanized and the second largest province of Pakistan yet suffers from serious challenges on primary, middle and secondary education. The province has a huge economic infrastructure; which contributes a significant share to the national GDP other than generating over 60 percent of country's revenue. Karachi, its capital is the financial and trade hub of the country. At the same time it paradoxically has a extremely high poverty level of 34 percent, urban rural disparities with rural poverty as high as 46 percent, as well as gender disparities with rural women and girls having the worst indicators on food security; nutrition; literacy and enrolment. Sindh's gross school enrolment rate of 84 is behind Punjab by 14 percent and behind the national GER by 8 percent. The overall gross rural enrolment in Sindh is behind the national rural GER by 14 percent. Sindh's rural females' gross enrolment is 55 compared to the national rural females' enrolment of 75 . The situation is gloomy as from 2004-05 to 2010-11; the GER has inched from 75 to 84 . In addition, the student learning levels assessed through various surveys and assessments reflect poor outcomes. The overall spending on education has increased from Rs. 27 billion in 2005-06 to Rs. 52 billion in 2010-11 and by 
2012-13 it has reached Rs. 100 billion. There are therefore increasing questions regarding the efficacy of public expenditure and its impact on education in Sindh. There are presently, 44,522 primary schools in Sindh and against these, there are only 2505 middle schools and 1641 secondary schools, which together constitute less than 10 percent of primary schools. The most interesting aspect of school portfolio is that about 56 percent of schools are mixed i.e these are attended by both girls and boys. Whereas the entire education portfolio across the country is segregated on gender lines. Therefore, presence of 56 percent of mixed schools contradicts the official segregation and results in various inefficiencies. The main aim of this study is to conduct an empirical investigation into Sindh's public school education, with the focus on measuring their technical efficiency.

\subsubsection{District context}

The districts in the province have different socio economic characteristics which are likely to impinge on the state of education in the given district. For instance, the district Karachi is altogether a peculiar case, given its demography, economy, urbanization, level of citizen's education and awareness. Then the district Hyderabad also has peculiar characteristics. It is the second largest city of the province and as such it can neither be clubbed with Karachi nor with the other relatively less developed districts. The districts of Sukkur, Mirpurkhas, Benazirabad, Khairpur, Nausheroferoze, Sanghar, Larkana and Dadu can be clubbed together as these have significant and comparable agriculture base, pockets of urban population together with segments of under developed populations. Tharparkar and Umerkot are the desert districts having scattered and sparsely populated villages where as Thatta and Badin are the two coastal 
districts having highly under developed scattered settlements. In the north Sindh, bordering Balochistan and south Punjab are the districts of Ghotki, Jacobabad, Kashmore, Kamber and Shikarpur which have strong feudal characteristics.

\subsubsection{Ambit of thesis}

This thesis attempts to assess technical efficiency of primary, middle and secondary schooling in the province and provides a detailed analysis by districts undertaken for the period from 2005-06 to 2010-11. Structural deficiencies are discussed and supported by cross-sectional survey of district education managers, review of expenditure and landscaping of policy landscape. Finally it explains the variations in technical efficiency by primary, middle and secondary school level as analyzed through panel data on both supply side factors as well as district profile of targeted beneficiaries.

\subsection{SUMMARY OF MAJOR EMPIRICAL FINDINGS}

The main objective of this study is to investigate whether there are inefficiencies in the production of Sindh's school education, and if there are; to investigate the sources of these inefficiencies. We used the estimated coefficients of the stochastic frontier production function to calculate indices of technical inefficiency for each district. SFA, a parametric approach, was employed in this thesis to empirically analyze the technical efficiency in Sindh's school education sector. To the best of my knowledge, no previous study of education sector in developing countries has employed a SFA at the district level. This study will contribute to the educational research on selecting Stochastic Frontier Analysis as a primary estimation method for analyzing the district efficiency of school education. 
A parametric approach was chosen for the reason that, the production process, especially in education, is characterized by stochastic elements. Based on the empirical findings of this study the major outcomes of this chapter can be summarized as follows:

\subsubsection{Technical efficiency: results from panel data}

This study brings out clearly that educational attainments are multi-dimensional and these are determined by a complex interaction among a variety of variables, with the importance of each variable being different for different stages of education. Key findings are summarized below:

$>$ In the context of impact of education expenditure on education outcomes with reference to enrolments, the panel data evidence reveals that the link between education outcomes and education expenditures at the primary level of education is weak. The results indicate a positive relationship between public expenditure on the primary level enrolment, though the coefficient is small. In case of primary education a 1 percent increase in public spending leads to an increase of only 0.01 percent in the enrolment at primary level.

There is a lot of variation in the efficiency of the districts at the primary level of education the lowest efficiency is for T.M. Khan district (mean efficiency 0. 09) and the highest efficiency is for Sukkur district (mean efficiency 0.98$)$. The mean efficiency at the primary level of education is 0.39 percent with two third districts falling below the mean efficiency line.

In case of the middle level enrolment, results show a statistically significant association between spending on education and enrolment, 
and the coefficient estimates are, positive and comparatively larger than the coefficient estimates for primary enrolment. Here a 1 percent increase in expenditure is resulting in 0.16 percent increase in middle level enrolment. This positive relationship is also reflective of the massive gap between the primary education resources and the middle school resources and there is obviously a crowding in on account of the pathetically low ratio of middle schools compared to primary.

Similarly there is variation in the efficiency of the districts at the middle level of education; the lowest efficiency is observed for T.M. Khan district (0.29) and the highest efficiency is observed for Khairpur district (0.95). The mean efficiency for middle level education is 0.64 .

The results for the secondary level enrolment indicate a statistically significant and positive relationship between public expenditure on the secondary level education. Here a1 percent increase in public spending on secondary education is showing an increase of 0.17 percent in enrolment at this level. This is similar to the situation in middle level education as both the middle and secondary school infrastructure constitutes less than 10 percent of the total schools. It is this constriction that leads to crowding in at middle and secondary level and the resultant surge in demand and enrolment.

$>\quad$ There are also important inter district variations in terms of technical efficiency. For the secondary level, district Larkana is the most efficient (mean efficiency 0.98) followed by Khairpur (mean efficiency 0.95) and Nausheroferoze (mean efficiency 0.95). Here 12 districts are above the mean efficiency level of 0.75 which is higher compared to the primary and middle 
level education efficiency. Jamshoro (mean efficiency 0.59) Thatta (mean efficiency 0.55 ) and T.M. Khan (mean efficiency 0.31 ) are the least efficient districts in providing secondary level education.

The above salient findings show that in the case of Sindh with gradual decline of the public education system, which is more evident in the urbanized districts, probably due to better household resources; people have shifted their preferences towards the private educational institutions. This exit of a higher income and literate group, having a stronger consumer voice, concurrently led to further deterioration in the public education system. Presently only the poor and the weaker segments of society are recipients of the public education in Sindh and unfortunately do not carry an effective voice to hold the system accountable for its continued non performance. The parents' of the students in the public sector schools are the major stakeholders; however they remain the weakest component of the system.

In the case of Sindh, together with the inability of the parents to seek accountability, the other major weakness is on account of supply side issues. Quality of school education is weak on numerous accounts other than in terms of fewer teachers and low number of classrooms as shown by our panel data. There is overriding number of primary schools comprising of one / two rooms and having a single teacher, making the overall school management and monitoring highly challenging. There is conspicuous crowding in at middle and secondary level exhibiting serious need for greater number of classrooms / schools at these levels. This big gap between primary, middle and secondary education is one of the main inhibiting factors for specially girls' students who after finding no nearby middle or secondary school drop out of the system. 


\subsubsection{Productivity differences across public and private managers}

School management issues are also more persistent in public sector schools over private schools as seen from the cross sectional survey. The school planning process in public sector does not involve school administrators and educators, lacks reliable data for effective management, and often falls short of utilizing school budget. This analysis relating to productivity differences among public and private-schools using non-parametric approach shows that the managers and teachers in public schools are more likely than their private school counterparts to have different management attributes and different management patterns. The personnel from both the organizations use similar teaching and management strategies. Public sector organizations show a much greater level of interdependence across organizational boundaries as compared to private sector organizations. This greater interdependence leads to more procedural steps and delays as a result of coordination and additional levels of approval required. Because of the increased number of constituents, it is more costly and takes longer to complete projects. Managers in the private sector organizations are more concerned with internal coordination while public sector managers are concerned with linkages outside the organization.

\subsubsection{Overarching structural issues}

Expenditure review and desk review of policy documents undertaken sheds further detail on supply side issues. There have been regular and sizeable budget increases for the sector in the last over two decades and especially in the last decade. However, teacher salary constitutes around 85 to 90 percent of education expenditure with less available for school supplies, repair maintenance and teacher training. The capacity of teachers is weak due to 
rapid expansion of school infrastructure without taking into account district availability of teachers with required education and absorptive capacity within district to manage the large number of government schools. The entire process of teacher recruitment; deployment and retention are also riddled with political patronage, lack of in-service training and absence of performance accountability. This further compromises the quality of teaching, and potentially leads to parents opting for private schools in urban and semi urban areas where private school markets exist.

These schools with almost no other input other than teacher salary are difficult to monitor and the SEMIS data shows that on an ordinary day, an average 30 per cent children do not attend schools. In addition the teacher availability in these, as well as other school supplies also remains questionable. Hence, while the public expenditure on availability of teachers and school infrastructure reflects increases over the 6 year period; these increases do not translate into corresponding improvements in enrolments or completion rates.

Overarching structural weaknesses in the delivery of public sector services and in development of public policies also bear out the internal efficiency premium calculations of system waste and inefficiency in allocating resources. Education policies have been largely developed through centralized processes and placed ambitious educational targets. Devolution to district level initiated in early 2000's transferred funds to district structures that had weak managerial capacity for effective financial planning and at the same time resulted in weak oversight by the province. Moreover district accountability has been weak due to lack of accompaniment of transfer of administrative powers, an absence of a teacher's performance evaluation system, and weak on- ground supervision. 
Structural weaknesses in the educational edifice hence causes substantial loss to the already constrained resource pool allocated to education in Sindh which has barely touched 2 percent of provincial GDP. It has been assessed that the government is incurring an annual loss of approximately Rs. 8.9 billion on account of inefficient and redundant resource allocation of two major inputs i.e. teachers and schools (see chapter 6). This amount could be saved provided that teacher recruitment and school construction is done under some rational policy framework.

\subsubsection{Relevant local evidence}

The findings of inefficiency reported by this thesis are supported by results of the few local surveys that document learning outcomes and monitor quality of education being delivered by the public sector. Amongst these are; The National Education Assessment System (NEAS), undertaken at the National Level (2005-09), Sindh Education Assessment System survey (2006 and 2010), the World Bank rural school survey (2006) and the Annual Status of Education Report (ASER),2010 and 2011. Almost all these bring out a dismal picture of any positively significant relationship between the resources spent and the progress achieved. This analysis adds to the empirical knowledge by not only looking at district wise school efficiency pattern but also underlying factors at the more immediate level, the managerial level, and the larger structural level.

\subsubsection{Relevant global evidence}

The literature on the effectiveness of public expenditure on education shows that there is a variable impact across regions, as well as within countries at a similar stage of development. Our results are in conformity with Al-Samarrai 
(2003), who finds that enrolment in basic education appears to have stagnated, and there are signs that enrolment in many types of government recognized primary schools is beginning to decline despite the fact that government resources devoted to education have increased considerably in real terms. His findings in a study relating to the relationship of public expenditure with primary education for three African countries showed that the composition of the resources and the institutions which managed these resources were important in determining the effectiveness of public spending and that at times the demand side improvements are also likely to impact the education outcomes positively. An ineffective allocation of resources by a district might not show results, whatever the mode and means of spending were. On the flip side of such analysis is another version measuring cognitive achievements indicates short-term changes in students' performance on standardized tests but resultantly ignores long-term outcomes.

Pritchett and Weijer (2010) argue in their recent work that fragile states have low capability and are less developed in one or more of the dimensions of stateness; either they have weak polity, or they have a weak administrative capability resultantly such countries are caught in a -Big Stuck or -capability trap. They contemplate that "wishful thinking, an overly optimistic perspective on level and possible pace of creation of state capability, can lead to a recurrent dynamics of failure and a capability trap. When an organization is overloaded with tasks it cannot perform the temptation is strong to retreat behind a façade of isomorphic mimicry". (P. 28).

As observed by Alderman et al. (2001), public educational expenditures are often used inefficiently, providing school buildings where they are unneeded, 
paying teachers that are unqualified or who do not perform, and providing school supplies that are inadequate and ill-timed. In summary, the results of this paper show that the effectiveness of service delivery is more important than the quantum of public spending.

\subsection{POLICY IMPLICATIONS}

A number of significant policy implications have become apparent from the findings of this thesis. First, the estimated efficiency is an important matter, as the education sector is a critical pillar of human development in Sindh's economy. To achieve high efficiency in government schooling, policy makers must revisit policies to target underlying drivers within the educational systems as well as address the over-arching structural challenges faced by the Education department. Hence evidence from the thesis calls for measures at different levels. Some of these include:

1. Policy measures are needed for improved allocative efficiency of budgetary planning and spending in education sector:

$>$ At the primary school level, curtailment is needed in unplanned expansion in number of primary schools as enhanced budget for schooling is resulting in only marginal gains in enrolment. Redirection of budgetary allocation is instead required from primary school infrastructure expansion towards operational expenses for improving availability of teachers which has a significant impact on enrolment, and other quality improvement measures. Investment in demand creation for primary schooling is also needed in illiterate population, as enrolment positively rises with increased literacy as shown by panel data analysis. 
At the middle and secondary school level, enhancement of spending results in significantly higher enrolment. Such funding needs to be made on infrastructure expansion in terms of both more classrooms in existing schools as well as putting up of new schools, so as to improve existing unfavorably high student: classroom ratios that are indicative of crowding. Placement of middle and secondary schools is needed in high population density areas as these improve enrolment rates as shown by panel data analysis. These necessarily do not need to be accompanied by demand creation communication strategies as sufficient demand is present due to the severe shortage of middle and secondary schools in both public and private sectors.

The Government of Sindh is already working on "school consolidation" policy aiming to merge multiple schools either in same premises or in nearby vicinity for facilitating more manageable; resource efficient school units. This has been under debate and is also supported by international donors given multiple efficiencies involved in the concept. Unfortunately alike many other structural corrections; this particular reform too is probably faced with weak implementation and needs to be put on ground.

2. Managerial capacity and work culture at district education offices needs to be strengthened to enable districts to improve school efficiency.

Utilization of school budgets is lower than private sector as shown by the managerial survey given in chapter 6 and requires involvement of district education mangers in provincial planning 
process so as to make education policies more realistic to absorptive capacity of districts, suited to contextual needs rather than a 'one size fits all approach', and building in of cost-effective local measures for strengthening schooling.

A shift needs to be made from the current practice of input based budgeting as discussed in chapters 3 , towards output based budgeting linking budget preparation with key performance targets including participation as well educational attainments.

A work culture for use of MIS data for planning and managerial purpose needs to be institutionalized in district education office which is presently missing. MIS data in public sector is perceived to be less reliable than private sector, as reported by the thesis in chapter 6 , and one key measure to improve reliability will be the use of data for planning which will result in MIS reporting being taken more seriously.

$>$ The practice of Monitoring and Evaluation (M\&E) of schools needs to be institutionalized in the public sector, which is currently missing as documented through the managerial survey given in chapter 6. M\&E will require a separate budgetary line, it is recommended that these activities be linked to performance based topping up of district and school budgets, and should involve both internal and external monitors for transparency.

3. A set of governance measures are required for improving supply of quality teachers, as teacher presence has been shown in the thesis to be a critical factor behind efficiency at all levels of schooling. 
Merit and accountability in recruitment and posting of teachers needs to be reinforced to counter political appointments made by elected representatives and local education department. This often serves as a convenient source of jobs for the ruling political parties, as identified earlier through desk review in chapter 3 . Though there are claims that teacher recruitments are on the basis of third party testing mechanisms but these are seen to be very broad-based tests at provincial level which do not test many critical teaching capabilities required for different levels of teaching. Also there is need to review the teacher transfer policies as the existing patronage based transfers invariably leads to teachers locating themselves in bigger urban centers. In the underserved districts facing scarcity of female teachers, mixed schools run by male teachers can be promoted at least for primary level schooling.

$>$ Teacher training, educational aids and other such quality improvement inputs need to be built into operational budgets, as presently the expenditure review given in chapter 3 indicates that school budgets predominantly comprise of staff salaries. Though lately there has been improvement in non salary budgets but unfortunately many of these non salary inputs remain in the control of the provincial education department with very little and slow transmittal and utilization at school level.

4. Innovations and reforms in provincial planning and oversight are called for to overcome some of the larger structural gaps in the education sector. With termination of the district devolution set-up and promulgation of $18^{\text {th }}$ 
Constitutional Amendment transferring policy making to provinces, the provincial level in the current set up enjoys an unusual level of legislative, budgetary and administrative planning powers.

A shift needs to be made from unplanned investment in infrastructure to quality assurance of existing infrastructure, and focal expansion in middle and secondary school levels in high density areas.

Visible growth in expenditure needs to be in the operational budgets for quality improvement rather than in development budgets for infrastructure expansion as has been the historic pattern so far. District autonomy in allocating school budgets needs to enhanced gradually for more effective school resources by gradually bringing in effective M\&E systems both at district and provincial levels.

District accountability needs to be strengthened by linking school efficiency parameters with resource allocation. Innovations in allocation mechanisms can involve performance contracts with districts, performance allocation competitive funds and performance based topping up of district budgets.

Administrative powers for teacher recruitment, transfer and suspension that remain centralized at the provincial level need to be devolved to districts for effective local accountability and oversight over teachers' availability and performance.

To conclude, this thesis provides policy recommendations for a series of interconnected policy measures at school, district and provincial levels, for maximizing output of Sindh government's spending on education. It maintains that unless a number of structural and innovative measures related to planning 
budgeting and monitoring are not implemented; increased funding will result in only marginal gains. These are vital to ensure that the sector remains robust and flexible in confronting likely critical changes.

\subsection{CONTRIBUTIONS OF THE STUDY}

According to the objectives and questions discussed above, the current thesis makes four significant contributions to the literature of efficiency in school education in Sindh province.

First, this thesis is the first to examine the issue of efficiency by employing the fixed effects estimation techniques and stochastic frontier analysis in the measurement of efficiency in public sector schools. Second, it incorporates multiple inputs. Third, to the best of my knowledge, this is the first study to provide detailed disaggregated analysis at the district level applying a district efficiency index in the public sector education to analyze efficiency, whereas other works have presented provincial / state and national level analysis. Finally, it adds to empirical knowledge within the South Asian context by measuring public sector education system efficiency in response to significant policy changes in education sector in the wake of devolutionary changes.

\subsection{LIMITATIONS OF THE STUDY}

Despite the relevance and urgency of this study and its theoretical and empirical merit, like any other study it has limitations; however, these offer an opportunity for further research to deepen the understanding of the efficiency of the Sindh's public sector school education. First, the current study uses the SFA methodology to compute technical efficiency. The stochastic frontier production has generally been estimated by Maximum Likelihood (ML) 
estimates. This will provide the correct results provided the likelihood function is correctly specified, and more important, there are no measurement errors in the variables. However, estimating this production function in practice is often complicated by multicollinearity. In addition, the specification may not make economic sense for all observations and thus need to be checked. For example, the estimated coefficients may imply for a particular observation that increasing inputs would lead to fewer outputs. It also requires that the individual specific component to be uncorrelated with all control variables and the error component. It is difficult to justify these assumptions in most real world situations.

Second, data availability is also somewhat limited in this study, because it was not possible to incorporate the contextual or non-discretionary factors into the empirical analysis. As a result, the present analysis did not examine the impact of environmental factors that could influence the efficiency and productivity of Sindh's public sector school education. Third the Institutional factors influencing efficiency, as the data limitations inhibiting the measurement of policy on a consistent basis across countries, are arguably more severe than those affecting the measurement of efficiency. Comparable cross-country data exist for only a limited number of measures of national policy that can be construed as affecting efficiency. Hence, any variable pertaining to policy and governance could have been beneficial for this study.

\subsection{CONCLUSION AND RECOMMENDATIONS}

The measurement of efficiency in education of how institutions can affect efficiency is hampered at the provincial level by a lack of comparable data. Choices need to be made that either limit the richness of the specification of the 
educational production function or limit the amount of information available over time. The fact that the results were comparatively weak at the provincial level may reflect both the limited number of policy indicators and the relatively few observations available. The small size of the national cross-section reduces the power of the non-parametric estimators, which are very data demanding. Hence, utilizing parametric estimators have taken care of this issue. Notwithstanding these shortcomings, the research was able to identify important differences in efficiency across different districts in Sindh and also to link some of these differences to differences in policy settings across the province. The analysis demonstrates that a considerable variation exists in levels of educational efficiency across the province. At the school level, the results indicate that when controlling for other factors, resource savings would be as much as one third for the median school if the school raised its level of efficiency to that of the best performing school in province. The analysis could not identify robustly aggregate institutional settings that were related to more efficiency in the school education sector, but greater decentralization appears to improve efficiency and policies which are conducive to better resource allocation reduce the variation in efficiency levels within countries. It also identified a number of policy settings at the school level that appear conducive to raising efficiency, such as greater decision-making autonomy and assessment policies that monitor student performance and allow for benchmarking between districts and also schools.

Based on the fore-going a question may arise as to why focus on technical efficiency if the objective of policy makers is to produce the most school output with the least amount of resources. While technical efficiency does not imply 
economic efficiency, it is a necessary condition for achieving economic efficiency for giving information that school districts are not achieving technical efficiency and thus, implies that they are not operating with economic efficiency. Also because production technology is almost the same in public schools across Sindh, the most technically efficient school districts may provide a benchmark for 'best practice' that other districts could follow the example.

Since the mid-1990s, Sindh has built an upward trend in real government expenditures on the education sector. It is not necessary that these expenditures are 'comparable' when comparing education expenditures across the country, as there are other factors that determine the size of expenditure on education. These include the size of the public sector, the size of the economy as a whole, the income level, the share of private sector, the number of service beneficiaries, etc. Hence, the optimum decisions are not attainable at the multilevel government structure, since district governments cannot internalize the full set of externalities which a particular decision brings about. The district government has its own preference structure which, in general, does not coincide with the federal government's pursuit of 'national interest'. Policy makers often assert that if the government spends more on educating its population, incomes will grow sufficiently to more than recover the investment. Economists and others have proposed many channels through which education may affect growth--not merely the private returns to individuals' greater human capital but also a variety of externalities. The analysis brings us to the conclusion that in the absence of transparent and efficient delivery system at all levels especially at the lowest level of administration; the effort towards universalizing school education is unlikely to be met. The analysis in this report 
suggests that the link between resources and education indicators are weak and that the achievement of the MDGs and EFA targets will require more than just increases in expenditure on primary education. Spending per student has increased dramatically and student-to-teacher ratios have declined, at the same time the scores on national assessments have stagnated, enrolment at primary, middle and secondary levels have increased marginally. Hence we are progressively spending more, without getting corresponding results.

The results indicate that simply spending more on education programs will not guarantee their attainment, as districts with similar characteristics and inputs display quite different results. This does not imply resources are unnecessary, merely that they are unlikely to be sufficient for achieving the education goals. Some of the key factors which play a central role in translating the resources into better schooling outcomes, these include; the composition of quality of education through supply side inputs; better education management and addressing structural issues relating to improving teacher recruitments, low district accountability, unplanned infrastructure expansion and ambitious policy targets. Hence simply spending as per earlier pattern is unlikely to yield results instead there is an urgent need to improve upon the education structure and system including management and accountability to make the public spending more effective. This calls for structural reform which is basically a political decision and without a strong political resolve it may not be possible to reform and evolve structures that are performing and are accountable for their performance. The system decay is such that it is unlikely to be cured through the business as usual approach. 


\section{BIBLIOGRAPHY}

ACEMOGLU, D., JOHNSON, S. and ROBINSON, J.A., 2005. INSTITUTIONS AS A FUNDAMENTAL CAUSE OF LONG-RUN GROWTH. In: Philippe AGHION and Steven N. DURLAUF,eds. Handbook of Economic Growth, Volume IA. New York: Elsevier. B.V, 2005,Chapter 6,pp.386-414.

AHMAD, I., MUSTAFA, U. and KHALID, M., 2007. National Finance Commission Awards in Pakistan: A Historical Perspective, PIDE Working Papers 33, pp.1-22.

AHSAN, MUHAMMAD., 2003. An analytical review of Pakistan's educational policies and plans: Research Papers in Education, 18:3, pp. 259-280.

AKHTAR, H., 1997. Education in Pakistan: fifty years of neglect. Pakistan Development Review. 26:4, pp.1-147.

ALDERMAN, H., BEHRMAN, Jere. R., ROSS, D. and SABOT, R., 1996. Decomposing the gender gap in cognitive skills in a poor rural economy. Journal of Human Resources 31 (1), pp. 229-254.

ALDERMAN, H., ORAZEM, P.F. and PATERNO, E.M., 2001. School Quality, School Cost, and the Public/Private School Choices of Low-Income Households in Pakistan. The Journal of Human Resources, 36 (2), pp. 304-326.

AL-SAMARRAI, S., 2003. Financing primary education for all: public expenditure and education outcomes in Africa, Brighton: Institute of Development Studies, 1-131.

ANALOUI, FARHAD., 1997. Senior Managers and their effectiveness, Avebury: Ashgate Pub.

ANWAR, TALAT., 2004. Impact of Globalization and Liberalization on Growth, Employment and Poverty: A case study of Pakistan, Retrieved from: http://rru.worldbank.org/Resources[acc 28 August 2009.

ANWAR, TALAT., 2004. Trends in Income Inequality in Pakistan between 1998-99 and 2001, paper presented at the 18th Annual General Meeting and Conference held in January 2004, Islamabad.

ARIF, G.M., and NAJUM US SAQIB., 2003. Production of Cognitive and Life Skills in Public, Private, and NGO Schools in Pakistan. Pakistan Development Review (PDR),42 (1), pp. 1-28 (Spring).

ASIAN DEVELOPMENT BANK., 2002. Poverty in Pakistan, Issues, Causes and Institutional Responses, Pakistan: Resident Mission, Islamabad.

ASLAM, Monazza, 2007. Female Autonomy and Gender Gaps in Education in Pakistan. RECOUP Working Paper No. 3, pp.1-44.

ASLAM, MONAZZA., 2007. The Relative Effectiveness of Government and Private Schools in Pakistan: Are Girls Worse Off? RECOUP Working Paper No. 4, pp.1-35.

BAKER, B.D., 2001. Can flexible non-linear modeling tell us anything new about educational productivity? Economics of Education Review 20 (1), pp. 81-92.

BALTAGI, B.H., 2008. Econometric Analysis of Panel Data, $3^{\text {rd }}$ edition. Sussex: John Wiley \& Sons, Ltd. 
BARRO, R.J. and LEE, J.W., 1996. International Measures of Schooling Years and School Quality. American Economic Review, 86 (2), pp. 218-223.

BARROW, M., 1991. Measuring local education authority performance: A frontier approach. Economics of Education Review, vol. 10 (1), pp.19-27.

BATTESSE, G. E., and COELLI, T.J., 1992. Frontier production functions, technical efficiency and panel data with application to paddy farmers in India. Journal of Productivity Analysis 3, pp.153-169.

BATTESE, G. E. and COELLI, T., 1995. A model for technical inefficiency effects in a stochastic frontier production function for panel data". Empirical Economics 20, pp.325-332.

BAUM, C.F., 2006. An Introduction to Modern Econometrics Using Stata, Stata Press.

BEATTIE, V., 2002. Notes for Faculty Talks, Malaysia. University of Stirling, Scotland, UK.

BECKER, G., 1962. Investment in Human Capital: A Theoretical Analysis, The Journal of Political Economy: 70 (5), pp. 9-49

BEHRMAN, J., ANDREW, D.F., MARK, R. Rosenzweig and VASHISHTHA, P., 1999. Women's Schooling, Home Teaching, and Economic Growth. Journal of Political Economy, University of Chicago Press, 107 (4), pp. 682-714.

BEHRMAN, J., DEOLALIKAR, A. and LEE-YING, S., 2002. Promoting Effective Schooling Through Education Decentralization in Bangladesh, Indonesia, and the Philippines. ERD Working Paper Series No. 23, Asian Development Bank, Manila, pp.1-56.

BEHRMAN,J.R., ROSS,D. and SABOT,R., 2008. Improving quality versus increasing the quantity of schooling: Estimates of rates of return from rural Pakistan. Journal of Development Economics 85, pp. 94-104.

BERTELSMANN STIFTUNG, BTI, 2012. Pakistan Country Report. Gutersloh:

Bertelsmann Stiftung, 2012, pp.1-24.

BILQUEES, F. and SAQUIB, N., 2004. DROP-OUT RATES AND INTER-SCHOOL MOVEMENTS:EVIDENCE FROM PANEL DATA, Pakistan Institute of Development Economics (PIDE), November 5, PP.1-41.

BRAND, J. and BOLLEN, K., 2010. A General Panel Model With Random And Fixed Effects: A Structural Equations Approach, Social Forces, 89 (1):1-34, doi: 10.1353/ sof.2010.007.

BRUNS, B., MINGAT, A. and RAKOTOMALALA, R., 2003. Achieving Universal Primary Education by 2015: A Chance for Every Child, World Bank.

CARDOSA , E. 1992. INFLATION AND POVERTY, NBER WORKINO PAPERS

SERIES, Working Paper No. 4006, Cambridge, pp. 1-52. 
CASTILLA, CAROLINA., 2008. Heteroskedasticity in Fixed-Effects One-way Error Components Models: Evaluating the Performance of Standard Tests Department of Agricultural, Environmental and Development Economics, The Ohio State University.

CHAKRABORTY, K., 2001. Measuring Productive Efficiency and Cost of Public Education, Emporia State University.

CHAKRABORTY, K., BISWAS, B. and LEWIS. C., 2000. Economies of scale in public education: An econometric analysis. Contemporary Economic Policy. 18 (2), pp. 23847.

CHAKRABORTY, K., BISWAS, B. and LEWIS.C., 2001.Measurement of technical efficiency In public education: A stochastic and nonstochastic production function approach. Southern Economic Journal 67 (4), pp. 889-905.

CLARKE, P., CRAWFORD Y, C., STEELEZ, and F. and VIGNOLES, A., 2010.The choice between fixed and random effects models: some considerations for educational research. DoQSS Working Paper No. 10-10, University of London.

COLEMAN, J.S., CAMPBELL, E.Q., HOBSON, C.J., MCPARTLAND, J., MOOD, A.M., WEINFIELD, F.D. and YORK, R.L., 1966. Equality of Opportunity, US Government Printing Office:Washington, D.C.

DAILY DAWN, Karachi, December 2, 3, 4, 52006.

DAWOOD, S., 2003. Country Report on Decentralization in the Education System of Pakistan: AEPAM, Ministry of Education, Government of Pakistan.

DEWEY, J., HUSTED, T.A. and KENNY, L.W., 2000.The Ineffectiveness of School Inputs: A Product of Misspecification?. Economics of Education Review, 19 (1), pp. 27-45.

DUKE UNIVERSITY, 1990. Planning Education Reforms in Developing Countries- The Contingency Approach. Duke University Press,1990.

DUNCOMBE, W., AND YINGER, J., 2005. How Much More Does a Disadvantaged Student Cost?. Economics of Education Review, 24, pp. 513-532.

DUNCOMBE, W., LUKEMEYER, A., YINGER, J., 2008. The No Child Left Behind Act: Have Federal Funds Been Left Behind? Public Finance Review 36 (4), pp. 381-407.

EASTERLY, W., 2001. The Political Economy of Growth Without Development: A Case Study of Pakistan, DRG, World Bank.

ERICKSON A. BEST., 1999. Secondary Data Bases and Their Use in Outcomes Research. Journal of Medical Systems, 23: 3.

FARRELL, J., 1957. The Measurement of Productive Efficiency. Journal of Royal Statistical Society, 120 (3), pp. 253-281.

FAZAL, H., QASIM, M., and SHEIKH, K., 2003. An Analysis of Public Expenditure on Education in Pakistan. The Pakistan Development Review: 42: 4, pp. 771-780.

FEDERAL BUREAU OF STATISTICS, 2007. Household Income and Expenditure Survey Frees, W., 2004. Longitudinal and Panel Data, Cambridge University Press. 
FREES, W., YOUNG, R. and LUO. Y., 2001. Case Studies Using Panel Data Models, North American Actuarial Journal, volume 5 (4), pp. 24-42.

GAZDAR, H., 2000. STATE, COMMUNITY, AND UNIVERSAL EDUCATION: A Political Economy of Public Schooling in Rural Pakistan, Asia Research Centre, London School of Economics.

GLUCK, C., 2011. Ready or Not Pakistan's resilience to disasters one year on from the floods, Oxfam Briefing Paper, Islamabad, pp. 1-9.

GHUMAN, S. AND C.B. LLOYD., 2007. Teacher absence as a factor in gender inequalities in access to primary schooling in rural Pakistan. Poverty, Gender, and Youth Working Paper No.1. New York: Population Council.

GLEWWE P. AND KREMER M., 2005. Schools, Teachers, and Education Outcomes in Developing Countries. Center for Global Development, and NBER, Harvard University.

GOLDHABER, D. D. and BREWER, D. J., 1997. Why don't schools and teachers seem to matter?: assessing the impact of unobservable on education production. Journal of Human Resources, 32 (3), pp. 197-210.

GOLEBIEWSKI, J., 2011. An Overview of the Literature Measuring Education Cost Differentials. Peabody Journal of Education: Issues of Leadership. Policy, and Organizations, 86 (1).

GOVERNMENT OF PAKISTAN, 2011. Academy of Educational Planning and Management (AEPAM), Ministry of Education, Islamabad.

GOVERNMENT OF PAKISTAN.1973, Constitution of the Islamic Republic of Pakistan 1973, Islamabad.

GOVERNMENT OF PAKISTAN, 2011. National Management Information system (NEMIS), Islamabad.

GOVERNMENT OF PAKISTAN, 2005. Pakistan Economic Survey 2005-2006, Federal Bureau of Statistics, Islamabad.

GOVERNMENT OF PAKISTAN, 2012. Pakistan Economic Survey 2011-12, Economic Adviser's Wing, Islamabad: finance division.

GOVERNMENT OF PAKISTAN. 2011. Pakistan: Framework for Economic Growth, Planning Commission, Islamabad.

GOVERNMENT OF PAKISTAN.2000. Population Census 1998, Islamabad.

GOVERNMENT OF PAKISTAN. 2010. Problems in the Implementation of National Education Policies (NEPs) at Elementary level, AEPAM , Research Study, 237, p.1-50. GOVERNMENT OF PAKISTAN, 2010. Report of the National Finance Commission. Islamabad: National Finance Commission Secretariat.

GOVERNMENT OF SINDH, 2012. Annual Development Plan 2011-12, Planning and Development Department, Karachi.

GOVERNMENT OF SINDH, 1978.Appointment, Transfer and Promotion Rules 1975, Karachi. 
GOVERNMENT OF SINDH,2006. Budget 2006-07, Department of Finance, Karachi.

GOVERNMENT OF SINDH,2012. Budget 2011-12, Department of Finance, Karachi.

GOVERNMENT OF SINDH, 2001. Devolution of Power under the Local Government Plan, Education Department, Karachi.

GOVERNMENT OF SINDH, 2003. Sindh Education Management Information System, Education Department, Karachi.

GOVERNMENT OF SINDH, 2012. Sindh Education Management Information System, Reform Support Unit, Education Department, Karachi.

GREENE, W., 1993. The Econometric Approach to Efficiency Analysis. In: The Measurement of Productive Efficiency, H. FRIED, K. LOVELL, AND S. SCHMIDT, eds., Oxford University Press, Oxford.

GYIMAH-BREMPONG, KWABENA AND ELIZABETH N. APPIAH., 2004. Technical Efficiency in Ghanaian Secondary Education. Paper presented at the 'Conference on Ghana's Economy', Accra, Ghana.

GREENE, W., 1997. Econometric Analysis, 3rd Edition, Upper Saddle River, N.J.:

Prentice-Hall, chapter 14.

GREENE, W., 1993. Frontier production functions. EC-93-20. New York, USA, Stern School of Business, New York University.

GRONBERG,T., JANSEN,.D.,TAYLOR, L., AND BOOKER, K., 2004. School Outcomes and School Costs: The Cost Function Approach. Texas A\&M University.

GUJARATI, D.N., 1995. Basic Econometrics, New York: McGraw-Hill Inc.

LEIGHTON, KEN and GILLESPY, Mike., 2006. Nottingham Express Transit Line 1: geometrical aspects. Proceedings of the Institution of Civil Engineers: Transport, 159 (TR2), pp.63-68.

GUOXING, YU., 2007. Research Evidence of School Effectiveness in Sub-Saharan Africa EdQual RPC, DFID, UK.

GUPTA, S., VERHOEVEN, M. and TIONGSON, E., 1999. Does Higher Government Spending Buy Better Results in Education and Health Care?' Fiscal Affairs Department: IMF Working Paper WP/99/21.

HANDY, C., 1993. Understanding Organizations. England:Penguin Books.

HANUSHEK, E.A., 1986. The Economics of Schooling: Production and Efficiency in Public Schools. Journal of Economic Literature, 24 (3), pp. 1141-1177.

HANUSHEK, E.A., 1989. The Effect of Differential Expenditures on School Performance. Education Researcher, 18 (4), pp. 45-51.

HANUSHEK, E.A., 1997. The Evidence on Class Size. Working Paper No.10, Wallen Wallis Institute of Political Economy, University of Rochester. 
HANUSHEK, E.A., 1997a. Effects of School Resources on Economic Performance, Education Evaluation and Policy Analysis, 19 (2), pp. 141-164.

HANUSHEK, E.A., 1999. The Evidence on Class Size. In: S.E. MAYER and P.E. PETERSON, eds., Earning and Learning: How Schools Matter, Brooking Institute Press: Washington, D.C., pp.131-168.

HANUSHEK, E.A., 2003. The Failure of Input-based Schooling Policies', Economic Journal, 113 (485), February, pp. 64-98.

HANUSHEK E. A. and LUQUE J. A., 2003. Efficiency and Equity in Schools around the World, Economics of Education Review, 22 (5), October, pp. 481-502.

HAQ, M.,1998. . Reflections on Human Development, Karachi: OUP.

HATHAWAY, R. and KUGELMAN, M., 2011. Reaping the Dividend Overcoming Pakistan's Demographic Challenges, The Woodrow Wilson International Center for Scholars, Washington.

HAUSMAN, J., 1978. Speciation tests in Econometrics. Econometrica, 46:1251-1271.

HEDGES, L.V., LAINE, R.D. AND GREENWALD, R.,1994. Does Money Matter? A Meta- Analysis of Studies of the Effects of Differential Inputs on Student Outcomes. Educational Researcher, 23, pp. 5-14.

HENDERSON, J., 2003. The Measurement of Technical Efficiency Using Panel Data, Binghamton: Department of Economics, State University of New York, pp.1-25.

HOLMES, JESSICA., 2003. Measuring the Determinants of School Completion in Pakistan: Analysis of Censoring and Selection Bias Economics of Education Review, 22.

HOXBY, C.M., 2000. Does Competition among Public Schools Benefit Students and Taxpayers? American Economic Review, 90, pp. 1209-1238.

HOXBY, C.M., 2000. 'The effects of class size on student achievement: new evidence from population variation'. Quarterly Journal of Economics, vol. 115 (3) (November), pp. 1239-85.

HSIAO, C., 2003. Analysis of Panel Data. Cambridge University Press.

HUSSAIN,. F, QASIM, A. and SHEIKH.K., 2003.Analysis of Public Expenditure on Education in Pakistan. The Pakistan Development Review, 42( 4),pp.771-780.

HUSSAIN, I., 2004. Pakistan's Economic Progress since 2000: False Dawn or Promising Start? A paper presented at a seminar at the School of Advanced International Studies, John Hopkins University, October $6^{\text {th }} 2004$.

HUSAIN, I., 2010. Pakiatan's Growth Experience, Business Review,(5)2,pp.1-23.

IMAZEKI, J., 2006. Assessing the Costs of K-12 Education in California Public Schools Downloaded on 9 June 2010, from: irepp.stanford.edu/documents/GDF/STUDIES/18Imazeki/Imazeki-Appendices.pdf. 
ISMAIL, Z., 1996. Gender Differentials in the Cost of Primary Education: A Study of Pakistan. The Pakistan Development Review 35 ( 4), pp. 835-849.

INSTITUTE OF SOCIAL AND POLICY SCIENCES (I-SAPS), 2011. Public Financing of Education in Pakistan: Analysis of Federal and Provincial Budgets 2010-11, Islamabad.

JACQUES, C. and BRORSEN, W., 2002. Relationship between types of school district expenditures and student performance. Applied Economics Letters, 9, pp.997-1002.

JOHNES, G. AND JOHNES,J., 2004. International Handbook on the Economics of Education, Edward Elgar Publishing Ltd, Cheltenham, UK.

KHALID, M., MUSTAFA, U. AND AHMED,I., 2007. National Finance Commission Awards in Pakistan: A Historical Perspective, PIDE Working Papers 2007:33.

KHAN, S.R. AND KIEFER, D. 2007. Educational Production Functions for Rural Pakistan: A Comparative Institutional Analysis. Education Economics. 15 (3),pp. 327 342.

KINGDON, G. AND ASLAM,M., 2007. Gender and Household Education Expenditure in Pakistan. GPRG-WPS-025,pp.1-44.

KIRJAVAINEN, T., 2007. Efficiency of Finish Secondary Upper Schools: An Application of Stochastic Frontier Analysis With Panel Data. Working Paper 428, Government Institute of Economic research. Helsinki, pp.1-53.

KRUEGER, A.B.,1999.Experimental Estimates of Education Production Functions. Quarterly Journal of Economics, 114 (2), pp. 497-532.

KRUEGER, A.B., 1999. Experimental estimates of education production functions. Quarterly Journal of Economics, vol. 114 (2) (May), pp. 497-532.

KRUEGER,A.B., 2002. Understanding the magnitude and effect of class size on student achievement. In: L. MISHEL and R. ROTHSTEIN, eds. The Class Size Debate, Washington, DC: Economic Policy Institute, pp. 7-35.

KRUEGER, A. B., 2000. Economic considerations and class size. Working Paper 447.Princeton University, 1-44.

KRUEGER, A.B., 2003. Economic Considerations and Class Size. The Economic Journal, 113:485, pp. F34-F63.

KUGELMAN, Michael and HATHAWAY, Robert M., eds., 2011.Reaping the Dividend: Overcoming Pakistan's Demographic Challenges. Woodrow Wilson International Center for Scholars, Washington, D.C., pp.1-191

LINZER, D. and CLARK, T., 2012. Should I Use Fixed or Random Effects? Department of Political Science, Emroy University.

LLOYD, C., B, CEM METE, and MONICA J. GRANT., 2007. Rural Girls in Pakistan: Constraints of Policy and Culture. In; M. LEWIS and M. LOCKHEAD,eds. Exclusion, Gender and Education: Case Studies from the Developing World. Washington, D.C.: Center for Global Development. 
LLOYD, C.B., C. METE, and SATHAR, Z., 2005. The effect of gender differences in primary school access, type, and quality on the decision to enroll in rural Pakistan. Economic Development and Cultural Change 53 (3), pp. 685-710.

LOCKHEED, M. and HANUSHEK, E., 1988. Improving Educational Efficiency in Developing Countries: What Do We Know? Compare 18 (1), pp. 21-38.

LOCKHEED, M. and HANUSHEK, E., 1994. Concepts of Educational Efficiency and Efectiveness. HROWP, pp.24: 1-17

MANDL, U., DIERX, A. and ILZKOVITZ, F., 2008. The Effectiveness and Efficiency of Public Spending. European Commission, Directorate-General for Economic and Financial Affairs. Brussels: Downloaded on 12 Sep 2011 from: //ec.europa.eu/economy_finance/publications.

CHINGOS, M., 2011. The False Promise of Class-Size Reduction, Centre for American Progress. Downloaded on 10 July 2010 from: http://www.americanprogress.org/issues/2011/04/pdf/class size.pdf.

MEEUSEN, W.J. and VAN DER BROECK., 1977. Efficiency Estimation from CobbDouglas Production Functions with Composed Error, International Economic Review, 18, pp. 435-444.

MEMON, M., 2001. 'Feasibility Study Report on Review of the Management of School Education in Sindh', Education Department, Government of Sindh, Karachi.

MINISTRY OF EDUCATION, 1998. National Education Policy 1998-2010.Islamabad.

MINISTRY OF EDUCATION, 2009. National Education Policy 2009. Islamabad.

MINISTRY OF EDUCATION, 1998. Pakistan Education Statistics, 2010-11. Academy of Educational Planning and Management.. Islamabad.

MINISTRY OF EDUCATION, and UNESCO,2003. FINANCING OF EDUCATION IN PAKISTAN, Islamabad.

MISHRA, S.K., 2007. A Brief History of Production Function. Working Paper Series, SSRN: Downloaded on 12 July 2010, from: http://ssrn.com/abstract=1020577.

MOOMAW and ADKINS., 2005. Analyzing the Technical Efficiency of School Districts. Oklahoma State University, pp.1-24.

NASCIMENTO, M., 2008. School Resources and Student Achievement: Worldwide Findings and Methodological Issues, Educate Special Issue (March), pp.19-30.

NASEER, M., 2012. Disasters in South Asia - A Regional Perspective, Pakistan Institute of Labor Education and Research, Karachi, pp.1-53.

NAVVED, A., and ALI, NAZIM., 2012. Clustered Deprivation, District Profile of Poverty in Pakistan, Sustainable Development Policy Institute, Islamabad, pp.1-95.

NAYAB, D., 2006. Demographic Dividend or Demographic Threat in Pakistan, PIDEWorking Papers, 2006:10, pp.1-37. 
NORTH, D.C., 1990. Institutions, Institutional Change, and Economic Performance. New York :Cambridge University Press.

PAKISTAN BUREAU OF STATISTICS, 2005. Pakistan Social\& Living Standards Measurement (PSLM) Survey 2004-05. Islamabad: Pakistan Bureau of Statistics.

PAKISTAN BUREAU OF STATISTICS, 2009. Pakistan Social\& Living Standards Measurement (PSLM) Survey 2008-09. Islamabad: Pakistan Bureau of Statistics.

PAKISTAN BUREAU OF STATISTICS, 2011. Pakistan Social\& Living Standards Measurement (PSLM) Survey 2010-11. Islamabad: Pakistan Bureau of Statistics.

PAKISTAN BUREAU OF STATISTICS, Pakistan Statistical Year Book 2011. Islamabad.

PAKISTAN INSTITUTE OF LEGISLATIVE DEVELOPMENT AND TRANSPARENCY (PILDAT), 2010. Financing Basic Quality Education For All in Pakistan, Briefing Papers, 38, pp.1-18.

PAKISTAN SOCIETY FOR DEVELOPMENT ECONOMICS (PIDE), 2004. Annual General Meeting and Conference, Budgetary Reforms for Growth and Poverty Reduction in Pakistan, Islamabad.

PAKISTAN and UNICEF., 2000. Country Program for Children, 1999-2003, Islamabad.

PATRON,R., 2006. Trade, Education and Skills: A Theoretical Survey. dECON.Universidad de la República, Uruguay.Downloaded on 5 January 2011, from URL: decon.edu.uy/publica/2006/1006.

POPULATION ACTION INTERNATIONAL, 2003. How Demographic Transition Reduces Countries' Vulnerability to Civil Conflict. Washington.

PRITCHETT, L AND WEIJER, F., 2010. FRAGILE STATES: STUCK IN A CAPABILITY TRAP? World Development Report, 2011, pp.1-45.

RODRIK, D., 2011. Growth after the Crisis, The Commission on Growth and Development, Working paper no. 65, pp. 1-40.

RODRIK, D., 2008. Second-best Institutions. American Economic Review: Papers and Proceedings 98 (2), pp.100-104.

SAADIA, H., SAJJAD, A. and DAWOOD,M., 2011 The Political Economy of Growth Without Development: A Case Study of Pakistan, Pakistan Institute of Trade and Development, MPRA Paper No. 30926, pp. 1-57.

SABIR, MUHAMMAD., 2002.Gender and Public Spending on Education in Pakistan: A Case Study of Disaggregated Benefit Incidence, The Pakistan Development Review 42: 4 Part II (Winter 2002), pp. 477-493.

SALA-I-MARTIN, XAVIER., 1997. I Just Ran Two Million Regressions. American Economic Review, Vol. 87, pp. 178-83. 
SATHAR, Z.A. and LLOYD, C.B., 1994. Who Gets Primary Schooling in Pakistan: Inequalities Among and Within Families. Pakistan Development Review, 33 (.2). pp.103-134.

SAWADA, Y., 1997. Human capital investments in Pakistan: implications of micro evidence from rural households. Pakistan Development Review, December 22, pp. 1 32.

SAWADA, Y, and LOKSHIN, M., 2001. Household Schooling Decisions in Rural Pakistan. Policy Research Working Paper No.2541. Washington D.C.: The World Bank Development Group, pp.1-36.

SAWADA, Y, and LOKSHIN, M., 2009. Obstacles to school progression in rural Pakistan: An analysis of gender and sibling rivalry using field survey data. Journal of Development Economics. 88 (2), pp. 335-347.

SCHULTZ, T. P., 2004. School Subsidies for the Poor: Evaluating the Mexican Progresa Poverty Program. Journal of Development Economics, 74 (1), June, pp. 199250.

SCHWAB, K., 2010. The Global Competitiveness Report 2010-2011, World Economic Forum.

SEMIS, 2011.COMPARATIVE REPORT ON EDUCATIONAL INDICATORS- 20062010, Reform support unit, Department of education, Government of Sindh.

SEMYKINA , A. and WOOLDRIDGE ,J., 2008. Estimating Panel Data Models in the Presence of Endogeneity and Selection: Theory and Application, downloaded from: mailer.fsu.edu/ asemykina/Select_IV_oct2006.pdf.

SHAMI, P., 2005. Development of education in Pakistan: AEPAM, Ministry of Education, Government of Pakistan, Islamabad.

SILBER, J. AND DEUTCH,J., 2009. Estimating an Educational Production Function for Five Countries of Latin America on the basis of the PISA data, RBLAC-UNDP,Israel.

SOCIAL POLICY DEVELOPMENT CENTER, 2003. Social Development in Pakistan: The State of Education, Annual Review, Karachi, pp.1-181.

SOCIAL POLICY AND DEVELOPMENT CENTRE,2005. Social Development in Pakistan. Combating Poverty: Is Growth Sufficient? Annual Review, Karachi, pp.1-192.

SOCIAL POLICY AND DEVELOPMENT CENTRE, 2006. Social Development in Pakistan, Trade Liberalization, Growth and Poverty, Annual Review Karachi, pp.1-189.

SOCIAL POLICY AND DEVELOPMENT CENTRE, 2007. Devolution and Human Development in Pakistan, Annual Review, Karachi, pp.1-214.

SOCIAL POLICY AND DEVELOPMENT CENTRE,2010. Annual Review, Social Impact of Security Crisis in Pakistan, Annual Review, Karachi, pp.1-137.

STATE BANK OF PAKISTAN ( SBP). 2006. Annual Report: 2005-2006, Review of the Economy, Karachi. 
STATE BANK OF PAKISTAN (SBP). 2005. Monetary Aggregates in Pakistan: Theoretical and Empirical Underpinnings, working paper series no. 07, pp. 1-24.

STEVENS, P.A., 2005. A Stochastic Frontier Analysis of English and Welsh Universities, Education Economics, 13: 4, pp. 355-374.

SURYADARMA, D., 2008. Public Spending, and Education Outcomes: Evidence from Indonesia, Research School of Social Sciences, the Australian National University, pp.1-19.

TAN, B., 2008. Cobb Douglas Production Function. Downloaded from:http://en.wikipedia.org/wiki/Cobb Douglas.

TEIXEIRA, P., 2007. Jacob Mincer - Founding Father of Modern Labor Economics, Oxford: Oxford University Press.

TODARO, M., and SMITH, C., 2003. Economic Development, 8th. edition, AddisonWesley.

TYAGI, P., YADAV,S. and SINGH,S., 2005. Efficiency analysis of schools using DEA: A case study of Uttar Pradesh state in India. Department of Mathematics, IIT, Roorkee, India. Downloaded From: http://astro.temple.edu/ banker/dea2009/paper/Tyagi.pdf

UNDP, 1995. Public Sector Management, Governance, and Sustainable Human Development, Discussion Paper 1, United Nations Development Program, New York.

UNDP, 2009. Growth and Income Distribution for Poverty Reduction: Pakistan's Experience, Policy Brief, Islamabad,1, pp. 1-26.

UNDP, 2003. Human Development Report, 2003. Karachi: Oxford University Press.

UNDP, 2012. Human Development Report 2011, Sustainability and Equity: A Better Future for All, New York.

UNESCO, 2011. Comparing Education Statistics Across the World, Global Education Digest, Montreal: UIS, pp. 1-308.

UNESCO, 2011. SITUATION ANALYSIS OF THE EDUCATION SECTOR, UNESCO, Pakistan, pp.1-144.

UNESCO-UIS, 2011. Global Education Digest 2011, Comparing Education Statistics Across the World, Montreal.

VAN DER BERG, S. and BURGER, R., 2003. Education and Socio-Economic Differentials: A Study of School Performance in the Western Cape. Development Policy Research unit Working Paper 03/73.

VIGNOLES, A., LEVACIC R., WALKER J., MACHIN, S. and REYNOLDS, D., 2000.The Relationship Between Resource Allocation and Pupil Attainment: A Review. Working paper, Centre for the Economics of Education. London: London School of Economics, pp.1-92. 
VIGNOLES, A and MESCHI, E., 2010. The Determinants of Non-Cognitive and Cognitive Schooling Outcomes. Centre for the Economics of Education. London: London School of Economics, pp.1-76.

VIGNOLES, A, CLARKE, P, C. AND STEELE,F., 2010. The Choice Between Fixed and Random Effects Models:Some Considerations for Educational Research. The Institute for the Study of Labor (IZA) in Bonn,Discussion Paper No. 5287.pp.1-36.

VITALIANO, D. and RUGGIERO, J., 1999. Assessin g the Efficiency of Public Schools using Data Envelopment Analysis and Frontier Regression. Contemporary Economic Policy, 17 (3), pp. 321-331.

WEST, E. G., 1997. Education Vouchers in Principle and Practice: A Survey. World Bank Research Observer. 12 (1), pp. 83-103.

WFP and SDPI., 2003. Food Insecurity in Rural Pakistan 2003, World Food Porgram, Pakistan, Pakistan, VAM unit, WFP- Islamabad.

WILLIAMSON, A. L., 2009. The Influence of Sector on Human Resource Management: Public, Charter, and Private Schools. Department of Public Management Suffolk University,.Boston, Downloaded from:awilliamson@suffolk.edu on 16 August 2013.

WÖBMANN, L, AND SCHÜTZ, G., 2006. Efficiency and Equity in European Education and Training Systems, Analytical Report for the European Commission. European Expert Network on Economics of Education (EENEE), Downloaded from www.education-economics.org ,on 16 August,2013.

WÖBMANN, L., 2000. Schooling Resources, Education Institutions, and Student Performance: The International Evidence. Working Paper No. 983. Germany: Kiel Institute of World Economics, pp.1-89.

WOOLDRIDGE, J., 2002. Econometric Analysis of Cross Section and Panel Data. Cambridge, MA: MIT Press.

WOOLDRIDGE, J., 2009. Introductory Econometrics: A Modern Approach, 4th ed., South-Western Cengage Learning. Chapter 6.

WORLD BANK., 2002. Achieving Education for All by 2015: simulation results for 47 low-income countries. Washington, DC: Human Development Network, Africa Region and Education Department, World Bank: 76.

WORLD BANK., 2002. Poverty in Pakistan: Vulnerabilities, Social Gaps, and Rural Dynamics, Washington, D.C.

WORLD BANK., 2004-2006. Economic Outlook, Islamabad.

WORLD BANK., 2003.Pakistan Poverty Assessment, World Bank PREM Sector Unit.

WORLD BANK., 2002. Poverty in Pakistan: Vulnerabilities, Social Gaps, and Rural Dynamics, Washington, D.C.

WORLD BANK., 2007. Sindh Education Sector Development Policy Credit Document, Islamabad. 
WORLD BANK., 1989. Women in Pakistan: An Economic and Social Strategy, World Bank. Washington D.C.

WORTHINGTON, A., 2001. An Empirical Survey of Frontier Efficiency Measurement Techniques in Education. Education Economics. 9 (3), pp. 245-268.

YINGER, JOHN., 2007. Production Functions and Cost Functions for Public Education. Education Finance and Accountability Program EFAP,pp.1-5.

ZAIDI, AKBAR., 2004. Economic Issues of Pakistan, Karachi:Oxford University Press.

ZAMORANO, M., 2004. Economic Efficiency and Frontier Techniques. Journal of Economic Surveys. 18 (1), pp.1-46. 


\section{APPENDICES}

APPENDIX 4-A

It is generally believed that Phillip Wicksteed (1894) was the first economist to algebraically formulate the relationship between output and inputs as $P=f\left(X_{1}, X_{2}, \ldots .\right.$. $X_{m}$ ). It was tested against statistical evidence by Charles Cobb and Paul Douglas in 1928. In 1928 Charles Cobb and Paul Douglas published a study in which they modeled the growth of the American economy during the period 1899-1922. They considered a simplified view of the economy in which production output is determined by the amount of labor involved and the amount of capital invested. While there are many other factors affecting economic performance, their model proved to be remarkably accurate (Tan, 2008, p. 1).

The function they used to model production was of the form:

$P(L, K)=b L^{\alpha} K^{B}$

Where:

- $\mathrm{P}=$ total production (the monetary value of all goods produced in a year)

- $\mathrm{L}=$ labor input (the total number of person-hours worked in a year)

- $\mathrm{K}=$ capital input (the monetary worth of all machinery, equipment, and buildings )

- $b=$ total factor productivity

- $\alpha$ and $\beta$ are the output elasticities of labor and capital, respectively.

Mishra (2007) is of the view that the Cobb-Douglas production function gave a readily convincing proof that in competitive equilibrium all inputs are paid their marginal product (and hence their respective real price), the entire product exhausts (as the sum of input elasticities of product sum up to unity), the constant returns to scale prevails, and the empirically observed constancy of relative shares of factors of production for long periods is fully explicable, justified and natural (Mishra, 2007, p. 15). 
REVIEW OF COST FUNCTION STUDIES

\begin{tabular}{|c|c|c|c|c|}
\hline Article & Year & State & Controls for Efficiency & Performance Measures \\
\hline Alexander, et al. & 2000 & Texas & Stochastic cost frontier & $\begin{array}{l}\text { Average value-added on TAAS performance (administered to all students in grades } 3 \\
\text { through } 8 \text { and in grade } 10 \text { ), percent of students who perform above criterion on the SAT or } \\
\text { ACT tests and the percent of students who complete and advanced course. }\end{array}$ \\
\hline Downes and Pogue & 1994 & Arizona & Fixed effects & $\begin{array}{l}\text { Mean standardized test scores for sixth and twelfth graders and scores for eleventh } \\
\text { graders from the previous year }\end{array}$ \\
\hline $\begin{array}{l}\text { Duccombe and } \\
\text { Johnston }\end{array}$ & 2004 & Kansas & $\begin{array}{l}\text { Per-pupil property values, per-pupil state aid, } \\
\text { median household income }\end{array}$ & $\begin{array}{l}\text { The average percentage of students passing exams-math given my fourth, seventh and } \\
\text { tenth and reading given in third, seventh and tenth grades, and dropout rates. }\end{array}$ \\
\hline $\begin{array}{l}\text { Duncombe and } \\
\text { Yinger }\end{array}$ & 1997 & Newyork & Data Envelopment Analysis (DEA) & $\begin{array}{l}\text { The average share above a reference point on third and sixth grade math and English } \\
\text { tests; the average share of students who pass several state-run standardized tests in high } \\
\text { school; and the share of students who stay in school }\end{array}$ \\
\hline $\begin{array}{l}\text { Duncombe and } \\
\text { Yinger }\end{array}$ & 1998 & Newyork & DEA & $\begin{array}{l}\text { Percent of students performing above a standard reference point on Pupil Evaluation } \\
\text { Program tests (reading and math), given in third and sixth grades, percent of students } \\
\text { receiving a Regents diploma upon graduation from high school, and the inverse of the } \\
\text { dropout rate. }\end{array}$ \\
\hline $\begin{array}{l}\text { Duncombe and } \\
\text { Yinger }\end{array}$ & 2000 & Newyork & DEA & $\begin{array}{l}\text { The average share above a reference point on third and sixth grade math and reading } \\
\text { tests; the share of students who receive a more demanding Regents diploma (which } \\
\text { requires passing a series of exams), and the graduation rate. }\end{array}$ \\
\hline $\begin{array}{l}\text { Duncombe and } \\
\text { Yinger }\end{array}$ & 2001 & Newyork & $\begin{array}{l}\text { Augmented district income, tax price, percent } \\
\text { elderly households, number of households per } \\
\text { child, dummy variables for upstate suburbs and } \\
\text { upstate rural }\end{array}$ & Percent of students' graduation with a Regents diploma and percent dropouts \\
\hline $\begin{array}{l}\text { Duncombe and } \\
\text { Yinger }\end{array}$ & $2005 a$ & Newyork & $\begin{array}{l}\text { Budget constraints measured by property value, } \\
\text { income, and state aid. }\end{array}$ & $\begin{array}{l}\text { Passing rates on fourth and eight grade math and regarding and passing rates on Regents } \\
\text { exams }\end{array}$ \\
\hline $\begin{array}{l}\text { Duncombe and } \\
\text { Yinger }\end{array}$ & $2005 b$ & Kansas & $\begin{array}{l}\text { Fiscal capacity (property wealth, income, state } \\
\text { aid), college educated adults, age } 65 \text {-and over } \\
\text { residents, homeowners, tax share of typical } \\
\text { voter, consolidation }\end{array}$ & $\begin{array}{l}\text { Percent of students reaching a certain threshold in performance on the Quality } \\
\text { Performance and Accreditation exams in math (grade 4,7,10) and reading (grades 5,8,11) } \\
\text { and the graduation rate }\end{array}$ \\
\hline
\end{tabular}




\begin{tabular}{|c|c|c|c|c|}
\hline $\begin{array}{l}\text { Duncombe and } \\
\text { Yinger }\end{array}$ & 2007 & California & $\begin{array}{l}\text { Log of median earnings; additions to voters' } \\
\text { effective income from unrestricted aid, categorical } \\
\text { aid, categorical aid, federal aid, and education } \\
\text { foundation contributions; number of parcels per } \\
\text { pupil; share of migrants, change in revenue limit, } \\
\text { share of intergovernmental support in form of } \\
\text { categorical grants. }\end{array}$ & $\begin{array}{l}\text { Academic Performance Index-weighted average of test results in several subjects from } \\
\text { grades2-11 }\end{array}$ \\
\hline $\begin{array}{l}\text { Duncombe, } \\
\text { Lukemeyer, and } \\
\text { Yinger }\end{array}$ & 2003 & Newyork & $\begin{array}{l}\text { Difference between a district and the average in } \\
\text { its peer group for per pupil income, per pupil } \\
\text { property values, and state aid as a percentage of } \\
\text { district income. }\end{array}$ & $\begin{array}{l}\text { Weighted average of fourth-and eighth-grade exam scores, and high school Regents exam } \\
\text { scores }\end{array}$ \\
\hline $\begin{array}{l}\text { Duncombe, } \\
\text { Lukemeyer, and } \\
\text { Yinger }\end{array}$ & 2006 & Kansas & $\begin{array}{l}\text { Per pupil income, per pupil property values, the } \\
\text { state aid ratio (includes federal and), local tax } \\
\text { share, college education variable, percent of the } \\
\text { population } 65 \text { or older, percent of housing units } \\
\text { that are owner occupied. }\end{array}$ & $\begin{array}{l}\text { Share reaching proficiency on criterion-referenced and exams in math and reading in three } \\
\text { grades (grades } 4,7 \text { and } 10 \text { for math, and grades } 5,8 \text { and } 11 \text { for reading) }\end{array}$ \\
\hline $\begin{array}{l}\text { Duncombe, } \\
\text { Lukemeyer, and } \\
\text { Yinger }\end{array}$ & $\begin{array}{l}2006 \\
\text { part } 2\end{array}$ & Missouri & $\begin{array}{l}\text { Per pupil income, per pupil property values, state } \\
\text { aid ratio, local tax share, college education } \\
\text { variable, percent of the population } 65 \text { or older, } \\
\text { percent of housing units that are owner occupied. }\end{array}$ & $\begin{array}{l}\text { Proficiency rates for three math and three reading exams (grades } 3,7 \text { and } 11 \text { for } \\
\text { communication arts, and grades } 4,8 \text { and } 10 \text { for math) }\end{array}$ \\
\hline $\begin{array}{l}\text { Duncombe, Ruggiero, } \\
\text { and Yinger }\end{array}$ & 1996 & Newyork & DEA & $\begin{array}{l}\text { The average share above a reference point on third and sixth grade math and reading test; } \\
\text { the share of students who receive a more demanding Regents diploma (which requires } \\
\text { passing a series of exams), and the inverse of the drop-out rate }\end{array}$ \\
\hline Gronberg,et al. & 2004 & Texas & Stochastic cost frontier & $\begin{array}{l}\text { Percent of students in each district who passed the TAAS in math and reading in grades5- } \\
8 \text { and } 10 \text { and the percentage of students in each district who passed in grades3-6 and } 8 \\
\text { two years earlier, the percent of students who perform above } 1100 \text { on the SAT or } 24 \text { on } \\
\text { the ACT, and the percent of students who complete and advanced course }\end{array}$ \\
\hline Hamadeh & 1998 & Georgia & DEA & $\begin{array}{l}\text { Average reading, math and science scores for third grade pupils in Curriculum Based } \\
\text { Assessment test and the percentage of } 11 \text { th grade students who passed spring English } \\
\text { and math graduation tests the first time }\end{array}$ \\
\hline Imazeki & 2001 & Illinois & None & $\begin{array}{l}\text { Composite scores on the EGAP exams in math and reading (Grades } 3,6,8 \text { and } 10 \text { ), and } \\
\text { science and social studies (grades } 4,7 \text {, and 11) and scores of the same cohort of students } \\
\text { in earlier years and grades }\end{array}$ \\
\hline Imazeki & 2006 & California & $\begin{array}{l}\text { Herfindahl index to measure public school } \\
\text { competition }\end{array}$ & Academic Performance Index and average California standards test passing rates \\
\hline
\end{tabular}




\begin{tabular}{|c|c|c|c|}
\hline $\begin{array}{l}\text { Imazeki and } \\
\text { Reschovsky }\end{array}$ & $2004 a$ & Texas & $\begin{array}{l}\text { Herfindahl index to measure public school } \\
\text { competition }\end{array}$ \\
\hline $\begin{array}{l}\text { Imazeki and } \\
\text { Reschovsky }\end{array}$ & $2004 b$ & Texas & $\begin{array}{l}\text { Herfindahl index to measure public school } \\
\text { competition }\end{array}$ \\
\hline $\begin{array}{l}\text { Imazeki and } \\
\text { Reschovsky }\end{array}$ & $2004 c$ & Texas & None \\
\hline $\begin{array}{l}\text { Imazeki and } \\
\text { Reschovsky }\end{array}$ & 2006 & Texas & $\begin{array}{l}\text { Herfindahl index to measure public school } \\
\text { competition }\end{array}$ \\
\hline $\begin{array}{l}\text { Reschovsky and } \\
\text { Imazeki }\end{array}$ & 1998 & Wisconsin & None \\
\hline $\begin{array}{l}\text { Reschovsky and } \\
\text { Imazeki }\end{array}$ & 2001 & Texas & DEA \\
\hline $\begin{array}{l}\text { Reschovsky and } \\
\text { Imazeki }\end{array}$ & $\begin{array}{l}2001 \\
\text { part2 }\end{array}$ & Wisconsin & DEA \\
\hline $\begin{array}{l}\text { Reschovsky and } \\
\text { Imazeki }\end{array}$ & 2003 & Texas & DEA \\
\hline
\end{tabular}

The average passing rate on the TAAS reading and mathematics exams administered to

students in grades 5 through 8 and in grade 10 and average passing rates in grades 5 through 8 and 10 from the year before, the annual retention rate, and the percentage of graduating seniors who achieve at least a 1100 on the SAT or a 24 on the ACT

The average passing rate on the TAAS reading and mathematics exams administered to students in grades 4 through 8 and in grade 10 and average passing rates in grades 3 through 8 and 10 from the year before, passing rate on State-Developed Alternative Assessment, annual retention rate, interaction of retention rate with percent of students enrolled in high school; percentage of graduating seniors who achieve at least a 1100 on the SAT or a 24 on the ACT

Scores on the Texas Assessment of Academic Skills and the scores from the previous year, the percent of students taking either the SAT I or the ACT exams and who achieve either a 1110 on the SAT I and a 24 on the ACT

Passing rates on the TAAS exam administered in grade 5-8 and in grade 10 and the passing rate in grades 3 through 8 and 10 from the year before, the passing rate on the SDAA exams (for special education students), the percent of graduating seniors who achieve a score of at least 1100 on the SAT and a 24 on his ACT, and the retention rate

Tenth grade standardized test results and eighth grade from two years earlier and a number of advanced courses offered

Composite TAAS scores for all students in the fourth through eighth grades and in the tenth grade and score in grade 3-7 from the year before and grade 8 from two years before, and student performance on the ACT exam

Tenth grade standardized test results and eighth grade results from two years earlier and a number of advanced courses offered

Composite TAAS score for all students in the fourth through eighth grades and in the tenth grade and score in grades3-7 from the year before and grade 8 from two years before, and student performance on the ACT exams

Source: Compiled from Golebiewski , 2011. 


\begin{tabular}{|c|c|c|c|c|c|}
\hline \multicolumn{6}{|c|}{ Frontier efficiency applications in education } \\
\hline Author(s) & Methodology & Sample b & Inputs, outputs, explanatory variables (if applicable) ${ }^{c}$ & Analytical technique & Main findings \\
\hline $\begin{array}{l}\text { Charnes, } \\
\text { Cooper and } \\
\text { Rhodes } \\
(1981)\end{array}$ & DEA & Throughs', 196749 U.S. 'Program Follow & $\begin{array}{l}\text { The percentage of mothers who are high school graduates, highest } \\
\text { occupation of a family member on a rating scale, parental school visit } \\
\text { index, parent-counselling index, number of teachers at a site. } \\
\text { Reading and mathematics test scores, 'Coopersmith Self-Esteem } \\
\text { Inventory' scores. } \\
\text { Previous year's test scores, percentage nonminority, students paying }\end{array}$ & Descriptive analysis. & $\begin{array}{l}\text { Application of DEA to a variety of } \\
\text { public programs where profit and } \\
\text { cost are not directly applicable. }\end{array}$ \\
\hline $\begin{array}{l}\text { Bessent, } \\
\text { Bessent, } \\
\text { Kennington and } \\
\text { Reagan }\end{array}$ & DEA & $\begin{array}{l}167 \text { Houston elementary } \\
\text { Schools, } 1978 .\end{array}$ & $\begin{array}{l}\text { full lunch price, and attendance, number of professional staff per } 100 \\
\text { pupils, local, state and federal expenditures per pupil, a number of specia } \\
\text { programs operated, percent of teachers with masters and more than } \\
\text { three years experience, and number of full- time equivalent teaching } \\
\text { days. }\end{array}$ & $\begin{array}{l}\text { a Descriptive analysis, tables of } \\
\text { input/output slacks, diagrammatic } \\
\text { analysis. }\end{array}$ & $\begin{array}{l}\text { Major problems in DEA include } \\
\text { obtaining data on inputs and } \\
\text { outputs, and communicating the } \\
\text { results. }\end{array}$ \\
\hline $\begin{array}{l}\text { Smith and } \\
\text { Mayston (1987) }\end{array}$ & DEA & $\begin{array}{l}96 \text { U.K. local Education } \\
\text { Authorities 1982/83. }\end{array}$ & $\begin{array}{l}\text { Teaching and non-teaching expenditure, percentage of pupils from a } \\
\text { high socioeconomic group, and not living in poor housing or single-parent } \\
\text { families. Percentage of maintaining school leavers attaining 'A' levels } \\
\text { and passed and graded 'O' levels. }\end{array}$ & $\begin{array}{l}\text { Descriptive analysis and } \\
\text { sensitivity to input- output } \\
\text { formulation. }\end{array}$ & $\begin{array}{l}\text { Sensitivity of DEA to the exclusion } \\
\text { of important outputs, possible use } \\
\text { of cluster analysis to identify } \\
\text { separate analyses. }\end{array}$ \\
\hline $\begin{array}{l}\text { Sengupta } \\
(1987)\end{array}$ & $\begin{array}{l}\text { DEA and } \\
\text { DFA }\end{array}$ & 1925 Californian school districts $1976 / 7$. & $\begin{array}{l}25 \text { Californians Average instructional expenditure, proportion of } \\
\text { minority students, average class Descriptive analysis. } \\
\text { School districts, size, index of assessed school quality. }\end{array}$ & & $\begin{array}{l}\text { Production frontier techniques } \\
\text { appear more stable in respect of } \\
\text { input data variations. }\end{array}$ \\
\hline $\begin{array}{l}\text { Mayston and } \\
\text { Jesson (1988) }\end{array}$ & DEA & Education authorities, 1982/83 & $\begin{array}{l}96 \text { U.K. local Education expenditure. } \\
\text { Percentage of maintaining school leavers attaining passed and graded } \\
\text { 'O' levels. } \\
\text { Percentage of pupils whose household head is in a high socioeconomic } \\
\text { group, single parent and unemployed. Measures. }\end{array}$ & Descriptive analysis & $\begin{array}{l}\text { Correlation between DEA and } \\
\text { correlation between measures } \\
\text { and residuals from OLS } \\
\text { residuals and DEA regression } \\
\text { analysis. }\end{array}$ \\
\hline $\begin{array}{l}\text { Sengupta } \\
\text { and Sfeir } \\
\text { (1988) }\end{array}$ & DEA & $\begin{array}{l}25 \text { Californian school } \\
\text { Districts, } 1976 / 77 \text {. }\end{array}$ & $\begin{array}{l}\text { Average teacher salaries, proportion of Anglo-American students, averag } \\
\text { class size, index of parental socioeconomic background. } \\
\text { Achievement scores. }\end{array}$ & $\begin{array}{l}\text { Descriptive analysis of sample } \\
\text { disaggregated by quartiles. }\end{array}$ & $\begin{array}{l}\text { DEA robust in situations where } \\
\text { input-output combinations } \\
\text { concentrated around the mean and } \\
\text { with non- normal error distributions. }\end{array}$ \\
\hline $\begin{array}{l}\text { Diamond and } \\
\text { Medewitz } \\
\text { (1990) }\end{array}$ & DEA & $\begin{array}{l}46 \text { U.S. Developmental, } \\
\text { Economic Education } \\
\text { Program classes, } \\
1988 .\end{array}$ & $\begin{array}{l}\text { Sum of verbal and math SAT scores, percentage of college } \\
\text { graduates amongst student mothers, percentage white, male, } \\
\text { previous course in economics, urban area, private/public school, } \\
\text { teacher's undergraduate/graduate hours in economics, total annual } \\
\text { instruction expenditure per student, DEEP vs. non-DEEP class. } \\
\text { Class average test results for Test of Economic Literacy (TEL). }\end{array}$ & $\begin{array}{l}\text { Descriptive analysis across } \\
\text { participating and non- } \\
\text { participating } \\
\text { Classes. }\end{array}$ & $\begin{array}{l}\text { Inconclusive evidence supporting } \\
\text { instructional program. }\end{array}$ \\
\hline $\begin{array}{l}\text { Barrow } \\
(1991)\end{array}$ & DFA & $\begin{array}{l}57 \text { U.K. local education } \\
\text { Authorities, 1980-1985. }\end{array}$ & $\begin{array}{l}\text { The gross cost per student, the number of pupils, number of } \\
\text { students receiving free meals, the proportion of students from low } \\
\text { socioeconomic background, index of additional educational needs, the } \\
\text { growth rate in student numbers, metropolitan vs. non-metropolitan } \\
\text { school, re-pricing index for educational expenditure. Student } \\
\text { grades. }\end{array}$ & $\begin{array}{l}\text { Descriptive analysis and } \\
\text { interpretation of the parameter } \\
\text { estimates. }\end{array}$ & $\begin{array}{l}\text { Inconclusive evidence supporting } \\
\text { the use of the panel over cross- } \\
\text { sectional data. }\end{array}$ \\
\hline $\operatorname{Ray}(1991)$ & DEA & $\begin{array}{l}122 \text { Connecticut } \\
\text { High schools, } 1980 / 81 .\end{array}$ & $\begin{array}{l}\text { Classroom teachers, support staff and administrative staff per pupil. } \\
\text { Mathematics, language, arts, writing, and reading scores per pupil. } \\
\text { Percentage of population with a college education, per capita income, } \\
\text { median value of owner-occupied housing, percentage of minority } \\
\text { students, those receiving welfare, families below the poverty line, } \\
\text { single parent families. }\end{array}$ & $\begin{array}{l}\text { Second-stage least squares } \\
\text { regression. Descriptive } \\
\text { analysis. }\end{array}$ & $\begin{array}{l}\text { Efficiency in utilization of school } \\
\text { inputs varies systematically } \\
\text { with } \\
\text { characteristics. }\end{array}$ \\
\hline
\end{tabular}




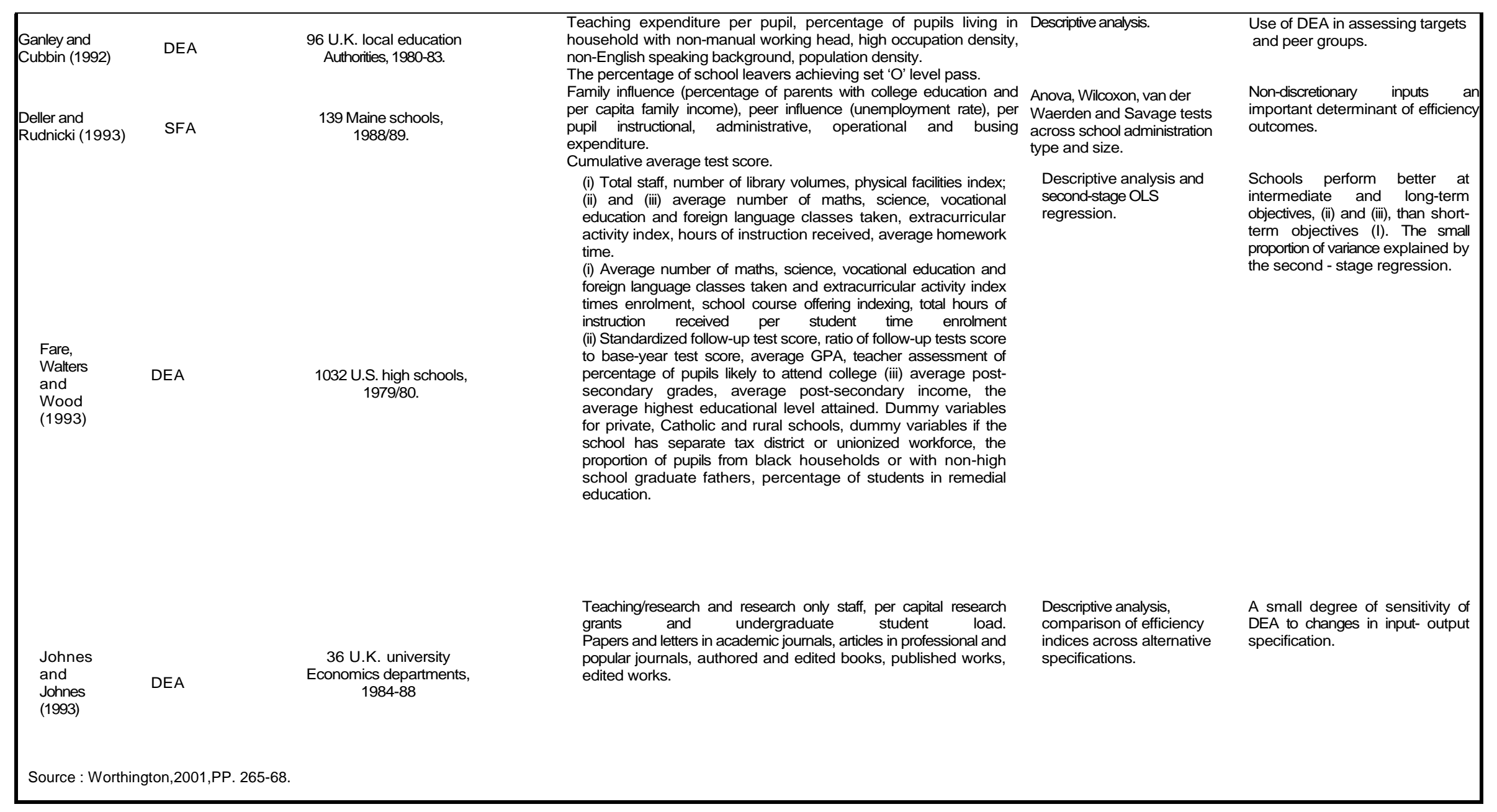


APPENDIX 4-D

Maximum likelihood estimates of the production function and its stochastic frontie

\begin{tabular}{|c|c|c|c|c|c|c|c|c|c|c|}
\hline & Grade 3 Coef & T Val & $\begin{array}{c}\text { Grade } 7 \\
\text { Coef }\end{array}$ & T Val & $\begin{array}{c}\text { Grade } 9 \\
\text { Coef }\end{array}$ & T Val & $\begin{array}{c}\text { Grade } 11 \\
\text { Coef }\end{array}$ & T Val & $\begin{array}{c}\text { Grade } 11 \\
\text { Coef }\end{array}$ & ssT Val \\
\hline Constant & -23.4839 & -15.76 & -0.142 & -0.12 & 2.017 & 0.86 & -5.499 & -3.41 & 5.386 & 2.355 \\
\hline In $\left(9^{\text {th }} \text { G. Score }\right)_{t-2}$ & & & & & & & & & 0.601 & 25.232 \\
\hline School Lunch & -0.0021 & -7.34 & -0.003 & -10.99 & -0.003 & -15.16 & -0.004 & -15.76 & -0.002 & -6.407 \\
\hline Minority & -0.0012 & -4.49 & -0.002 & -8.36 & -0.002 & -8.01 & -0.001 & -5.91 & $2.42 E-04$ & 0.958 \\
\hline LEP & 0.0011 & 0.95 & 0.001 & 0.93 & -0.001 & -0.94 & $-3.27 E-04$ & -0.33 & 0.002 & 2.185 \\
\hline $\ln (I \$ / S)$ & 6.2109 & 8.47 & -0.583 & -1.04 & -0.768 & -0.97 & 0.898 & 1.25 & -1.352 & -1.548 \\
\hline $\ln (O \$ / S)$ & 1.0680 & 1.51 & 1.664 & 2.99 & 1.239 & 2.20 & 1.599 & 2.26 & 0.286 & 0.388 \\
\hline $\ln ^{2}(I \$ / S)$ & -0.3438 & -3.38 & 0.079 & 1.08 & 0.126 & 1.50 & -0.080 & -0.82 & -0.094 & -0.936 \\
\hline $\ln ^{2}(O \$ / S)$ & -0.0040 & -0.12 & -0.081 & -2.92 & -0.014 & -0.45 & -0.152 & -3.93 & -0.236 & -5.469 \\
\hline $\ln (I \$ / S) \ln (O \$ / S)$ & -0.1268 & -0.99 & -0.062 & -0.67 & -0.133 & -1.38 & 0.074 & 0.60 & 0.405 & 3.391 \\
\hline Constant & 2.6665 & 7.69 & 2.046 & 8.47 & 1.351 & 5.03 & 1.674 & 6.82 & 1.058 & 2.112 \\
\hline Salary & -0.0002 & -7.69 & -0.00011 & -7.65 & $-4.87 E-05$ & -2.92 & -0.00010 & -5.59 & $-2.72 E-05$ & -1.241 \\
\hline Adv. Degree & -0.0071 & -5.24 & -0.003 & -3.36 & -0.005 & -4.91 & -0.001 & -0.82 & -0.001 & -0.985 \\
\hline \multirow[t]{2}{*}{ Yrs. Experience } & 0.0298 & 3.98 & -0.010 & -2.13 & -0.035 & -3.97 & -0.017 & -3.06 & -0.068 & -5.562 \\
\hline & -0.2163 & -6.23 & -0.147 & -4.14 & -0.187 & -25.68 & -0.197 & -19.25 & -0.130 & -8.488 \\
\hline 2 & 0.0052 & 6.19 & 0.004 & 4.33 & 0.005 & 18.85 & 0.005 & 12.82 & 0.003 & 4.872 \\
\hline Student / Teacher & -4.214 & -3.10 & -4.584 & -2.63 & -35.460 & -2.64 & 0.371 & 0.37 & -32.700 & -2.370 \\
\hline$\sigma^{2}$ & 0.2084 & 10.94 & 0.079 & 9.16 & 0.124 & 6.56 & 0.119 & 8.08 & 0.102 & 5.269 \\
\hline r & 0.9380 & 118.10 & 0.881 & 53.71 & 0.935 & $\begin{array}{c}101.4 \\
2\end{array}$ & 0.919 & 72.09 & 0.918 & 46.024 \\
\hline
\end{tabular}

Source: Moomaw and Adkins,2005, p.22.

APPENDIX 4-E

\begin{tabular}{|c|c|c|c|c|c|c|c|}
\hline \multicolumn{4}{|c|}{ Grade V student sample means } & \multicolumn{4}{|c|}{$\begin{array}{l}\text { Grade V teacher and school sample means, } 43 \\
\text { schools of each type }\end{array}$} \\
\hline Institutional type & Government & Private & NGO & & & & \\
\hline \multirow{3}{*}{$\begin{array}{l}\text { Comprehension score (\%) } \\
\text { Mathematics score (\%) } \\
\text { Male } \\
\text { Age }\end{array}$} & 42.8 & 55.8 & 66.5 & Institutional type & Government & Private & NGO \\
\hline & $\begin{array}{l}43.1 \\
0.686\end{array}$ & $\begin{array}{l}46.7 \\
0.624\end{array}$ & $\begin{array}{l}50.0 \\
0.573\end{array}$ & Teacher credential: Matric & 0.116 & 0.186 & 0.140 \\
\hline & 11.42 & 10.98 & 10.92 & & & & \\
\hline Percentage of days absent & 14.0 & 19.5 & 11.2 & Teacher credential: Intermediate & 0.465 & 0.465 & 0.372 \\
\hline Number of siblings & 3.59 & 3.38 & 3.45 & & & & \\
\hline Father missing & 0.087 & 0.124 & 0.092 & Teacher credential: Bachelors & 0.256 & 0.233 & 0.372 \\
\hline Mother missing & 0.017 & 0.030 & 0.024 & & & & \\
\hline Father's education (years) & 7.908 & 7.908 & 8.076 & Teacher credential: Masters & 0.163 & 0.093 & 0.116 \\
\hline Mother's education (years) & 1.641 & 3.475 & 3.124 & & & & \\
\hline Extremely poor & 0.136 & 0.058 & 0.050 & Years of teacher experience & 9.953 & 5.405 & 4.465 \\
\hline Poor & 0.523 & 0.262 & 0.297 & & & & \\
\hline Middle & 0.314 & 0.507 & 0.499 & Monthly wage (rupees) & 3567 & 1800 & 2317 \\
\hline Rich & 0.027 & 0.173 & 0.154 & Percentage of days teacher & & & \\
\hline Punjab Province & 0.545 & 0.494 & 0.468 & absent & 9.20 & 7.40 & 6.80 \\
\hline Sindh Province & 0.277 & 0.367 & 0.270 & & & & \\
\hline Balochistan Province & 0.035 & 0.053 & 0.066 & Teacher comprehension test(\%) & 79.9 & 77.9 & 81.3 \\
\hline North West Frontier Province & 0.143 & 0.086 & 0.195 & & & & \\
\hline Observations & 748 & 607 & 696 & Teacher mathematics test (\%) & 58.5 & 63.4 & 58.9 \\
\hline \multirow{9}{*}{\multicolumn{2}{|c|}{ Source: Khan and Kiefer ,2007, p.332 }} & & & Student-teacher ratio & 17.5 & 14.3 & 16.2 \\
\hline & & & & School fees (rupees per month) & 2.93 & 120.7 & 107.9 \\
\hline & & & & $\begin{array}{l}\text { Primary unit part of middle } \\
\text { school }\end{array}$ & 0.163 & 0.326 & 0.442 \\
\hline & & & & Primary unit part of high school & 0.070 & 0.279 & 0.233 \\
\hline & & & & Monthly testing & 0.116 & 0.149 & 0.256 \\
\hline & & & & Chairs available in class rooms & 0.442 & 0.814 & 0.953 \\
\hline & & & & All-boy school & 0.349 & 0 & 0 \\
\hline & & & & All-girl school & 0.372 & 0 & 0.070 \\
\hline & & & & Source: Khan and Kiefer ,2007, p. & & & \\
\hline
\end{tabular}




\section{APPENDIX 4-G}

\section{COST FUNCTION OF PRIMARY AND SECONDARY EDUCATION}

The cost function of primary and secondary education is specified as follows:

EDUEXPi $=\alpha 0+\alpha 1$ PRIMENROL $i=\alpha 2$ SECENROLi $+\alpha 3$ AREAi $+\alpha 4$ URBANi + $n_{\mathrm{t}}$

Where;

EDUEXP $=$ District's Recurring Expenditures on Education by the ith district in the province

PRIMENROL $=$ Primary School in the ith district in the province SECENROL $=$ Middle and High school in the ith district in the province AREA $=$ Area per Square Kilometer of the ith district in the province URBAN = Level of urbanization in the ith district

$n_{\mathrm{t}}=$ Error term

Of the 34 districts of the Punjab the estimated equation is EDUEXP $_{i}=-200.6908+0.0011$ PRIMENROL $_{i}+0.0010$ SECENROL $_{i}+0.0082$ AREA $_{i}$ $(-2.049$ *) $(2.782$ *) (3.254) (1.159)

+1422.5190 URBAN $_{\mathrm{i}}$

$\mathrm{R} 2=0.901$, F-Statistics $=76.462$, Degree of Freedom $=30, \mathrm{DW}=2.121$

The marginal cost of primary and secondary is, more or less, the same. This probably indicates greater excess capacity in the secondary school system. Also, costs rise with a larger geographical area indicating the impact of lower residential density. Further, the positive coefficient of the urbanization variable demonstrates that the quality of education is higher in cities and towns and higher costs are due also to larger $s$ in technical education.

Source: SPDC,2007, p. 133. 
APPENDIX 6-A

District wise STR

\begin{tabular}{|c|c|c|c|c|c|c|c|}
\hline District & Boys & Girls & Total & Male & Female & Total & STR \\
\hline Badin & 121,111 & 80,020 & 201,131 & 4,416 & 867 & 5,283 & 38 \\
\hline Dadu & 154,356 & 80,945 & 235,301 & 5,411 & 1,318 & 6,729 & 35 \\
\hline Ghotki & 131,356 & 57,914 & 189,270 & 3,519 & 487 & 4,006 & 47 \\
\hline Hyderabad & 88,937 & 88,055 & 176,992 & 4,350 & 4,260 & 8,610 & 21 \\
\hline Jacobabad & 80,732 & 38,836 & 119,568 & 3,452 & 775 & 4,227 & 28 \\
\hline Jamshoro & 54,387 & 32,432 & 86,819 & 2,008 & 654 & 2,662 & 33 \\
\hline Kambar & 89,962 & 49,704 & 139,666 & 3,178 & 829 & 4,007 & 35 \\
\hline Karachi & 285,360 & 350,343 & 635,703 & 9,579 & 19,807 & 29,386 & 22 \\
\hline Kashmore & 88,092 & 34,141 & 122,233 & 2,829 & 470 & 3,299 & 37 \\
\hline Khairpur & 192,503 & 108,622 & 301,125 & 7,146 & 1,871 & 9,017 & 33 \\
\hline Larkana & 120,137 & 75,115 & 195,252 & 4,318 & 1,524 & 5,842 & 33 \\
\hline Mirpur & 88,934 & 51,685 & 140,619 & 3,910 & 1,688 & 5,598 & 25 \\
\hline Mitiari & 64,407 & 37,520 & 101,927 & 2,619 & 598 & 3,217 & 32 \\
\hline Naushero & 153,395 & 94,713 & 248,108 & 5,119 & 1,547 & 6,666 & 37 \\
\hline Nawab & 119,970 & 58,413 & 178,383 & 4,309 & 862 & 5,171 & 34 \\
\hline Sanghar & 153,867 & 74,477 & 228,344 & 7,599 & 1,744 & 9,343 & 24 \\
\hline Shikarpur & 84,276 & 38,758 & 123,034 & 3,560 & 904 & 4,464 & 28 \\
\hline Sukkur & 85,483 & 55,679 & 141,162 & 3,725 & 1,526 & 5,251 & 27 \\
\hline TandoAllahyar & 43,785 & 25,935 & 69,720 & 1,408 & 395 & 1,803 & 39 \\
\hline TandoM Khan & 38,595 & 22,042 & 60,637 & 1,498 & 373 & 1,871 & 32 \\
\hline Tharparkar & 82,908 & 58,981 & 141,889 & 4,117 & 512 & 4,629 & 31 \\
\hline Thatta & 110,118 & 69,223 & 179,341 & 4,563 & 915 & 5,478 & 33 \\
\hline Umerkot & 62,589 & 31,252 & 93,841 & 2,672 & 603 & 3,275 & 29 \\
\hline Total & $2,495,260$ & $1,614,805$ & $4,110,065$ & 95,305 & 44,529 & 139,834 & 29 \\
\hline
\end{tabular}

Source : Compiled from SEMIS,2005. 
APPENDIX 6-B

Dropout Rate( Numbers) Boys and Girls

\begin{tabular}{|c|c|c|c|c|c|c|c|c|c|c|c|}
\hline Gender & year & I & $\mathrm{Ii}$ & lii & iv & $\mathrm{v}$ & vi & vii & Viii & ix & $x$ \\
\hline \multirow[t]{6}{*}{ Boys } & 2004 & 464991 & 298042 & 241606 & 204845 & 179289 & 107767 & 92678 & 83694 & 79218 & 69638 \\
\hline & 2005 & 486958 & 329967 & 260220 & 222297 & 189197 & 121776 & 108844 & 96330 & 76674 & 70201 \\
\hline & 2006 & 481030 & 329774 & 271422 & 219237 & 183144 & 118708 & 106559 & 97661 & 84955 & 74848 \\
\hline & 2007 & 473947 & 316437 & 265616 & 226621 & 184890 & 117677 & 105605 & 99025 & 89073 & 77238 \\
\hline & 2008 & 395821 & 308259 & 275877 & 238832 & 204477 & 118178 & 108347 & 99985 & 97399 & 85810 \\
\hline & 2009 & 384524 & 293412 & 260368 & 240980 & 204551 & 129842 & 114002 & 104035 & 98241 & 91995 \\
\hline \multirow[t]{6}{*}{ Girls } & 2004 & 291518 & 184252 & 149224 & 125046 & 109759 & 69944 & 64284 & 60627 & 52350 & 46475 \\
\hline & 2005 & 319204 & 200770 & 163289 & 141080 & 115162 & 69632 & 61957 & 58326 & 52433 & 47522 \\
\hline & 2006 & 314308 & 205219 & 171582 & 141084 & 119240 & 77291 & 68508 & 65327 & 57232 & 50761 \\
\hline & 2007 & 312678 & 195449 & 168493 & 143445 & 118004 & 77712 & 70871 & 67511 & 58168 & 51374 \\
\hline & 2008 & 247877 & 190140 & 175754 & 153533 & 131560 & 76743 & 73911 & 68384 & 61593 & 55502 \\
\hline & 2009 & 252222 & 184870 & 169696 & 157886 & 136577 & 89994 & 76896 & 72450 & 64732 & 58863 \\
\hline \multirow[t]{6}{*}{ Total } & 2004 & 756509 & 482294 & 390830 & 329891 & 289048 & 177711 & 156962 & 144321 & 131568 & 116113 \\
\hline & 2005 & 806162 & 530737 & 423509 & 363377 & 304359 & 191408 & 170801 & 154656 & 129107 & 117723 \\
\hline & 2006 & 795338 & 534993 & 443004 & 360321 & 302384 & 195999 & 175067 & 162988 & 142187 & 125609 \\
\hline & 2007 & 786625 & 511886 & 434109 & 370066 & 302894 & 195389 & 176476 & 166536 & 147241 & 128612 \\
\hline & 2008 & 643698 & 498399 & 451631 & 392365 & 336037 & 194921 & 182258 & 168369 & 158992 & 141312 \\
\hline & 2009 & 636746 & 478282 & 430064 & 398866 & 341128 & 219836 & 190898 & 176485 & 162973 & 150858 \\
\hline
\end{tabular}

Source: SEMIS various issues 
APPENDIX 6-C

Dropout Rate (\%) Boys and Girls

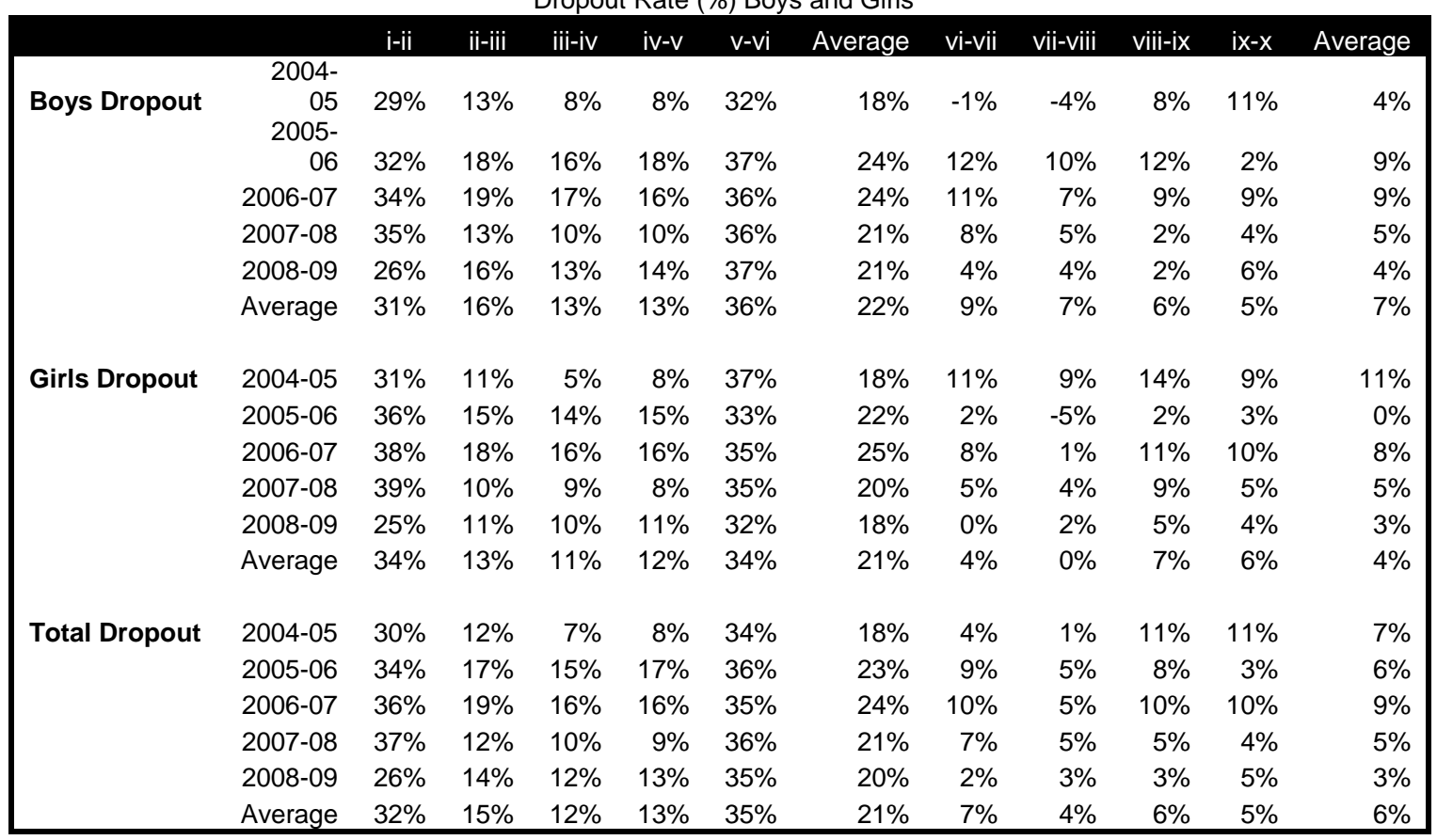

Source: SEMIS various issues 
APPENDIX 6-D

Completion Rates in Government Schools

\begin{tabular}{|c|c|c|c|c|c|c|c|c|c|c|c|}
\hline Gender & year & I & ii & iii & iv & v & vi & vii & Viii & ix & $\mathrm{X}$ \\
\hline \multirow[t]{6}{*}{ Boys } & 2004 & 464991 & 298042 & 241606 & 204845 & 179289 & 107767 & 92678 & 83694 & 79218 & 69638 \\
\hline & 2005 & 486958 & 329967 & 260220 & 222297 & 189197 & 121776 & 108844 & 96330 & 76674 & 70201 \\
\hline & 2006 & 481030 & 329774 & 271422 & 219237 & 183144 & 118708 & 106559 & 97661 & 84955 & 74848 \\
\hline & 2007 & 473947 & 316437 & 265616 & 226621 & 184890 & 117677 & 105605 & 99025 & 89073 & 77238 \\
\hline & 2008 & 395821 & 308259 & 275877 & 238832 & 204477 & 118178 & 108347 & 99985 & 97399 & 85810 \\
\hline & 2009 & 384524 & 293412 & 260368 & 240980 & 204551 & 129842 & 114002 & 104035 & 98241 & 91995 \\
\hline \multirow[t]{6}{*}{ Girls } & 2004 & 291518 & 184252 & 149224 & 125046 & 109759 & 69944 & 64284 & 60627 & 52350 & 46475 \\
\hline & 2005 & 319204 & 200770 & 163289 & 141080 & 115162 & 69632 & 61957 & 58326 & 52433 & 47522 \\
\hline & 2006 & 314308 & 205219 & 171582 & 141084 & 119240 & 77291 & 68508 & 65327 & 57232 & 50761 \\
\hline & 2007 & 312678 & 195449 & 168493 & 143445 & 118004 & 77712 & 70871 & 67511 & 58168 & 51374 \\
\hline & 2008 & 247877 & 190140 & 175754 & 153533 & 131560 & 76743 & 73911 & 68384 & 61593 & 55502 \\
\hline & 2009 & 252222 & 184870 & 169696 & 157886 & 136577 & 89994 & 76896 & 72450 & 64732 & 58863 \\
\hline \multirow[t]{6}{*}{ Total } & 2004 & 756509 & 482294 & 390830 & 329891 & 289048 & 177711 & 156962 & 144321 & 131568 & 116113 \\
\hline & 2005 & 806162 & 530737 & 423509 & 363377 & 304359 & 191408 & 170801 & 154656 & 129107 & 117723 \\
\hline & 2006 & 795338 & 534993 & 443004 & 360321 & 302384 & 195999 & 175067 & 162988 & 142187 & 125609 \\
\hline & 2007 & 786625 & 511886 & 434109 & 370066 & 302894 & 195389 & 176476 & 166536 & 147241 & 128612 \\
\hline & 2008 & 643698 & 498399 & 451631 & 392365 & 336037 & 194921 & 182258 & 168369 & 158992 & 141312 \\
\hline & 2009 & 636746 & 478282 & 430064 & 398866 & 341128 & 219836 & 190898 & 176485 & 162973 & 150858 \\
\hline
\end{tabular}

Source: SEMIS various issues

APPENDIX 6-E

\section{Completion Rate ( \% )}

\begin{tabular}{|l|c|r|c|}
\hline Completion Rate & i-v & vi-viii & ix-x \\
\hline Boys & $28 \%$ & $83 \%$ & $94 \%$ \\
Girls & $31 \%$ & $84 \%$ & $96 \%$ \\
Total & $29 \%$ & $83 \%$ & $95 \%$ \\
\hline
\end{tabular}

Source: SEMIS various issues 
APPENDIX 6-F

Q1 -Data collected for plans are reliable and valid * School type Cross tabulation

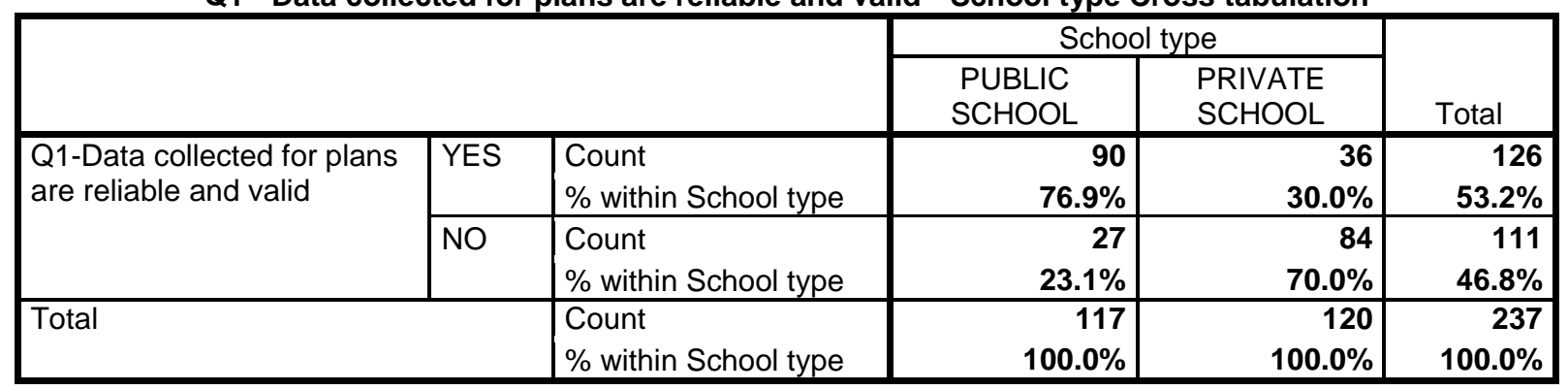

Chi-Square Tests

\begin{tabular}{|c|c|c|c|c|c|}
\hline & Value & df & $\begin{array}{l}\text { Asymp. Sig. } \\
\text { (2-sided) }\end{array}$ & $\begin{array}{l}\text { Exact Sig. } \\
\text { (2-sided) }\end{array}$ & $\begin{array}{l}\text { Exact Sig. } \\
\text { (1-sided) }\end{array}$ \\
\hline $\begin{array}{l}\text { Pearson Chi-Square } \\
\text { Continuity Correction }^{\mathrm{b}} \\
\text { Likelihood Ratio } \\
\text { Fisher's Exact Test } \\
\text { Linear-by-Linear } \\
\text { Association } \\
\text { N of Valid Cases }\end{array}$ & \begin{tabular}{|r|}
$52.384^{\mathrm{a}}$ \\
50.516 \\
54.587 \\
52.163 \\
237 \\
\end{tabular} & $\begin{array}{l}1 \\
1\end{array}$ & $\begin{array}{l}.000 \\
.000 \\
.000 \\
\\
.000\end{array}$ & .000 & .000 \\
\hline
\end{tabular}

a. 0 cells $(.0 \%)$ have expected count less than 5 . The minimum expected count

is 54.80 .

b. Computed only for a $2 \times 2$ table

\section{APPENDIX 6-G}

Q2-Objectives of the plans are clear to the data collectors. * School type Cross tabulation

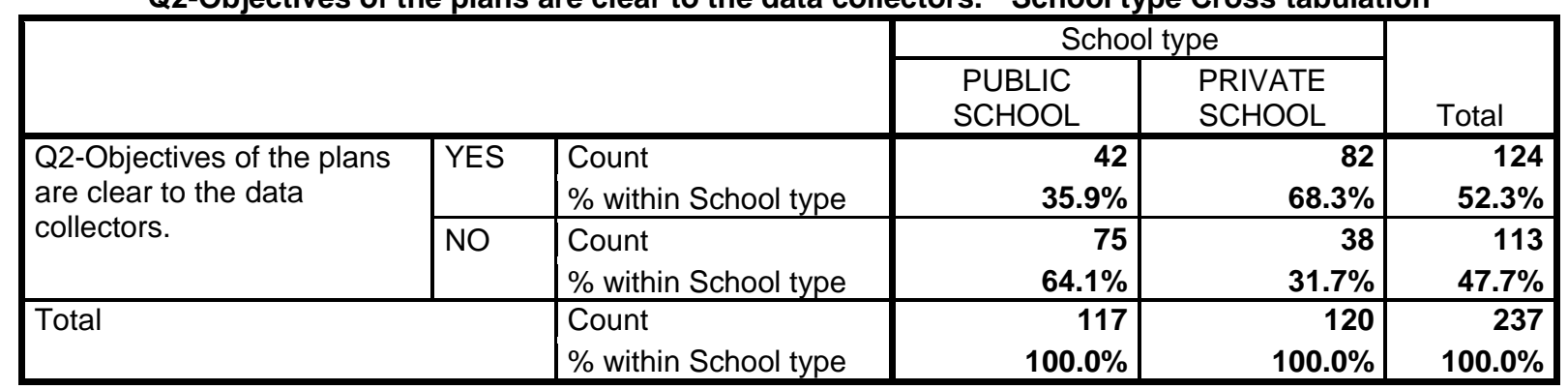

Chi-Square Tests

\begin{tabular}{|l|r|r|r|r|r|}
\hline & Value & df & $\begin{array}{r}\text { Asymp. Sig. (2- } \\
\text { sided) }\end{array}$ & $\begin{array}{r}\text { Exact Sig. } \\
\text { (2-sided) }\end{array}$ & $\begin{array}{r}\text { Exact Sig. (1- } \\
\text { sided) }\end{array}$ \\
\hline $\begin{array}{l}\text { Pearson Chi-Square } \\
\text { Continuity Correction }\end{array}$ & 24.984 & 1 & .000 & & \\
Likelihood Ratio & 23.701 & 1 & .000 & & \\
Fisher's Exact Test & 25.440 & 1 & .000 & .000 & .000 \\
Linear-by-Linear Association & 24.879 & 1 & .000 & & \\
N of Valid Cases & 237 & & & & \\
\hline
\end{tabular}

a. 0 cells $(.0 \%)$ have expected count less than 5 . The minimum expected count is 55.78 .

b. Computed only for a $2 \times 2$ table 
APPENDIX 6-H

Q3-The plans are prepared on the basis of authentic and correct data. * School type Cross tabulation

\begin{tabular}{|c|c|c|c|c|c|}
\hline & & & \multicolumn{2}{|c|}{ School type } & \multirow[b]{2}{*}{ Total } \\
\hline & & & PUBLIC SCHOOL & $\begin{array}{l}\text { PRIVATE } \\
\text { SCHOOL }\end{array}$ & \\
\hline \multirow{2}{*}{$\begin{array}{l}\text { Q3-The plans are prepared on } \\
\text { the basis of authentic and } \\
\text { correct data. }\end{array}$} & YES & $\begin{array}{l}\text { Count } \\
\% \text { within School type }\end{array}$ & $\begin{array}{r}71 \\
60.7 \% \\
\end{array}$ & $\begin{array}{r}81 \\
67.5 \% \\
\end{array}$ & $\begin{array}{r}152 \\
64.1 \% \\
\end{array}$ \\
\hline & $\mathrm{NO}$ & $\begin{array}{l}\text { Count } \\
\% \text { within School type }\end{array}$ & $\begin{array}{r}46 \\
39.3 \%\end{array}$ & $\begin{array}{r}39 \\
32.5 \%\end{array}$ & $\begin{array}{r}85 \\
35.9 \%\end{array}$ \\
\hline \multicolumn{2}{|l|}{ Total } & $\begin{array}{l}\text { Count } \\
\% \text { within School type }\end{array}$ & $\begin{array}{r}117 \\
100.0 \%\end{array}$ & $\begin{array}{r}120 \\
100.0 \%\end{array}$ & $\begin{array}{r}237 \\
100.0 \%\end{array}$ \\
\hline
\end{tabular}

Chi-Square Tests

\begin{tabular}{|c|c|c|c|c|c|}
\hline & Value & df & $\begin{array}{l}\text { Asymp. Sig. } \\
\text { (2-sided) }\end{array}$ & $\begin{array}{l}\text { Exact Sig. } \\
\text { (2-sided) }\end{array}$ & $\begin{array}{l}\text { Exact Sig. } \\
\text { (1-sided) }\end{array}$ \\
\hline \multirow{6}{*}{$\begin{array}{l}\text { Pearson Chi-Square } \\
\text { Continuity Correction } \\
\text { Likelihood Ratio } \\
\text { Fisher's Exact Test } \\
\text { Linear-by-Linear } \\
\text { Association } \\
\text { N of Valid Cases }\end{array}$} & $1.197^{\mathrm{a}}$ & 1 & .274 & & \multirow{6}{*}{.169} \\
\hline & .919 & 1 & .338 & & \\
\hline & 1.198 & 1 & .274 & & \\
\hline & & & & .282 & \\
\hline & 1.192 & 1 & .275 & & \\
\hline & 237 & & & & \\
\hline
\end{tabular}

a. 0 cells $(.0 \%)$ have expected count less than 5 .

The minimum expected count is 41.96 .

b. Computed only for a $2 \times 2$ table

APPENDIX 6-I

Q4-Data flaws are admittedly an inescapable handicap in comparative analysis, they do not necessarily invalidate the results. * School type Cross tabulation

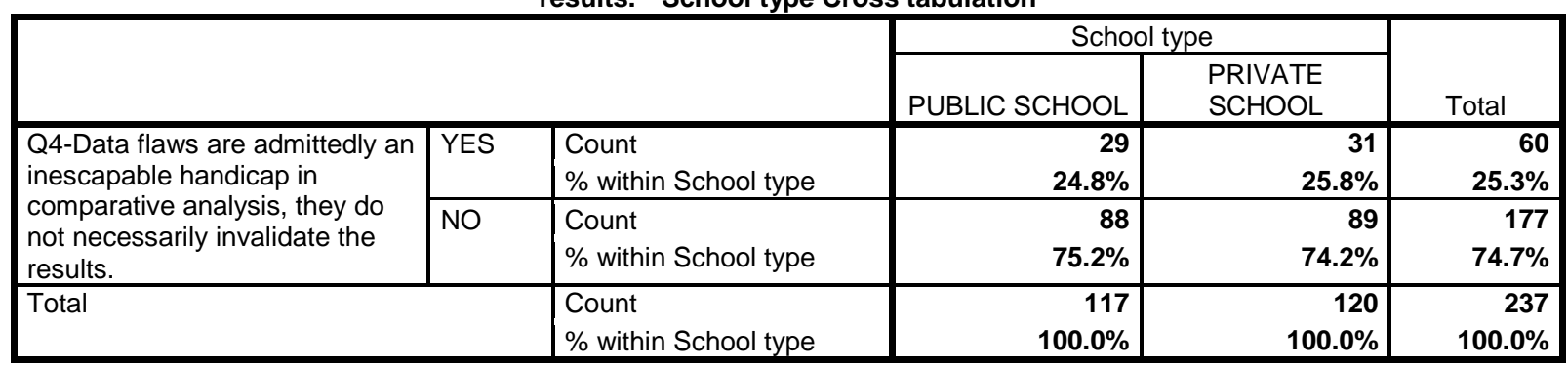

\begin{tabular}{|c|c|c|c|c|c|}
\hline \multicolumn{6}{|c|}{ Chi-Square Tests } \\
\hline & Value & Df & $\begin{array}{l}\text { Asymp. Sig. (2- } \\
\text { sided) }\end{array}$ & $\begin{array}{l}\text { Exact Sig. } \\
\text { (2-sided) }\end{array}$ & $\begin{array}{c}\text { Exact Sig. (1- } \\
\text { sided) }\end{array}$ \\
\hline $\begin{array}{l}\text { Pearson Chi-Square } \\
\text { Continuity Correction }{ }^{\text {b }} \\
\text { Likelihood Ratio } \\
\text { Fisher's Exact Test } \\
\text { Linear-by-Linear Association } \\
\text { N of Valid Cases }\end{array}$ & $\begin{array}{l}.034^{\mathrm{a}} \\
.001 \\
.034 \\
\\
.034 \\
237\end{array}$ & $\begin{array}{l}1 \\
1 \\
1 \\
1\end{array}$ & $\begin{array}{l}.853 \\
.971 \\
.853 \\
.853\end{array}$ & .882 & .486 \\
\hline
\end{tabular}

a. 0 cells $(.0 \%)$ have expected count less than 5 . The minimum expected count is 29.62 .

b. Computed only for a $2 \times 2$ table 
APPENDIX 6-J

Q5-Educational administrators are involved in the plan preparation * School type Crosstabulation

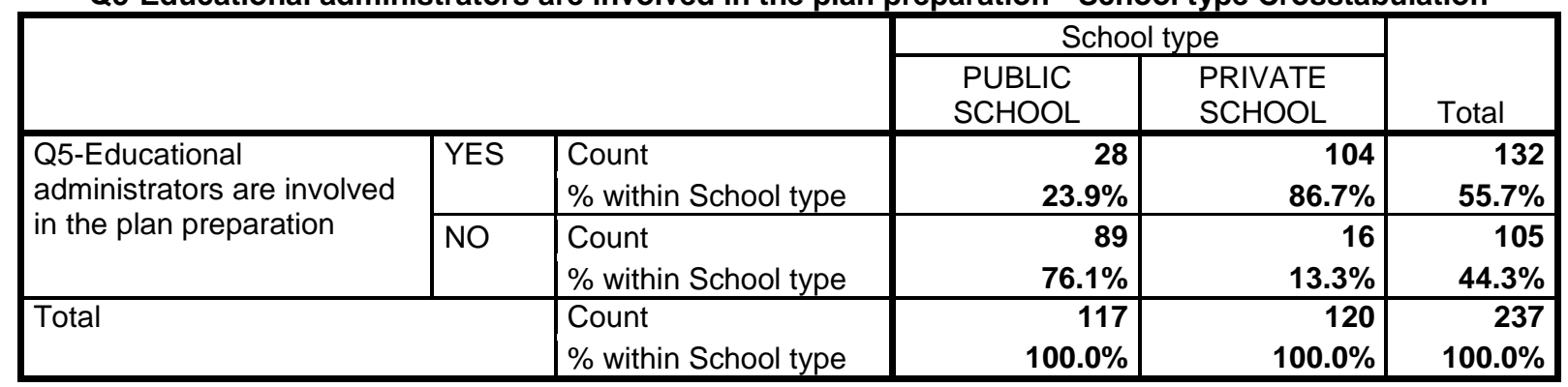

Chi-Square Tests

\begin{tabular}{|c|c|c|c|c|c|}
\hline & Value & Df & $\begin{array}{l}\text { Asymp. Sig. (2- } \\
\text { sided) }\end{array}$ & $\begin{array}{l}\text { Exact Sig. } \\
\text { (2-sided) }\end{array}$ & $\begin{array}{l}\text { Exact Sig. } \\
\text { (1-sided) }\end{array}$ \\
\hline Pearson Chi-Square & $94.487^{\mathrm{a}}$ & 1 & .000 & & \\
\hline Continuity Correction & 91.962 & 1 & .000 & & \\
\hline Likelihood Ratio & 102.459 & 1 & .000 & & \\
\hline Fisher's Exact Test & & & & .000 & .000 \\
\hline $\begin{array}{l}\text { Linear-by-Linear } \\
\text { Association } \\
\mathrm{N} \text { of Valid Cases }\end{array}$ & $\begin{array}{r}94.088 \\
237\end{array}$ & 1 & .000 & & \\
\hline
\end{tabular}

APPENDIX 6-K

Q6-Educationists are consulted in educational planning process. * School type Crosstabulation

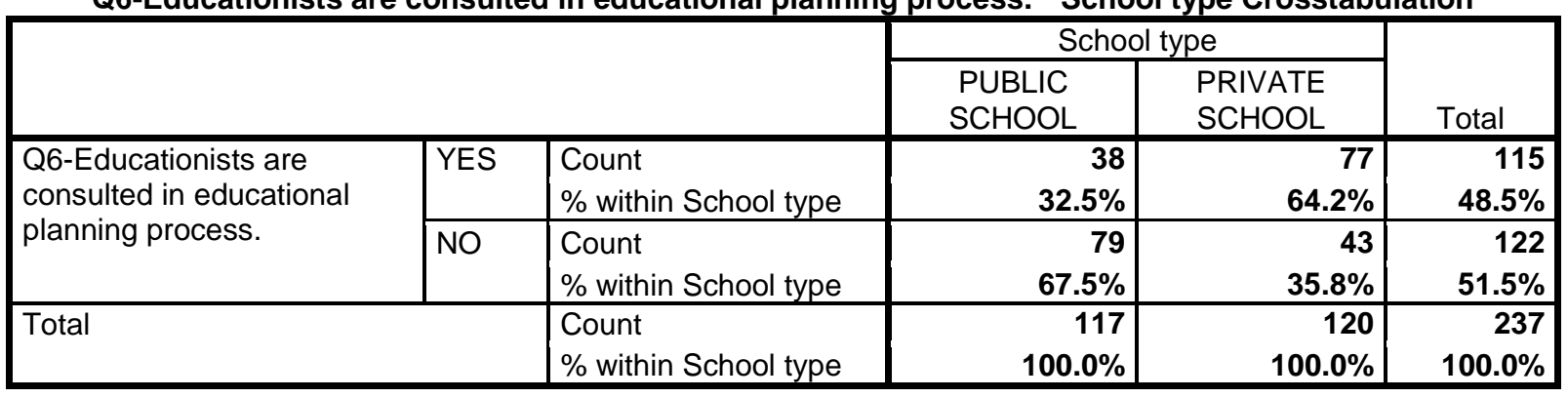

\begin{tabular}{|l|r|r|r|r|r|}
\hline & Chi-Square Tests \\
& \multicolumn{1}{|c|}{ Value } & df & $\begin{array}{c}\text { Asymp. Sig. } \\
\text { (2-sided) }\end{array}$ & $\begin{array}{l}\text { Exact Sig. } \\
\text { (2-sided) }\end{array}$ & $\begin{array}{c}\text { Exact Sig. } \\
\text { (1-sided) }\end{array}$ \\
\hline Pearson Chi-Square & $23.815^{\mathrm{a}}$ & 1 & .000 & & \\
Continuity Correction & 22.563 & 1 & .000 & & \\
Likelihood Ratio & 24.237 & 1 & .000 & .000 & .000 \\
Fisher's Exact Test & & & .000 & & \\
Linear-by-Linear Association & 23.714 & 1 & .000 & & \\
N of Valid Cases & 237 & & & & \\
\hline
\end{tabular}

a. 0 cells $(.0 \%)$ have expected count less than 5 . The minimum expected count is

56.77 .

b. Computed only for a $2 \times 2$ table 
APPENDIX 6-L

Q7- Appropriate targeting of interventions across localities * School type Crosstabulation

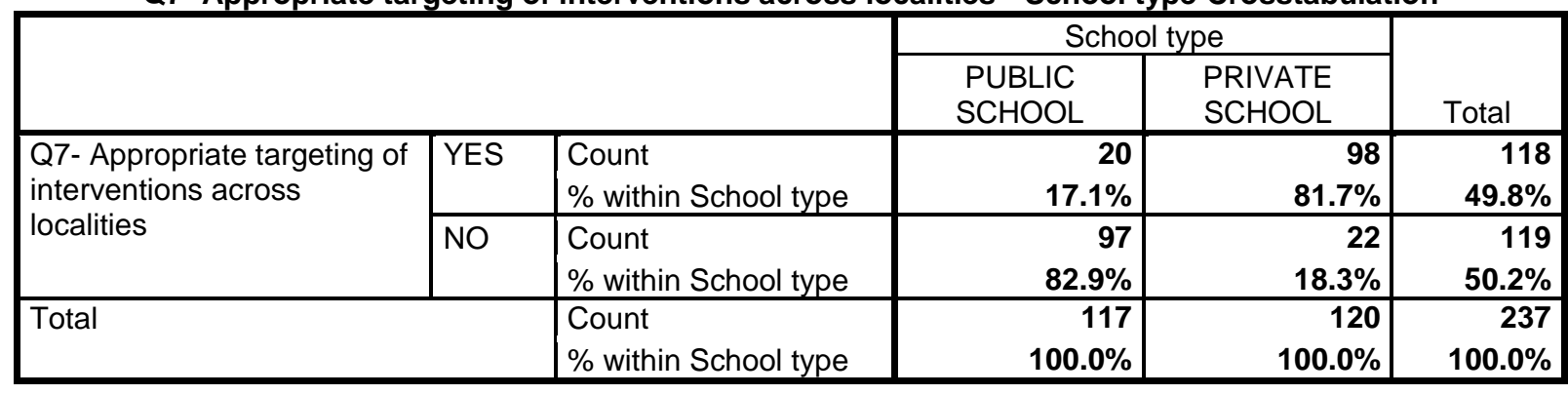

Chi-Square Tests

\begin{tabular}{|c|c|c|c|c|c|}
\hline & Value & df & $\begin{array}{l}\text { Asymp. Sig. } \\
\text { (2-sided) }\end{array}$ & $\begin{array}{l}\text { Exact Sig. } \\
\text { (2-sided) }\end{array}$ & $\begin{array}{l}\text { Exact Sig. } \\
\text { (1-sided) }\end{array}$ \\
\hline $\begin{array}{l}\text { Pearson Chi-Square } \\
\text { Continuity Correction }{ }^{\text {b }} \\
\text { Likelihood Ratio } \\
\text { Fisher's Exact Test } \\
\text { Linear-by-Linear Association } \\
\text { N of Valid Cases }\end{array}$ & $\begin{array}{r}98.806^{a} \\
96.240 \\
107.184 \\
\\
98.389 \\
237\end{array}$ & $\begin{array}{l}1 \\
1 \\
1 \\
1\end{array}$ & $\begin{array}{l}.000 \\
.000 \\
.000 \\
.000\end{array}$ & .000 & .000 \\
\hline
\end{tabular}

a. 0 cells $(.0 \%)$ have expected count less than 5 . The minimum expected count is 58.25 .

b. Computed only for a $2 \times 2$ table

APPENDIX 6-M

Q8-Maximization of cost-effectiveness * School type Crosstabulation

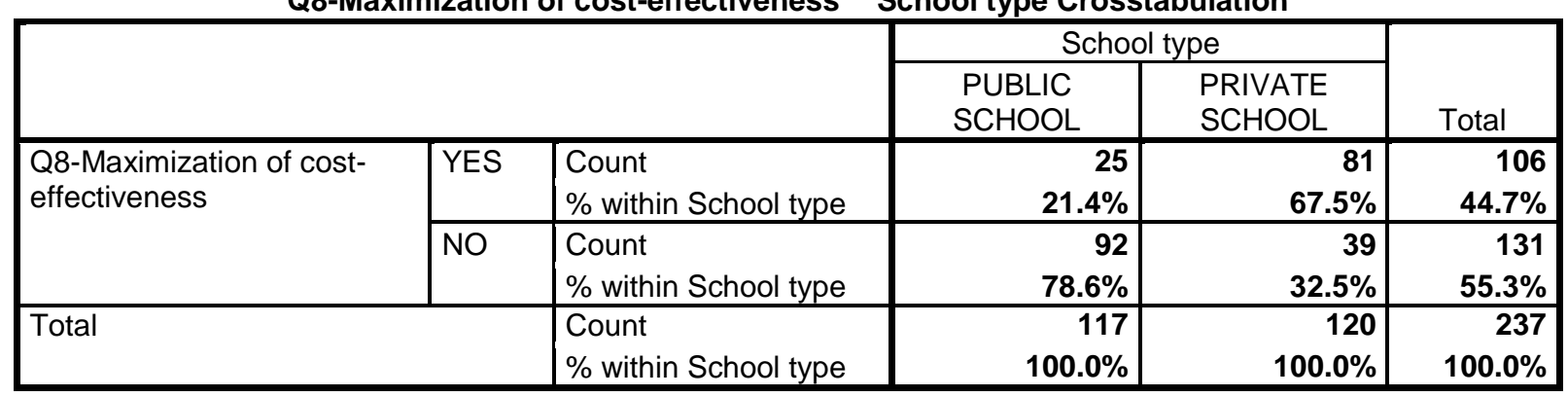

Chi-Square Tests

\begin{tabular}{|l|r|r|r|r|r|}
\hline & \multicolumn{1}{|c|}{ Value } & df & $\begin{array}{c}\text { Asymp. Sig. } \\
\text { (2-sided) }\end{array}$ & $\begin{array}{r}\text { Exact Sig. } \\
\text { (2-sided) }\end{array}$ & $\begin{array}{r}\text { Exact Sig. } \\
\text { (1-sided) }\end{array}$ \\
\hline Pearson Chi-Square & $50.998^{\mathrm{a}}$ & $\mathbf{1}$ & .000 & & \\
Continuity Correction & $\mathbf{4 9 . 1 4 9}$ & $\mathbf{1}$ & .000 & & \\
Likelihood Ratio & 53.174 & 1 & .000 & .000 & .000 \\
Fisher's Exact Test & 50.783 & 1 & .000 & & \\
Linear-by-Linear Association & 237 & & & & \\
N of Valid Cases & & & & \\
\hline
\end{tabular}

a. 0 cells $(.0 \%)$ have expected count less than 5 . The minimum expected count is 52.33 .

b. Computed only for a $2 \times 2$ table 


\section{APPENDIX 6-N}

Q9-Officers responsible for monitoring are trained and experienced in monitoring and evaluation. * School type Crosstabulation

\begin{tabular}{|c|c|c|c|c|c|}
\hline & \multicolumn{2}{|c|}{ School type } & \multirow[b]{2}{*}{ Total } \\
\hline & & & $\begin{array}{l}\text { PUBLIC } \\
\text { SCHOOL }\end{array}$ & $\begin{array}{l}\text { PRIVATE } \\
\text { SCHOOL }\end{array}$ & \\
\hline \multirow{2}{*}{$\begin{array}{l}\text { Q9-Officers responsible for } \\
\text { monitoring are trained and } \\
\text { experienced in monitoring } \\
\text { and evaluation. }\end{array}$} & YES & $\begin{array}{l}\text { Count } \\
\% \text { within School type }\end{array}$ & $\begin{array}{r}18 \\
15.4 \%\end{array}$ & $\begin{array}{r}27 \\
22.5 \%\end{array}$ & $\begin{array}{r}45 \\
19.0 \%\end{array}$ \\
\hline & $\mathrm{NO}$ & $\begin{array}{l}\text { Count } \\
\% \text { within School type }\end{array}$ & $\begin{array}{r}99 \\
84.6 \% \\
\end{array}$ & $\begin{array}{r}93 \\
77.5 \% \\
\end{array}$ & $\begin{array}{r}192 \\
81.0 \%\end{array}$ \\
\hline \multicolumn{2}{|l|}{ Total } & $\begin{array}{l}\text { Count } \\
\% \text { within School type }\end{array}$ & $\begin{array}{r}117 \\
100.0 \% \\
\end{array}$ & $\begin{array}{r}120 \\
100.0 \%\end{array}$ & $\begin{array}{r}237 \\
100.0 \%\end{array}$ \\
\hline
\end{tabular}

Chi-Square Tests

\begin{tabular}{|l|r|r|r|r|r|}
\hline & \multicolumn{1}{|c|}{ Value } & \multicolumn{1}{c|}{ df } & $\begin{array}{c}\text { Asymp. Sig. } \\
\text { (2-sided) }\end{array}$ & $\begin{array}{c}\text { Exact Sig. } \\
\text { (2-sided) }\end{array}$ & $\begin{array}{r}\text { Exact Sig. } \\
\text { (1-sided) }\end{array}$ \\
\hline Pearson Chi-Square & $1.950^{\mathrm{a}}$ & 1 & .163 & & \\
Continuity Correction & 1.515 & 1 & .218 & & \\
Likelihood Ratio & 1.962 & 1 & .161 & & \\
Fisher's Exact Test & & & .187 & .109 \\
Linear-by-Linear Association & 1.942 & 1 & .163 & & \\
N of Valid Cases & 237 & & & & \\
\hline
\end{tabular}

a. 0 cells $(.0 \%)$ have expected count less than 5 . The minimum expected count is 22.22 .

b. Computed only for a $2 \times 2$ table

APPENDIX 6-O

Q10-There is a co-ordination among different agencies responsible for planning, release of funds and implementation. * School type Crosstabulation

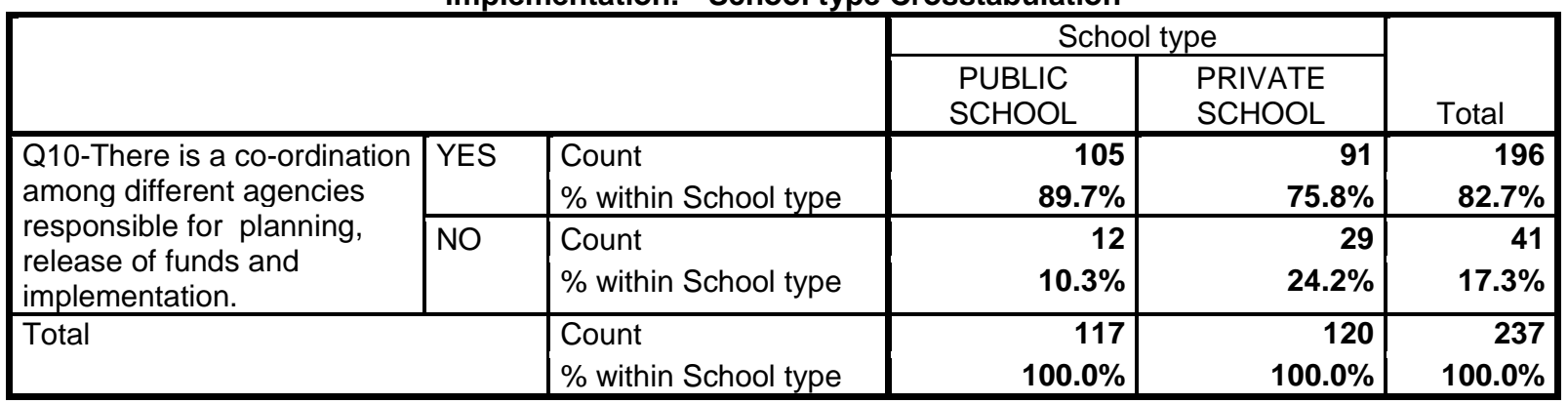

Chi-Square Tests

\begin{tabular}{|l|r|r|r|r|r|}
\hline & \multicolumn{1}{|c|}{ Value } & \multicolumn{1}{c|}{ df } & $\begin{array}{c}\text { Asymp. Sig. } \\
\text { (2-sided) }\end{array}$ & $\begin{array}{l}\text { Exact Sig. } \\
\text { (2-sided) }\end{array}$ & $\begin{array}{r}\text { Exact Sig. } \\
\text { (1-sided) }\end{array}$ \\
\hline Pearson Chi-Square & $8.012^{\mathrm{a}}$ & 1 & .005 & & \\
Continuity Correction $^{\mathrm{b}}$ & 7.069 & 1 & .008 & & \\
Likelihood Ratio $^{\text {Fisher's Exact Test }}$ & 8.229 & 1 & .004 & .006 & .004 \\
Linear-by-Linear Association & 7.978 & 1 & .005 & & \\
N of Valid Cases & 237 & & & & \\
\hline
\end{tabular}

a. 0 cells $(.0 \%)$ have expected count less than 5 . The minimum expected count is 20.24 .

b. Computed only for a $2 \times 2$ table 
APPENDIX 6-P

Q11-Total funds provide are not utilized properly. * School type Crosstabulation

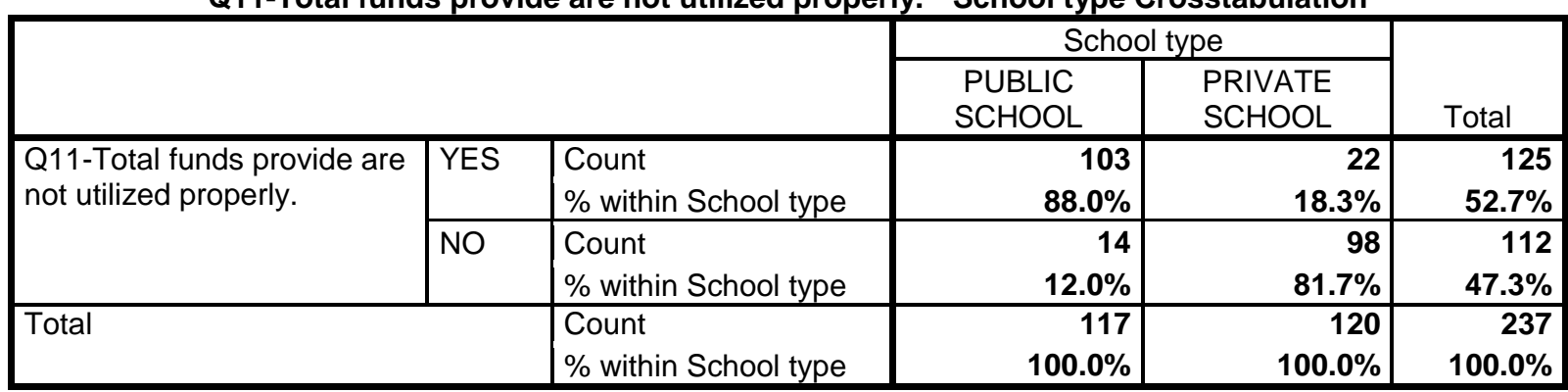

Chi-Square Tests

\begin{tabular}{|c|c|c|c|c|c|}
\hline & Value & Df & $\begin{array}{c}\text { Asymp. Sig. } \\
\text { (2-sided) }\end{array}$ & $\begin{array}{c}\text { Exact Sig. } \\
\text { (2-sided) }\end{array}$ & $\begin{array}{l}\text { Exact Sig. } \\
\text { (1-sided) }\end{array}$ \\
\hline $\begin{array}{l}\text { Pearson Chi-Square } \\
\text { Continuity Correction }^{\mathrm{b}} \\
\text { Likelihood Ratio } \\
\text { Fisher's Exact Test } \\
\text { Linear-by-Linear Association } \\
\mathrm{N} \text { of Valid Cases }\end{array}$ & $\begin{array}{r}115.469^{a} \\
112.689 \\
127.799 \\
114.981 \\
237\end{array}$ & $\begin{array}{l}1 \\
1 \\
1 \\
1\end{array}$ & $\begin{array}{l}.000 \\
.000 \\
.000 \\
.000\end{array}$ & .000 & .000 \\
\hline
\end{tabular}

a. 0 cells $(.0 \%)$ have expected count less than 5 . The minimum expected count is 55.29 .

b. Computed only for a $2 \times 2$ table

APPENDIX 6-Q

Q12-Projects in public sector organizations are more likely to go over budget. * School type Crosstabulation

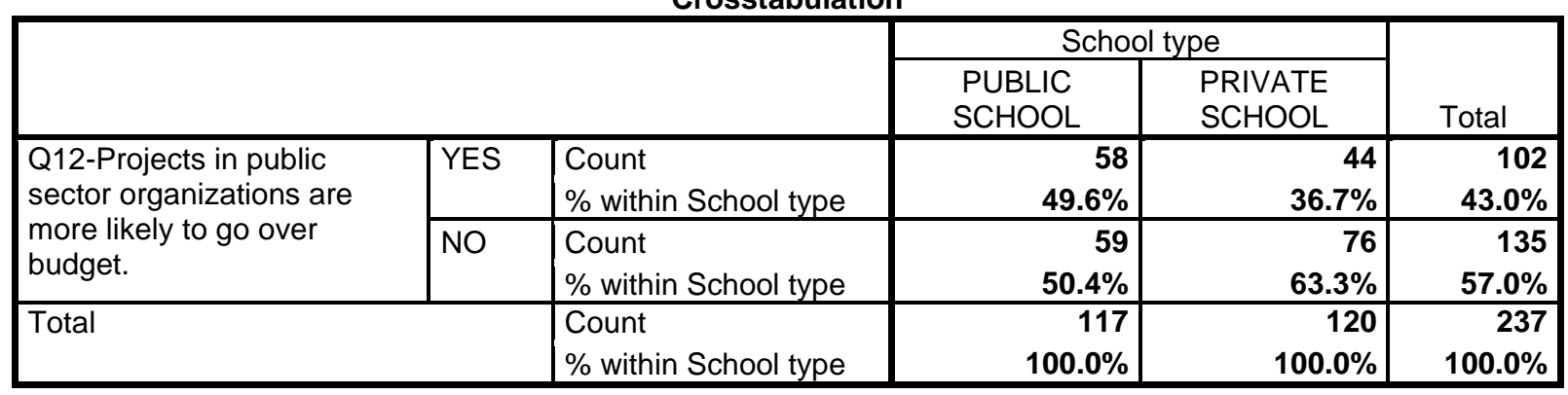

Chi-Square Tests

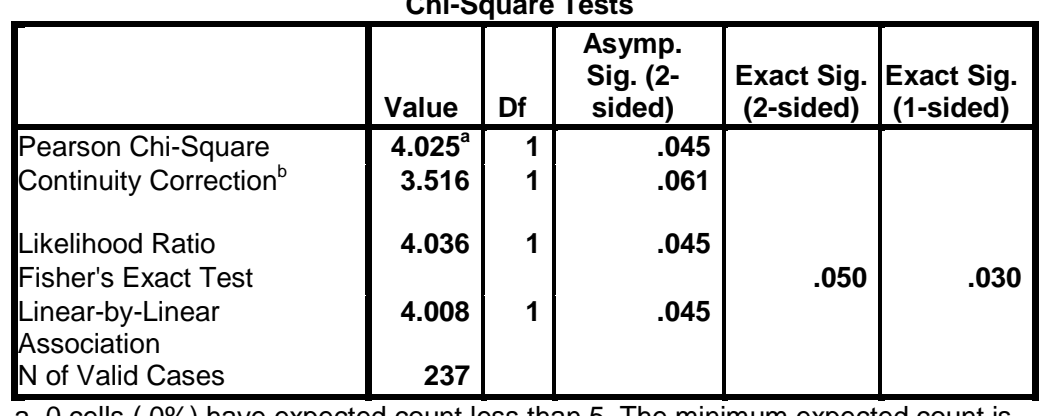

a. 0 cells $(.0 \%)$ have expected count less than 5 . The minimum expected count is

50.35. b. Computed only for a $2 \times 2$ table 


\section{APPENDIX 6-R}

Q13-Projects in public sector organizations are more likely to be delivered late i.e time over run. * School type Crosstabulation

\begin{tabular}{|c|c|c|c|c|c|}
\hline & \multicolumn{2}{|c|}{ School type } & \multirow[b]{2}{*}{ Total } \\
\hline & & & $\begin{array}{l}\text { PUBLIC } \\
\text { SCHOOL }\end{array}$ & $\begin{array}{l}\text { PRIVATE } \\
\text { SCHOOL }\end{array}$ & \\
\hline \multirow{2}{*}{$\begin{array}{l}\text { Q13-Projects in public } \\
\text { sector organizations are } \\
\text { more likely to be delivered } \\
\text { late i.e time over run. }\end{array}$} & YES & $\begin{array}{l}\text { Count } \\
\% \text { within School type }\end{array}$ & $\begin{array}{r}69 \\
59.0 \%\end{array}$ & $\begin{array}{r}56 \\
46.7 \%\end{array}$ & $\begin{array}{r}125 \\
52.7 \%\end{array}$ \\
\hline & $\mathrm{NO}$ & $\begin{array}{l}\text { Count } \\
\% \text { within School type }\end{array}$ & $\begin{array}{r}48 \\
41.0 \%\end{array}$ & $\begin{array}{r}64 \\
53.3 \%\end{array}$ & $\begin{array}{r}112 \\
47.3 \%\end{array}$ \\
\hline Total & & $\begin{array}{l}\text { Count } \\
\% \text { within School type }\end{array}$ & $\begin{array}{r}117 \\
100.0 \%\end{array}$ & $\begin{array}{r}120 \\
100.0 \%\end{array}$ & $\begin{array}{r}237 \\
100.0 \%\end{array}$ \\
\hline
\end{tabular}

Chi-Square Tests

\begin{tabular}{|l|r|r|r|r|r|}
\hline & \multicolumn{1}{|c|}{ Value } & df & Asymp. Sig. (2-sided) & $\begin{array}{c}\text { Exact Sig. (2- } \\
\text { sided) }\end{array}$ & $\begin{array}{r}\text { Exact Sig. } \\
\text { (1-sided) }\end{array}$ \\
\hline Pearson Chi-Square & $3.600^{\mathrm{a}}$ & 1 & .058 & & \\
Continuity Correction $^{\mathrm{b}}$ & 3.123 & 1 & .077 & & \\
Likelihood Ratio $^{\text {Fisher's Exact Test }}$ & 3.610 & 1 & .057 & .069 & .038 \\
Linear-by-Linear & 3.585 & 1 & .058 & & \\
Association & & & & & \\
N of Valid Cases & 237 & & & & \\
\hline
\end{tabular}

a. 0 cells $(.0 \%)$ have expected count less than 5 . The minimum expected count is 55.29.b. Computed only for a $2 \times 2$ table

\section{APPENDIX 6-S}

Q14-Guidance from foreign experts in plan preparation, elaboration and implementation without tailoring it according to social, political needs and situation of the country is one of the causes of plan failure. * School type

\begin{tabular}{|c|c|c|c|c|c|}
\hline \multicolumn{6}{|c|}{ Crosstabulation } \\
\hline & & & \multicolumn{2}{|c|}{ School type } & \multirow[b]{2}{*}{ Total } \\
\hline & & & PUBLIC SCHOOL & $\begin{array}{l}\text { PRIVATE } \\
\text { SCHOOL }\end{array}$ & \\
\hline \multirow{4}{*}{$\begin{array}{l}\text { Q14-Guidance from foreign } \\
\text { experts in plan preparation, } \\
\text { elaboration and implementation } \\
\text { without tailoring it according to } \\
\text { social, political needs and } \\
\text { situation of the country is one of } \\
\text { the causes of plan failure. }\end{array}$} & YES & Count & 86 & 75 & 161 \\
\hline & & $\%$ within School type & $73.5 \%$ & $62.5 \%$ & $67.9 \%$ \\
\hline & $\mathrm{NO}$ & Count & 31 & 45 & 76 \\
\hline & & $\%$ within School type & $26.5 \%$ & $37.5 \%$ & $32.1 \%$ \\
\hline \multirow[t]{2}{*}{ Total } & & Count & 117 & 120 & 237 \\
\hline & & \% within School type & $100.0 \%$ & $100.0 \%$ & $100.0 \%$ \\
\hline
\end{tabular}

\section{Chi-Square Tests}

\begin{tabular}{|c|c|c|c|c|c|}
\hline & Value & Df & $\begin{array}{l}\text { Asymp. } \\
\text { Sig. (2- } \\
\text { sided) }\end{array}$ & $\begin{array}{l}\text { Exact Sig. } \\
\text { (2-sided) }\end{array}$ & $\begin{array}{c}\text { Exact Sig. (1 } \\
\text { sided) }\end{array}$ \\
\hline $\begin{array}{l}\text { Pearson Chi-Square } \\
\text { Continuity Correction }{ }^{\text {b }} \\
\text { Likelihood Ratio } \\
\text { Fisher's Exact Test } \\
\text { Linear-by-Linear Association } \\
\mathrm{N} \text { of Valid Cases }\end{array}$ & $\begin{array}{r}3.293^{\mathrm{a}} \\
2.807 \\
3.308 \\
\\
3.279 \\
237\end{array}$ & $\begin{array}{l}1 \\
1 \\
1\end{array}$ & $\begin{array}{l}.070 \\
.094 \\
.069 \\
.070\end{array}$ & .073 & .047 \\
\hline
\end{tabular}

a. 0 cells $(.0 \%)$ have expected count less than 5 . The minimum expected count is 37.52 .

b. Computed only for a $2 \times 2$ table 
APPENDIX 7 - A

MODIFIED WALD TEST FOR GROUPWISE HETEROSKEDASTICITY

\section{For PRIMARY LEVEL EDUCATION}

Modified Wald test for groupwise heteroskedasticity

in fixed effect regression model

$\mathrm{H} 0$ : sigma(i)^2 = sigma^2 for all $\mathrm{i}$

$\operatorname{chi} 2(23)=2025.30$

Prob $>$ chi2 $=0.0000$

For MIDDLE LEVEL EDUCATION

Modified Wald test for groupwise heteroskedasticity

in fixed effect regression model

$\mathrm{H} 0$ : sigma(i)^2 = sigma^2 for all $\mathrm{i}$

$\operatorname{chi} 2(23)=720.48$

Prob $>$ chi2 $=0.0000$

\section{For SECONDARY LEVEL EDUCATION}

Modified Wald test for groupwise heteroskedasticity

in fixed effect regression model

HO: sigma(i)^2 = sigma^2 for all $i$

$\operatorname{chi2(23)}=\quad 396.76$

Prob $>$ chi2 $=0.0000$ 
POTENTIAL SCALE-RELATED HETEROSKEDASTICITY IN OUR MODEL - TWO TESTS: BP and White's general test For PRIMARY LEVEL EDUCATION

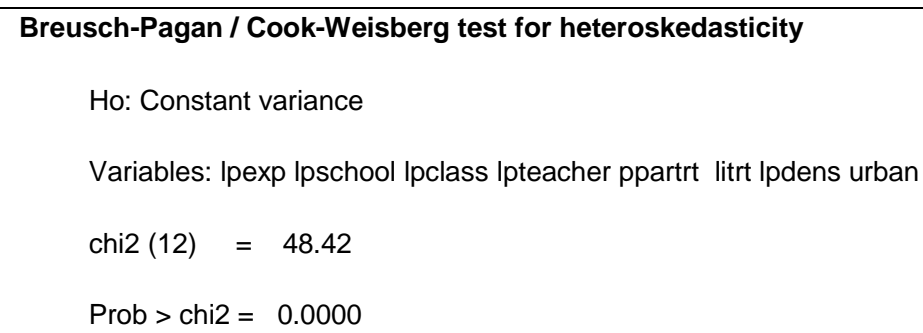

White's test for Ho: homoskedasticity

against $\mathrm{Ha}$ : unrestricted heteroskedasticity

chi2 $(90)=123.29$

Prob $>$ chi2 $=0.0114$

Cameron \& Trivedi's decomposition of IM-test

Source chi2 df $p$

Heteroskedasticity $\quad 123.29 \quad 90 \quad 0.0114$

$\begin{array}{llll}\text { Skewness } \quad 26.04 \quad 12 & 0.0106\end{array}$

$\begin{array}{llll}\text { Kurtosis } & 0.19 & 1 & 0.6664\end{array}$

Total $\quad 149.52 \quad 103 \quad 0.0019$

\section{For MIDDLELEVEL EDUCATION}

Breusch-Pagan / Cook-Weisberg test for heteroskedasticity

Ho: Constant variance

Variables: Imexp Imschool Imclass Imteacher litrate urban

chi2 $(10)=24.99 \quad$ Prob $>$ chi2 $=0.0054$

White's test for Ho: homoskedasticity

against $\mathrm{Ha}$ : unrestricted heteroskedasticity

$\operatorname{chi} 2(65)=90.24$

Prob $>$ chi2 $=0.0209$

Cameron \& Trivedi's decomposition of IM-test

$\begin{array}{cccc}\text { Source } & \text { chi2 } & \text { df } & p \\ \text { Heteroskedasticity } & 90.24 & 65 & 0.0209 \\ \text { Skewness } & 24.84 & 10 & 0.0057 \\ \text { Kurtosis } & 0.16 & 1 & 0.6876 \\ \text { Total } & \mathbf{1 1 5 . 2 4} & \mathbf{7 6} & \mathbf{0 . 0 0 2 5}\end{array}$




\section{For SECONDARY LEVEL EDUCATION}

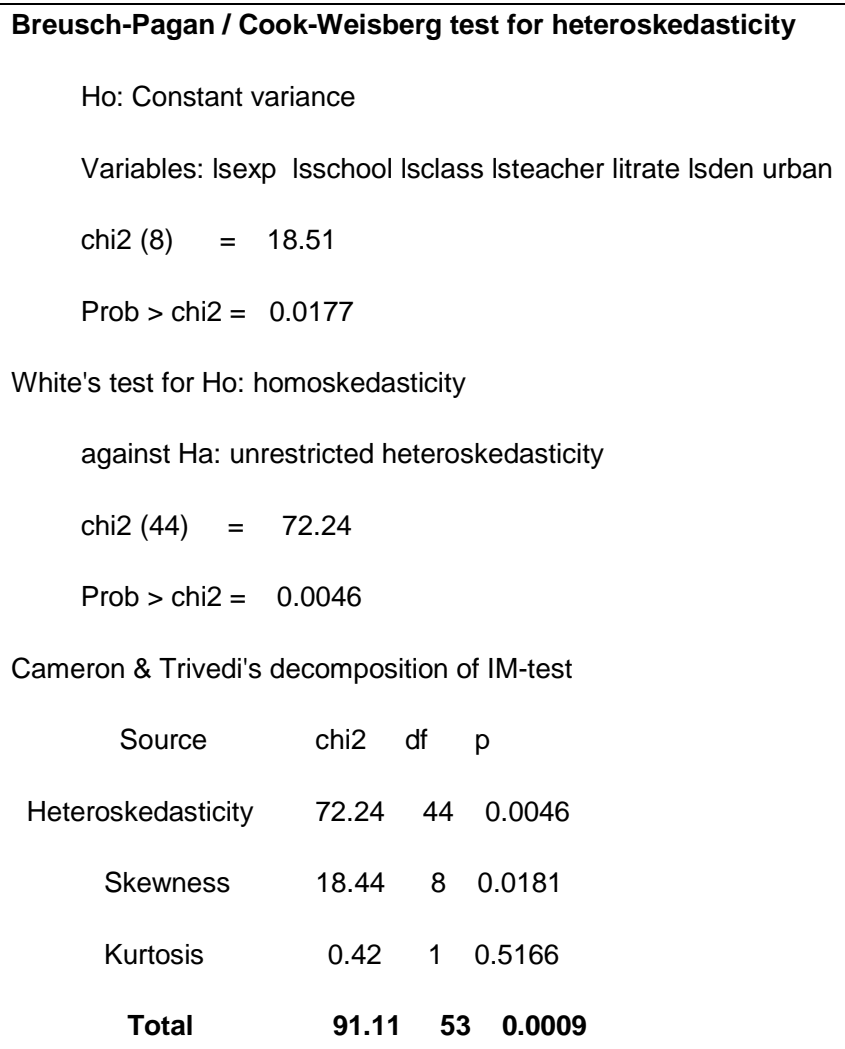


APPENDIX 7-B

Stochastic Frontier Estimation - Time varying decay inefficiency model Primary Education

Dependent Variable: Log of primary enrolment (Class I to V)

Independent Variables

Log of primary education expenditure

Log of number of primary schools

Log of number of classrooms

Log of number of teachers

Log of population density

Primary participation rate

Literacy rate

Percent of urban population

Constant

\section{Coefficients}

0.023491

$(4.29)^{* * *}$

$-0.04306$

(-1.12)

0.019949

(2.1)*

0.039287

(1.34)

1.627667

$(49.89)^{* * *}$

0.689927

$(11.55)^{* * *}$

0.040579

(0.78)

$-1.83633$

$(-3.6) * * *$

6.967519

(22.31)

Wald chi2 $(8)=506.43$

Log likelihood $=260.79118$

Prob $>$ chi2 $=0.0000$

No of Obs $=138$

Gamma=0.999514 sigma_u2 0.617941 sigma_v2 0.000301

z-statistics in parentheses ${ }^{* *} p<0.01,{ }^{* *} p<0.05,{ }^{*} p<0.1$ 
APPENDIX 7-C

Stochastic Frontier Estimation - Time invariant decay inefficiency model Middle education

Dependent Variable: Log of middle enrolment (Class VI to VIII) Independent Variables Coefficients

Log of middle education expenditure 0.188569 $(9.91)^{* *}$

Log of number of middle schools $-0.16442$

Log of number of classrooms $(9.91)^{* * *}$

0.313827

$(-2.89)^{* * *}$

Log of number of teachers

0.071638

Literacy rate

0.060621

Percent of urban population

1.076912

$(0.25)^{* * *}$

Constant

4.942596

$(3.21)^{* * *}$

Wald chi2(6) $=179.52$ 
APPENDIX 7-D

Stochastic Frontier Estimation - Time invariant decay inefficiency model Secondary education

Dependent Variable: Log of secondary enrolment (Class IX to X)

\section{Independent Variables}

Log of secondary education expenditure

Log of number of secondary schools

Log of number of classrooms

Log of number of teachers

Literacy rate

Log of population density

Percent urban population

Constant

\section{Coefficients}

$$
\begin{gathered}
0.199688 \\
(11.08)^{* * *} \\
0.405908 \\
(2.96)^{* * *} \\
-0.28534 \\
\left(-2.52^{* *}\right) \\
0.438911 \\
(3.31)^{* * *} \\
0.238903 \\
(0.82) \\
0.135933 \\
(2.16)^{*} \\
-0.37544 \\
(-0.59) \\
2.465379 \\
\left(3.33^{* * *}\right)
\end{gathered}
$$

Wald chi2(6) $=276.92$ Log likelihood $=75.736013$ Prob $>$ chi2 $=0.0000$ 